Tom Kleffmann (Hg.)

\title{
Das Buch der Bücher
}

Seine Wirkungsgeschichte in der Literatur

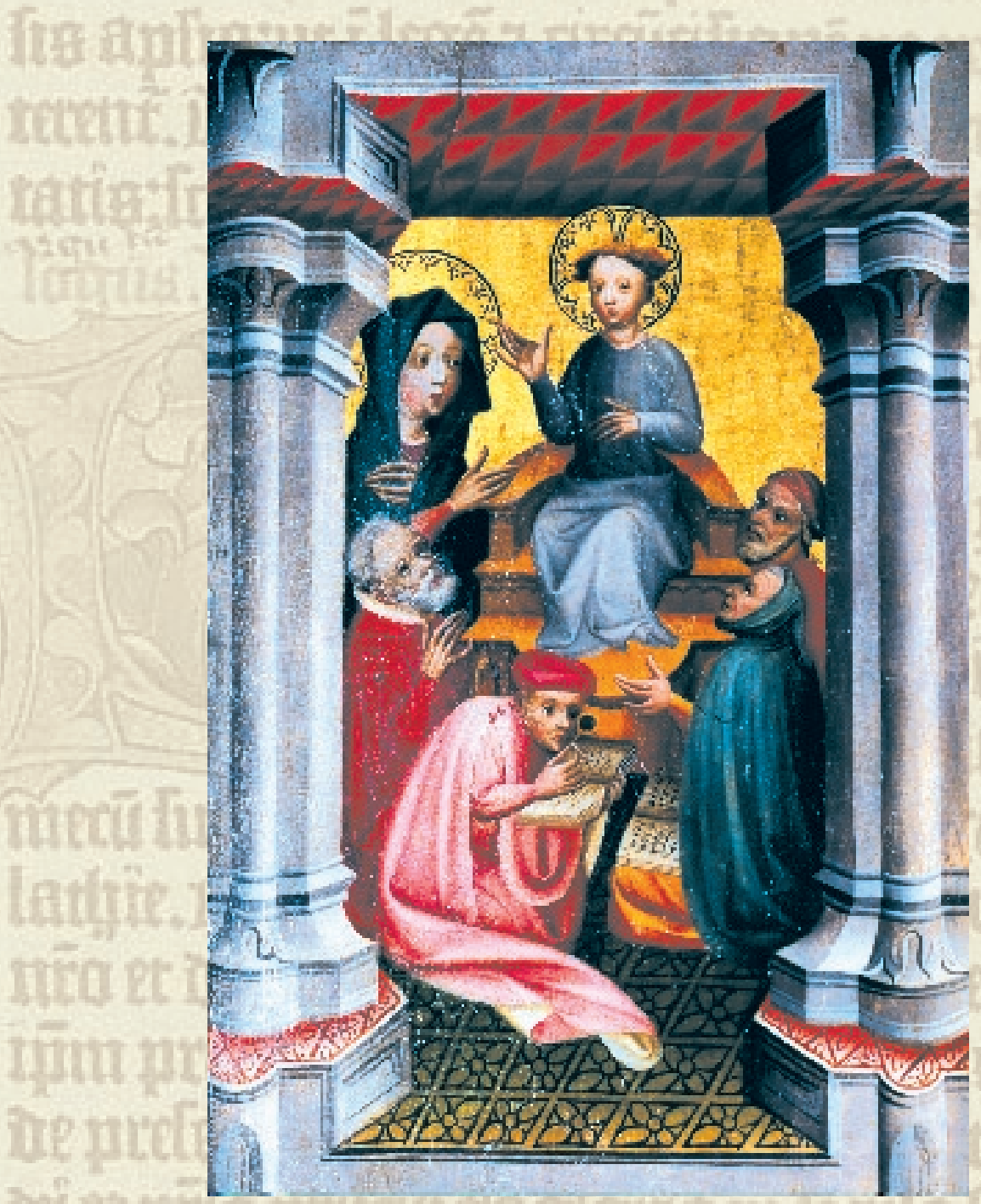

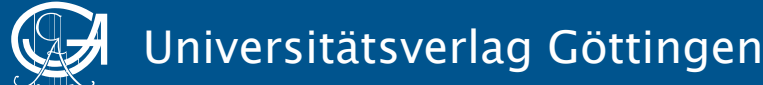



Tom Kleffmann (Hg.)

Das Buch der Bücher

Except where otherwise noted, this work is licensed under a Creative Commons License

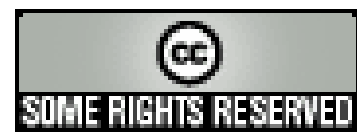


erschienen im Universitätsverlag Göttingen 2004 
Tom Kleffmann (Hg.)

Das Buch der Bücher

Seine Wirkungsgeschichte in der Literatur

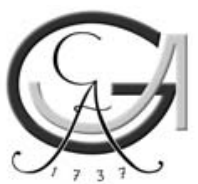

Universitätsverlag Göttingen 2004 
Bibliografische Information Der Deutschen Bibliothek

Die Deutsche Bibliothek verzeichnet diese Publikation in der Deutschen

Nationalbibliografie; detaillierte bibliografische Daten sind im Internet über $<$ http//dnb.ddb.de $>$ abrufbar.

(C) Alle Rechte vorbehalten, Universitätsverlag Göttingen 2004

Umschlagabbildung:

Im Vordergrund der zwölfjährige Jesus im Tempel, Detail der Sonntagsseite des Flügelaltars der Göttinger St. Jacobi-Kirche, 1402.

Aufnahme Hans Starosta, Göttingen

Im Hintergrund der Galaterbrief aus der Göttinger Gutenberg-Bibel (fol. 266r), gedruckt um 1454, digitalisiert vom Göttinger Digitalisierungszentrum.

Satz: Publicitus.com, Göttingen

Abb. S. 92 mit freundlicher Genehmigung der University of Wisconsin Press 


\section{Inhalt}

Thomas Kaufmann

Geleitwort . . . . . . . . . . . . . . . . . .7

Tom KlefFmann

Vorwort ..........................

Gerhard LAUER

„Hiob, o Hiob! Sprachst du wirklich

nichts anderes als diese Worte?"

Das Buch Hiob und die Literatur . . . . . . . . . . . . . . 11

Siegmar Döpp

Eine weithin unbekannte Schöne:

Die lateinische Bibelepik der Spätantike. . . . . . . . . . . . . . .29

JÜRGEN VON STACKELBERG

Die Bibel in der französischen Literatur:

Voltaire, Gide, Giraudoux . . . . . . . . . . . . . . . 53

JÜRGEN GIDION

„Die Vertreibung aus dem Paradies“

Der Ursprungsmythos (Genesis 3) als

Herausforderung in Philosophie und Literatur der Neuzeit . . . . 73

THEODOR Wolpers

Shakespeare und die Bibel . . . . . . . . . . . . . . . . . 89

DANIEL GÖSKE

Die Heilige Schrift und die Schriftstellerei in Amerika: der Fall Melville . . . . . . . . . . . . . . . . . . . . . . 117 
IRMELA VON DER LÜHE

„Ein Fest der Erzählung“

Thomas Manns Romanzyklus Joseph und seine Brüder . . . . . . . 135

REINHARD LAUER

Wiederkehrender und revolutionärer Christus

in der russischen Literatur . . . . . . . . . . . . . . . . . . . . 151

Autorin und Autoren . . . . . . . . . . . . . . . . 175 


\section{Geleitwort}

Im letzten Jahr fand in der Göttinger Jakobikirche eine hochkarätige und deshalb zu Recht viel beachtete Vorlesungsreihe zur Wirkungsgeschichte der Bibel statt. Diese nun gedruckt vorliegende Vorlesungsreihe ist nicht nur ein Beispiel für das gute Zusammenleben von Universität und Stadt, wie es typisch für Göttingen ist. Sie ist darüberhinaus Beispiel für ein fruchtbares Gespräch zwischen Wissenschaft und Kirche, wie es auch außerhalb der akademischen Theologie möglich und nötig ist.

Für die Dokumentation dieser beeindruckenden Vorlesungsreihe ist dem Universitätsverlag sehr zu danken.

Prof. Dr. Thomas Kaufmann

Dekan der Theologischen Fakultät

Georg-August-Universität Göttingen 



\section{Vorwort}

Gott ein Schriftsteller! - Die Eingebung dieses Buchs ist eine ebenso große Erniedrigung und Herunterlassung Gottes als die Schöpfung des Vaters und die Menschwerdung des Sohnes (Johann Georg Hamann).

Für das christliche Selbstverständnis ist die Bibel als Menschenwort zugleich Wort Gottes. Das heißt, es gilt als mögliche Erfahrung, daß Gott selbst sich in der menschlichen Sprache der Bibel äußert - nicht nur hier, aber doch hier in besonderer, ursprünglicher Weise. Diese Offenbarung gilt dabei nicht als supranaturale Information, nicht als starre autoritative Norm. Vielmehr ist sie neutestamentlich im Christusgeschehen begründet - in der völligen Herunterlassung Gottes zum Menschen, als zu seinem Wesen gehörig. Diesem Gedanken der Kondeszendenz Gottes zum Menschen entspricht dann, daß die Bibel als Wort Gottes zugleich ganz menschlich ist. Deshalb ist sie, anders als der Koran im islamischen Selbstverständnis, auch in jede Sprache zu übersetzen. Ihr Sinn erfüllt sich im lebendigen Gespräch.

Im Gedanken der Kondeszendenz Gottes zum Menschen verstanden ist die Bibel heilige Schrift - und als heilige Schrift Buch der Bücher: universaler Schlüssel des Verstehens, Schlüssel der Wahrheit des Buchs der Natur, des Buchs der Geschichte, aber auch aller anderen Bücher vom Leben - Schlüssel des Verstehens, aber auch selbst Urform menschlicher Rede von Leben und Tod, Wahrheit und Lüge, Glück und Leid.

Aber inwiefern ist die Bibel auch faktisch das Buch der Bücher? Das läßt sich nur im philologischen Blick auf die Bücher selbst feststellen. Die faktische Wirkung der Bibel auf die Sprache und die Bücher ist ja nicht im Glauben normiert, sondern Ausdruck einer prinzipiell offen scheinenden Geistesgeschichte. Wie steht es mit der Wirkungsgeschichte der Bibel im säkularen Raum? Gibt es hier wesentliche Unterschiede in den europäischen Kulturen (einschließlich der europäisch geprägten Kultur Nordamerikas)? Wirkt sie über ihre Motive und Formen, über ihre Sprache, über ihre Perspektiven? Wo wirkt sie unterschwellig, wo in der Abgrenzung von ihr, wo ausdrücklich und offensichtlich?

Um zur Klärung solcher Fragen beizutragen, um Schlaglichter zu werfen, Querschnitte zu ziehen, fand von September bis November 2003 eine 
Vorlesungsreihe in der Göttinger St. Jacobi-Kirche statt. Namhafte Vertreter bester Göttinger Philologie fanden hier ihr Publikum - interessiert, oft gelehrt, aber in seinem Interesse nicht auf eine fachwissenschaftliche Binnendiskussion beschränkt. Die Atmosphäre war konzentriert, manchmal beinahe festlich. Der Herbst hatte die Kirche schon in ein farbiges Halbdunkel getaucht. Dagegen war der Altarraum hell erleuchtet. Das wirkte durchaus nicht unpassend - obwohl es doch nichts als Philologie war, was dort geboten wurde.

Überhaupt kann es scheinen, daß St. Jacobi der ideale Raum für Vorhaben wie dieses ist - Inbegriff einer seltenen Symbiose von Geist und Kunst, von Gottesdienst und Freiheit, von Heiligkeit und Nüchternheit. Das ist vor allem Dirk Tiedemann zu verdanken. Seit 16 Jahren ist er Pastor dieser Gemeinde. Entwurf und Organisation dieser Vorlesungsreihe sind sein Werk.

Wie der Leser schnell bemerken wird, wurde für den Druck die Vortragsform und überhaupt der besondere Charakter einer Vorlesung im Kirchenraum beibehalten; das schließt den Verzicht auf einen umständlichen Anmerkungsapparat ein.

St. Jacobi in Göttingen, Sommer 2004

Tom Kleffmann 


\section{„Hiob, o Hiob! Sprachst du wirklich nichts anderes als diese Worte?" Das Buch Hiob und die Literatur}

\section{Gerhard LAUER}

Im Herbst des Jahres 1843 erschien in Kopenhagen eine Reihe von Briefen eines namenlosen jungen Mannes, die ein gewisser Constantin Constantius herausgegeben haben soll. In seiner Vorbemerkung behauptet der Herausgeber, die nachfolgenden Briefe von einem unglücklich verliebten Menschen erhalten zu haben, der an jener Krankheit zum Tode litt, die seit Goethes Werther jeden aufrichtig und zugleich hoffnungslos Liebenden begleitet. Es war den Kopenhagenern damals nicht schwer, zu wissen, wer dieser junge Mann war, der da so litt und doch so virtuos zugleich sein eigener Herausgeber war. Es war Sören Kierkegaard, der seine religionsphilosophischen Schriften stets unter Pseudonymen zu veröffentlichen pflegte, dabei aber auffällig genug lebte, um jederzeit und hinter jedem intelligenten Pseudonym erkannt zu werden.

In diesen Briefen, die unter dem Titel Die Wiederholung erschienen, schreibt unter dem Eintrag des 19. September der namenlose Freund an seinen scheinbaren Herausgeber Constantius:

Mein verschwiegener Mitwisser!

Hiob! Hiob! O Hiob! Hast du wirklich nichts andres gesprochen als diese schönen Worte: Der Herr hat's gegeben, der Herr hat's genommen, der Name des Herrn sei gelobet? Hast du nicht mehr gesagt? Bist du in aller deiner Not dabei geblieben, nichts zu tun als sie zu wiederholen? Warum schwiegest du sieben Tage lang und sieben Nächte, was ging da in deiner Seele vor? Als das ganze Dasein über dir zusammenbrach und, Topfscherben gleich, rings um dich lag, hattest du da alsogleich die übermenschliche Fassung, hattest du alsogleich der Liebe Dolmetschung, des Vertrauens und des Glaubens Freimut? Ist deine Tür gleichfalls verschlossen vor dem Leidtragenden, darf er von dir keine andere Linderung erwarten als die, welche weltliche Weisheit kümmerlich bietet, indem sie einen Paragraphen über des Lebens Vollkommenheit vorträgt? Weißt du nicht mehr zu sagen, wagst du nicht mehr zu sagen als was die beamteten Tröster wortkarg dem Einzelnen zumessen, was die beamteten Tröster, steifen Zeremonienmeistern gleich, dem Einzel- 
nen vorschreiben, daß es nämlich in Stunden der Not ziemlich sei zu sprechen: Der Herr hat's gegeben, der Herr hat's genommen, der Name des Herrn sei gelobet, nicht mehr und nicht weniger, ebenso wie man Prosit sagt zu dem Niesenden! (Die Wiederholung, S. 68).

Nein, es ist nicht ziemlich, so in den Stunden der Not zu reden, wie es Hiob in den Mund gelegt wird. Daran lässt Kierkegaard nicht lange Zweifel aufkommen. Zu tun ist anderes, den Finger ins Dasein zu stecken und zu fragen:

Wo bin ich? Was heißt denn das: die Welt? Was bedeutet dies Wort. Wer hat mich in das Ganze hinein betrogen, und läßt mich nun dastehen? Wer bin ich? Wie bin ich in die Welt hineingekommen; warum hat man nicht vorher gefragt, warum hat man mich nicht erst bekannt gemacht mit Sitten und Gewohnheiten, sondern mich hineingestukt in Reih und Glied als wäre ich gekauft von einem Menschenhändler? Wie bin ich Teilhaber geworden in dem großen Unternehmen, das man die Wirklichkeit nennt? Warum soll ich Teilhaber sein? Ist das nicht Sache freien Entschlusses? Und falls ich genötigt sein soll es zu sein, wer ist denn da der verantwortliche Leiter - ich habe eine Bemerkung zu machen - ? Gibt es keine verantwortlichen Leiter? An wen soll ich mich wenden mit meiner Klage? Das Dasein ist ja eine Diskussion, darf ich bitten, meine Betrachtung mit zur Verhandlung zu stellen? Wenn man das Dasein nehmen soll wie es ist, wäre es denn dann nicht das Beste, man erführe wie es ist? (Die Wiederholung, S. 70f).

Kierkegaard gibt seinem alter ego viele Worte der Klage. Aber die Klage ist nicht zuerst die über das eigene Leiden, sondern die Klage darüber, nicht über dieses Leiden sprechen zu können. Die vielen Worte wollen daher nichts anderes sein, als jene Worte Hiobs, die ihm die Tradition seiner Ausleger genommen hat. Denn dort hat man Hiob zur Ikone des gottgefälligen Dulders erhoben, der zwar klagt, aber am Ende alle Fragen an das Dasein einstellt, wenn es zum Lob Gottes kommt, als habe am Ende das ganze Buch Hiob nur sagen sollen: „Der Name der Herrn sei gelobet".

Die Sprachlosigkeit Hiobs in der Tradition seiner Ausleger hängt freilich mit dem Buch Hiob selbst zusammen. Genau genommen ist es 
eine redaktionelle Zusammenstellung verschiedener Überlieferungen, die sich selbst für den ungeübten Leser leicht unterscheiden lassen. Da ist die Anfangserzählung von dem frommen und reichen Mann im Lande Uz, der mit der Erlaubnis des Herrn durch den Satan in der Standhaftigkeit seines Glaubens angefochten wird. Drei Freunde treten auf, Eliphas, Bildad und Zophar, um Hiob ihre Teilnahme über sein Unglück zu bezeugen, sitzen bei dem Aussätzigen sieben Tage und sieben Nächte schweigend. Da bricht diese Geschichte schon ab, um erst später und dann unvollständig mit dem Tadel des Herrn über Eliphas fortgesetzt zu werden, um schließlich zur Restitution des Verlustes überzuleiten. Hiob wird vom Herrn zwiefach ersetzt, was ihm genommen wurde. Hiob kann „alt und lebenssatt“ sterben. Das ist die erbauliche Geschichte, die den Frommen am Ende belohnt.

Dem Umfang nach machen diese Geschehnisse aber den geringsten Teil des Buchs Hiob aus. Denn in diesen Bericht ist ein großes Gedicht eingefügt, die Klage Hiobs in der Form eines Zyklus von Wechselreden mit seinen Freunden. Während seine Freunde von der Schuld Hiobs überzeugt sind, insistiert Hiob in steigernder Folge auf seiner Schuldlosigkeit, ja er wechselt zwischen Selbstverwünschung und Gottesherausforderung. „Schrey ich zu dir / so antwortestu mir nicht/ Trette ich erfur / so achtestu nicht auff mich“, klagt Hiob und fügt hinzu: „Du bist mir verwandelt in einen Grawsamen / vnd zeigest deinen gram an mir mit der stercke deiner Hand. Du hebst mich auff / vnd lessest mich auff dem winde faren / vnd zurschmelzest mich krefftiglich. Denn ich weis du wirst mich dem Tod vberantworten / da ist das bestimpte Haus aller Lebendigen: Doch wird er nicht die Hand ausstrecken ins Beinhaus / vnd werden nicht schreien fur seinem verderben. Ich weinete ja in der harten zeit / und meine Seele jamert der armen. Ich wartete des Guten / Vnd kompt das böse / Ich hoffte auffs Liecht / vnd kompt finsternis. Mein eingeweide sieden / vnd hören nicht auff / Mich hat vberfallen die elende zeit. Ich gehe schwarz einher / vnd börnet mich doch keine Sonne nicht / Ich stehe auff in der Gemeine vnd schreie" (Kap. 30, Übersetzung Luther, 1545). Erst nachdem Hiob so geklagt hat, erhebt der Herr seine Stimme. Der aufmerksame Leser sieht und hört auch hier, wie fremd und unvermittelt die Rede des Herrn neben der Hiobs steht. Auf dessen Klage, wenn nicht Anklage geht die Rede des Herrn nicht ein. Passen bei genauem Lesen schon das gegen den 
Herrn aufbegehrende Gedicht und die fromme Erzählung nicht fraglos zusammen, so ist mindestens ebenso umstritten, wie die Weisheit des Herrn und die Klage des Hiob zueinander gehören. Dabei ist die Klage des Gerechten über das ihm widerfahrene Unglück nicht neu. Sie findet sich in vielen Literaturen der alten Welt vor dem Buch Hiob. Auch dort gibt es Erklärungen für das Leiden des Gerechten, sei es als Prüfung, als Läuterung oder als Ausdruck übermenschlicher Weisheit. Das Buch Hiob nutzt diese vorantike Tradition und verbindet sie mit Weisheitslehren. Historisch mag das Buch daher vielleicht nur eine spätere redaktionelle Zusammenstellung verschiedener Texte mit ähnlichem Sujet sein. Wie immer die Teile des Buches einmal ursprünglich zusammengehört haben mögen, die für den Philologen sichtbaren Widersprüche sind nicht die der Tradition seiner Auslegung. Im Gegenteil. Die Widersprüche hat man aufzulösen gewußt, indem man jeweils unterschiedliche Teile des Buches als wesentlich herausgehoben hat, mal die Klage, mal die Prüfung, mal den Schluss des Buches.

Wir müssen - und können - die redaktionellen Konflikte des Buches Hiob nicht entscheiden, können aber sehen, wie die weiteren Generationen mit dem Buch Hiob und seinen Widersprüchen umgegangen sind. Man wird dann hier Kierkegaard Recht geben müssen, dass man in der Auslegungstradition doch deutlich bemüht war, Hiob in den Stunden der Not stets „ziemlich“ sprechen zu lassen. Schon die frühen aramäischen Übersetzungen des Buches, die Targumim, haben Hiob als Dulder verstanden, die Midraschim als wahrhaft Gottesfürchtigen oder als rechtschaffenen Nichtjuden. Den „unziemlichen“ Redner Kierkegaards kennt die Tradition der Hiob-Auslegung nicht. Die rabbinische Tradition - die etwa zeitgleich mit dem Christentum das uns geläufige Judentum ausbildet - hat ihn, wo sie Hiob nicht einfach als Gotteslästerer gesehen hat, als Schuldigen gesehen. Hiob, so sagt es der Talmud (b Sot 11a), habe an den Beratungen über das Schicksal der Israeliten in Ägypten teilgenommen, dort aber geschwiegen, statt für den Auszug aus Ägypten zu stimmen. Daher die Strafe Gottes. Das mittelalterliche Judentum, vor allem in seinem frömmigkeitsgeschichtlich für das aschkenasische Judentum wichtigsten Buch, dem Sefer Chassidim (,Buch der Gerechten'), parallelisiert das Leiden Hiobs mit dem Leiden des jüdischen Volkes. 
Beides sei Folge der eigenen Sünden und daher Prüfung Gottes. Selbst die mittelalterlichen sephardischen Rationalisten wie Saadja Gaon oder Maimonides billigen den Klagen Hiobs nur eine begrenzte Einsicht in die Weisheit Gottes zu, wenn sie ihn nicht gar als verwerflichen Aristoteliker vorführen. So bleiben nicht viele Worte Hiobs angesichts der Weisheit Gottes bestehen.

In dieser Hinsicht unterscheiden sich die christlichen Kommentierungen nicht prinzipiell von den jüdischen. Der schon bald als Heiliger verehrte Papst Gregor der Große hat bestimmend für die christliche abendländische Tradition im 6. Jahrhundert das Buch Hiob als eine Anleitung zum asketisch-monastischen Vollkommenheitsideal ausgelegt. Seine Moralia in Job wurden zur Sittenlehre der mittelalterlichen Theologie, oft abgeschrieben und ausgelegt, aber an keiner Stelle eine „unziemliche“ Klage. Erst Thomas von Aquin hat in seinem Hiob-Kommentar mit der tropologischen, d.h. moraltheologischen Deutung gebrochen und eine literaltheologische Deutung versucht. Sie ist freilich auch nicht auf Klage ausgerichtet, sondern sucht vielmehr im Leiden Hiobs die Vorsehung Gottes aufzuzeigen. Dem korrespondiert in der ikonographischen Tradition Europas die Darstellung Hiobs als gottgefälligen Dulders, der oft nackt und mit Aussatz behaftet abgebildet wird. In den illuminierten Handschriften Byzanz, in der romanischen Wandmalerei oder in der gotischen Kapitellplastik sind Stationen des Lebens Hiobs wiedergegeben: Hiobs Wohlstand, der Tod seiner Knechte und seiner Kinder, sein Aussatz, Hiob auf dem Dunghaufen, der Herr spricht aus den Wettern, der Herr setzt Hiob in sein altes Glück ein oder als typologisches Gegenbild zu Christus im Elend oder als Präfiguration der Passion Christi. Auf der Baptisteriumskanzel in Pisa figuriert Hiob neben Noah und Daniel als einer der drei Gerechten des Alten Bundes. In seiner Not - so sagen es die Darstellungen wie die Bücher - hat Hiob nicht mehr gesagt, als „der Herr hat's genommen, der Name des Herrn sei gelobet“.

Wir können es drehen und wenden, wie wir wollen. Das Buch Hiob ist ein Buch der Moral, mal subtiler, mal schlichter, aber immer in moralischer Absicht ausgelegt. Seine Hauptfigur wird nirgends zum Helden. Kaum eine Handlung hat sich selbst in der außerkanonischen Literatur wie etwa dem Hiob-Testament entwickelt. In der ganzen Tradition der Hiob-Literatur ist kein keuscher Joseph zu bewundern, sind keine Verwicklungen 
eines König David zu berichten und keine Liebesgeschichte eines Samson zu erzählen. Eine Geschichte, ein Stück Literatur ist das Buch Hiob über die Jahrtausende nicht geworden. Das mag in dieser Verallgemeinerung vielleicht nicht gleich einleuchten, sondern fordert die Frage heraus, warum dann Hiob nie eine literarische Geschichte geworden ist, die man erzählt und der man mit Spannung zuhört? Erzählen wir uns nicht vom Unglück anderer Geschichten, ja ist nicht die Literaturgeschichte nichts anderes als eine Aneinanderreihung von Geschichten über Unglücke, solcher der Liebe oder der Macht?

Im berühmten 13. Kapitel seiner Poetik handelt Aristoteles davon, „was man beim Zusammenfügen der Fabeln erstreben und was man dabei vermeiden muß und was der Tragödie zu ihrer Wirkung verhilft“ (S. 38f). Drei Geschichten sind demnach ungeeignet, um erzählt oder als Tragödie auf die Bühne gestellt zu werden. Man dürfe nicht zeigen, wie „Schufte einen Umschlag vom Unglück zum Glück erleben“. Noch darf man zeigen, „wie der ganz Schlechte einen Umschlag vom Glück ins Unglück erlebt“. Vor allem aber - und Aristoteles setzt diesen Fall ganz oben an - darf man nicht zeigen, „wie makellose Männer einen Umschlag vom Glück ins Unglück erleben; dies ist nämlich“ - so begründet es Aristoteles - „weder schaudererregend noch jammervoll, sondern abscheulich“ (1452b 30ff). Genau das ist nun die Geschichte Hiobs. Sie ist abscheulich, weil Hiob keinen Fehler, keine Hamartia aufweist. Er ist der Gerechte, aber damit kein mittlerer Held zwischen Schuft und makellosem Gerechtem, wie ihn die Literatur als Vorlage braucht. Die makellos Gerechten haben keine tragödienfähige Geschichte, die Jammern und Schaudern hervorruft. Ihr Unglück ist abscheulich, literarisch damit aber ohne Wert. Denn sie lösen keine anderen Affekte als den der Abscheu über das Schicksal aus. Sie taugen damit zur Lehrfabel, nicht aber zur Tragödie. Das Unglück des Gerechten mag moralisch und theologisch einige Fragen aufwerfen. Aber eine Geschichte ergibt das noch nicht.

Was Aristoteles festgestellt hat, sind gültige Anforderungen an eine erzählenswerte Geschichte, der auch wir noch folgen. Wir erzählen uns ja nicht beliebig viele Geschichten, sondern eigentlich nur ein sehr kleines Inventar von Handlungskonstellationen, die wir variierend und kombinierend fortspinnen. Das sind die immer ähnlichen Muster der Ausfahrt und Heimkehr, die geschlechtliche Reproduktion (oder deutlicher geredet: Hans kriegt seine Grete), Rivalitätskämpfe, Aufdeckung des Unbekannten 
und Schuld und Sühne. Hiob fährt nicht aus, kriegt keine Grete, er redet nur und kämpft nicht, er entdeckt nichts Unbekanntes. Für was er Sühne leisten muss, ist nur ansatzweise in der späteren Kommentarliteratur nachgetragen worden, etwa sein Verhalten beim Auszug der Israeliten aus Ägypten. Nur mit solchen Zusätzen erhält Hiob ansatzweise eine literarische Geschichte. Ein Held ist er nicht, schon gar nicht ein mittlerer Held, wie ihn Aristoteles fordert. Wenn es einen Spannungsbogen in diesem Buch Hiob gibt, dann ist er ein moralphilosophischer, kein erzählerischer. Ein erzählerischer Spannungsbogen setzt bestimmte Verlaufserwartungen voraus, die uns rühren und die erzählten Ereignisse zu einer Geschichte zusammenfügen. Diese Ordnung der Ereignisse zu einer emotional bewegenden Geschichte erzeugen jene Katharsis, also Reinigung der eigenen Affekte des Lesers und Zuschauers, die auf die Eudaimonia, die Glückseligkeit, zielen. Weder ein narrativer Spannungsbogen noch eine emotionale Affektreinigung gewährt das Buch Hiob. Der Wechsel vom Glück ins Unglück ist so unmittelbar und kaum hinreichend motiviert, wie die schlußendliche Restitution Hiobs am Ende des Buches. Da ist kein Ödipus zu beweinen, der zugleich schuldlos und doch schuldig wäre, keiner, der durch sein Handeln das tragische Geschehen antreibt. Hiob wird nicht zufällig in der Kunstgeschichte als statische Figur dargestellt, der auf dem Misthaufen sitzt und mit Aussatz geschlagen ist. Hiob handelt nicht, er erleidet. Eben das nimmt ihm sein literarisches Potential.

Noch Herder, der sich im 18. Jahrhundert so intensiv darum bemühen sollte, die Bibel als ein Buch der Literatur zu sehen, vermochte Hiob nur als ein Gedicht zu lesen, nicht aber als eine erzählenswerte Geschichte: „Das vortreffliche Buch Hiob!“, schreibt Herder über den ,Geist der Ebräischen Poesie', „woher nimmt es alle seine Schäzze der Schönheit“, „seine herrlichen Bilder“ und die „kurze, majestätische Donnersprache des Schöpfers" (Herder, Vom Geist, S. 284)? Weder Bilder noch Sprache allein formen eine Geschichte. Dazu gehören Figuren und Handlungen. Beides besitzt das Buch nur ansatzweise. Hiob, das ist ein Buch für theologische und moralische Kommentare, kein Stück der Literatur.

Fast, nicht ganz - und damit kehre ich zur Literaturgeschichte zurück. Denn seit dem 19. Jahrhundert hat es nicht an Versuchen gefehlt, das Buch Hiob gegen seine eigene Statik zu erzählen. Das hängt damit zusammen, dass erst in diesem Jahrhundert die psychologische Innensicht der Figuren als ein Handlungs- und Darstellungsfeld der Literatur zur 
Routine wird. Wir müssen nicht die Säkularisierung oder den modernen Nihilismus bemühen, um zu erklären, warum Hiob erst so spät eine literarische Geschichte werden konnte. Die Menschen früherer Zeiten haben mindestens ebenso verzweifelte Fragen an ihr Dasein gerichtet wie wir. Nur die Psychologisierung der Figuren, in denen sie sich die Geschichten ihres Unglücks erzählt haben, waren andere.

Kierkegaard ist der erste, der nicht mehr nur Motive aus dem Buch Hiob übernimmt, wie etwa die Verhandlungen zwischen Gott und Satan über den Knecht Hiob. Kierkegaards alter ego, dieser namenlose Freund, anverwandelt sich Hiob in seiner Verzweiflung: „Mein unvergesslicher Wohltäter, Hiob, du Vielgeplagter! Wage ich's mich deiner Gesellschaft anzuschließen, darf ich auf dich hören? Stoß mich nicht fort, ich stehe nicht mit falscher List bei deinem Aschenplatz, meine Tränen sind nicht unecht, ob ich gleich nicht in der Lage bin, bloß deinetwegen zu weinen. Gleich wie der Frohe die Freude sucht, teilnimmt an ihr, wiewohl das, was zu allernächst ihn freut, die Freude ist, die in ihm selber wohnt, ebenso sucht, der da Leid trägt, das Leid“ (S. 70). Die Wahlverwandtschaft im Leiden ist eine psychologische. Was für Kierkegaards Figur zählt, ist die Ähnlichkeit der Emotionen im Leid. Der Gegenstand des Leidens ist dagegen denkbar verschieden. Hiob hat seine Familie, sein Haus, alles was ihm lieb und teuer ist, verloren. Kierkegaards Figur ist nur unglücklich verliebt und wird nicht erhört. Die Ähnlichkeit stellt Kierkegaard und mit ihm das 19. Jahrhundert darüber her, dass es Hiob eine moderne Psychologie verleiht. Denn im biblischen Buch ist Hiob dann wieder zufrieden, wenn ihn Gott in seinen Ehren wieder einsetzt und ihm doppelt das Verlorene ersetzt. Dass in dieser Welt selbst Gott die toten Kinder Hiob nicht wieder geben kann, interessiert die biblische Psychologie gar nicht. Die Zahl, nicht die Namen der Kinder entscheiden über den Status einer Figur. Sie allein ist berichtenswert. Uns wäre aber genau der Verlust der Kinder der schmerzlichste, den keine Ehren aufzuwiegen vermöchten. Wir würden die Namen, nicht die Zahl erzählen wollen. So aber argumentiert das biblische Buch Hiob nicht. Es folgt nicht unserer modernen Psychologie.

Kierkegaards Verfahren der Psychologisierung Hiobs und seine Anverwandlung an den modernen Gefühlshaushalt ist provokativ. Sie gibt Hiob eine Redemacht wieder, die mehr sein soll, als die Rede von der Moral es sein kann. Nein, kein Trost soll diese Rede sein: „Heutzutage meint man, 
des Leides eigentlicher Ausdruck, der Leidenschaft verzweifelte Sprache müsse den Dichtern überlassen bleiben, welche also als Anwälte eines Verunrechteten die Sache des Leidenden vertreten vor dem Richtstuhl des menschlichen Mitleids. Weiter wagt niemand sich vor" (S. 69). So fasst Kierkegaard den Konsens der Moderne zusammen, die Klage nur als literarische zu kennen scheint. Genau dagegen argumentiert Kierkegaards Briefschreiber:

Darum zähle du es alles her, unvergeßlicher Hiob! Wiederhole es alles, was du gesagt, du gewaltiger Fürsprech, welcher vor den Richtstuhl des Allerhöchsten unerschrocken hintritt gleich einem brüllenden Leu! In deiner Rede ist Sinn, in deinem Herzen ist Gottesfurcht, auch wenn du klagest, wenn du für deine Verzweiflung dich wehrst wider deine Freunde, welche Räubern gleich sich erheben, um dich mit ihren Reden zu überfallen, auch wenn du, von deinen Freunden aufgebracht, ihre Weisheit zertrittst, und ihre Verteidigung Gottes des Herrn verachtest, als wäre es eines abgelebten Hofmanns oder eines staatsklugen Regierungsmanns elende Klügelei. Deiner bedarf ich, du bist ein Mann, der laut zu klagen weiß, daß es im Himmel widerhallt, allwo Gott Rates pflegt mit dem Satan, um Pläne zu spinnen wider einen Menschen! Erheb Klage, der Herr hat keine Furcht, er vermag es sehr wohl sich zu verteidigen; aber wie sollte er sich denn verteidigen können, wenn niemand Klage zu erheben wagt, wie es einem Menschen ansteht (S. 69).

Damit Kierkegaards Hiob wieder so mächtig jenseits irdischer Moral und all ihrer Nützlichkeiten die Klage erheben kann, bedient sich Kierkegaard eines typischen Verfahrens der modernen Psychologisierung. Kierkegaards neuer Hiob schreibt Briefe, mehr noch. Diese Briefe sind Teil einer Liebesgeschichte, die für den Leser alles Zeug hat, eine zweite Wertheriade zu werden, eine unglückliche Liebesgeschichte mit Selbstmord am Schluss. Man sieht daran, wie aus Hiob eine Geschichte wird. Erst hier bei Kierkegaard wird Hiob zu einem modernen Helden, der handelt und durch seine Handlungen die Geschichte vorantreibt, ja erst eigentlich hervorbringt. Damit hört er auf, der stille Dulder zu sein. Ob Hans nun seine Grete bekommt, das ist immer eine Geschichte wert, so auch hier. Und wenn diese Liebe so tragisch zu sein scheint wie bei diesem 
Namenlosen, fiebern wir mit. Die Geschichte kommt von den Höhen der Moralphilosophie herunter nah an unser modernes Herz.

Freilich: Auch Kierkegaards Narrativierung eines nur begrenzt poetischen Stoffes stößt auf dessen Grenzen. An seinen starken Eingriffen in das eigene Manuskript kann man ablesen, wie Kierkegaard von dem in der Logik der Handlung liegenden tragischen Liebesgeschick abweicht. Ein fast komödienhafter Schluss biegt die Geschichte um in eine glückliche Heirat, statt auf den Selbstmord des Protagonisten zuzulaufen. Der Hans hat seine Grete doch noch und so unvermittelt bekommen, wie Hiob seinen Besitz wieder erstattet bekommt. Das ist kein ganz befriedigender Schluss für denjenigen, der eine Wertheriade erwartet hatte. Der Versuch in der experimentierenden Psychologie - so der Untertitel - macht am Ende aus Hiob einen glücklich verheirateten Dichter. Damit verliert der Versuch seinen Selbstanspruch, unziemliche Rede über alle bekannte Literatur hinaus sein zu wollen. Hiobs Klage wird zur Komödie moderner Psychologie, ein Spott auf den Dichter und sein ästhetisches Stadium, das zu überwinden wäre. Wird Hiob zur komischen Figur des Dichters, hört er auf noch die biblische Figur zu sein. Er hält am Ende weder „unziemliche“ Reden noch weiß er den Herrn zu loben. Er ist nur lächerlich. Hiob ist Kierkegaard nur deshalb zu einem erzählbaren Stoff geworden, weil er ihn nicht mehr in der Statik der biblischen Figur auftreten lässt, sondern als modernen Menschen mit der Lächerlichkeit seiner ganzen Psychologie zeichnet. Hiob ist ein Symbol, aber kein Erzählstoff.

Kierkegaards Schwierigkeiten, von Hiob zu erzählen, sind beispielhaft für alle weiteren Adaptionen. Wenn in George Bernard Shaws Kurzgeschichte Ein Negermädchen sucht Gott das kleine Mädchen Gott sagt: „Ein Gott, der mir meine Fragen nicht beantworten kann, nützt mir nichts. ... Hiob muß sehr dumm gewesen sein, daß er dich nicht durchschaut hat", dann ist das keine Hiob-Geschichte, sondern nur das Zitat einer Gottesfrage. Allenfalls für eine Kurzgeschichte wie Brechts Erzählung Der Blinde taugt die Hiob-Adaption. Aber auch hier reduziert sich die Geschichte auf die Geste der Rebellion, die Gott nicht verzeihen will. Hiob ist die zitierte Folie für ganz neue Figuren. Gewiss, die großen Romane wie Döblins Berlin Alexanderplatz oder Kafkas Prozeß statten ihre Hauptfiguren mit Zügen Hiobs aus, so dass Gershom Scholem 1928 
ganz selbstverständlich Kafkas Roman als Hiobgeschichte bezeichnen kann: „Ich finde den Prozeß von absoluter Großartigkeit, es ist die erste Rekonstruktion der Welt des Buches Hiob, die seitdem einem Menschen, und natürlich nur einem Juden, aufgegangen ist. Ich bin selten von etwas so ergriffen worden" (an Werner Kraft, 10.5.1928; in: Scholem, Briefe, S. 235). Aber Hiobsgeschichten sind sie als ganze nicht. Sie geben ihren Figuren einen mindestens negativen Status als Helden, den Hiob nicht hat, geben ihnen Handlungen von ungewissem Ausgang. Kein Zufall daher, dass Hiob ein Zitat ist, dienlich für die Ausformung von Figuren, eine Metapher für die moderne Lyrik von Mascha Kaleko bis Nelly Sachs, ein Symbol für das leidgeprüfte Volk bei Ernst Wiechert nicht anders als bei Karl Wolfskehl, aber doch keine Geschichte (vgl. Langenhorst, Ijob und Hahn, Hiobsgeschichten).

Aber hat nicht Joseph Roth einen ganzen Roman Hiob (1930) überschrieben, wird man einwenden. Dieser Roman eines einfachen Mannes, wie es im Untertitel heißt, versucht in der Tat die Geschichte eines modernen Hiob zu erzählen: Dem frommen Mendel Singer wird Prüfung um Prüfung abverlangt: die Geburt seines schwachsinnigen und epileptischen Sohnes, die seinem Glauben zuwider laufende Einberufung des ältesten Sohns zum Militär, die Flucht seines zweiten Sohnes nach Amerika, die Entdeckung, dass sich seine einzige Tochter mit einem Kosaken eingelassen hat, seine eigene Flucht nach Amerika, der Verlust seiner Söhne im Weltkrieg, der Tod seiner Frau nach ihrem Gram über den Tod ihrer Söhne, schließlich der Wahnsinn seiner Tochter. Mendel Singer schwört Gott ab, betet nicht mehr und lebt still, bis ihn unerwartet sein kranker Sohn findet. Der ist auf wundersame Weise von seiner Krankheit geheilt und ein berühmter Komponist und gefeierter Dirigent geworden. Er nimmt seinen Vater zu sich: „Mendel schlief ein. Und er ruhte aus von der Schwere des Glücks und der Größe der Wunder", wie es am Schluss heißt.

Schon die zeitgenössische Literaturkritik hat zu diesem erfolgreichen Roman angemerkt, dass seine wunderbare Wendung ohne Motivation bliebe, die vorausgehenden Handlungen eigentlich nur die Addition immer gleicher Schicksalsschläge sei und der Roman doch einen eher kitschigen Schluss biete. Roth hat selbst dieser kritischen Beurteilung zugestimmt. Uns wirft das einmal mehr die Frage auf, ob Literatur überhaupt so vom Leiden der Menschen, gar der Gerechten erzählen kann, 
wie wir das üblicherweise voraussetzen. Uns ist doch Literatur gerade ein Ort, an dem die Verhandlungen geführt werden, die in den alltäglichen Nützlichkeitsabwägungen keinen Platz haben. Literatur sei da etwas ganz anderes, vieldeutig zwar, aber mit den Grundfragen der menschlichen Existenz betraut. Wenn, dann müsse doch dort Platz für unsere Ängste und für das Leiden sein. Das meint nicht nur Kierkegaards Briefschreiber.

Auf die Gefahr hin, enttäuschen zu müssen, will ich aus meiner Antwort keinen Hehl machen und sagen, dass das die Literatur überfordert. Wie immer wir es wenden, Literatur erzählt immer geordneter und bedeutsamer als es das Leben ist. Wir verlieben uns nicht nach Filmdrehbüchern und leiden nicht so tragisch wie König Ödipus. Das heißt nicht, daß wir weniger lieben oder leiden würden. Nur das Skript dafür ist ein anderes. Literatur greift von unseren möglichen Erfahrungen nur diejenigen heraus, die sich zu einer Geschichte fügen lassen. Und das sind nicht alle und auch nicht in beliebiger Folge. Die Aneinanderreihung von bitteren Unglücksfällen ergibt noch keine Geschichte. Vom wirklichen Leiden kann daher die Literatur nur begrenzt erzählen, fast gar nicht von dem namenlosen Leid vieler, gar von Völkermord. Die Erwartung der Literaturkritik und der Literaturwissenschaft, in der Literatur kämen die stummen Stimmen der Gequälten und Toten zu Wort oder die Unvorstellbarkeit der Katastrophe der Juden-Vernichtung könne nur in der Literatur angemessen zur Sprache kommen, trügt. Auch die Holocaust-Literatur erzählt nach keinen anderen Regeln als die übrige Literatur. Denn auch hier werden Geschichten einzelner erzählt, verdichtet und zu Erzählverläufen geordnet, etwa in so bezwingenden Büchern wie Imre Kertesz Roman eines Schicksallosen. Für diese Helden und ihr Unglück nehmen wir uns Zeit und Herz, nicht für Millionen ungerecht Leidender. Und nicht nur das, wir brauchen für unsere Aufmerksamkeit auch das, was Goethe mit Blick auf die Novelle als „unerhörte Begebenheit“ bezeichnet hat. „Unerhört“ meine die Außergewöhnlichkeit und Nicht-Alltäglichkeit des Geschilderten, „Begebenheit“ die Anordnung der Handlung in eine spannungserheischende Verlaufsform.

Hiobs Geschichte ist unerhört, aber keine Begebenheit. Wenn sie das sein soll, dann muss der Autor die Begebenheit dazu erzählen und Hiob zum handelnden Protagonisten verändern, der er der biblischen Tradition nach gerade nicht ist. Hiob ist daher für die Theologie eine Geschichte, für die Literatur ist sie ein Symbol, dem die Geschichte erst hinzuerfunden 
werden muß. Meine skeptische Einschätzung des Buches Hiob soll den geringen literaturgeschichtlichen Befund verständlich machen, warum nur selten und nicht ausführlich vom Leiden des Gerechten erzählt wird. Die skeptische Einschätzung macht auch deutlich, daß wer immer Hiobgeschichten erzählen will, stets Gefahr läuft, anstelle der Geschichte eine Moral zu erzählen. Und das tut der Geschichte nicht unbedingt gut. Hören wir zu, wie es trotzdem gelingen kann, eine Hiobsgeschichte zu erzählen.

1996 meldet die Presse den Abdruck einer Geschichte, die „gewaltiger als das Buch Hiob“ sei (Der Spiegel 49 vom 2.12.1996). Die Rede ist von einer Geschichte, die in ihrer Einleitung behauptet, in den Ruinen, Jiddisch: „Churwes“, des Warschauer Ghettos geschrieben worden zu sein. In der Umschrift liest sich das so:

In ejner vun die Churwes vun Warschewer Getto, zwischen Hojfens vun varsmaljete Stejner un menschliche Bejner, is gefunden geworen, varsteckt un varstoppt in a klejn Fläschel, der folgender Testament, geschrieben vun a Jiden mit'n Nomen Jossl Rakover in die letzte Scho'en [Stunden] vun Warschewer Getto (Kolitz, Jossel Rakovers, S. 8).

Tatsächlich haben die jüdischen Widerstandskämpfer solche Flaschen mit Aufzeichnungen vergraben, die von ihrem verzweifelten Kampf Zeugnis nach ihrem Tode ablegen sollten. Aber das hier ist eine erfundene Aufzeichnung, die kein Warschauer Untergrundkämpfer geschrieben hat. Geschrieben hat sie in Wirklichkeit ein Mitglied der Hagana namens Zvi Kolitz, der gegen die britischen Kolonialtruppen in Palästina kämpfte, niemals aber in Warschau war. In einer Nacht in Buenos Aires des Jahres 1946 schreibt Kolitz die Geschichte eines Hiob auf. Damit es eine Geschichte wird, berichtet er nicht von den namenlosen Leid der damals 1943 in Warschauer allein gelassenen und auf verlorenem Posten kämpfenden Juden, sondern erfindet die Geschichte des Gerechten, des „Chossid vun Gerer Reben un Opstammiger vun die Zadikim, Gedojlim un Kedojschim [der Gerechten, Gelehrten und Heiligen] vun die Mischpoches Rakover un Meisls“ (S. 8). Dieser gerechte Jossel Rakover liegt in einem der brennenden und bald zusammenstürzenden Häuser des Warschauer Ghettos, so erzählt es Kolitz' Geschichte. Verblieben sind ihm ein paar Benzinflaschen, um gegen die anrückenden deutschen Truppen 
zu kämpfen, eine letzte, um sich selbst das Leben zu nehmen. Dieser Jossel scheint nun seine unerhörte Geschichte des Unglücks zu erzählen, als sich die vertraute Welt in ihr Gegenteil zu verkehren begann:

Millionen Menschen ojf der weiter, grojsser Welt, Varliebte in Tog, in Sunn un in Licht wejsen gornit, hoben gar kejn Ahnung nit, wie viel Finsternisch un Umglick sie hot uns gebracht. Sie is varwandelt geworen in a Instrument in die Hänt vun die Reschoim [die Verbrecher] un sej hoben sich banutzt mit ihr wie mit a Proshektor kedej [um uns] zu antdeckn die Tritt vun di vun sej Antlojfende. Wenn ich hob mit mein Froij un meine Kinder - sechs is gewen sejer Zohl - sich in Wälder bahalten hot die Nacht, nor die Nacht, uns bahalten in ihr Busim: Der Tog hot uns ojsgeliefert zu die Suchers vun unsere Neschomes [Seelen]. $\mathrm{Zi}$ wel ich denn vargessen dem tog vun jenem deitschen Feier Hogel ojf tojsenter Plitim [Flüchtlinge] ojf'n Weg vun Grodne kejn Warsche? Mit'n Ojfgang vun der Sunn senen ojfgegangen die Aeroplanen un in Mejschech vun a ganzen Tog [während des ganzen Tages] hoben sej umojfherlich gemordet. In der dosiger Luft-Schchite [Luftschlacht] senen umgekummen mein Froj mit an Ojfele [Säugling] vun sieben Monat ojf ihre Orems, un zwej andere vun meine gebliebene finf Kinder senen in jenem Tog spurlos varschwunden. Dowid un Jehuda hoben sej gehejssen. Ejner vier, der anderer sechs Johr alt (S. 12f).

Hier haben die Figuren Namen, ein Alter, eine Geschichte, einen Vater, der sie verzweifelt nach Einbruch der Dämmerung sucht und der weiter erzählt, immer weiter, wie seine Tochter Rachel zu Tode kam:

Rochale hot mir nit derzählt vun ihr Plan sich arojszuganwenen vun Getto [sich aus dem Ghetto zu stehlen] - a Varbrechen, farwos men hot bastroft mit Tojt -, un zusammen mit a Chawerte ihre [mit ihrer Freundin], a Mejdele in ihr Älter, hot sie sich gelost ojf'n gefährlichen Weg. In der Nacht Finsternisch is sie awek vun der Hejm un mit Sunn Ojfgang is sie mit ihr Chawerte [Freundin] bamerkt worden ojsserhalb die Getto Tojeren. Nazische Getto Schojmrim [Gettowächter der Nazis] zusamen mit zehndliger pojlische Mithelfer hoben bald ongehojben a Gejäg noch die jidische Kinder wos hoben gewagt zu suchen Sticklech Brojt in a Mistkasten kedej nit ojszugehn vun Hunger [nicht 
zu verhungern]. Mensch wos hoben dem dosigen Gejäg beigewojnt hoben nicht gegloibt wos sejere Ojgen sehen. Afile [selbst] in Getto is gewen a Neies. Men hot gekonnt mejnen as do jogt men sich noch antlofene gefährliche Varbrecher. Zehndlige Reschoim [eine furchbare Meute] hoben sich gelost in an 'amok'Gelojf noch zwej zehn johrige varhungerte Kinder wos hoben lang nit ojsgehalten die Varmestung [den Wettlauf] un ejne vun sej, mein Kind, is ojsloifendig ihre letzte Kojches [Kräfte] gefallen an erscheppte ojf der Erd und die Nazis hoben ihr dann durchgestochen ihr Kopp (S. 17f).

Der Schrecken der verfolgten und schließlich ermordeten Kinder hat eine Geschichte, die wir in ihrer ganzen Monstrosität unmittelbar nachempfinden können, auch heute mehr als ein halbes Jahrhundert später, eben weil es eine erzählbare Geschichte ist und ihre Figuren handeln, nicht nur erdulden. Die Geschichte ist uns darum authentischer als die wirklichen Berichte.

Am Ende bleibt Jossel Rakover nur noch der Tod als Erlösung. Zuvor aber legt er ein Bekenntnis seines Glaubens ab. Und hier geht nun die Erzählung zu Ende, beginnt ein Gebet, eine Klage an Gott:

Ich glojb in Gott vun Isroel ojb afile [obwohl] er hot alz getun as ich soll in ihm nit glojben. Ich glojb in seine Gesetzen ojb afile ich kenn nit matzdik sein seine Meissim [auch wenn ich seine Taten nicht rechtfertigen kann]. Mein Baziehung $\mathrm{zu}$ ihm is mehr nit wie vun a Knecht zu sein Harr nor wie vun a Talmid [Schüler] zum Rebben. Ich bojg mein Kopp far sein Grojsskeit, ober ich wel nit kuschen die Rut mit welche er schlogt mir. Ich hob ihm lieb, ober sein Tojre hob ich lieber [seine Tora habe ich lieber], un wenn ich wollt sich afile in ihm antojscht wollt ich sein Tojre gehit. Gott hejsst Religje, ober sein Tojre hejsst - a Lebens Stejger [eine Lebensweise], un wos mehr mir starben far'n dosigen Lebens Stejger alz mehr umsterblich wert er. ... (S. 37f). ... Ich bin ihm nochgegangen afile wenn er hot mir derweitert vun sich [auch wenn er mich von sich gestoßen hat]; ich hob gefolgt sein Gebot afile [auch] wenn er hot mir geschlogen derfar; ich hob ihm lieb gehat, ich bin gewen, un gelbieben varliebt in ihm afile wenn er hot mir zu der Erd derniederigt, zum Tojt gepeinigt, zu Schand un zu Spott gemacht. ... Du, ober, tust alles as ich soll in Dir nit glojben. 
Kojm ober fallt Dir ein as Dir wet gelingen mit die dossige Nissjojnes [Versuchungen] mir aropzufihren vun richtigen Weg, melde ich dir, Gott meiner un Gott vun meine Elteren, as Dir wet es gornit helfen. Megstu mir baleidigen, megstu mir schlogen, megstu aweknehmen vun mir dos Teierste un Beste wos ich hob ojf der Welt, megstu mir zum Tojt peinigen - ich in Dir wel ständig glojben. Ich Dir wel ständig lieb hoben, ständig - dir allejn ojf Zeloches [dir zum Trotz] (S. 49f).

Das ist schon ein Gebet, ein rechtendes Gebet freilich, keine Geschichte mehr. Die Geschichte kehrt damit zurück, woher sie kommt. Der Autor der Geschichte Zvi Kolitz war klug genug zu wissen, wie weit Hiob als eine literarische Geschichte trägt und wo sie Gebet werden muss. Damit gelingt die Geschichte in den Grenzen, die der Hiob-Stoff vorgibt. Weil nun ihr Autor Zvi Kolitz vergessen, die Geschichte aber weitergereicht wurde, schien es bald, als wäre die Geschichte tatsächlich in den Ruinen des Warschauer Ghettos geschrieben worden und ihr Autor selbst ein moderner Hiob. So wurde aus der Zeitungsgeschichte des Zvi Kolitz aus Buenos Aires das authentische Zeugnis des Jossel Rakover aus Warschau, immer wieder nachgedruckt als Geschichte wie als Zeugnis und Gebet und schließlich in die Gebetbücher der jüdischen Gemeinden Amerikas aufgenommen. Dort liest man sie, die Geschichte vom Leiden des Gerechten am Jom Kippur und liest sie als Gebet.

Am Ende der Hiobgeschichte vom schwer vorstellbaren, aber doch erzählbaren Leiden sagt auch diese Geschichte dann nur:

Un dos senen ojch meine letzte Werter zu Dir, mein zorndiger Gott: Es wet Dir gornit helfen! Du host alz getun kedej [damit] ich soll sich in Dir antojschen, kedej ich soll in Dir nit glojben, - ich starb ober, punkt wie ich hob gelebt, an umderschitterlicher Glojbiger in Dir. ... 'Schma Isroel! Haschem Elokejnu, Haschem Echod! Bejadcho Haschem afik ruchi' [Höre Israel! Der Herr ist unser Gott, der Her ist Einer! In Deine Hände, o Herr, empfehle ich meinen Geist!] (S. 49).

Am Ende mündet auch diese Geschichte dorthin ein, wohin auch das biblische Buch Hiob führt, dorthin, wovon sich Kierkegaards Hiob lösen 
wollte, als er sich aufmachte, eine Geschichte von sich selbst zu erzählen. Am Ende mündet alles zu dem „Der Herr hat's gegeben, der Herr hat's genommen, der Name des Herrn sei gelobet“. Wenn das sich dann nicht anhört wie ein Prosit, das man einem Niesenden sagt, dann liegt das an dem, was dazwischen erzählt wird, zwischen dem „der Herr hat's gegeben“ und dem „der Herr hat's genommen“. Wenn die Literatur etwas zu Hiob zu sagen hat, dann eben diese Geschichten zwischen den Gebetszeilen. Sie allein erzählt eine Geschichte und sagt dabei doch nur „Gelobt sei der Name der Herrn“.

\section{Literaturhinweise}

Aristoteles: Poetik. Griechisch / Deutsch. Hg. und übersetzt von Manfred Fuhrmann. Stuttgart 1982.

Barbara Hahn: Hiobsgeschichte. Übersetzungen und Umschriften von Martin Luther bis Martin Buber. In: Deutsche Vierteljahrsschrift für Literaturwissenschaft und Geistesgeschichte 71, 1 (1997), S. 146-163.

Johann Gottfried Herder: Vom Geist der Ebräischen Poesie. Eine Anleitung für Liebhaber derselben und der ältesten Geschichte des menschlichen Geistes [1782]. In: Ders.: Sämtliche Werke. Hg. von Bernhard Suphan. Bd. 11. Berlin 1877. Sören Kierkegaard: Die Wiederholung. In: Ders.: Gesammelte Werke. 5. und 6. Abteilung. Düsseldorf, Köln 1955, S. 1-97.

Georg Langenhorst: Ijob - Vorbild in Demut und Rebellion. In: Heinrich Schmidinger (Hg.): Die Bibel in der deutschsprachigen Literatur des 20. Jahrhunderts. Bd. 2: Personen und Figuren. Mainz 1999, S. 259-280.

Zvi Kolitz: Jossel Rakovers Wendung zu Gott. Zweisprachige Ausgabe mit einem Faksimile des rekonstruierten Originals. Hg. von Paul Badde. München 1999. R. P. Schmitz / L . Hödl / G. Jászai: Art. Job (Hiob). In: Verfasserlexikon. Die deutsche Literatur des Mittelalters. Berlin, New York $1977 \mathrm{ff}$.

Gershom Scholem: Briefe I. Hg. von Itta Shedletzky. München 1994. 



\title{
Eine weithin unbekannte Schöne: Die lateinische Bibelepik der Spätantike
}

\author{
SiEgMar DöPP
}

I.

Am Anfang mögen Verse stehen, mit denen ein berühmter deutscher Schriftsteller des 18. Jahrhunderts sein Hauptwerk, ein großes Gedicht, einleitet. Es handelt sich um sieben Hexameter, die heute ein wenig altertümlich klingen. Der Dichter ruft dort nicht, wie es in der Poesie lange üblich war, die Muse als Quelle der Inspiration an, sondern seine Seele, die er als unsterblich betrachtet. Wenn er von ,Menschheit' spricht, meint er die Menschwerdung Gottes in Christus, mit ,Juda' die Bewohner der Landschaft, die sich von Jerusalem bis zum Toten Meer erstreckt. In gedrängter Form spielt der Dichter auf Kreuzigung und Auferstehung an. Die sieben Hexameter lauten:

Sing, unsterbliche Seele, der sündigen Menschen Erlösung, die der Messias auf Erden in seiner Menschheit vollendet, und durch die er Adams Geschlecht zu der Liebe der Gottheit, leidend, getödtet, und verherrlichet, wieder erhöht hat. Also geschah des Ewigen Wille. Vergebens erhub sich Satan gegen den göttlichen Sohn; umsonst stand Juda gegen ihn auf: er thats, und vollbrachte die große Versöhnung.

Mit diesen Versen eröffnet Friedrich Gottlieb Klopstock sein religiöses Epos Der Messias, das er zwischen 1748 und 1773 nach und nach veröffentlichte und bis zu seinem Lebensende im Jahre 1803 unermüdlich überarbeitete; insgesamt wurden es 20 als, Gesänge' bezeichnete Bücher, rund 20000 Verse. Gegenstand der ersten 10 Bücher ist die Passion Christi; sie wird eingefügt in einen kosmischen Rahmen, den Kampf zwischen Himmel und Hölle. Das Passionsgeschehen folgt im Wesentlichen den Berichten des Neuen Testaments. Der zweite Teil des Epos, Buch 11-20, verherrlicht sodann den Erlöser; geschildert werden die Auferstehung, der Sieg über Satan, Visionen des künftigen Gerichts und der Aufstieg zum himmlischen Thron Jehovas. Die Auffassung, welche die 
Naturwissenschaft der Klopstock-Zeit vom Weltall hatte, verbindet sich mit einer traditionellen Vorstellung von Himmel und Hölle. Adam und Eva, die Erzväter, die ungeborenen Seelen - sie alle sind als Zeugen mit Erinnerungen und Visionen in die Darstellung einbezogen und rücken die Stationen der Heilsgeschichte nahe an die Gegenwart heran. Bei der Deutung der Bibel wendet der Dichter ein altes exegetisches Verfahren an: die Typologie, das heißt: er lässt Personen, Ereignisse oder Einrichtungen der Zeit Christi in einer weit zurückliegenden Vergangenheit präfiguriert sein. Diese Weise der Geschichtsschau ist bereits in der Bibel anzutreffen; dort erscheint etwa David als Typus des künftigen Heilskönigs (2 Sam 7,12 ) oder Adam als Typus Christi (Röm 5,12-21). Derartige Bezüge stellt nun auch Klopstock mehrfach her. In einem erhabenen Ton geschrieben, erregte sein Epos bei den Zeitgenossen größtes Aufsehen - kaum eine andere literarische Schöpfung hat die Gemüter des 18. Jahrhunderts so bewegt wie der Messias.

Dieses Werk repräsentiert als eines der letzten eine sehr lange, über die Renaissance und über das Mittelalter bis in die Spätantike zurückreichende literarische Tradition, die so genannte Bibelepik, also erzählende Dichtung über biblische Ereignisse und Gestalten, überwiegend in daktylischen Hexametern, während des Mittelalters aber auch in elegischen Distichen verfasst.

In lateinischer Sprache entstehen Bibelepen seit dem vierten nachchristlichen Jahrhundert; sie gehören zu den herausragenden poetischen Schöpfungen der Spätantike. Die wichtigsten Repräsentanten sind folgende. Der spanische Presbyter Iuvencus schreibt um 330 n. Chr. mit den Euangelia ein Epos, das die Lebensgeschichte Jesu im Wesentlichen nach dem Evangelisten Matthäus darstellt, aber auch die anderen Evangelien berücksichtigt. In der zweiten Hälfte des vierten Jahrhunderts schafft Faltonia Betitia Proba, eine römische Aristokratin, ein Gedicht, das ausgewählte Ereignisse aus dem Alten und dem Neuen Testament erzählt und ganz aus Versen besteht, die den Werken des klassischen Dichters Vergil (70-19 v. Chr.) entlehnt sind, es handelt sich also um einen Vergil-Cento. Claudius Marius Victorius ist Autor eines Werks, das, um 425 n. Chr. geschrieben, unter dem Titel "Wahrheit“ (Alethia) biblisches Geschehen von der Schöpfungsgeschichte bis zum Fall von Sodom und Gomorra erzählt. Ebenfalls im fünften Jahrhundert verfasst Sedulius sein „Ostergedicht“, Paschale carmen: Den Titel hat er gewählt, 
weil Christus als unser Osterlamm geopfert worden sei. Das erste Buch erzählt die im Alten Testament berichteten Wundertaten des dreieinigen Gottes, die Bücher 2-5 sind dem Leben sowie den Heils- und Wundertaten Christi gewidmet. Zu Ende des fünften Jahrhunderts entsteht Avitus' Gedicht „Begebenheiten der geistlichen Geschichte“ (De spiritalis historiae gestis), worin Erschaffung und Fall des Menschen, Vertreibung aus dem Paradies, Sintflut und Durchzug durch das Rote Meer dargestellt werden. Arator schließlich, dem sechsten Jahrhundert angehörend, behandelt Begebenheiten der Apostelgeschichte; das Werk wird zumeist unter dem Titel De actibus apostolorum zitiert. Der Autor hat sein Gedicht an vier Tagen im April und Mai 544 n. Chr. in der römischen Kirche St. Petri ad vincula (San Pietro in vincoli) vor einem großen Kreis von Klerikern und Laien rezitiert, immer wieder durch Beifall unterbrochen und zu Wiederholungen veranlasst.

In ihrer Anlage und ihrer Erzählweise unterscheiden sich die spätantiken Bibelepen außerordentlich stark voneinander. Was aber alle Schöpfungen gemein haben, ist eine didaktische Intention: Die Gedichte möchten beim Leser die Kenntnis biblischen Geschehens erweitern oder festigen und ihn so in seinem Glauben stärken. Ebenfalls gemeinsam ist den spätantiken Bibelepiken ein dem Hymnischen angenäherter Ton. Der christliche Dichter trägt stets das Lob des Herrn vor, gemäß der Weisung des Psalmisten (Psalm 105): „Singt ihm und spielt ihm!“ (cantate ei et psallite ei); der christliche Epiker folgt der sich unmittelbar anschließenden Aufforderung: „Erzählt alle seine Wunder!“ (narrate omnia mirabilia eius).

Lateinische Bibelepen gibt es nun nicht nur in der Spätantike. Als Sprache dieses Genres behauptet sich das Lateinische über das Mittelalter bis weit in die Renaissance. Die nachantiken Autoren schließen sich durchweg eng an die lateinische Bibelepik des vierten bis sechsten Jahrhunderts an. Spätestens seit dem neunten Jahrhundert werden Bibelepen auch in den Volkssprachen geschaffen; in der Regel sind auch für diese Werke die lateinischen Gedichte der Spätantike wichtige Vorbilder. Das gilt nicht zuletzt für die wohl bedeutendsten religiösen Gedichte der neuzeitlichen englischen Literatur, die beiden in Blankversen geschriebenen Epen John Miltons über den Verlust und über die Wiedergewinnung des Paradieses: Paradise Lost (1663; Endfassung 1674) und Paradise Regained (1671). 
Dass die spätantiken Autoren ihre Themen nicht in Prosa, sondern in poetischer Form behandeln - was hat es damit auf sich?

Genau wie die heidnischen Autoren waren die christlichen der Ansicht, im Vergleich zur Prosa besitze die Poesie bestimmte Vorzüge. So schreibt beispielsweise der Bibeldichter Sedulius: Einer Prosadarstellung folge der Leser eher unaufmerksam. Was aber durch den Reiz und Wohlklang der Verse versüßt sei, finde sehr viel rascher und besser Zugang zu seinem Gemüt, seinem Herzen. Dem poetisch Geformten widme sich der Leser daher mit besonderer Hingabe; durch mehrfaches Wiederholen bewahre und verankere er es tief im Gedächtnis, und auf diese Weise werde sein Glaube gestärkt und vertieft (Sedulius, Epistola ad Macedonium). Die poetische Gestaltung unterstützt also in den Augen des Bibeldichters die didaktische Grundintention des Autors.

Die Entscheidung freilich, erzählende Poesie in lateinischen Hexametern zu schaffen, hatte für die christlichen Schriftsteller der Spätantike eine unausweichliche Konsequenz: Sie konnten gar nicht umhin, an die durchweg hexametrische Epik des Altertums anzuknüpfen, und hier lag durchaus ein Problem. Das antike Epos war für eine nichtchristliche Welt, eine Welt der Mythologie mit ihrem Polytheismus konzipiert; Sprache und stilistisches Arsenal der Gattung trugen den Stempel des Heidentums. Angesichts dieser Situation halfen sich die christlichen Autoren mit einer Methode, für welche sie im zweiten Buch Mose gleichsam ein Muster fanden (Ex 3,21f; 12,35f): Dort wird geschildert, wie die Israeliten zwar die Götzenbilder der Ägypter verabscheuten, aber beim Verlassen des Landes heimlich aus deren Besitz goldene und silberne Gefäße mitnahmen. Das sei auf Weisung Gottes geschehen mit dem Ziel, Gegenstände, die die Ägypter nicht in der rechten Weise gebraucht hätten, einer besseren Verwendung zuzuführen. Wie Christian Gnilka gezeigt hat, folgen zahlreiche christliche Autoren dem Vorbild der Israeliten, wenn sie daran gehen, mit ihrem Schaffen an antik-pagane Literatur anzuknüpfen. Auch der Bibelepiker versteht sich als jemand, der das von den Heiden Geschaffene und Gepflegte dem rechten Gebrauch (usus iustus) zuführt, indem er beispielsweise aus der Poesie das mythologische und polytheistische Element verbannt.

In diesem Sinne erklärt etwa der Dichter Iuvencus in der poetischen Praefatio zu seinen Euangelia, dieses Werk lasse dank dem christlichen 
Gehalt die berühmte Epik der Antike weit hinter sich. Und jene Aristokratin Proba äußert in dem Gedicht, mit dem sie eine Abschrift ihres Vergil-Centos Kaiser Arcadius widmet, die Ansicht, mit ihrem Werk werde der Autor des Prätextes „zum Besseren verwandelt“ (... Maronem I mutatum in melius...).

Die Tradition der paganen Poesie ist freilich nur die kleinere der beiden Quellen, aus denen sich die spätantike Bibelepik speist. Die andere, weitaus bedeutendere ist, wie sich von selbst versteht, die Heilige Schrift; zunächst dient die sogenannte Itala als Vorlage, das sind die in Italien umlaufenden lateinischen Übersetzungen, seit dem Ende des vierten Jahrhunderts dann die von Hieronymus geschaffene Vulgata.

Doch wie soll sich der Bibelepiker zu dem Werk verhalten, dem er seinen Stoff entnimmt? Versuchen wir eine Antwort über einen Umweg! Als in der Zeit des Augustus Vergil es unternahm, seine Aeneis zu dichten, empfahl es sich zwar, von der überlieferten Sage auszugehen; die AeneasSage, die Vergil vorfand, stellte aber nicht mehr als ein Grundgerüst dar. Es stand Vergil frei, vielmehr, es war seine Aufgabe, das Vorgefundene durch eigene Erfindung zu erweitern, durch Gestalten, Ereignisse, Motive, Empfindungen; so haben denn an der vollendeten Aeneis die Modifikationen früherer Sagenversionen einen großen Anteil. Hingegen befindet sich der Bibeldichter in einer grundlegend anderen Situation: Nicht nur dass sein Stoff vorgegeben und dem Leser im Allgemeinen bekannt ist, er hat es bei der Bibel mit einem heiligen Text zu tun, der kanonische Gültigkeit beansprucht; von vorneherein ist bei der Rezeption der biblischen Berichte der Spielraum für eigene Erfindung wesentlich geringer als etwa im Falle Vergils.

Das, was die biblischen Texte aussagen, darf vom christlichen Epiker nicht verändert, nicht angetastet werden - dieses Erfordernis steht angesichts des autoritativen Charakters der Heiligen Schrift fest. Aber was sagen die biblischen Texte aus? Als Wort Gottes verfügen sie über ein unerschöpfliches Sinnpotential, das immer wieder in neuen historischen Verhältnissen ausgelegt und aktualisiert werden muss. In jedes literarische Werk, das sich ernsthaft auf die Bibel als Prätext bezieht, geht folglich Exegese des Bibeltexts ein. Diese Exegese kann ausdrücklich, als Kommentar, formuliert werden, sie kann aber auch gleichsam zwischen den Zeilen stehen, also im Erzähltext impliziert sein. 
Beispiele für explizite Auslegung sind die Erläuterungen zu einzelnen Büchern der Bibel, die Bibelkommentare, die im Laufe der Jahrhunderte von den Kirchenvätern in großer Zahl verfasst werden.

Als Beispiele impliziter Auslegung lassen sich Schriften anführen, wie sie seit dem zweiten vorchristlichen Jahrhundert im palästinischen Judentum entstehen: Die Autoren dieser so genannten Pseudepigraphen bringen ihre theologische Auffassung dadurch zur Geltung, dass sie Texte des Pentateuch erweiternd oder verkürzend nacherzählen und dabei neue Akzente setzen; zu nennen sind zum Beispiel das auf der Genesis fußende Jubiläenbuch (Liber Iubilaeorum), ein Werk, das etwa auch als Kleine Genesis oder Testament des Mose bezeichnet wird, sowie aus der Reihe der Qumran-Schriften das sogenannte Genesis-Apokryphon. Für das narrative Verfahren, das in solchen Werken geübt wird, hat sich in der Forschung seit etwa vier Jahrzehnten der englische Ausdruck rewriting the Bible eingebürgert. Die spätlateinischen Bibelepen kann man durchaus dem Phänomen des rewriting zuordnen, nur dass die Autoren eben nicht palästinische Juden sind, sondern lateinisch schreibende Christen und dass das Neuschreiben der Bibel nicht in Prosa erfolgt, sondern in poetischer Form.

Die Bibelepik kennt aber auch die andere, die explizite Vermittlungsform der Exegese: Wieder und wieder finden sich in den Werken neben den rein narrativen Partien auch solche, welche den Bibeltext auslegen, kommentieren; hier treten die Dichter also in unmittelbare Konkurrenz zu den Kommentaren der Kirchenväter.

II.

Nunmehr wollen wir aus zwei Bibelepen jeweils einen Abschnitt näher anschauen! Der erste, kürzere, stammt aus dem Paschale carmen („Ostergedicht") des Caelius Sedulius, der dem fünften Jahrhundert angehört; über seine Lebensumstände, über seine Herkunft weiß man nichts Näheres. Im zweiten der fünf Bücher seines Gedichts behandelt er eine Ereignisfolge, die viele Bibeldichter zu besonderer Ausgestaltung gereizt hat: den Besuch der drei Weisen (magi) oder, wie die Einheitsübersetzung der Bibel sie nennt, der drei Sterndeuter in Bethlehem und den durch diesen Besuch ausgelösten Kindermord, welcher Herodes d. Ä. (Herodes I.) zugeschrieben wird, der von 37 bis 4 v. Chr. regierte (Paschale carmen 2,76-133). 
Bei Matthäus wird dieses Geschehen 2,1-18 folgendermaßen geschildert (ich gebe den Text der Einheitsübersetzung leicht gekürzt wieder):

„Als Jesus zur Zeit des Königs Herodes in Bethlehem geboren worden war, kamen Sterndeuter aus dem Osten nach Jerusalem und fragten, wo der neugeborene König der Juden sei. Sie hätten seinen Stern aufgehen sehen und seien gekommen, um ihm zu huldigen. Als der König dies hörte, erschrak er und mit ihm ganz Jerusalem. Er ließ alle Hohenpriester und Schriftgelehrten [Gesetzeslehrer] des Volkes zusammenkommen und erkundigte sich bei ihnen, wo der Messias geboren werden solle. Sie antworteten ihm, in Bethlehem, wie es beim Propheten [Micha] stehe. Danach rief Herodes die Sterndeuter heimlich zu sich und ließ sich von ihnen genau sagen, wann der Stern erschienen war. Dann schickte er sie nach Bethlehem und sagte: ,Geht und forscht sorgfältig nach, wo das Kind ist; und wenn ihr es gefunden habt, berichtet mir, damit auch ich hingehe und ihm huldige'. Nach diesen Worten des Königs machten sie sich auf den Weg. Und der Stern, den sie hatten aufgehen sehen, zog vor ihnen her bis zu dem Ort, wo das Kind war; dort blieb er stehen. Als sie den Stern sahen, wurden sie von sehr großer Freude erfüllt. Sie gingen in das Haus und sahen das Kind und Maria, seine Mutter. Da fielen sie nieder und huldigten ihm. Dann holten sie ihre Schätze hervor und brachten ihm Gold, Weihrauch und Myrrhe als Gaben dar. Weil ihnen aber im Traum geboten wurde, nicht zu Herodes zurückzukehren, zogen sie auf einem anderen Weg heim in ihr Land.

Als die Sterndeuter wieder gegangen waren, erschien dem Josef im Traum ein Engel des Herrn und sagte: ,Steh auf, nimm das Kind und seine Mutter und flieh nach Ägypten; dort bleibe, bis ich dir etwas anderes auftrage; denn Herodes wird das Kind suchen, um es zu töten.' Josef tat, wie ihm der Engel geheißen; er, Maria und das Kind blieben in Ägypten bis zum Tod des Herodes ... Als Herodes merkte, dass ihn die Sterndeuter getäuscht hatten, wurde er sehr zornig, und er ließ in Bethlehem und der ganzen Umgebung alle Knaben bis zu einem Alter von zwei Jahren töten, genau der Zeit entsprechend, die er von den Sterndeutern erfahren hatte. Damals erfüllte sich, was durch den Propheten Jeremia gesagt worden ist: ,Ein Geschrei war in Rama zu hören, Weinen und Klagen; Rahel weinte um ihre Kinder, und wollte sich nicht trösten lassen, denn sie waren dahin." “ 
So weit der biblische Bericht. Die jetzt folgenden Überlegungen zu Sedulius verdanken viel der Interpretation von Cornelia Braun-Irgang.

Auch Sedulius lässt die drei Sterndeuter mit Herodes zusammentreffen. Auf die Kunde von der Geburt eines neuen Königs (2,76-78a) und das dadurch ausgelöste Erschrecken (78b-80a) folgt in seiner Erzählung sofort der Auftrag an die Sterndeuter, das Kind zu suchen (2,80b-81). Die Befragung der Hohenpriester und der Schriftgelehrten, die nach Matthäus vor der Unterredung mit den Sterndeutern erfolgt, fehlt bei Sedulius. Stattdessen konzentriert sich das Interesse des Erzählers ganz auf die Gestalt des Herodes. Dass der König erschrak, als sich die Sterndeuter in Jerusalem nach dem Neugeborenen erkundigten, hatte der Evangelist gleich zu Anfang mit einem Satz berührt, danach hatte er sich über Herodes' Sorgen nicht mehr geäußert, sie allerdings in dessen Handeln sichtbar werden lassen. Anders Sedulius: Er beschränkt sich nicht auf die allgemeine Formulierung „Herodes erschrak“, sondern konkretisiert unverzüglich dessen Befürchtung, nämlich als Angst um den Thron: „Der grausame Lenker des jüdischen Hofes“, so heißt es bei Sedulius, „ist heftig erregt, weil er glaubt, jener [Knabe] könne ihm, dem Herrscher, bald nachfolgen" (... ferus arbiter aulae / aestuat Hebreae ratus hunc succedere posse / mox sibimet ..., 2,78b-80a). Der vom König geäußerte Wunsch, dem Kind seine Verehrung zu zeigen, wird durch den Erzähler sogleich als Heuchelei entlarvt: „Dann“, so schreibt Sedulius nämlich weiter, „erteilt Herodes, mit heiterer Stirn, in seinem Inneren dunkles Gewölk wachsen lassend, heimlich den Auftrag, der Knabe sei überall zu suchen, als solle er verehrt werden" (tunc fronte serena / nubila mentis alens clam mandat ubique requiri/sicut adorandum, 2,80b-82a). Während im Matthäus-Evangelium Herodes den Beschluss des Kindermords erst fasst, als er feststellen muss, dass die Sterndeuter aus Bethlehem nicht nach Jerusalem zurückkehren, lässt Sedulius den König den ruchlosen Plan von Anfang an verfolgen: Jene Formulierung, Herodes habe den Knaben heimlich suchen lassen, „als solle er verehrt werden“ (sicut adorandum), setzt Sedulius nämlich fort mit dem Relativsatz: „den er mit Trug zu töten unternimmt“ (quem tractat fraude necandum, 2,82b).

An dieser Stelle wendet sich Sedulius von seinem primären Publikum $a b$ und redet den Judenkönig unmittelbar an; für dieses rhetorische Verfahren, die Apostrophe, gibt es in der Bibelpartie kein Vorbild: „Was rasest du, Herodes? Zu Christus bekennst du dich mit Worten und in 
deinem Sinn trachtest du, ihn meuchlings zu ermorden ... Ein anderer Herodes wird erleben, was du in Gang setzest" (Quid furis, Herodes? Christum sermone fateris / et sensu iugulare cupis. / Herodes alius, quod tu molire, uidebit, 2,83-88). Der letzte Satz weist auf den Nachfolger des Herrschers voraus, auf Herodes Antipas, unter dessen Regierung (4 v. - 39 n. Chr.) Christus den Kreuzestod erleiden wird. Die aus dem antiken Epos vertraute Technik des Vorverweises verknüpft der Dichter hier funktional mit der exegetischen Methode typologischer Ausdeutung: Der Herodes des Kindermords erscheint bei ihm als Typus des ,anderen Herodes“, des Herodes der Kreuzigung.

Nach der Apostrophe schildert Sedulius, wie die Sterndeuter den Weg nach Bethlehem antreten (2,89-92). Es folgt eine ausführliche Erläuterung zu den drei mitgebrachten Gaben, die für den Neugeborenen bestimmt sind (2,93-101a). Wie auch viele andere antike Schriftsteller deutet Sedulius die Geschenke für Jesus allegorisch: Das Gold gelte dem künftigen König, der Weihrauch Gott, die Myrrhe dem Grab, die Dreizahl verweise auf das dreieinige Wesen Gottes, der immer da sei, immer da gewesen sei und immer da sein werde.

Die Schilderung, wie die Sterndeuter entgegen dem Befehl des Königs von Bethlehem aus in ihre Heimat zurückkehren (2,101b-104a), lässt Sedulius in eine Ermahnung an die Christen münden: „So sollten auch wir, sobald wir einmal zu Christus gekommen sind, nicht mehr die ungerechte Existenz wiederaufnehmen, wenn wir endlich die heilige Heimat erreichen möchten" (sic nos quoque sanctam / si cupimus patriam tandem contingere, posquam / uenimus ad Christum, iam non repetamus iniquum, 2,104b-106).

An dieser Stelle folgt bei Matthäus die Schilderung, wie Joseph, von einem Engel veranlasst, mit Maria und dem Jesuskind nach Ägypten flieht. Diesen Teil der Handlung hat Sedulius fortgelassen; er beschränkt sich darauf, an späterer Stelle seiner Erzählung den Hinweis anzubringen, dass Jesus nicht unter den getöteten Kindern gewesen sei $(2,131)$.

Dadurch dass Sedulius im Bisherigen bereits auf das Kommende vorausgedeutet hat, steht bei ihm schon die Sterndeuter-Episode ganz im Schatten des Kindermords. Dessen Schilderung schließt sich nun unmittelbar an.

Matthäus hatte den Befehl zum Kindermord folgendermaßen formuliert: „Als Herodes merkte, dass ihn die Sterndeuter getäuscht hatten, 
wurde er sehr zornig, und er ließ in Bethlehem und der ganzen Umgebung alle Knaben bis zum Alter von zwei Jahren töten"; damals habe sich erfüllt, was durch den Propheten gesagt worden sei. Es folgt als Schluss des Ganzen das Jeremia-Zitat über Rahel, die um ihre Kinder trauert (Mt 2,16f). Aus dieser knappen Darstellung wird bei Sedulius eine Szene von siebenundzwanzig Versen (2,107-133); sie lauten:

Ergo ubi delusum se conperit, impius iram rex aperit (si iure queat rex ille uocari, qui pietate caret, propriam qui non regit iram) ereptumque gemens facinus sibi, ceu leo frendens, cuius ab ore tener subito cum labitur agnus, in totum mouet arma gregem manditque trahitque molle pecus trepidaeque uocant sua pignora fetae nequiquam et uacuas implent balatibus auras: haut secus Herodes Christo stimulatus adempto sternere conlisas paruorum strage cateruas inmerito non cessat atrox. Quo crimine simplex turba perit? Cur qui uixdum potuere creari iam meruere mori? Furor est in rege cruento, non ratio; primosque necans uagitus et audens innumerum patrare nefas puerilia mactat milia plangoremque dedit tot matribus unum. Haec laceros crines nudato uertice rupit, illa genas secuit, nudum ferit altera pugnis pectus et infelix mater (nec iam modo mater) orba super gelidum frustra premit ubera natum. Quis tibi tunc, lanio, cernenti talia sensus? Quosue dabas fremitus, cum uulnera feruere late prospiceres arce ex summa uastumque uideres misceri ante oculos tantis plangoribus aequor? Extinctisque tamen quamuis infantibus absens, praesens Christus erat, qui sancta pericula semper suscipit et poenas alieno in corpore sentit. 
„Als er begreift, dass er getäuscht worden ist, lässt der gottlose Herrscher seinem Zorn freien Lauf (wenn denn mit Recht jemand Herrscher genannt werden kann, der des frommen Sinns ermangelt und den eigenen Zorn nicht beherrscht) und klagt, ihm sei die Gelegenheit zu einem Verbrechen [gemeint sein muss: die Sterndeuter zu töten] entrissen worden (107110a). Wie ein mit den Zähnen knirschender Löwe, wenn ihm das zarte Lamm plötzlich aus dem Maul gleitet, seine Waffen [die Zähne] gegen die ganze Herde wendet und das nicht abgehärtete Vieh verschlingt und zerreißt - und die ängstlichen Mütter schreien vergeblich nach ihren Jungen und erfüllen die weite Luft mit ihrem Geblöke (110b-114): ebenso beeilt sich der grässliche Herodes, gereizt, weil man ihm Christus entzogen hat, die ohne Schuld niedergemetzelten Kinder aufeinander zu häufen (115-117a). Aufgrund welcher Schuld kommt die arglose Schar um? Wieso verdienten sie es, die kaum geboren werden konnten, schon wieder zu sterben? Wut beherrscht den blutrünstigen König, nicht Vernunft: Das erste Wimmern tötend und es wagend, eine grenzenlose Untat zu begehen, schlachtete er Tausende von Knaben hin und veranlasste ebenso viele Mütter zu einem einzigen Wehklagen: Die eine riss sich das zerraufte Haar vom entblößten Haupt, die andere zerkratzte sich die Wangen, eine dritte schlug sich mit den Fäusten ihre nackte Brust und wieder eine andere unglückliche Mutter (und schon nicht mehr Mutter) presste ihr erkaltetes Kind an ihre jetzt kinderlose Brust (117b-126). Was hast du, Henker, damals bei diesem Anblick gedacht und empfunden? Was für Laute hast du ausgestoßen, als du von der Höhe deiner Burg herab weithin brennende Wunden erblicktest und sahst, wie sich vor deinen Augen die so großen Wehklagen zu einem Tränenmeer vereinigten? (127130). Obwohl Christus nicht unter den ausgelöschten Kindern war, war er doch da, der in Gefahren stets bei seinen Heiligen ist und die Schmerzen im fremden Körper mitfühlt (131-133).“

Wie ist Sedulius in diesem Abschnitt mit dem Matthäus-Text umgegangen, durch welche Elemente hat er den biblischen Bericht erweitert?

Wie schon im Vorangegangenen betont Sedulius das Affektische: Er lässt Herodes nicht nur in Zorn geraten, sondern auch klagen, die Heimkehr der Sterndeuter habe ihn der Möglichkeit beraubt, ein Verbrechen zu begehen. Auch wirft Sedulius die Frage auf, ob Herodes zu Recht als Herrscher (rex) bezeichnet werden könne: Anspruch auf diesen Titel habe 
nur, wer seinen Zorn beherrsche (regit). Die Formulierung dieses Gedankens hat im Lateinischen den Charakter einer Etymologie (rex - regere).

Des Weiteren wird Herodes mit einem wütenden Löwen parallelisiert (2,110b-114). Dieses Gleichnis ist ganz nach klassisch-epischer Tradition gestaltet; etwas sehr Ähnliches findet sich etwa in Vergils Aeneis (9,339f; 12,7f).

Die Ausführung der Untat, deren Schilderung mit dem Löwengleichnis einsetzt, wird vom Dichter mit so genannten rhetorischen Fragen begleitet, Fragen also, auf die keine Antwort erwartet wird: „Aufgrund welcher Schuld kommt die arglose Schar um? Wieso verdienten sie es, die kaum geboren werden konnten, schon wieder zu sterben?“ (117b-119a).

Die Darstellung des Todes der unschuldigen Kinder lässt eine hochpathetische Schilderung des um 60 n. Chr. schreibenden Epikers Lucan anklingen (Pharsalia 2,108f).

Nicht eigens referiert hat Sedulius die Jeremia-Prophetie; er hat sie aber nicht einfach fortgelassen, sondern gleichsam in Handlung umgesetzt, indem er in epischer Manier die Reaktionen der unglücklichen Mütter schildert (2,121-126). Wenn es dabei über eine der Mütter heißt, sie sei schon nicht mehr Mutter, so hat diese Formulierung ihr Vorbild in Ovids Epos Metamorphosen: Dort ist über Daedalus, der seinen Sohn Icarus verloren hat, gesagt: „Aber der unglückliche Vater, schon nicht mehr Vater, rief ,Icarus!'..." (at pater infelix nec iam pater: „Icare!” dixit, met. 8,321).

Wie schon früher wendet sich der Dichter in einer Apostrophe unmittelbar an Herodes, den er dabei als Henker (lanio) tituliert (2,127130). Diese Verse sind wiederum in enger Anlehnung an Vergils Aeneis (4,408-411) gestaltet.

Hatte am Ende der Darstellung bei Matthäus das gewichtige Zitat aus Jeremia gestanden, so schließt Sedulius seine Erzählung mit einer als Paradoxon formulierten Aussage über Christus, der allezeit den Seinen beistehe und ihre Leiden auf sich nehme, auch wenn er nicht zugegen sei: absens / praesens. Durch das Tröstliche, das in diesem Hinweis auf Christi Präsenz liegt, wird das Grausame der vorangegangenen Darstellung aufgefangen.

Alles in allem hat sich ergeben: Sedulius behält im Wesentlichen den Gang des Geschehens bei. Allerdings lässt er das eine oder andere Detail des biblischen Berichts fort; vor allem aber erweitert er ihn ganz erheblich, und dies namentlich durch Elemente wie Apostrophe, Gleichnis, 
Vorverweis und rhetorische Fragen. Die meisten dieser Verfahren werden auch in den klassischen Epen der Römer gerne angewandt. Immer wieder klingen Formulierungen und Techniken jener Werke an. Die Exegese der biblischen Vorlage erfolgt in der Regel implizit. Mit der allegorischen Ausdeutung der Gaben hat Sedulius aber auch ein Beispiel für explizite Bibelauslegung gegeben. Trotz aller Veränderungen bleibt aber die Substanz des biblischen Berichts erhalten. Gegenüber dessen monumentaler Schlichtheit ist allerdings im Bibelgedicht des Sedulius das Emotionale entschieden verstärkt.

Seit dem sechsten Jahrhundert wurde Sedulius' Epos viel gelesen, das ganze Mittelalter hindurch. Fast alle größeren Klosterbibliotheken besaßen ein oder mehrere Exemplare des Werks; zahlreiche, stark benutzte Handschriften zeugen noch heute von der weiten Verbreitung. Humanisten nannten Sedulius den „allerchristlichsten Dichter“ (Christianissimus poeta), und Martin Luther hat diese Bezeichnung von ihnen übernommen.

\section{III.}

Das zweite Beispiel ist dem Epos des Avitus entnommen. Er heißt mit vollem Namen Alcimus Ecdicius Avitus und stammt aus einer senatorischen Familie in Vienna/Vienne in der Auvergne (Burgund); für das Jahr 494 n. Chr. wird er als Bischof seiner Vaterstadt genannt. In seinem Epos „Begebenheiten der geistlichen Geschichte“ (De spiritalis historiae gestis) behandelt Avitus zunächst, in Buch I, die Erschaffung des Menschen und das Paradies, im zweiten Buch wendet er sich der so genannten Erbsünde $\mathrm{zu}$; diesem Buch ist unser Beispiel entnommen (2,145-232).

Biblische Vorlage ist ein kurzer Abschnitt der Genesis, der oft als Darstellung des Sündenfalls verstanden wird (3,1-6). Im unmittelbar Vorangehenden hatte Gott dem Menschen, der im Paradies lebt, das Gebot erteilt, er dürfe von allen Bäumen des Gartens Eden essen, nur nicht von dem Baum der Erkenntnis; wenn er von diesem einen Baum esse, müsse er sterben $(2,16 f)$. Nachdem Adam und Eva (in 3,6) die verbotene Frucht gekostet haben, werden sie in einem späteren Abschnitt der Erzählung von Gott verflucht (3,16-19). Innerhalb dieses Kontextes verdankt sich die Partie 3,1-6, um die es jetzt gehen soll, einer impliziten, innerbiblischen Exegese: Sie ist der Frage gewidmet, wie sich die Androhung des Todes in 2,16f zum tatsächlichen Ausgang des Geschehens, zur Verfluchung (3,16- 
19), verhält. Im Hinblick auf diese Frage thematisiert die Partie 3,1-6 die Sterblichkeit des Menschen: Er wird zwar nicht unmittelbar nach seiner Tat sterben, aber das ewige Leben verlieren (3,22.24). Zugleich setzt der Abschnitt 3,1-6 die Frau ins Bild, die, als Gottes Gebot erging, noch gar nicht existierte, nun aber wissbegierig und wissentlich schuldig wird (vgl. Kratz / Spieckermann).

In unserer Partie erscheint eine redende Schlange, die einen Dialog mit der ersten Menschenfrau, mit Eva, führt. Die Schlange wird ausdrücklich als eines derjenigen Tiere bezeichnet, die Gott erschaffen hat. Was sie aus der Menge der übrigen Tiere heraushebt, ist nicht etwa besondere Bösartigkeit, sondern Schlauheit. Im Sinne des Genesis-Erzählers dient das Agieren der Schlange dazu, etwas zu veranschaulichen, das sich im Inneren des Menschen abspielt: Sie hat die dramaturgische Funktion einer inneren Stimme, die bestimmte Konstituenten des menschlichen Geistes repräsentiert, etwa Misstrauen und den krankhaften Zwang zum Zweifeln. Mit einer dämonischen Macht, die von außen dem Menschen gegenübertritt, sich feindlich zwischen ihn und Gott schiebt, hat die Schlange in der Genesis-Erzählung nichts zu tun.

Der einschlägige Text lautet in der Einheitsübersetzung:

(1) Die Schlange war schlauer als alle Tiere des Feldes, die Gott, der Herr, gemacht hatte. Sie sagte zu der Frau: „Hat Gott wirklich gesagt: ,Ihr dürft von keinem Baum des Gartens essen?'“ (2) Die Frau entgegnete der Schlange: „Von den Früchten der Bäume im Garten dürfen wir essen; (3) nur von den Früchten des Baumes, der in der Mitte steht, hat Gott gesagt: ,Davon dürft ihr nicht essen und daran dürft ihr nicht rühren, sonst werdet ihr sterben"“. (4) Darauf sagte die Schlange zur Frau: „Nein, ihr werdet nicht sterben. (5) Gott weiß vielmehr: Sobald ihr davon esst, gehen euch die Augen auf; ihr werdet wie Gott und erkennt Gut und Böse“. (6) Da sah die Frau, dass es köstlich wäre, von dem Baum zu essen, dass der Baum eine Augenweide war und dazu verlockte, klug zu werden. Sie nahm von seinen Früchten und aß; sie gab auch ihrem Mann, der bei ihr war, und auch er aß.

Die Schlange eröffnet das Gespräch auf behutsame Weise: mit einer noch ganz allgemeinen Frage, durch die sie den Eindruck erweckt, als wolle sie ernsthaft Näheres über die Weisung Gottes erfahren: „Hat Gott wirklich 
gesagt ...?“ Die Frage enthält freilich eine Verdrehung, denn Gott hatte keineswegs gesagt, dass die Menschen von keinem Baum essen dürften. Ohne dass die Schlange den Baum der Erkenntnis erwähnt, sucht sie den Gehorsam der Frau zu unterminieren. In ihrer Antwort stellt die Frau die Verdrehung richtig. Nunmehr lässt die Schlange die Maske, unter der sie ernsthaftes Interesse geheuchelt hatte, fallen und behauptet mit Entschiedenheit, das, was Gott gesagt habe, sei nicht wahr. Der Frau wird damit suggeriert, dass die Schlange Gott besser kennt, als sie ihn kennt. Auch unterstellt die Schlange Gott eine missgünstige Absicht: Er neide dem Menschen die Möglichkeit, zu einem Wissen zu gelangen, das ihn wie Gott sein lasse. Wenn dieses Wissen als das Erkennen von Gut und Böse ausgewiesen wird, so ist wohl gemeint: das Erkennen dessen, was dem Menschen förderlich und was ihm abträglich ist. Die Worte der Schlange veranlassen die Frau, den gläubigen Gehorsam gegenüber Gott, das Vertrauen in ihn preiszugeben. Wichtiger als das Gebot Gottes wird ihr somit das, was die Schlange ihr in Aussicht stellt: die Möglichkeit klug zu werden. Durch das Erkennen des Förderlichen und Abträglichen, so hat man den Entschluss der Frau wohl zu verstehen, hofft sie ihr Dasein zu steigern: Es reizt sie somit die Möglichkeit, „zu sein wie Gott“. Es ist Claus Westermann zufolge diese Möglichkeit, die in der Verführungsszene aufgedeckt wird.

Erst in späterer Zeit brachte man die Schlange mit dem Teufel, mit Satan in Zusammenhang. Satan seinerseits erscheint im Alten Testament als eigenständige Gestalt namentlich im ersten der beiden Chronikbücher, das im vierten vorchristlichen Jahrhundert entstanden ist (1 Chr 21,1), sowie in Hiob 1,6-12. Im Neuen Testament ist Satan sodann der Böse schlechthin. In der Offenbarung des Johannes wird er mit der Schlange gleichgesetzt: Dort ist nämlich davon die Rede, wie der große Drache auf die Erde gestürzt werde, „die alte Schlange, die Teufel oder Satan heißt und die ganze Welt verführt" (Offb 12,9; s. noch 14f). Ferner bezeichnen Johannesevangelium $(8,44)$ und erster Johannesbrief Satan als Mörder und Sünder „von Anfang an“. Wichtig sind in diesem Zusammenhang auch alttestamentliche Pseudepigraphen, z.B. die griechische Apokalypse des Mose (Apc Mos) sowie die lateinische Erzählung Leben Adams und Evas (Vita Adae [Adam] et Euae), eine erweiterte Fassung der Apokalypse des Mose. Beide Schriften gehen Jan Dochhorn zufolge auf jüdische Schriftgelehrte im Palästina des 1./2. Jahrhunderts n. Chr. zurück, die mit dem 
hebräischen Bibeltext arbeiteten. Apc Mos 16,5 erscheint die Schlange als Werkzeug des Teufels, der durch ihren Mund spricht. In Vit Ad 12-17 wird ein Gespräch zwischen Adam und dem Teufel wiedergegeben; dabei behauptet der Teufel, von Gott um Adams willen aus der Gemeinschaft der Engel ausgestoßen und auf die Erde geworfen worden zu sein: Das sei geschehen, fügt der Teufel hinzu, weil er sich dem Befehl Gottes, Adam als dessen Ebenbild zu verehren, widersetzt habe. Als Rebell gegen die Gottesherrschaft wird der Teufel schließlich von dem Griechen Origenes (ca. 185 - ca. 253 n. Chr.) in De principiis dargestellt.

Wenn der Epiker Avitus die Verführung Evas durch die Schlange erzählt, dann folgt er nicht allein dem Bibeltext, sondern steht auch unter dem Eindruck der späteren Deutungen von Genesis 3,1-6. Das gilt ebenso für Details. So war der Baum der Erkenntnis in der Genesis botanisch nicht spezifiziert worden; Avitus versteht darunter wie manche andere vor ihm einen Apfelbaum. Die Anlage der Genesis-Erzählung hat Avitus beibehalten, die Szene allerdings außerordentlich stark erweitert und vornehmlich durch Psychologisieren angereichert.

Der Kontext der ausgewählten Partie (2,145-232) ist folgender. In seliger Freiheit leben Adam und Eva ein engelgleiches Dasein. Da naht der tückische Feind (hostis), also der Teufel. Er ist, literarhistorisch gesprochen, ein früher Ahn des Satans in John Miltons Paradise Lost. Vor Zeiten, so heißt es bei Avitus weiter, war der Teufel ein Engel gewesen, der seinem Schöpfer hatte gleich sein wollen. Den Hochmütigen, sich Überhebenden warf der Allmächtige aus dem Himmel, aber er beließ ihm die Fähigkeit, verborgene und zukünftige Dinge zu erkennen. Dieses Vermögen nutzt der Teufel für seine Absicht, die Geschöpfe ihrem Schöpfer zu entfremden. Um sein Ziel zu erreichen, nimmt Satan ganz unterschiedliche Gestalten an, die eines Vogels, einer schönen Jungfrau oder auch die von Geld. Auf das Glück der beiden Menschen ist er besonders neidisch, weil ihnen vergönnt ist, was Gott ihm selbst verwehrt. Die Menschen, so beschließt Satan, sollen durch eben das stürzen, was seinen eigenen Sturz verursacht hat: durch Selbstüberhebung.

So verwandelt er sich denn in eine Schlange, die über eine sanfte Stimme verfügt, und begibt sich zu dem Hain, in dem Adam und Eva gerade rötliche Äpfel pflücken. Da die Schlange fürchtet, es könnte ihr nicht gelingen, den festen Sinn des Mannes zu berücken, schlüpft sie in den Wipfel des Baums und wendet sich, im Laub verborgen, mit leiser 
Stimme allein an Eva. Eva wird hier $(2,144)$ wie noch mehrfach vom Dichter als leicht verführbar bezeichnet. Die teuflische Schlange beginnt - in Abweichung von der Genesiserzählung - mit extensiven Schmeicheleien; so unterstellt sie V. 148f, dass Eva als erste geschaffen wurde. Sogar den abseits stehenden Gatten bezieht die Schlange in ihre Rede ein; erst ganz zum Schluss stellt sie ihre Frage. Die Worte der Schlange lauten:

O felix mundique decus pulcherrima uirgo, ornat quam roseo praefulgens forma pudore, tu generi uentura parens, te maximus orbis exspectat matrem, tu prima et certa uoluptas solamenque uiri, sine qua non uiueret ipse; ut maior, sic iure tuo subiectus amori praedulcis coniunx, reddes cui foedere prolem. Vobis digna datur paradisi in uertice sedes, uos subiecta tremit famulans substantia mundi: quod caelum, quod terra creat, quod gurgite magno producit pelagus, uestros confertur in usus.

Nil natura negat, datur ecce in cuncta potestas.

Non equidem inuideo; miror magis, ut tamen una contineat liber dulci super arbore tactus. Scire uelim: quis dura iubet, quis talia dona inuidet et rebus ieiunia miscet opimis?

„O Glückliche, Zierde der Welt, herrlichste Jungfrau, die eine von errötender Schamhaftigkeit strahlende Schönheit schmückt, du künftige Ahnherrin des Menschengeschlechts, dich erwartet der riesige Erdkreis als Mutter, du, die Erste und die wahre Freude und der Trost des Mannes, ohne die er selbst nicht leben würde. Zwar ist er der Stärkere, aber doch zu Recht deiner Liebe untertan, er, der zärtliche Gatte, dem du dank eurem Bund Nachkommen schenken wirst. Euch ist ein würdiger Wohnsitz in der Mitte des Paradieses gegeben; euch unterworfen, euch dienend, zittert das Gefüge der Welt vor euch: Was der Himmel, was die Erde erzeugt, was das Meer in gewaltiger Tiefe hervorbringt, wird zu eurem Nutzen zusammengebracht. Nichts verweigert euch die Natur; siehe da, über alles ist euch Gewalt gegeben. Ich bin durchaus nicht neidisch; vielmehr wundere ich mich, wie es dazu kommt, dass hinsichtlich eines einzigen 
süßen Baums die freie Berührung verboten ist. Ich wüsste gern: Von wem kommt der harte Befehl, wer missgönnt euch solche Gaben und mischt Mangel in den Reichtum?" (2,145-160).

Wie in der Genesis erlaubt sich die Schlange, das göttliche Wort zu verdrehen: Von einer Einschränkung des Nahrungsangebots hatte Gott keineswegs gesprochen - das Paradies zeichnet sich vielmehr durch einen Überfluss an Nahrung aus (2,1-19). Erst durch den Sündenfall wird jener Mangel heraufbeschworen, den die Schlange hier unterstellt.

An dieser Stelle wendet sich der Erzähler mit einer Apostrophe an Eva; er rügt, dass sie sich auf ein Gespräch mit einem Tier einlasse:

Quis stupor, o mulier, mentem caligine clausit? Cum serpente loqui, uerbum committere bruto non pudet, ut uestram praesumat belua linguam?

Et monstrum pateris responsumque insuper addis?

„Welche Dummheit, Frau, schloss deinen Geist in Finsternis ein? Schämst du dich denn nicht, mit einer Schlange zu reden, an ein gefühlloses Wesen das Wort zu richten, so dass sich ein wildes Tier eure Sprache anmaßt? Und du lässt das Scheusal dies tun und gibst ihm gar noch Antwort? (2,162-165).“

Mit dieser Schelte weicht Avitus von Genesis 3,1-6 insofern ab, als sich dort keine abwertende Charakterisierung der Schlange findet; erst nachdem Eva vom verbotenen Baum gegessen hat, spricht der Gott der Bibel einen Fluch über die Schlange aus (Gen 3,14f). Wenn nun Eva die Schlange anrede und mit ihr ein Gespräch führe, werde, so meint der Dichter, die gottgewollte Ordnung auf den Kopf gestellt, der zufolge das Tier, der Sprache ermangelnd, dem Menschen untertan sei.

Durch die Schmeicheleien der Schlange zeigt sich Eva beeindruckt. In ihrer Antwort stellt sie zunächst - wie in der Genesis - die Verdrehung, die die Schlange gegenüber dem göttlichen Wort vorgenommen hatte, richtig. Und genau wie in der Genesis schreibt sie der Schlange offensichtlich den Besitz besonderen Wissens zu. So trägt Eva denn die Bitte vor, die Schlange möge ihr erklären, was Gott mit der Drohung gemeint habe, bei Übertretung seines Gebotes würden sie sterben. 
Suauibus o pollens coluber dulcissime dictis, non, ut rere, Deus nobis ieiunia suasit

nec prohibet largo curari corpora pastu.

Ecce uides epulas, totus quas porrigit orbis:

omnibus his licito Genitor promptissimus uti

praestitit et totas uitae laxauit habenas.

Haec sola est nemoris medii, quam perspicis, arbor

interdicta cibis, haec tantum tangere poma

non licitum, diues praesumit cetera uictus.

Nam si libertas temeraret noxia legem,

iurans terribili praedixit uoce Creator

quadam nos statim luituros morte reatum.

Quid uocitet mortem, tu nunc, doctissime serpens, pande libens, quoniam rudibus non cognita res est!

„Höchst liebliche Schlange, in angenehmer Rede mächtig, nicht hat uns Gott, wie du glaubst, Mangel angeraten noch hindert er uns, mit reichlicher Nahrung den Körper zu versorgen. Da siehst du die Speisen, die der ganze Erdkreis bietet: Der Schöpfer gewährte es höchst bereitwillig, sie alle erlaubterweise zu genießen, und ließ alle Zügel der Lebensweise locker. Einzig dieser Baum, den du in der Mitte des Haines siehst, ist für die Speise untersagt, einzig diese Früchte zu berühren ist nicht erlaubt; reichlicher Lebensunterhalt jedoch darf alles Übrige beanspruchen. Doch falls verbrecherische Eigenmächtigkeit das Gebot verletzen sollte, dann müssten wir, kündigte uns der Schöpfer mit Furcht erregender Stimme unter Eid an, das Vergehen mit etwas, das er Tod nannte, büßen. Was er aber mit Tod meint, lege uns, höchst gelehrte Schlange, jetzt bereitwillig dar, da uns in unserer Unerfahrenheit die Sache nicht bekannt ist (2,169-182).“

Die Schlange antwortet, wie Sedulius fortfährt, als Lehrmeisterin des Todes (leti ... magister, 2,183); dabei versteht sie die seinerzeit von Gott erwähnte Gabe der Unterscheidung von Gut und Böse in einem weiten, einem metaphysischem Sinne: als Erkennen des Wahren und des Falschen: 
Terroris uacuum formidas femina nomen;

non ueniet uobis rapidae sententia mortis:

sed Pater inuisus sortem non contulit aequam

nec uos scire dedit, sibimet quae summa reseruat.

Quid iuuat ornatum comprendi aut cernere mundum

et caecas misero concludi carcere mentes?

Corporeos pariter sensus oculosque patentes

sic brutis natura creat, sol omnibus unus

seruit et humano non distat belua uisu.

Consilium mage sume meum mentemque supernis

insere et erectos in caelum porrige sensus.

Namque hoc, quod uetitum formidas tangere, pomum

scire dabit, quaecumque Pater secreta reponit.

Tu modo suspensos tantum ne contine tactus,

nec captiua diu frenetur lege uoluptas.

Namque ubi diuinum libaueris ore saporem,

mox purgata tuo facient te lumina uisu

aequiperare deos, sic sancta ut noxia nosse,

iniustum recto, falsum discernere uero.

„Du hast Angst, Frau, vor einem leeren Schreckenswort. Kein schnelles Todesurteil wird euch zuteil werden; vielmehr hat der Vater euch neidisch, wie er ist, ein ungerechtes Los zugeteilt und er gewährte euch nicht das Wissen, das er sich selbst als Höchstes vorbehält. Was macht es für Freude, wenn man die Schönheit der Welt erfasst und sie wahrnimmt und zugleich seine Vernunft in elender Haft dumpf gefangen sein lässt? In gleicher Weise schafft die Natur körperliche Sinneswahrnehmung und offene Augen auch für die Tiere; eine einzige Sonne ist für alle da, und die Sehkraft unterscheidet sich beim Tier nicht von der des Menschen. Folge lieber meinem Rat, richte deinen Geist auf überirdische Dinge und lass den Sinn erhaben zum Himmel reichen! Denn diese Frucht, die du als verbotene zu berühren dich scheust, wird dir das Wissen um all das geben, was der Vater bei sich als Geheimnis bewahrt. Halte nur nicht länger unentschlossen den Griff nach der Frucht zurück, und die lange unterdrückte Lust soll nicht mehr durch das Gebot gezügelt werden! Denn sobald du mit deinem Mund den himmlischen Geschmack gespürt hast, wird deine geschärfte Wahrnehmung bewirken, dass du an Kraft 
des Erkennens den göttlichen Wesen gleichkommst, dass du ebenso wie das Unheilige auch das Heilige erkennst, dass du das Ungerechte vom Gerechten, das Falsche vom Wahren unterscheidest (2,185-203).“

Hatte es in der Genesis lediglich geheißen, die Frau habe gesehen, dass die Frucht köstlich war, so lässt Avitus alle Sinne Evas beteiligt sein und malt ihre Gier mit einem bewegten Hin und Her von Gesten aus:

Talia fallaci spondentem dona susurro credula submisso miratur femina uultu.

Et iam iamque magis cunctari ac flectere sensum incipit et dubiam leto plus addere mentem. Ille ut uicino uictam discrimine sensit, atque iterum nomen memorans arcemque deorum unum de cunctis letali ex arbore malum detrahit et suaui pulchrum perfundit odore. Conciliat speciem nutantique insuper offert, nec spernit miserum mulier male credula munus, sed capiens manibus pomum letale retractat. Naribus interdum labiisque patentibus ultro iungit et ignorans ludit de morte futura.

$\mathrm{O}$ quotiens ori admotum compuncta retraxit audacisque mali titubans sub pondere dextra cessit et effectum sceleris tremefacta refugit! Dis tamen esse cupit similis serpitque uenenum ambitione nocens. Rapiunt contraria mentem hinc amor, inde metus. Pulsat iactantia legem interdumque etiam lex subuenit. Aestuat anceps diuidui cordis dura inter proelia fluctus.

Nec tamen incentor desistit fallere serpens ostentatque cibum dubiae queriturque morari et iuuat in lapsum pendentis prona ruinae. Vt tandem uictae grauior sententia sedit aeternam temptare famem per criminis escam, serpentem satiare cibo, quem sumeret ipsa, adnuit insidiis pomumque uorata momordit. Dulce subit uirus, capitur mors horrida pastu. 
„Über die Schlange, die mit lügnerischem Zischen derartige Gaben verspricht, zeigt sich die leichtgläubige Frau mit gesenktem Blick voller Verwunderung. Und schon beginnt sie, immer mehr zu schwanken und ihre Meinung zu ändern und ihren unentschlossenen Geist sich stärker dem Tode zuneigen zu lassen. Sobald die Schlange jedoch bemerkte, dass die Frau schon besiegt war und die Entscheidung unmittelbar bevorstand, da pflückt sie, nochmals den Namen und den erhabenen Wohnsitz der göttlichen Wesen erwähnend, von dem todbringenden Baum einen einzigen Apfel aus all den vielen und übergießt ihn in seiner Schönheit mit süßem Duft. Sie preist seine Lieblichkeit an und bietet ihn obendrein der Schwankenden dar. Die zu leichtgläubige Frau verschmäht die elende Gabe nicht; sie nimmt vielmehr die tödliche Frucht und prüft sie mit den Händen. Bisweilen hält sie die Frucht aus eigenem Antrieb an die Nase und an die Lippen und spielt, ohne es zu wissen, mit dem künftigen Tod. Ach, wie oft nahm die Frau reuevoll die bereits zum Munde geführte Frucht zurück, wie oft wich die rechte Hand aus, schwankend unter dem Gewicht der verwegenen Untat, und scheute zitternd vor der Ausführung des Verbrechens zurück! Dennoch begehrt sie, den Göttern ähnlich zu sein, und das Gift kriecht weiter, das infolge ihres Ehrgeizes Schaden stiftet. Gegenteilige Empfindungen zerren sie innerlich hin und her: auf der einen Seite das Verlangen, auf der anderen die Furcht. Es versetzt ihre Selbstüberhebung dem Verbot einen Schlag, dann wieder kommt ihr das Verbot auch zu Hilfe. Unentschieden wogt das Auf und Ab bei den harten Kämpfen ihres geteilten Herzens. Doch die Anstifterin, die Schlange, hört nicht auf mit ihrer Täuschung, führt der Schwankenden die Speise vor Augen, beklagt ihr Zögern, und die Frau, zum Sturz in das drohende Verderben geneigt, unterstützt sie darin noch. Als sich endlich bei der Unterlegenen der Entschluss festigte, durch die verbrecherische Speise ewigen Hunger zu erproben und die Schlange mit der Nahrung, die sie selbst von ihr annehmen wollte, zu sättigen, - da willigte sie in den Anschlag der Schlange ein und biss selber, [von der List des Gegners] völlig eingenommen, in den Apfel. Süß dringt das Gift in sie, und mit der Nahrung wird der schreckliche Tod aufgenommen (2,204-232).“

So weit die Darstellung bei Avitus. Dank ihrer Anschaulichkeit und ihrem gedanklichen Reichtum braucht sie den Vergleich mit theologischer Bibelkommentierung gewiss nicht zu scheuen. Poetische Erzählungen wie diese und die zuvor behandelte des Sedulius können vielleicht erkennen 
lassen, dass die Beschäftigung mit lateinischer Bibelepik der Spätantike etwas durchaus Reizvolles ist.

\section{Literaturhinweise}

\section{Textausgaben und Übersetzungen}

Sedulius:

Sedulii opera omnia, recensuit et commentario critico instruxit Ioannes Huemer (CSEL 10), Wien 1885.

Avitus:

Alcimo Ecdicio Avito, De spiritalis historiae gestis. Introduzione scelta e traduzione a cura di Salvatore Costanza, Messina 1971.

Avit de Vienne, Histoire spirituelle. Tome I (Chants I-III). Introduction, texte critique, traduction et notes par Nicole Hecquet-Noti (Sources chrétiennes 444), Paris 1999.

Alcimi Ecdicii Aviti, Viennensis episcopi, opera quae supersunt, edidit Rudolphus Peiper (Monumenta Germaniae Historica A.A. VI/2), Berlin 1883.

Apokalypse des Mose und Leben Adams und Evas:

Apocalypses apocryphae Mosis, Esdrae, Pauli, Ioannis, item Mariae dormitio, additis evangeliorum et actuum Apocryphorum supplementis, ed. Constantinus Tischendorf, 1866, X-XII; 1-23; Jan Dochhorn, Die Apokalypse des Mose. Text, Übersetzung, Kommentar, Tübingen 2004 (im Druck);

Vita Adae et Evae. Herausgegeben und erläutert von Wilhelm Meyer (Abhandlungen der philosophisch-historischen Classe der königlich bayerischen Akademie der Wissenschaften, Band 14.3), München 1878, 178-250.

\section{Monographien und Aufsätze}

Braun-Irgang, Cornelia: Untersuchungen zum Verhältnis von spätantiker und mittellateinischer Bibelepik, in: Udo Kindermann/Wolfgang Maaz/Fritz Wagner (Hg.), Festschrift für Paul Klopsch (Göppinger Arbeiten zur Germanistik 492), Göppingen 1988, S. 1-45.

Döpp, Siegmar: Virgilius Evangelisans. Zu Praefatio und Prooemium von Alexander Ross' Christias (1638), in: Nachrichten der Akademie der Wissenschaften in Göttingen, I. Philosophisch-historische Klasse Jahrgang 2000, Nr. 6, Göttingen 2000, S. 259-299.

Ehlers, Wilhelm: Bibelszenen in epischer Gestalt: Ein Beitrag zu Alcimus Avitus, in: Vigiliae Christianae 39, 1985, S. 353-369.

Fuhrmann, Manfred: Rom in der Spätantike. Porträt einer Epoche, München/ Zürich 1994 (S. 304-307: Übersetzung von Avitus 2,136-234).

Gnilka, Christian: Chrêsis. Die Methode der Kirchenväter im Umgang mit der 
antiken Kultur, Band I: Der Begriff des „rechten Gebrauchs“, Basel/Stuttgart 1984; Band II: Kultur und Conversion, Basel 1993.

Herzog, Reinhart: Die Bibelepik der lateinischen Spätantike. Formgeschichte einer erbaulichen Gattung, Band 1, München 1975.

Hofmann, Norbert Joh.: Die „nacherzählte“ Bibel. Erwägungen zum sogenannten „Rewritten-Bible-Phänomen“, in: Salesianum 62, 2000, S. 3-17.

Klopstock, Friedrich Gottlieb: Der Messias. Band 1: Text. Herausgegeben von Elisabeth Höpker-Herberg (Friedrich Gottlieb Klopstock: Werke und Briefe. Historisch-kritische Ausgabe. Abteilung Werke: IV/I), Berlin/New York 1974. Kratz, Reinhard G. / Spieckermann, Hermann: Schöpfer/Schöpfung II, in: Theologische Realenzyklopädie 30, 1999, 258-283.

Rost, Leonhard: Einleitung in die alttestamentlichen Apokryphen und Pseudepigraphen einschließlich der großen Qumran-Handschriften, Heidelberg 2. Aufl. 1979.

Smolak, Kurt: Lateinische Umdichtungen des Schöpfungsberichtes, in: Studia Patristica 12 (= Texte und Untersuchungen zur Geschichte der altchristlichen Literatur 115): Papers presented to the Sixth International Conference on Patristic Studies held in Oxford 1971, Part I, edited by Elizabeth A. Livingstone, Berlin 1975, S. 350-360.

Springer, Carl P. E.: The Gospel as Epic in Late Antiquity: The Paschale Carmen of Sedulius (Supplements to Vigiliae Christianae, vol. 2), Leiden/New York/Kopenhagen/Köln 1988.

Westermann, Claus: Schöpfung. Was die Naturwissenschaft fragt - was die Bibel antwortet, Freiburg-Basel-Wien 1989, 133-140.

Für kritische Lektüre und nützliche Hinweise danke ich Marcus Deufert (Leipzig), Jan Dochhorn, Andrea Harbach, Rolf Heine (Göttingen), Manfred Hoffmann (München) und Reinhard G. Kratz (Göttingen). 


\section{Die Bibel in der französischen Literatur: \\ Voltaire, Gide, Giraudoux}

JÜRGEN VON STACKELBERG

Die Bibel hat in der französischen Literatur der Neuzeit - ich spreche nicht vom Mittelalter - weniger Spuren hinterlassen, als in der deutschen oder englischen. Das erklärt sich zum einen durch den Triumph des Katholizismus, der im 17. Jahrhundert von Ludwig XIV erzwungen wurde, es erklärt sich zum anderen aus dem Klassizismus, der im selben Jahrhundert zur offiziellen Literaturdoktrin erhoben wurde. Wie in anderen katholischen Ländern wachte auch in Frankreich die Kirche über die richtige Religionsauffassung. Da brauchte man die Bibel nicht selbst zu lesen - und das spiegelt sich in deren relativ geringer literarischer Rezeption.

Solange es in Frankreich noch Protestanten gab, die etwas zu sagen hatten, hat es dort auch biblische Dichtungen gegeben. Ich nenne nur Clément Marot, der ein Sympathisant der Reformierten war und um die Mitte des 16. Jahrhunderts die Psalmen in Verse faßte, die Calvin in sein Gesangbuch aufnahm. Und ich nenne Guillaume du Bartas, der 1579 ein Schöpfungsepos in 6000 Versen verfaßte, das einen großen, über Frankreich hinausreichenden Erfolg gehabt hat.

Mit der Durchsetzung der „Doctrine classique“, die auf den Kardinal Richelieu zurückzuführen ist und sich hauptsächlich auf das Theater bezog, wurde die geistliche Dichtung aus dem französischen Parnass verbannt. Predigten, hat ein Zeitgenosse Corneilles gesagt, gehörten in die Kirche, nicht auf die Bühne. Hatte es im französischen Barocktheater noch Märtyrerdramen und biblische Stücke gegeben, so stehen Corneilles Polyeucte von 1642 und Rotrous Saint Genest von 1646 als Versuche, christliche Helden auf die Bühne zu stellen, ebenso vereinzelt da wie die beiden biblischen Dramen des alternden Racine, Esther und Athalie. Sie waren auch nicht für öffentliche Aufführungen, sondern nur für die Rezitation im Mädchenpensionat der Mme de Maintenon bestimmt. - Die Tragödien der französischen Klassik behandeln durchweg Stoffe des antiken Mythos oder der Geschichte - und für die Oper gilt weitgehend dasselbe. - Da das 18. Jahrhundert sich weiter klassizistisch gebärdete, hat sich daran auch in diesem Zeitalter nicht viel geändert. Versifizierte 
Bibelwiedergaben wie die „Poèmes sacrés“ von Racines frommen Sohn Louis sind die Ausnahme, die die Regel bestätigt.

Der neben Mme de Staël und Victor Hugo wichtigste Wegbereiter der französischen Romantik, Chateaubriand, hat dann zu Beginn des 19. Jahrhunderts eine Offensive gegen die achristliche oder sogar christentumsfeindliche Tradition der Aufklärung gestartet. 1802 erschien sein Génie du Christianisme, in dem der Religion der ihr gebührende Platz in Kunst und Literatur eingeräumt werden sollte. Da Chateaubriand selbst in jahrzehntelanger Arbeit mit einer neuen, originalgetreuen Miltonübersetzung aufwartete und mit seiner in apologetischer Absicht verfaßten Erzählung Atala ungeheuren Anklang gefunden hatte, wäre zu erwarten gewesen, daß auch die Bibel von nun an im literarischen Frankreich zu Ehren gekommen wäre. Dem ist aber, wenn ich recht sehe, nicht so gewesen. Außer einigen frommen Gedichten in Victor Hugos Légende des Siècles und außer Flauberts Salome-Novelle L'Hérodiade wüßte ich keine Dichtung von Rang zu nennen, die uns hier interessieren könnte. Erst im 20. Jahrhundert wird das anders werden. Erst da nehmen sich wieder namhafte Schriftsteller der Bibel an, geben Episoden daraus wieder oder stellen biblisches Geschehen auf die Bühne. Zwei dieser Werke will ich in der Folge besprechen.

Doch ich kehre zum 18. Jahrhundert zurück, weil da eine bemerkenswerte Ausnahme von der französischen Bibelignoranz zu nennen ist. Es geht um niemand geringeren als Voltaire, Frankreichs größten Aufklärer und notorischen Christentumskritiker. Er war ein ungewöhnlich emsiger Bibelleser - wenn auch kein frommer und zustimmender, sondern ein kritischer und respektloser. Aber Kritik und Respektlosigkeit sind, zumal bei Voltaire, kein Beweis für Interesselosigkeit - im Gegenteil. Es gibt nichts Unsinnigeres, als Voltaire echtes Interesse an der Bibel oder gar an der christlichen Religion überhaupt abzusprechen, wie es noch vor einer Generation in der deutschen Romanistik gang und gäbe war. Seit dem Mammutwerk von Frankreichs größtem Voltaireforscher, René Pomeau, das 1974 unter dem bezeichnenden Titel La Religion de Voltaire erschienen ist, wissen wir, daß Voltaire sich selbst in der Rolle eines Religionsstifters sah, nämlich einer undogmatischen Lehre vom Gottglauben ohne Priester und Kirche, dem „Theismus“. Doch davon will ich hier nicht reden: ich will nur ein erzählerisches Produkt seiner Bibellektüre vorstellen, den Taureau blanc aus dem Jahre 1774. 
Als Bibelkritiker hatte Voltaire in den gelehrten Bibelforschern seiner Zeit, vor allem in Richard Simon, Vorläufer. Aber konsequenter als alle anderen legte er den Maßstab des aufgeklärten Verstandes an die Bibel an. Wir haben es noch nicht, oder nur ausnahmsweise, mit philologischer Bibelkritik zu tun, sondern mit einer Exegese, die Plausibles bejaht, Nicht-Einleuchtendes verneint, so wie Voltaire das in seiner Geschichtsschreibung ganz allgemein getan hat. Die Bibel galt ihm als ein historisches Dokument wie andere, nicht als „Gottes Wort“. Als Erzeugnis einer Phantasie, die den alten Juden in besonders hohem Maße zueigen gewesen sein mußte, ist Voltaire am Alten Testament mehr interessiert gewesen als am Neuen. Man kenne es zu wenig, schreibt er einmal an eine vornehme Dame der Pariser Gesellschaft, und er empfiehlt ihr, „seinen Freund Hesekiel“ zu lesen, das werde ihr „für ein gutes Viertelstündchen die Zeit vertreiben“.

Er selbst hat sehr viel mehr Zeit auf seine Bibellektüre verwandt. Anders ist nicht zu erklären, daß er mehrere Bände seiner Euvres complètes mit bibelkritischen Anmerkungen füllen konnte, darunter eine umfängliche Schrift des Titels La Bible enfin expliquée. Wie viel oder wie wenig davon auch dem heutigen Bibelforscher noch bedenkenswert erscheinen mag, kann ich nicht beurteilen. Von einem Desinteresse wie bei der Mehrzahl seiner Landsleute und Zeitgenossen kann bei Voltaire jedenfalls nicht die Rede sein. Und damit bin ich schon bei der Erzählung, zu der die Bibel Voltaire angeregt hat, dem „Weißen Stier“.

Voltaire war achtzig Jahre alt, als er die Geschichte erfand, die in der kritischen Ausgabe von René Pomeau 66 Seiten umfaßt. Er hatte eine schwere Krankheit überstanden und fühlte sich auch dadurch erleichtert, daß nun endlich der Jesuitenorden verboten worden war. Das hielt er nicht zu Unrecht für einen Sieg der Aufklärung.

Und wieder vertiefte er sich in die Bibel. Als er im vierten Buch Daniel die Geschichte von Nebukadnezars Traum, seiner Deutung durch Daniel und der Bestrafung des herrscherlichen Hochmuts durch die Verwandlung in einen Stier las, müssen Voltaire die Metamorphosen des Ovid in den Sinn gekommen sein.

War es in der gelehrten Bibelforschung der Zeit üblich, die Schriften der Heiden, wenn sie mit der Bibel übereinstimmten, als Bestätigungen für die Wahrheit des biblischen Berichts aufzufassen, so ging Voltaire den umgekehrten Weg: die Verwandlung Nebukadnezars in ein grasfressendes 
Tier bewies, daß das Alte Testament wie die Metamorphosen Ovids eine Dichtung war. In der Bibel stand zwar nur, Nebukadnezar sei aus der Welt der Menschen verbannt und ins Reich der Tiere verwiesen worden, da müsse er sieben Jahre lang Gras fressen „ut bos“, aber seit den Kirchenvätern war es umstritten, ob der König der Könige wirklich in einen Stier verwandelt worden war oder ob er nur dem Wahn erlag, ein weidendes Rind zu sein. Im Kommentar des Benediktiners Dom Calmet, den Voltaire vorzugsweise benutzte, wurde die Verwandlung ernst genommen. Davon ging Voltaire, gleichsam als der „lectio difficilior“, aus. Warum auch nicht? Schließlich war das ja nicht die einzige Metamorphose, von der in der Bibel die Rede ist.

War der Plan einer „Kontamination von Bibel und Ovid“ einmal gefaßt, mußte nur noch eine Fabel erfunden und die Erzählung in ein passendes Gewand gekleidet werden. Über die Fabel sage ich gleich etwas, die Form aber, das lag für Voltaire als Liebhaber der Märchen von 1001 Nacht nahe, mußte die des Märchens sein. Die Bibel, Ovid, 1001 Nacht: solche Mixturen amüsieren natürlich den Literarhistoriker, als der ich (das bitte ich nicht zu vergessen) hier spreche. Wer die französischen Märchen kennt, weiß, daß diese - im Gegensatz zu denen der Brüder Grimm - mehr oder minder parodistisch eingefärbt sind. Das gilt schon für Grimms französischen Urahn, Charles Perrault, und es gilt, wenn nicht für die von Galland aus dem Arabischen übersetzten Märchen, so doch für die zahlreichen Fortsetzungen und Nachahmungen, die es davon in Frankreich gab, darunter Voltaires Zadig. So trägt denn auch der „Weiße Stier" parodistische Züge.

Erschienen ist das biblisch-ovidische Märchen übrigens in Grimms Correspondance littéraire, einer Zeitschrift, die handschriftlich an die aufgeklärten Fürsten Europas verschickt wurde und nicht der Zensur unterlag. Voltaire behauptete, die Geschichte vom weißen Stier sei aus dem Syrischen übersetzt und in Memphis erschienen. In einer Ausgabe spricht er dem Benediktiner Dom Calmet die zweifelhafte Ehre zu, der Übersetzer zu sein, in einer anderen nennt er Mamaki, den Dolmetscher des englischen Königs, als Übersetzer. Solche Versteckspiele waren Voltaire, auch wenn ein Einschreiten der Zensur gar nicht zu befürchten stand, zur lieben Gewohnheit geworden.

Die Fabel läuft, so könnte man sagen, auf einen Konflikt zwischen Liebe und Staatsräson hinaus. Amasis, der in Wirklichkeit ein Verbünde- 
ter Nebukadnezars war und den man von Herodot her kennt, wird von Voltaire zu einem Feind des Herrschers von Babylon gemacht. Er hat eine Tochter namens Amaside, die ist 24 Jahre alt und wunderschön. Und sie hat einen Erzieher, den Eunuchen und Magier Mambres, der ist „ungefähr dreizehnhundert Jahre alt“. In jungen Jahren hatte er gegen Moses andebattiert, war aber unterlegen, berichtet Voltaire nach Dom Calmet, der Mambres in den Paulusbriefen (2. Tim 3, 8) aufgelesen hat. Amaside ist traurig. Sie vergießt Tränen, heißt es zu Beginn der Erzählung, weil sie ihren Geliebten verloren hat. Der war der schönste aller Jünglinge, herrschte über Babylon, ist nun aber verschwunden - keiner weiß wohin. Tot sei er jedoch nicht, sagen die Weisen Ägyptens. Leider darf die Prinzessin den Namen ihres Geliebten nicht nennen, denn wenn sie das täte, würde ihr Vater ihr den Kopf abschlagen, das hat er versprochen. Infolgedessen spricht sie nur die erste Silbe aus: „Ne...“, da legt Mambres ihr schon, wie der ägyptische Gott Harpokrates, den Finger auf die Lippen. ,Den Mund halten!' heißt die Devise am Hofe des Amasis. Schweigend ergehen sich denn auch die Prinzessin, ihre Begleiterinnen und Mambres an den Ufern des Nils. Da erblicken sie eine alte, in Lumpen gekleidete Frau, die an einer Eisenkette einen wunderschönen, weißen Stier oder Ochsen auf die Weide führt. Nicht weit davon sieht man eine Eselin, einen Hund und einen Ziegenbock. Etwas weiter abseits ringelt sich eine Schlange durch das Gras, deren Haut in allen Farben schillert und deren Blicke voller Zärtlichkeit sind. Zur Hälfte ragt ein großer Fisch aus dem Wasser, und auf dem Zweig des nächsten Baumes sitzen ein Rabe und eine Taube.

Ich unterbreche hier schon 'mal meinen Bericht und verrate, wer diese Gestalten und Tiere waren, was kundige Bibelleser natürlich längst gemerkt haben. Die alte Frau ist „die Hexe von Ensor“" (wie Luther sie nennt), 1. Sam 28; die Eselin gehört Bileam und kann sprechen, 4.Mose 22. Der Fisch ist der, der Jonas verschlungen hatte, 2. Mose 1. Der Hund ist der, der Tobias nachlief, 1. Mose 13. Den Ziegenbock braucht man bloß in die Wüste zu schicken, um seine Sünden loszuwerden, 3. Mose 16. Rabe und Taube entstammen der Genesis, 1.Mose 8,7 - und der weiße Stier? Nein, das ist nicht der Stier, in den Jupiter sich verwandelt hatte, um Europa zu entführen, es ist auch nicht die entzückende Färse, in die Isis sich einmal verwandelte, wie Ovidkenner vielleicht vermuten könnten. Zu erfahren, wer er ist, wird Amaside manch weitere Träne und den Erzähler mehrere Kapitel kosten. Da ein unerklärliches Gefühl 
die Prinzessin zu dem Stier hinzieht und dieser seinerseits vor ihr in die Knie geht und Tränen vergießt - nur leider kann er nicht sprechen -, will Amaside verständlicherweise wissen, wer der „Cherub“ ist. (Cherub“ heiße im Chaldäischen der Stier, behauptet Dom Calmet, und Voltaire glaubt es ihm.)

Das einzige Wesen, das der Prinzessin das Rätsel lösen kann, das nicht einmal der weise Mambres zu lösen vermag, ist „le serpent“, also die Schlange, die im Französischen bekanntlich männlich ist. Und so kann man denn im dritten Kapitel nachlesen, wie Amaside die Schlange befragt, die schon unserer Urmutter - ach, wie hieß sie doch? Eva, natürlich! - so galant entgegengekommen war. Man erinnert sich an die Geschichte mit dem Apfel. Auch in diesem Gespräch geht es galant zu. Und die Schlange verrät Amaside schließlich, was wir längst wissen, daß der weiße Stier nämlich in Wahrheit Nebukadnezar ist.

Ich bedauere sehr, daß ich meinen Bericht hier abbrechen muß, denn wir haben noch anderes vor. Sagen will ich nur, daß Amaside und Mambres fliehen müssen, um den Verfolgungen des bösen Amasis zu entgehen. Sie gelangen schließlich nach Memphis und erfahren dort, daß der Gott Apis gestorben ist. Man sucht einen Nachfolger für ihn - und Mambres bietet den weißen Stier an: er soll also ein Gott werden. Doch dazu kommt es nicht, weil die sieben Jahre um sind, der Stier sich wieder in einen schönen Jüngling zurückverwandelt und er und Amaside ein Paar werden. Die eingangs genannten Tiere haben alle mehr oder minder zum Glück der beiden beigetragen, ein paar Propheten in zerlumpten Gewändern, die sich in Elstern verwandeln, spielen auch noch in das Geschehen hinein... Doch alle Welt bewundert nun den menschgewordenen Stier, der lieber ein König als ein Gott sein wollte. Und jedes Mal, wenn der König von seinen Satrapen, Magiern, Schatzmeistern oder Frauen betrogen worden ist, aber seine Fehler wiedergutmacht, ruft das Volk von Babylon: „Es lebe unser großer König, der kein Ochse mehr ist - vive notre grand Roi, qui n'est plus bœuf!“

Das war Le Taureau blanc, eine von Voltaire erfundene, den Personen und Tieren des Alten Testaments angedichtete Geschichte, nicht etwa eine „Nacherzählung“ der Bibel. Der spielerische, witzige und spöttische Ton läßt es angebracht erscheinen, von einem Rokokokunstwerk zu sprechen. Zum Zeitpunkt seines Erscheinens, 1772, war das schon fast ein Anachronismus: auf der Tagesordnung stand die Empfindsamkeit 
und der Tränenkult Rousseaus oder Diderots. Aber Voltaire hat da nicht mitgemacht, oder nur ganz ausnahmsweise. Er hielt daran fest, daß man die Ideen der Aufklärung am besten entweder in klassizistischer oder eben, wie hier, in Rokokoform an den Mann bringt. Daraus, daß Voltaire sich über die Absonderlichkeiten und Widersprüche der Bibel lustig macht, ist also nicht zu schließen, daß dahinter keine kritischen Aufklärerabsichten stünden. Aber wenn der Taureau blanc eine bibelkritische Erzählung ist, was nicht zu leugnen ist, so überwiegt beim Leser der Geschichte von der Prinzessin Amaside und ihrem in einen Stier verwandelten Geliebten der Spaß - und so dürfte es Voltaire selbst auch gegangen sein. Er nimmt zwar die Gelegenheit wahr, sich über die Magier, die Metamorphosen, die Funktion der Schlange im Paradies oder die Geschichte von der Arche Noah zu mokieren (wer gab eigentlich den Tieren zu fressen?), aber selbst das geschieht nicht in der ernsthaften, engagierten und militanten Weise, wie der Alternde zur gleichen Zeit die Willkürjustiz fanatisierter Richter bekämpft. Die Vermenschlichung Gottes, wie sie die Bibel vornimmt, war Voltaire ein Stein des Anstoßes, die Zoolatrie der alten Ägypter erst recht, aber er schüttelt darüber nur noch amüsiert den Kopf, seine Leidenschaft spart er sich für anderes auf. Wie der Achtzigjährige mit den Folianten „jongliert“, den 30 Bänden von De Sacys Bibel, den 43 Bänden der Bibelkritik von Richard Simon und vielen weiteren gelehrten Werken, und wie er daraus die unterhaltsame Fabel vom „Weißen Stier“" extrahiert, ist bewundernswert. Es ist ein Genuß, sie zu lesen - aber ergreifen lassen muß man sich davon nicht.

Ganz anders verhält es sich mit meinem zweiten Textbeispiel, André Gides Nacherzählung des Gleichnisses vom verlorenen Sohn. Ich kenne keinen ernsteren, ja innigeren der Bibel nachgestalteten Text aus der französischen Literatur. Die 1907 verfaßte Erzählung beginnt mit einem Prolog, der gleich schon den Ton zu erkennen gibt, in dem sie gehalten ist.

Er sei, schreibt Gide, wie der Stifter eines Altarbildes neben dem verlorenen Sohn niedergekniet und habe ihm unter Tränen zugelächelt: „le visage trempé de larmes“. - Ich zitiere das Original und nicht die Übersetzung von Rilke, die zu preisen ich anderen überlassen muß. Sie ist teils manieriert, teils so eng an den französischen Text angelehnt, daß sie undeutsch wirkt. So schreibt Rilke, nicht Gide. Aber eine andere Übersetzung ist meines Wissens nicht auf dem Markt. Leider. 
Das eine oder andere über André Gide, sein Elternhaus und seine Erziehung wird nachher einzuflechten sein, um die Besonderheiten seines Retour de l'enfant prodigue zu erklären. Zunächst scheint es mir wichtiger, an das biblische Gleichnis nach Lukas 15,11-21 zu erinnern, denn wie anders können wir feststellen, was Gide davon beibehalten, was er verändert hat?

Es werde „Freude sein vor den Engeln Gottes über einen Sünder, der Buße tut" lautete der letzte Satz von Lukas 14, auf den das Gleichnis folgt. Der jüngere der beiden Söhne eines Mannes, heißt es dann, ließ sich sein Erbteil auszahlen, verließ das Elternhaus und verpraßte das Geld. Eine Teuerung brach aus; der Ausreißer mußte dienen und sein Dasein als Schweinehirt fristen. Nicht einmal die Treber, die die Säue fraßen, bekam er zu essen. Da ging er in sich und erinnerte sich an das Landgut seines Vaters, wo selbst die Tagelöhner genug zu essen bekamen. Er beschließt heimzukehren, um vor den Vater hintretend zu sagen, er habe gegen den Himmel und gegen ihn gesündigt und sei es zufrieden, künftig bei ihm als der letzte der Knechte zu dienen. Doch der Vater sieht ihn kommen, eilt ihm entgegen, begrüßt ihn froh, umarmt ihn und schenkt ihm einen Ring. Er läßt ihn festlich kleiden und ein Kalb schlachten, um seine Rückkehr zu feiern. Der ältere Bruder beobachtet das alles voller Neid und fragt den Vater, warum er den feiere, der davongelaufen sei und sein Gut durchgebracht habe, während er ihm allezeit pflichttreu gedient habe. Da sagt der Vater zum älteren Sohn, er sei ja immer bei ihm gewesen, der jüngere aber sei „tot gewesen und wieder lebendig geworden, er sei verloren gegangen und wurde wiedergefunden." Damit endet die Parabel.

Sie sollte lehren, daß einer, der gesündigt hat, aber seine Sünden bereut, dem Herrn willkommener ist als einer, der nie einer Versuchung erlegen ist, stets seine Pflicht getan hat, aber sich dessen brüstet und auf den Sünder herabschaut. Es geht um eine Lektion in Barmherzigkeit: Schwächen sind menschlich, man kann sie verzeihen, wenn sie korrigiert werden. Guter Wille verdient Anerkennung, Verzeihen ist eine christliche Tugend.

Faßt man Inhalt und Sinn des biblischen Gleichnisses so zusammen, zeigt sich, daß Gide sich nicht damit begnügt hat, beides zu wiederholen - das tut er auf seine Weise auch -, sondern daß er einiges hinzugefügt und der Parabel einen zusätzlichen, wenn nicht sogar gegensätzlichen Sinn gegeben hat. Aus der biblischen Botschaft sollte schließlich eine Gide'sche werden. 
Den Auftakt zu seiner Erzählung macht der Entschluß des verlorenen Sohns zur Rückkehr ins Elternhaus. Er ängstigt sich zwar vor dem Zorn des Vaters, aber er sagt sich - wie in der Bibel -, wenn er für tot gehalten wurde und nun lebend wieder erscheine, werde der Vater sich vielleicht freuen. Vom Gipfel eines Hügels herabblickend sieht er das Haus. Es ist Abend, aus den Dächern steigt der Rauch auf. Doch der Zurückkehrende hält inne: er will die Dunkelheit abwarten, damit seine Schande nicht offenbar werde. Dann erst steigt er herab. Er vernimmt die Stimme des Vaters, hört den Hund bellen und erblickt die Mutter auf dem Vorplatz. Da eilt er mit letzter Kraft, denn der Hunger plagt ihn, auf das Haus zu. Der Vater hat ihn erspäht, er geht ihm entgegen, umarmt ihn. Der verlorene Sohn bekennt seine Sünden, sagt, er wolle dem Vater künftig als der geringste der Knechte dienen. Doch dieser befiehlt seinen Knechten, schöne Kleider zu bringen, schenkt ihm einen Ring und läßt ein Kalb schlachten. Dies alles wird in enger Anlehnung an den biblischen Text geschildert. Das gilt auch für den älteren Bruder, der abseits steht, der Begrüßung zuschaut, den festlichen Lärm vernimmt und sich mit gerunzelter Stirn zu den anderen setzt: „Au pêcheur repenti, pourquoi plus d'honneur qu'à lui, qui n'a jamais péché “ fragt er den Vater vorwurfsvoll: „Warum dem reuigen Sünder mehr Ehre antun als ihm, der niemals gesündigt hat?" - Im Stillen hofft er, die Eltern würden dem jüngeren Bruder am nächsten Tag die Leviten lesen. Damit lenkt Gide zu den Gesprächen über, die nun folgen. Und damit beginnt die Wiedergabe, sich vom Bibeltext zu entfernen. Aber auch der Prolog enthielt schon eine Abweichung. In einem Zwiegespräch mit sich selbst hatte der "fils prodigue“ gefragt, warum er eigentlich fortgegangen sei: was habe er denn in der Fremde gesucht?

Darauf läßt Gide den verlorenen Sohn eine merkwürdige Antwort geben. Er sagt nämlich, es sei „le dénuement“, die Entbehrung gewesen, die er gesucht habe. Das Wort müssen wir uns merken. Es wird wiederkehren. In der Fremde, heißt es weiter, habe er das Glück, das er suchte, nicht gefunden, und „'ivresse“, die „Trunkenheit" des Aufbruchs, habe auch nicht lange angehalten. Auch das ist ein Gide’scher, kein biblischer Begriff. Zum ersten Mal erfahren wir hier etwas über die Gründe, die den Ausreißer von zu Hause haben fortgehen lassen. In jedem der folgenden Gespräche werden wir andere genannt bekommen. Das macht Gides Erzählung psychologisch interessant: sie ist komplexer als das biblische Gleichnis. 
Das erste Gespräch ist das mit dem Vater. Gide kündigt es mit einer Erzählerintervention an, in der er selbst sich Gott zuwendet und bekennt, es sei ihm ähnlich gegangen wie dem verlorenen Sohn. Trotzdem wolle er nun wissen, was weiter geschah. Solche Einmischungen des Autors in seinen Text werden später nicht mehr vorkommen, aber diese eine genügt, um zu erkennen, daß Gide existenzielle Gründe hatte, die biblische Geschichte nachzuerzählen. - Mit dem Zwiegespräch zwischen Vater und Sohn tritt die biblische Wahrheit weiter hinter der Gide'schen zurück. Denn da sagt der Zurückgekehrte, er habe nur das Elternhaus verlassen, nicht den Vater. Ihm habe er sich immer nahe gewußt. Das Haus sei ja auch nicht vom Vater, sondern von anderen gemacht. Das kann nur heißen, der "fils prodigue” habe lediglich die Kirche verlassen, in der er sich eingesperrt fühlte, nicht Gott den Herrn selbst. Gide sähe also in dem verlorenen Sohn nur einen Einzelgänger und Individualisten, vielleicht sogar so etwas wie einen „Protestanten“ im Wortsinn, nicht aber einen, der seinen Gottglauben verlor. Wir sind dem Autor einen Schritt näher gekommen - und fühlen uns vielleicht auch an die aufklärerische Tradition französischer Kirchenfeindschaft erinnert, die von Deisten (wie Voltaire) getragen wurde. Im übrigen, sagt der verlorene Sohn zum Vater, er habe sein Geld nicht in Genuß, sondern in „Poesie“ und in „Durst“ umsetzen wollen. Und dieses Wort liegt nahe bei „dénuement“, der Vokabel, die wir schon kennen. Gide war der Sohn reicher Eltern und ist ohne Entbehrungen aufgewachsen: von daher schien ihm darin eine Erfahrungsbereicherung zu liegen. Das überträgt er auf den verlorenen Sohn, in dem wir nun erst recht Gides alter ego erkennen.

Wenn er weiter erklärt, er sei aus „paresse“, also Trägheit und aus „lâcheté“, also Feigheit, zurückgekehrt, widerspricht das dem nicht. Die Strapazen der Wüste, Hunger und Durst, seien unerträglich geworden, da sei er umgekehrt, wohl wissend, daß er sich (wie Gide sagt) „nach dem Geschmack der wilden Eicheln, der trotz allem im Munde zurückgeblieben ist" zurücksehnen werde. Auch das steht natürlich im Gegensatz zur biblischen Parabel.

Das Gespräch mit dem älteren Bruder, das nun folgt, stellt insofern eine Novität dar, als wir erfahren, dieser und nicht der Vater habe im Hause das Sagen. Er hat die Bewirtschaftung übernommen, er sorgt für Ordnung und Disziplin, er verlangt Gehorsam und Unterordnung. Wer sich nicht fügt, erklärt er, sei hochmütig: in seinen Augen ist es „orgueil“, 
Stolz, was den jüngeren Bruder hat ausbrechen lassen. Auch wenn wir die Sicht nicht vergessen dürfen, aus der heraus so gesprochen wird, kann man doch sagen: Wieder fällt ein anderes Licht auf den Weggang des verlorenen Sohns. Nimmt man noch die Formel hinzu, die Gide dem älteren Bruder in den Mund legt, nämlich: „Tiens ferme ce que tu as - halte fest, was Du hast!", so wird erst recht klar, was Gide im Sinn hatte, als er den älteren Bruder auftreten ließ. Er verkörpert das bürgerliche Besitzstreben und die Autorität, steht für „law and order“, und erscheint daher hier in noch weit ungünstigerem Licht als in der Bibel. Gewiß, unbarmherzig und neidisch oder selbstgerecht und hochfahrend ist der ältere Bruder auch hier, aber verabscheut wird er vor allem als Repräsentant einer Bourgeoisie, die dem Autor verhaßt ist. Nicht ohne Grund läßt Gide den älteren Bruder sagen, er spreche für den Vater, der einmal dies, ein andermal jenes sage. "J'en reste l'unique interprète, et qui veut comprendre le Père doit m'écouter - ich bin sein einziger Interpret und wer den Vater verstehen will, muß mich hören“. Ich denke, man kann auch hier den Widerwillen des Individualisten heraushören, der sich seine Vorstellung von Gott nicht vorschreiben lassen will. Für den älteren Bruder ist das Anarchismus.

Spielte sich das Gespräch mit dem älteren Bruder in einer Atmosphäre der Kälte ab, so fließen nun, im Gespräch mit der Mutter, die Tränen. Kaum versteht der verlorene Sohn noch, warum er eigentlich wegwollte. Wahrscheinlich, sagt er, war es weder die Freiheit, noch das Glück, noch die Trunkenheit oder der „Durst“ und der Verzicht auf das Wohlleben, es war die Suche nach dem eigenen Ich, eine Identitätssuche, die den Heranwachsenden zwangsläufig von den anderen wegführen mußte. Daß das der Wahrheit am nächsten kommt, wird sich im letzten Gespräch, dem mit dem jüngeren Bruder, bestätigen. Was diesen betrifft, so beschwört die Mutter den Zurückgekehrten, von nun an zu Hause zu bleiben - sie will ihm auch eine Frau aussuchen, mit der er eine Familie gründen kann -, und er soll den jüngsten Sohn überreden, nicht von zu Hause fortzugehen, was dieser offensichtlich vorhat.

Tatsächlich versucht der verlorene Sohn nun, im letzten der vier Gespräche der Gide'schen Nacherzählung, den Jüngeren davon abzuhalten, von zu Hause fortzugehen. Er warnt ihn vor der Unbill, die ihn in der Ferne erwartet - muß aber bald einsehen, daß es zwecklos ist, denn der Bruder ist fest entschlossen zu gehen. Er will fort von den Zwängen, fort von der Routine des Alltags: wie konnte der Ältere nur zurückkehren? 
Das hieß doch darauf verzichten, er selbst zu sein: „Tu as renoncé à être celui que tu voulais être - Du hast es aufgegeben, der zu sein, der du sein wolltest!“, sagt er, und das gibt der verlorene Sohn zu. Er gesteht: „j’ ai failli - ich habe versagt", und bestärkt den jüngeren Bruder erst recht in seinem Vorhaben: „Sois fort, oublie-nous, oublie-moi, puisses-tu ne pas revenir - Sei stark, vergiß uns, vergiß mich! Mögest du nicht zurückkehren!“ Das sind die letzten Worte des verlorenen Sohns. Sie enthalten die Botschaft, um derentwillen Gide das biblische Gleichnis nacherzählt hat. Sie besteht in einer Aufforderung zur Emanzipation, zum Ausbrechen aus dem Elternhaus und der Familie, zum Bruch mit dem Herkömmlichen, um in der Freiheit des selbstgewählten Lebensweges sich selbst zu finden. Es ist die Botschaft der Bibel nicht, eher schon diejenige Nietzsches. Aber Gide brauchte Nietzsche nicht, um zu denken wie er.

Ich ende meinen Bericht über Gides Erzählung mit einem Wort zur Sekundärliteratur. Da wird Le retour de l'enfant prodigue meistens als eine Antwort an Claudel aufgefaßt, der versucht hatte, Gide zum Katholizismus zu bekehren. Der Hinweis hat seine Berechtigung. Gide mußte sich nicht nur der Bekehrungsversuche Claudels, sondern auch anderer katholischer Freunde erwehren - und hat das energisch getan. Die Reaktion von katholischer Seite blieb nicht aus. Gide schien für die Sache der Kirche verloren. Man sollte jedoch L'enfant prodigue nicht auf den Sinn einer Antwort an Claudel reduzieren. Es ist evident, daß die Schrift eine allgemeinere, weitergehende Bedeutung hat. „Gide erhöht in diesem dichterischen Kleinod ein persönliches Problem gleichnishaft ins Universal-Gültige" schreibt Gero von Wilpert im Lexikon der Weltliteratur. Recht hat er.

Ich komme zu meinem dritten und letzten Beispiel. Es ist ein Theaterstück von Jean Giraudoux aus dem Jahre 1931: Judith. In meiner Ausgabe von Giraudoux' Theater folgt es dem bekannteren Amphitryon von 1929. Das noch bekanntere Stück über den trojanischen Krieg, La guerre de Troie n'aura pas lieu entstand 1935. Wie die meisten Dramen von Giraudoux war auch Judith für die Inszenierung durch Louis Jouvet bestimmt. Der erfahrene Regisseur hat offenbar seinen Teil dazu beigetragen, das Redetheater Giraudoux' bühnentauglich zu machen. Judith ist das ganz ohne Zweifel, obwohl darin, wie immer bei Giraudoux, viele längere Reden geführt werden. Aber das entspricht in Frankreich einer großen Tradition, der der Klassik. Das allein legt es schon nahe, Giraudoux einen „Klassiker 
der Moderne“ zu nennen. Die Angehörigen meiner Generation haben ihn als eine der großen Entdeckungen der Nachkriegszeit in Erinnerung. Heute ist er weitgehend vergessen. Das ist schade. Ich nehme jedenfalls den Anlaß wahr, auf ihn als einen der bedeutendsten neueren Bühnendichter Frankreichs hinzuweisen. Unsere Theater sollten ihn ruhig mal wieder aufführen. Und warum nicht die Judith?

Giraudoux - auch das möchte ich noch vorausschicken - war ein guter Kenner der deutschen Literatur. Zu seiner Judith hat er sich wahrscheinlich von Hebbel anregen lassen, der 1841 ein Judith-Drama geschrieben hat. Es weist einige Änderungen am biblischen Stoff auf, die Giraudoux beibehalten hat. Andererseits bleibt bei Hebbel manches im Unklaren, so daß man nicht so recht weiß, worauf das Stück eigentlich hinauslaufen soll. Das dürfte den französischen Dramatiker erst recht gereizt haben, nach neuen Antworten auf die Fragen zu suchen, die die biblische Legende stellt. An einer Stelle hat Giraudoux sich wahrscheinlich auch an Schillers Jungfrau von Orleans erinnert, und wie bei Gide liegt es auch hier nahe, an Nietzsche zu denken, den Giraudoux gut gekannt hat. - Wie in seinen Nachdichtungen mythologischer Stoffe der Antike hat Giraudoux auch hier versucht, das Geschehen psychologisch plausibel zu machen. Er vermenschlicht die Figur der Bibel. Aber während das bei Ödipus oder Orest, Antigone oder Elektra nicht weiter riskant ist, kann oder muß die Vermenschlichung hier zu einem gefährlichen Spiel werden. Giraudoux ist sich dessen sicher bewußt gewesen. Er schrieb nicht wie Sartre ein politisch-engagiertes Theater, er wollte nur erklären, wie die Ermordung des Holofernes durch Judith motiviert erscheinen und von einem heutigen Zuschauer oder Leser akzeptiert werden kann. Das zwang ihn zu gewissen Änderungen der biblischen Vorlage, obwohl die Mission Judiths, was ihren Erfolg anlangt, nicht angetastet werden durfte. Giraudoux hat den biblischen Mythos zuerst zerstört, sich aber im letzten Akt bemüht, ihn wieder aufzubauen. $\mathrm{Ob}$ ihm das wirklich gelungen ist, ist die Frage. Die aber macht das Stück erst recht interessant. Wir haben es mit einem Drama zu tun, das zu unterschiedlichen Deutungen Anlaß geben kann und das an die grundsätzlichen Probleme dichterischer Gestaltung biblischer Stoffe rührt. Das Thema, um das es kreist, war heikel, denn seit der Dramatisierung Hebbels schien es unumgänglich, Judith den Holofernes lieben und ihn dennoch umbringen zu lassen. 
Im Buch Judith, das apokryph ist - und über das ich infolgedessen nach der Vulgata berichte -, ist von Liebe nicht die Rede. Da wird zuerst des Langen und Breiten erzählt, wie Holofernes ein Land nach dem anderen erobert und sich untertan gemacht hat. Nun hat er die Stadt Bethulia umzingelt, in der sich die Juden verschanzt haben. Sie werden sich nicht mehr lange halten können, weil Holofernes die Brunnen zugeschüttet und alle Zugänge zur Stadt besetzt hat. Fällt die Stadt, ist der Weg nach Jerusalem frei und der Staat der Juden dem Untergang geweiht. Daher ruft der Oberrabbiner Eliachim die Bethuler dazu auf, Gott anzuflehen: nur Gott, nicht menschliche Kraft, könne sie retten. - Unterdessen befragt Holofernes den Ammoniter Achior, der auf seiner Seite steht, welche Tugenden und welche militärische Macht die Juden hätten. Achior antwortet genau wie der Priester Eliachim, sie könnten nur von Gott, nicht aus eigener Kraft gerettet werden. Das erzürnt Holofernes, und er jagt Achior fort; er solle zu den Juden gehen und auf die Hilfe von deren Gott hoffen, er werde ihn ebenso wie all seine Freunde erschlagen und die Stadt erobern.

Diese Figur, die bei Hebbel etwa die gleiche Rolle spielt wie in der Bibel, hat Giraudoux eliminiert. Da sie der religiösen Apologetik diente, deutet die Streichung auf eine gewisse Tendenz zur Entsakralisierung hin. Es war nicht Giraudoux' Absicht, die Juden zu ermahnen, sie müßten auf Gott hoffen und dürften nicht von ihm abfallen.

Judith, die Witwe ist, erfährt von der aussichtslosen Lage der Stadt. Sie fastet und betet wie alle anderen, ist aber, wie ausdrücklich betont wird, von außergewöhnlicher Schönheit: „eleganti aspectu nimis“. Das muß Giraudoux im Ohr geklungen haben, als er seine Judith schuf. In der Bibel heißt es außerdem, sie sei beim Volke beliebt. Das will Giraudoux nun wieder nicht glauben, wie wir sehen werden. - Judith beschließt, nächtens zum Tor hinauszueilen und sich zu Holofernes zu begeben. Niemand soll ihr im Wege stehen, niemand sie nach ihrer Absicht befragen. Nach einem flehentlichen Gebet begibt sie sich, duftend gesalbt und geschmückt, ins feindliche Lager und zu Holofernes. Der Feldherr sitzt auf einem purpurnen, mit Edelsteinen verzierten Thron in seinem Zelt. Er erblickt die schöne Jüdin und fragt, was sie begehre. Da stimmt Judith ein Loblied auf Nebukadnezar und seinen siegreichen Feldherrn an, als dessen Magd sie gekommen sei. Ihr Volk sei von Gott abgefallen, wie Achior es befürchtet habe, es lebe in Angst und Schrecken, sei am Verhungern und Verdursten, 
da sei sie aus der Stadt geflohen, um ihn, den großen Feldherrn, um Hilfe zu bitten. Holofernes ist von der Redegewandtheit des Mädchens ebenso beeindruckt wie von seiner Schönheit. Er läßt Judith drei Tage Zeit, um ihren Durst zu löschen und zu beten: am vierten werden sie gemeinsam speisen und trinken. Das Mahl findet statt, aber Holofernes trinkt dabei so unmäßig, daß er ermüdet zu Bett geht und einschläft: ,iacebat in lecto ebrietate sopitus". Judith spricht unter Tränen ein letztes Gebet, ergreift den am Bettpfosten hängenden Säbel, packt den schlafenden Holofernes beim Schopf und sticht ihm zweimal in den Hals. Dann trennt sie das Haupt vom Rumpf, reißt den Bettvorhang nieder und übergibt den Kopf der Dienerin, die mit ihr gekommen ist und die ihn in ihren Proviantsack steckt. Unbehelligt gelangen beide zurück in die Stadt. Dort werden sie im Triumph empfangen, der Rabbiner segnet sie und dankt Gott, daß er Israel errettet hat - denn nun wird es ein Leichtes sein, die Feinde zu schlagen...

Ich habe das so wiedergegeben, wie es in der Vulgata steht. Der Realismus der Mordszene ist unerhört. Nie und nimmer konnte sie im klassizistischen Frankreich so krude wiedergegeben werden. Auch Giraudoux schreckt davor zurück. - Ansonsten gleicht seine Darstellung in vielen Einzelheiten derjenigen der Bibel. Ich hebe nur hervor, wodurch sie sich von ihr - und von Hebbel - unterscheidet. Als erstes gilt es festzustellen, daß Judith nicht aus eigenem Entschluß handelt. Die Priester haben sie vielmehr für ihre Opfertat ausersehen, und sie haben das Volk angestachelt, sie zu bestürmen. Kinder und Greise, vor allem die letzteren, bedrängen sie, zu Holofernes zu gehen, ihn zu verführen und umzubringen: sie sei von Gott dazu bestimmt! War Judith in der Bibel eine Witwe, so hatte der deutsche Dichter sich einfallen lassen, ihre Ehe sei nicht vollzogen worden, weil Menasse, ihr Mann, impotent war. Das berichtet die Zofe. Da war Judith also eine jungfräuliche Witwe! Giraudoux läßt sie einfach unverheiratet sein. Sie ist die Tochter eines reichen Bankiers, ist emanzipiert, reitet, geht ins Theater und betätigt sich caritativ. Sie flirtet mit allen Dandies der Stadt. Zuerst weigert sie sich, dem Drängen der Leute nachzugeben. Wie kommen sie dazu, sie zu etwas zu überreden, das sie gar nicht will? Ihr Onkel, der Bankier Joseph, bestärkt sie in dieser Haltung. Er spricht von einer „hystérie collective“ - und das denkt Judith auch. Doch dann tritt Jean, ihr Verlobter, auf. Er ist Offizier und schildert ihr die verzweifelte Lage der Stadt: nur ein paar alte Wächter stünden noch an 
den Toren, die würden bei nächster Gelegenheit überrumpelt, Holofernes' Sieg sei nicht mehr aufzuhalten. Das aber duldet Judiths Stolz nicht. Sie sagt, sie werde die Sache in die Hand nehmen - und wäre es nur, um die Militärs, diese Schwächlinge, zu beschämen. Der Priester Joachim bestärkt sie in ihrem Entschluß. Jean und der Onkel, die sie zurückhalten wollten, haben verlorenes Spiel - so scheint es.

Doch der Offizier hat eine List ersonnen. Er hat eine Dirne, Suzanne, ausfindig gemacht, die Judith ähnlich sieht. Sie soll an deren Statt zu Holofernes gehen - und ist auch bereit, das zu tun. (Diese Figur dürfte von Hebbel angeregt sein, denn da schlägt Judith nach dem Mord an Holofernes vor, ihre Begleiterin, Mirza, solle behaupten, den Feldherrn erschlagen zu haben. Doch das ist da nur ein Einfall, der keine weiteren Folgen hat. Suzanne hingegen, Judiths Doppelgängerin, bekommt bei Giraudoux eine wichtige Funktion.) Nächtens, wie in der Bibel, begibt sich Judith zu dem assyrischen Feldherrn. Als die Offiziere des Holofernes von ihrer bevorstehenden Ankunft erfahren, beschließen sie - auf Anraten Sarahs, einer aus dem Bankiershause davongejagten Dienerin, die Judith haßt-, einen Betrug zu inszenieren. Ein Offizier, der gut reden kann, Egon, den seine Kameraden den Päderasten nennen, soll den Holofernes spielen, er bekommt den Feldherrnmantel umgehängt - und Judith fällt auf die Farce herein. Sie erkennt nicht, wie weiland Jeanne d'Arc, der sich Dunois als König vorstellte, den Richtigen, und fühlt sich gedemütigt, als Sarah sie darüber aufklärt. In letzter Not ruft sie nicht nach Gott, sondern nach - Holofernes, und dieser erscheint. Beide begeben sich ins Feldherrnzelt, Judith schmeichelt Holofernes, in den sie sich sofort verliebt hat. Und sie sucht Trost bei ihm. Holofernes richtet sie auf: die Episode mit dem Päderasten Egon, der Judith auf den Mund geküßt hatte, worauf sie sich angeekelt abwandte, hat keine Bedeutung! Judith ist für Holofernes da. Und hier, im Zelt, hat ihr auch kein Gott etwas dreinzureden: es ist ein Raum, in dem nur die Menschlichkeit zählt, nicht die Angst vor Gott oder den Priestern. Giraudoux' Holofernes ist ein Freigeist, der den richtigen Ton im Umgang mit der Bankierstochter findet. Das stellt sich erst recht heraus, als - Coup de théâtre! - Suzanne als angebliche Judith angemeldet und ins Zelt eingelassen wird. Die echte Judith reagiert wie zu erwarten empört, die falsche Judith muß gehen, ihr Rettungsversuch ist mißlungen. 
Holofernes zieht sich ins Innere des Zeltes zurück; und Judith führt ein letztes, rätselhaftes Gespräch mit einem Taubstummen, der dazu da ist, sie sich aussprechen zu lassen. Gott schweigt. Dann geht die jungfräuliche Jüdin zu Holofernes, der ihr vorausgegangen ist und sie auf seinem Lager erwartet.

Der erste Akt von Giraudoux' Stück spielte in der Stadt nicht, wie bei Hebbel und in der Bibel, im Feldlager. So konnte die "Massenhysterie“ der Stadtbevölkerung ins Spiel kommen und wir Näheres über Judith und ihren Stand, ihre Lebensweise und ihren Charakter erfahren. Das schien Giraudoux wichtiger, als über die Siege des Holofernes zu berichten. Der zweite Akt spielt vor und im Zelt des Feldherrn, bringt zuerst Judiths Verhöhnung, dann das Zwiegespräch mit Holofernes. Danach fällt der Vorhang und wir wissen Judith mit ihrem Geliebten allein. Der dritte Akt spielt wieder vor dem Zelt.

Dort befinden sich Judiths Verlobter Jean und die Dirne Suzanne, die sich heimlich vor Tagesanbruch ins feindliche Lager begeben haben und auf Judith warten. Suzanne hat deren Kleider auf dem Schoß. Da ruft Jean laut nach Judith - und sie tritt aus dem Zelt. In einen Soldatenmantel gehüllt, apostrophiert sie fröstelnd die Morgenröte, dieses „Stückchen rote Watte am Horizont", sie spricht von dem eisigen Atem, der die Gräser auf dem Feld und die Haare der Gefallenen sich sträuben läßt, und sie zeigt auf einen Hund, der unterm Zelt hervorlugt und leise mit dem Schwanz wedelt, „seul signe de bonté dans ce monde implacable - einziges Zeichen von Güte in dieser unerbittlichen Welt". Jean fragt, ob es vollbracht sei. Judith sagt: „Ja“. Ob die Nacht gut war? „Kurz war sie“, sagt Judith. Ob sie noch Jungfrau sei? „Nein“, sagt sie. - Da berichtet Jean, die Bethuler hätten von Judiths Verrat erfahren, Sarah, die rausgeschmissene Zofe, habe hinterbracht, daß sie sich in Holofernes verliebt habe. Die Leute hätten das Haus des Bankiers angezündet, die Diener gesteinigt, den Onkel verwundet. Judith scheint das alles nicht zu interessieren. „Ich habe Abschied genommen“, sagt sie, und: „ich gehöre nur noch einem: Holofernes - bis in den Tod“. Aber was ist mit ihm? Er scheint noch zu schlafen. Da stürzt Jean mit gezücktem Schwert in das Zelt, um ihn zu erschlagen - und kehrt sogleich zurück: der Feldherr lag in seinem Blut, Judith hatte ihm den Dolch ins Herz gestoßen! Jean bleibt nur noch übrig, das Haupt vom Rumpf zu trennen und es auf einer Pike triumphierend durch das Lager zu tragen, während die Assyrer in Panik davonlaufen. 
Inzwischen sind die Priester und Stadtoberen im Anmarsch, die Judith als Verräterin bestrafen wollten. Sie erfahren von der frohen Botschaft - und Judith hat gerade noch Zeit, Suzanne zu erklären, wie alles zugegangen ist, ehe die Abgeordneten da sind. Sie habe Holofernes getötet, sagt sie, weil die Liebesnacht mit ihm die Erfüllung ihres Lebens bedeutete, weil es nichts gibt, das darüber hinausführen kann, weil sie nicht ins Alltagsleben zurück will, und weil sie dachte, die Wachsoldaten würden sie ohnehin gleich erschlagen: sie erwartete ihren Tod. Doch Suzanne hört nicht zu. Aus Verzweiflung darüber, daß sie kein Gehör fand, wendet Judith sich einem Wachsoldaten zu, der da liegt und schnarcht. Er schläft seinen Rausch aus.

„Schläfst du?" fragt sie. Der Soldat brummt: „Ja“. „Wach auf“, sagt Judith: „es lohnt sich!“. „Ah, eine Frau, une femme“, murmelt der Soldat: „was hat sie getan“? „Qu'est-ce qu'elle a fait?“

Judith: Ton roi, Holoferne, elle l'a tué.

Le Garde: Elle l'a quoi?

Judith: Tué...

Le Garde: Ah! Elle l'a tué! Ça c'est mal.

Judith: Et tu veux savoir pourquoi? Par amour.

Le Garde: Par quoi?

Judith: Par amour.

Le Garde: Par amour? Ah, ça c'est bien.

So weit diese genialste aller Szenen des Stücks. - Da erscheinen die Leute aus Bethulia und preisen Judith. Das weckt den Wachsoldaten vollends auf. Er steht auf, um wie ergriffen die Stimme zu erheben. Judith sei eine Heilige, sagt er, sie habe den Feind Gottes erschlagen, ohne sich zu beschmutzen. Judith versucht, den Mann zum Schweigen zu bringen, doch der ist nicht zu halten. Er scheint inspiriert zu sein: ein Wunder sei geschehen, verkündet er... Da herrscht Judith den Rabbiner an, er solle dem Menschen die Zunge ausreißen, damit er nicht noch mehr ausplappere. Der Rabbiner verspricht es, ergreift aber die Gelegenheit zu sagen, er werde Judith für den Rest ihrer Tage in die Synagoge einsperren. Dort werde sie als Richterin fungieren und über die sündigen Juden die gebührenden Strafen verhängen. Die Geistlichkeit, nicht Judith, bekommt das letzte Wort. 
Das ist das Ende von Giraudoux’ Drama, das vor allem gegen Schluß an Shakespeare gemahnt. Der trunkene Wachsoldat ist vielleicht der Narr, der die Wahrheit sagt. Vielleicht.

Luther soll gesagt haben, berichtet Elisabeth Frenzel in ihren Stoffen der Weltliteratur, das „Buch Judith“ gebe „eine gute, ernste, tapfere Tragödie $a b$ “. Weiter schreibt sie, Judith habe Holofernes aus Liebe getötet, füge sich aber ,in der Erkenntnis getan zu haben, was Gott von ihr forderte, der heroischen Auslegung durch die Priester“. Das klingt eindeutiger als Giraudoux' Deutung. Sicher ist nur, daß es bei ihm um die Geradlinigkeit der biblischen Aussage, die Judith von Anfang bis Ende fromm sein und Holofernes mit einem Gebet auf den Lippen töten läßt, geschehen ist. Auch ihre Keuschheit hat Giraudoux' Heldin verloren, so daß der trunkene Wachsoldat sie einmal als Heilige, ein andermal als Hure apostrophieren kann. Ob sie Holofernes tötete, weil sie sich ihrer Mission erinnerte, das aber selbst nicht wahrhaben wollte, wissen wir nicht. Es ist auch denkbar, $\mathrm{da}$ sie in dem freigeistigen Holofernes einen ihr verwandten Geist erkannt und gefunden hatte, es sei für sie beide kein Platz in einer Welt, wo die Priester das Sagen haben. Um der Einmaligkeit ihrer Liebe willen hätte Judith ja auch sich selbst töten können. Nun aber überlebt sie resigniert und fügt sich: zumindest ihr Stolz scheint gebrochen... Eine jüdische Patriotin ist Giraudoux' Judith jedenfalls so wenig wie eine Heilige. Allenfalls „eine Heilige wider Willen“.

Wie anders hätte der moderne Dichter das Problem lösen sollen, vor das ihn die biblische Geschichte stellte? Wie konnte er die Tat der Judith motivieren, nachdem das religiöse Sendungsbewußtsein entfallen war? Schwerlich anders, als indem er Judith selbst nicht wissen ließ, was sie tat. Mit diesem Nichtwissen müssen wir uns wohl oder übel zufrieden geben. Es ist immer noch besser als zu meinen, wir wüßten etwas, was wir nicht wissen können. 



\section{„Die Vertreibung aus dem Paradies“ \\ Der Ursprungsmythos (Genesis 3) als Herausforderung in Philosophie und Literatur der Neuzeit \\ JÜRGEN GIDION}

Rückblick

Schön der Mensch

wer leugnets

Schön

sein aufrechter Gang

seine Augen geniale Maler

sein Wortschatz

Gefühl aus Feuer und Eis

helle und dunkle Gedanken

helle und dunkle Absichten

Schön der Mensch

wer leugnets

Sein Drang zu schaffen

Menschen zu schaffen

Menschen aus der Welt zu schaffen

Mit schönen Händen

Städte bauend

Häuser mit mächtigen Öfen

Wer leugnet

daß der helle Menschenverstand

stehnbleibt

vor den mächtigen Öfen

der schönen Menschen 
Rose Ausländers Gedicht Rückblick - 1979 in Treffpunkt der Winde veröffentlicht - gibt, dem Menschen' (als Gattungswesen wird über ihn gesprochen) in den 22 Zeilen ein ungewöhnliches Attribut bei („schön“), das in seiner beharrlichen Wiederholung wie die Abweisung von Frage oder Einwand wirkt. Es ist, als solle ein ,Ja doch!' mitgehört werden, das sich im skeptischen Gelächter von Realisten behaupten will. Mit dem gleichfalls leitmotivisch gesetzten „Wer leugnets?" wird dem Hinweis vorgebeugt, hier werde etwas schlicht übersehen.

Die Sätze - Aussagen, fast einsam in ihrer asyndetischen Reihung - sagen anthropologisch Elementares über den Menschen aus: Aufrechter Gang, freier, produktiver Blick, Sprachfülle, Intensität und Kontrastreichtum an Gedanken und Gefühlen: heiß - kalt; hell - dunkel.

Reichtum des schönen Menschen: Von dessen Güte, auf deren Nennung man wohl wartet, ist ausdrücklich nicht die Rede. Keine „Kalokagathie“ also. Fast beiläufig wird vielmehr deren Gegenteil - das Böse - in das Register eingefügt. Wenn die Ambivalenz des schönen Schaffensdranges einmal genannt ist, ist die Schönheitsbeglaubigung nur noch als Wehmut oder gar Zynismus zu lesen. Homo Faber läßt sich ästhetisierend nicht mehr undialektisch, seine Produktivität nur noch in erschreckender Ambivalenz verstehen. Der Bau „mächtiger Öfen“ - solcher nämlich zum Verbrennen anderer „schöner Menschen“ - ist Zeichen eines „stehngebliebenen“ Verstandes; die Formulierung ließe sich auch positiv verstehen als Ausdruck der Hoffnung, daß hier der einhaltgebietende Verstand, dem ein moralischer Protest sich denn doch aufdrängt, sich zu Wort meldet.

Der Titel des Textes weist auf Erfahrenes hin. Das Gedicht stellt seine Fragen - grundsätzlich, wie sie sind - nur implizit. Es wird im Lakonismus der schlichten Setzungen an Urprobleme erinnert, zum Nachdenken über scheinbar Evidentes aufgefordert.

In der Erzählung der „Ältesten Urkunde“, von deren Fort- und Fernwirkung die Rede sein soll, kommt Verwandtes zu Sprache. Solche Weise des lapidar verknappenden oder ins Bild fassenden Ausdrucks gehört vornehmlich zum Stil mythisch zu nennender Dokumente, wo nämlich nicht psychologisch Individuelles kommentiert wird, sondern wo es um Menschlich-Allgemeines geht. 
Vom Paradies ist hier freilich nicht die Rede, aber von, dem 'Menschen in seiner Ambivalenz außerhalb des Gartens.

Eingestimmt durch den Text von Rose Ausländer werde ich in folgender Ordnung von der Wirkungsgeschichte der Erzählung von der Vertreibung aus dem Paradiese sprechen:

1. rufe ich kurz Genesis 3 in Erinnerung, stelle dabei, Gewinn und Verlust kennzeichnend, das mythische Material in seiner Spannungsfülle und herausfordernden Bedeutungstiefe dar.

2. führe ich ein in ein Deutungsgespräch, das in den Jahrzehnten von 1786 bis 1810 zwischen Weimar, Königsberg, Jena, Berlin einen Höhepunkt erreichte:

- Kant: Mutmaßlicher Anfang der Menschengeschichte;

- Schiller: Etwas über die erste Menschengesellschaft am Leitfaden der mosaischen Urkunde (so der Titel seiner Vorlesung);

- Kleist: Über das Marionettentheater (so der Titel der Folge von Zeitungsartikeln).

3. kommentiere ich ein Theaterstück von Peter Hacks: Adam und Eva als Beispiel für Spätfolgen der Ursprungsgeschichte - unbekümmert modern, also frech auch in seinen Tabubrüchen, zitierlustig, sich als Komödie verstehend.

4. Ich schließe, wie ich begonnen habe: mit einem Gedicht.

I.

Über das Leben im Paradies setzt die Erzählung Genesis 2-4 die Lesenden umfassend ins Bild:

Ein fruchtbarer Garten als Lebensraum, „hortus conclusus“, häufig bildlich dargestellt; Bebauen und Bewahren als mühelos zu erfüllende Aufgabe; Partnerschaft von Frau und Mann, ohne Scham, also unbefangen; Sprachkompetenz zur spannungsfreien Kommunikation untereinander und zur Benennung der Tiere und Pflanzen; im ganzen: Harmonie zwischen Gott, Menschen, Natur.

Wenn da die beiden Bäume nicht wären, der der Erkenntnis und der des Lebens - umzäunt vom Verbot Gottes, sowie die Schlange, die „kleine Privatdozentin“, wie der Spötter Heine sie zu benennen nicht lassen kann. 
Nach dem ,Sündenfall', dem Ungehorsam also gegenüber dem Vater, findet sich die Negation alles Bisherigen: kein geschützter Lebensraum mehr für das Menschenpaar; Arbeit auf einem Acker voller Disteln „im Schweiße deines Angesichtes“; gestörtes Verhältnis zu Gott, dem Partner, den Tieren; Spielraum für Selbstentscheidung mit der Konsequenz der Notwendigkeit, über Gut und Böse zu urteilen.

Die Rezeptionsgeschichte ist in ihrer Fülle und Vielfalt unübersehbar geworden. Mitsprache im theologisch-exegetischen Gespräch überlasse ich den Fachleuten.

\section{Kant, Schiller, Kleist}

Als sich Immanuel Kant 1786 - in der Berliner Monatsschrift vom 7. Januar - als Kommentator unserer Bibelstelle zu Wort meldete, geschah das eigentümlich behutsam, nahezu respektvoll.

Eben darum, und da ich hier eine bloße Lustreise wage, darf ich mir wohl die Gunst versprechen, dass es mir erlaubt sei, mich einer heiligen Urkunde dazu als Karte zu bedienen.

Kant bleibt, umsichtig frühe Entwicklungsstufen menschlicher Entfaltung bedenkend, im wesentlichen interessiert an den moralischen Chancen und Folgen, die sich aus der „Entlassung aus dem Naturtriebe“, wie er die Gewinnung der Erkenntniskraft bezeichnet, ergeben könnten:

Der Mensch „entdeckte in sich ein Vermögen, sich selbst eine Lebensreise auszuwählen und nicht gleich anderen Tieren an eine einzige gebunden zu sein. Auf das augenblickliche Wohlgefallen, das ihm dieser bemerkte Vorzug erwecken mochte, musste doch sofort Angst und Bangigkeit folgen: wie er, der noch kein Ding nach seinen verborgenen Eigenschaften und entfernten Wirkungen kannte, mit seinem neu entdeckten Vermögen zu Werke gehen sollte. Er stand gleichsam am Rande eines Abgrunds (...) aus diesem einmal gekosteten Stande der Freiheit war es ihm gleichwohl jetzt unmöglich in den der Dienstbarkeit (unter der Herrschaft des Instinkts) wieder zurück zu kehren.“ 
Hier ist gleich zu Beginn der „intellektuellen Lustreise“, zu der Kant aufgebrochen war, ein höchst bedenklicher Ton angeschlagen. Der wahlmächtig gewordene Mensch steht an einem Abgrund. Die Freiheit von der Alleinherrschaft des Instinkts ist eine Gefahr, denn sie eröffnet unendliche Möglichkeiten außer der einen: der Rückkehr in den „Stand der Dienstbarkeit“, es ließe sich auch sagen: der unfreien Unschuld. „Frei - gefangen": das ist die Antinomie, in der sich der Mensch nach dem Genuß der Frucht vom Baum der Erkenntnis befindet. Was liegt näher, als einen Rückzug in Geborgenheit, welcher Art sie auch immer sei, zu versuchen? Kant hebt die produktive Konsequenz gerade für den Bereich der Sinnlichkeit hervor, die sich durch Hochwertung des Vernunftgebrauches ergibt. Er denkt nach über den „Instinkt zum Geschlecht und seine Veredelung durch die Vernunft":

Der Mensch fand bald: dass der Reiz des Geschlechts, der bei den Tieren bloß auf einem vorübergehenden, größtenteils periodischen, Antriebe beruht, für ihn der Verlängerung und so gar Vermehrung durch die Einbildungskraft fähig sei, welche ihr Geschäft zwar mit mehr Mäßigung, aber zugleich dauerhafter und gleichförmiger treibt, je mehr der Gegenstand den Sinnen entzogen wird, und dass dadurch der Überdruß verhütet werde, den die Sättigung einer bloß tierischen Begierde bei sich führte. Das Feigenblatt war also das Produkt einer weit größeren Äußerung der Vernunft, als sie in der ersteren Stufe ihrer Entwickelung bewiesen hatte. Denn eine Neigung, dadurch inniglicher und dauerhafter zu machen, daß man ihren Gegenstand den Sinnen entzieht, zeigt schon das Bewußtsein einiger Herrschaft der Vernunft über Antriebe.

Solche Humanisierung der Sinnlichkeit ist eine Kompensation des Verlustes von Sicherheit. Kant weiß genau, dass durch Vernunft eine Möglichkeit der Vorsicht gegeben ist, deren lähmende Form die Sorge ist, also die ängstliche Erwartung des drohenden Künftigen. Somit ist eine Ersatzvorstellung notwendig geworden, um den Menschen an seiner Situation als Mängelwesen nicht verzweifeln zu lassen. Kant führt dazu den Gedanken der Gattung ein: 
Aus dieser Darstellung der ersten Menschengeschichte ergibt sich, daß der Ausgang des Menschen aus dem, ihm durch die Vernunft, als erster Aufenthalt seiner Gattung vorgestellten, Paradiese nicht anders, als der Übergang aus der Rohigkeit eines bloß tierischen Geschöpfes in die Menschheit, aus dem Gängelwagen des Instinkts zur Leitung der Vernunft, mit einem Worte: aus der Vormundschaft der Natur in den Stand der Freiheit gewesen sei. Ob der Mensch durch diese Veränderungen gewonnen, oder verloren habe, kann nun nicht mehr die Frage sein, wenn man auf die Bestimmung seiner Gattung sieht, die in nichts als im Fortschreiten zur Vollkommenheit besteht.

In der Zukunft also, auf die der Begriff Gattung ja verweist, mag sich also wieder so etwas herstellen wie eine Beruhigung, in der sich die ewigen Antinomien der menschlichen Existenz nach der Vertreibung auflösen.

Kant hat in Friedrich Schiller, der sich 1790 im 11. Heft der „Thalia“ dieses Themas annahm, einen Schüler gefunden, der nur ein wenig poetischer sagt, was bei Kant schon zu lesen stand. Schiller hielt in diesem Jahr in Jena eine Reihe von Vorlesungen zur Universalgeschichte, darunter eine mit dem Titel „Etwas über die erste Menschengesellschaft nach dem Leitfaden der mosaischen Urkunden. "Hier findet sich eine der Formulierungen dessen, was man eine idealistische Erklärung (oder Verklärung) des säkularisierten Menschen nennen kann.

Das Paradies als Ursprungsambiente: damit fängt auch Schiller, fast behaglich schildernd, seinen geschichtsphilosophischen Text an:

Setzen wir also, die Vorsehung wäre auf dieser Stufe mit ihm stillgestanden, so wäre aus dem Menschen das glückliche und geistreichste aller Tiere geworden - aber aus der Vormundschaft des Naturtriebs wär er niemals getreten. In einer wollüstigen Ruhe hätte er eine ewige Kindheit verlebt.

So konnte es nicht weitergehen, denn es gibt neben dem einfachen Verlauf der Naturprozesse einen komplizierteren Gang der Erfüllung menschlicher Bestimmung. Von dieser spricht Schiller wie von einem Naturgesetz: 
Aus einem Paradies der Unwissenheit und Knechtschaft sollte er sich, wär es auch nach späten Jahrtausenden, zu einem Paradies der Erkenntnis und der Freiheit hinaufarbeiten, einem solchen nämlich, wo er dem moralischen Gesetze in seiner Brust ebenso unwandelbar gehorchen würde, als er anfangs dem Instinkte gedient hatte, als die Pflanze und die Tiere diesem noch dienten.

Schiller beschreibt mit der Wortlust des Poeten Kampf und Geschichte der Entwicklung des Menschen von der Tierheit zur Menschheit, faßt also sein Schicksal nach der Vertreibung - Folge eines „malum“- als „bonum“ auf. Nur so ist die Würde des Menschen zu erreichen gewesen:

Von dem Instinkte nur von ferne begleitet, warf er sich in das wilde Spiel des Lebens, machte er sich auf den gefährlichen Weg zur moralischen Freiheit. Wenn wir also jene Stimme Gottes in Eden, die ihm den Baum der Erkenntnis verbot, in eine Stimme seines Instinktes verwandeln, der ihn von diesem Baume zurückzog, so ist sein vermeintlicher Ungehorsam gegen jenes göttliche Gebot nichts anders als - ein Abfall von seinem Instinkte - also erste Äußerung seiner Selbsttätigkeit, erstes Wagestück seiner Vernunft, erster Anfang seines moralischen Daseins. (...) Der Mensch wurde aus einem unschuldigen Geschöpf ein schuldiges, aus einem vollkommenen Zögling der Natur ein unvollkommenes moralisches Wesen, aus einem glücklichen Instrumente ein unglücklicher Künstler. Der Philosoph (Kant!) hat Recht, es einen Riesenschritt der Menschheit zu nennen, denn der Mensch wurde dadurch aus einem Sklaven des Naturtriebes ein frei handelndes Geschöpf, aus einem Automat ein sittliches Wesen.

Ein sittliches Wesen: Schiller hatte diesen Text vor der zweiten, der Schrekkensphase der französischen Revolution geschrieben. In dieser hatte sich das „sittliche Wesen“ (der „schöne Mensch“) in seiner gewalttätigen Form gezeigt - wissend und praktizierend, was gut und böse ist, und zwar dogmatisch, ein für alle Mal, für alle gültig. Verkörpert in St.Just, Robespierre, den Jacobinern.

Schiller war auf der Suche nach einer Synthese - in seiner Begrifflichkeit: einer Verbindung von Anmut und Würde, oder Sinnlichkeit und 
Vernünftigkeit. „Über die ästhetische Erziehung des Menschen“ hieß die Schrift, mit der er über die Möglichkeit nachdachte, den mit der Freiheit der Entscheidung begabten Menschen zur Politik fähig zu machen, also die Mängel auszugleichen, die die Kehrseite seiner Autonomie bildeten.

Heinrich von Kleist, der dritte Autor, hat nach anfänglicher Aufklärungseuphorie Vernunft und Verstand eher skeptisch eingeschätzt. Er hat nicht systematisch dagegen argumentiert, wohl aber in Bildern und poetischen Gleichnissen in seinem Text über das Marionettentheater. Werner Frick - in „Kleists Wissenschaft"1997 - spricht von der „unordentlichen Synthesis der Poesie“, deren Einsichten mindestens so nachdenklich stimmen können wie die einer rationalen Methode verpflichteten Texte.

Kleists Aufsatz Über das Marionettentheater erschien am 15. Dezember 1810 im Journal Berliner Abendblätter, und zwar an vier Tagen hinter einander. Am Wochenende war der Artikel abgeschlossen ohne eine Unterbrechung durch den Sonntag. Von Fortsetzung zu Fortsetzung wird eine Steigerung erreicht. In der ersten Nummer wird der Mechanismus der Marionetten geschildert, in der nächsten ihre Überlegenheit gegenüber menschlichen Tänzern entwickelt, die dritte bringt mit der Spiegelanekdote das Motiv des Sündenfalls, die letzte die Schlussfolgerung des Ganzen mit der Fechteranekdote.

„Ein Meisterwerk, das ich immer wieder anstaune“, urteilt Rilke, einer der vielen Bewunderer dieses Textes, 1913 in einem Brief an die Fürstin von Thurn und Taxis.

Thomas Mann - ein zweiter Bewunderer - las ihn schon 1897, nannte ihn 1910 bei wiederholter Lektüre „die großartigste Parabel von der Geschichte des Menschen“ und notierte verständnisvoll:

Ich hier oben an meinem Fenster erlaube mir die Beobachtung, dass ein ,sicheres Auftreten' in den meisten Fällen auf Dummheit beruht, dass bei einem gewissen Grade von Klugheit kein sicheres Auftreten vorhanden ist und dass ein sehr hoher Grad von Klugheit nötig ist, um aufs neue ein sicheres Auftreten zu besitzen.

Man kann diese Notiz als eine Übersetzung bezeichnen, die der Intention von Kleists Text recht nahe kommt.

Eine andere „Übersetzung“ hat Hans Magnus Enzensberger vorgenommen in seinem Gedicht von 1995 Balanceakt. 
Balanceakt

Wie er das nur fertig bringt,

dieser hinkende Engel,

zu gehen, zu gehen, zu gehen,

jahrzehntelang,

auf zwei einsamen Beinen,

ohne ohnmächtig zu werden,

ohne der Waagrechten

anheim zu fallen...

Eine Art Seiltanz, hundertmal

Stolpernd strauchelnd stürzend

Mühsam erlernt;

Eine schwindelerregende Laufbahn,

ein Schaukeln und Taumeln,

links unten vorne rechts hinten,

der Schwerkraft entgegen.

Tief im Innern des Schädels

Der Kreiselkompaß,

ein wogendes Feld von Fühlern

im Labyrinth.

Der Körper weiß nicht, was er tut, wenn er geht.

Wüßte er es,

er wäre verloren.

Ein „wogendes Feld von Fühlern“; der „hinkende Engel“: auf solche vielsagenden Bilder hätte sich Kleist wohl eingelassen. Er verstand sich wie kaum einer auf ausweglose, auf „gegensätzische“ Lagen.

Dass Kleists Aufsatz bis heute Gegenstand zahlloser kontroverser Deutungen und Bewertungen ist, verwundert nicht. Man tut gut, sich noch einmal der Substanz des Textes zu vergewissern:

In einer dreistufigen Reihe von Bildern und Beispielgeschichten sucht Kleist die These plausibel zu machen, dass die bei der Vertreibung (Gen 3) gewonnene Vernunftkompetenz mit hohem Verlust verbunden ist. Würdegewinn hin, Autonomieverleihung her - Verlust von „Grazie“ auf 
jeden Fall. In dem Gespräch zwischen dem Erzähler und seinem Partner heißt es:

Es scheine, versetzte er, indem er eine Prise Tabak nahm, dass ich das dritte Kapitel vom ersten Buch Moses nicht mit Aufmerksamkeit gelesen; und wer diese erste Periode aller menschlichen Bildung nicht kennt, mit dem könnte man nicht füglich über die folgenden, um wieviel weniger über die letzte, sprechen. Ich sagte, dass ich gar wohl wüßte, welche Unordnungen, in der natürlichen Grazie des Menschen, das Bewußtsein anrichtet. Ein junger Mann von meiner Bekanntschaft hätte, durch eine bloße Bemerkung, gleichsam vor meinen Augen, seine Unschuld verloren und das Paradies derselben, trotz aller ersinnlichen Bemühungen, nachher niemals wiedergefunden.

Kleist bietet keine Lösung, lässt mit Entschiedenheit offen, weil auf die Lage des Menschen keine Formel passt, vielmehr einzig in Paradoxien darüber gesprochen werden könne:

Nun, mein vortrefflicher Freund, sagte Herr C...., so sind Sie im Besitz von allem, was nötig ist, um mich zu begreifen. Wir sehen, daß in dem Maße, als, in der organischen Welt, die Reflexion dunkler und schwächer wird, die Grazie darin immer strahlender und herrschender hervortritt. - Doch so, wie sich der Durchschnitt zweier Linien, auf der einen Seite eines Punkts, nach dem Durchgang durch das Unendliche, plötzlich wieder auf der andern Seite einfindet, oder das Bild des Hochspiegels, nachdem es sich in das Unendliche entfernt hat, plötzlich wieder dicht vor uns tritt: so findet sich auch, wenn die Erkenntnis gleichsam durch ein Unendliches gegangen ist, die Grazie wieder ein; so daß sie, zu gleicher Zeit, in demjenigen menschlichen Körperbau am reinsten erscheint, der entweder gar keins oder ein unendliches Bewußtsein hat, d.h. in dem Gliedermann, oder in dem Gott. - Mithin, sagte ich ein wenig zerstreut, müßten wir wieder von dem Baum der Erkenntnis essen, um in den Stand der Unschuld zurückzufallen? - Allerdings, antwortete er; das ist das letzte Kapitel von der Geschichte der Welt. 
Kleist erwägt in vielen Texten die Chance der Bewahrung von Unbefangenheit, am markantesten in der Paradoxe: Von der Überlegung.

Diese ist ja nicht der Bewußtlosigkeit gleichzusetzen, vielmehr bezeichnet sie jenen Zustand der Existenz des Menschen, in der er nicht reflektierend neben sich steht, also außer sich ist, sondern geborgen in seiner Ganzheit.

Hier wird nicht mehr nur der Verlust von Grazie gefürchtet, als vielmehr die Handlungsfähigkeit des Menschen durch Reflexion überhaupt in Frage gestellt.

\section{Peter Hacks: Adam und Eva}

Der 1928 geborene Dramatiker Peter Hacks ist vor kurzem gestorben. Nur gut über ihn zu reden, ist mir gleichwohl nicht möglich. Sein politisches Handeln war zweideutig, seine Parteinahme hat immer wieder zu Diskussionen Anlaß gegeben. Sein Stück von 1973, Adam und Eva, indes zählt zu seinen besten.

Hacks kommentiert das Werk in einem klugen Essay. Er wisse sich mit einer Tendenz der modernen Kunst einig, so schreibt er, indem er sich eines der „großen Bilder“ als Vorlage bedient. „Bilder sind wichtig als Impulse; die Wissenschaft weiß nicht alles, und dort, wo sie weiß, taugt sie noch längst nicht für die Kunst.“

Zu den Reservoiren „großer Bilder“ zählt Hacks die Bibel, die Schöpfungsgeschichte vor allem, sodann die griechischen Mythen. „Das große Bild vom Sündenfall war schon für Hegel das Beste am ganzen Christentum. Es birst von Dialektik. Aber das Paradies ist zu, so sagt der Jahvist.“ Kein Grund, darüber nicht zu schreiben:

Sobald wir, im Denken oder Tun, in die wirkliche Welt eintreten, betreten wir das Reich, wo es dialektisch hergeht. Die Paradiesgeschichte, dieses große Bild vom Anfang des Menschen, ist vom Verfasser ausgelegt worden als das große komische Bild vom Betreten der wirklichen Welt.

Damit ist auch das Arbeitsprogramm für einen atheistischen Schriftsteller vorgestellt, den fast zwei Jahrhunderte zunehmender Säkularisierung von den „klassischen“ Autoren trennen, der gleichwohl noch im Wirkungsbereich der großen Bilder von Sündenfall und Vertreibung steht, aber auf 
seine Unabhängigkeit von Textvorbildern ausdrücklich verweist. Er verneigt sich, seinen Essay abschließend, noch vor einem großen Kollegen:

Der Verfasser, welcher das Paradise Lost - von zwei oder fünf Artigkeitszitaten abgesehen - nicht benutzt hat, versteht sein Paradise Lost and Regained als eine Hommage für Milton.

Bei der Kommentierung des Stücks beschränke ich mich auf drei Aspekte: das Gottesbild, das Menschenbild und die Freiheitsprobe.

Das Personal des Stückes steht in klarer Hierarchie: Gottvater an der Spitze, unter ihm die Engel, vertreten durch Gabriel, und der Teufel, vertreten durch Satanael, wiederum unter ihnen als „Objekte“ Adam und Eva. Die Schlange ist in diesem Paradies ohne Bedeutung.

Hacks gestaltet seine Gottesfigur lebendig-widersprüchlich und facettenreich, sie verbindet Güte und philosophisch-theologischen Tiefsinn mit Humor, Selbstironie und Witz. Welt und Mensch sind entsprungen der Langeweile und der Einsamkeit Gottes: Einsam, weil unbegriffen von seinen bisherigen Geschöpfen (Engel und Teufel), hat er nach seinem eigenen Bilde den Menschen geschaffen und sich damit auf das „Abenteuer Wirklichkeit" eingelassen.

Die Menschen, aus göttlichem Stoff also, sollen in solchem Gleichgewicht wirken, dass sie sowohl zur Bejahung wie zur Verneinung fähig sind. Gott kann sein großes Experiment mit dem Menschen beginnen, nachdem er im Vorspiel Engel und Teufel in ihre Rollen eingesetzt hat. Er bestellt Gabriel zum Hüter der paradiesischen Ordnung und reizt gleichzeitig Satanael zu deren Störung an, letzteres dadurch, dass er ihm den Sinn des Experiments auf verwirrende Weise zugleich enthüllt und verbirgt:

Zur steten Probe nämlich ihrer Losgebundenheit und Gabe des Auch-Anders verbot ich jenen beiden, die sich nähren Von allen Paradiesesfrüchten, eine:

Den Apfel....

Die eine Pflicht, gemischt ins heitere Dürfen, beweist, wird sie erfüllt, mir ihre...

Freiheit und tüchtiges Mirähnlichsein. 
Mir ahnt, mit anderm Wort, ich weiß:

Dies wird gelingen. Der Kniff ist tief, die Lösung steckt verborgen.

Ah, meine Wege sind sehr wunderbar.

Auf den Prolog im Himmel aus dem Faust wird unaufdringlich, aber deutlich angespielt; alles läuft auf eine „Freiheitsprobe“ hinaus.

Wie diese verstanden werden soll, hängt an der Deutung des Wortes „erfüllt", in dem Bedingungssatz, der sich auf die ,eine Pflicht“ bezieht: Gott unterscheidet, sein Gebot betreffend, zwischen „Wortlaut" und „Sinn“, sowie zwischen „vollziehen“ und „erfüllen“:

Den Wortlaut zu vollziehn, kann ich ihn zwingen, den Sinn des Worts erfüllen kann nur er.

Denn den erfüllen, heißt: es übertreffen

Und so auch nicht erfüllen.

Zum Wollen dessen, was

Man soll, mithin, gehört das Wollenkönnen

Von allem, was man nicht soll. So beschloß

Ich über Adam, Satans Gegenwart

Als Probe zu gebrauchen seiner Freiheit,

Die seinen Wert ausmacht.

Den Sinn des Gebotes erfüllen heißt seinen Wortlaut verletzen: Dies und nichts anderes also ist der „tiefe Kniff“ und „verborgene Lösung“, die Gott dem Menschen zu finden aufgegeben hat - ein dialektisches Paradoxon. Es besagt dreierlei: dass Wert und Würde des Menschen an seiner Freiheit hängen; dass Selbstbestimmung mit einem Akt der Emanzipation von Fremdbestimmung anhebt; und dass Gott den Menschen frei will, selbst wenn diese Freiheit lediglich um den Preis der Rebellion gegen die göttlich-väterliche Autorität zu verwirklichen ist.

Gott, allmächtig, aber sehr nachdenklich, sieht sich vor nicht geringen Problemen angesichts seines Konzepts für die Schöpfung des Menschen: 
Gott:

„Der Haken war doch der: wie welche schaffen

Nach meinem Bild? Bin ich denn ein Geschaffner?

Kann ein Geschaffener nach meinem Bild sein?

Nein, selber mussten diese, so wie ich

Es hielt mit mir, sich schaffen. (...)

(...) Ich schenkte ihnen

Spielraum, den Weg zu wählen und das Ziel,

Und pflanzte ihnen den berühmten Baum

Als Probstück ihrer Ähnlichkeit mit mir (...)“

Adam ist in seiner dialektischen Gewitztheit Gottes Meisterstück, weil er nicht nur selbständig handelt, sondern versteht, warum und mit welchen Folgen:
Adam:
„Ich bin sehr lustig, Herr (...)
Und sehe klar: Ihr Wille ist erfüllt,
Seit er verletzt ist, alles wird sehr gut,
Weil es nie gut wird, und das Paradies,
Es war gewonnen, als wir es verloren."

Gerade die Vollkommenheit des Paradieses also ist Kennzeichen seiner Unvollkommenheit, weil es sein Gegenteil, das Unvollkommene, nicht einschließt. Somit schließt es das wahrhaft Vollkommene aus: die unendliche geschichtliche Bewegung in Richtung auf das Ziel der Vollkommenheit. Die Anklänge an Kants Vorstellung sind unüberhörbar. Die abschließende Auseinandersetzung mit Gott zeigt vollends, wie Hacks den Sündenfall säkularisiert, d.h. als Archetypus menschlicher Emanzipation oder als Modell für Aufklärung verstanden wissen möchte.

Die Komik der Geschichte vom Betreten der wirklichen Welt ist natürlich vor allem verbunden mit der Beziehung des Menschenpaars zueinander. Das heitere Element wird gesteigert durch die Indirektheit der Darstellung: Die Liebesvereinigung der beiden kann nur als Mauerschau gestaltet werden. Neugierig angezogen wie prüde irritiert bezeugen die beiden Engel den Akt der Vereinigung. Gott fasst zusammen, was er weiß, aber nur vermittelt zu sehen bekommt: 
Zwei Unvollkommene verspüren ein vollkommenes

Vergnügen beim vergeblichen Versuch mitsammen

ein Vollkommenes auszumachen. (...)

Es muss schon toll sein (...)

Wo bist du, Adam?

Der Rest wird der Phantasie der Zuschauer überlassen.

Die ursprüngliche Vertreibung wegen einer Sünde wird zum Freispruch, zu befriedigter Anerkennung der gewährten und genützten Autonomie. Gott, als in seine Geschöpfe verliebter Vater, als gütiger Pädagoge zugleich, winkt seinen Kindern, die die Freiheitsprobe bestanden haben, am Ende zu und ruft ihnen nach: „Menschen, ihr habt recht. Geht euren Weg.“

Hier hört die Dialektik auf. Sie wird erst wieder beginnen auf dem Weg, den die Menschen zu gehen haben - in Freiheit, konfrontiert mit der Notwendigkeit, sich zu entscheiden.

Die Fragen, die der Ur-Text gestellt hat: Gewinn - Verlust? bleiben offen. Die Schlußwendung des modernen Dramatikers zeugt von einem optimistischen Vertrauen in die Orientierungsfähigkeit des „ersten Freigelassenen der Schöpfung" (Herder), vor allem aber von der Annahme, daß die Geschichte sich schon in der „richtigen Richtung“ entwickeln werde und mit ihr der Mensch. Hingegen ist schon Kleists „Gegendiskurs“ (Frick) von hartnäckiger Skepsis geprägt, die sich in radikaler Form später auch in Gottfried Benns Gedicht „Verlorenes Ich“ findet: „Du möchtest dir ein Stichwort borgen / Allein bei wem?" Kleist bleiben mehr Rätsel im Zusammenhang mit dem aufgeklärten Wesen Mensch, der so souverän auf seinen Vernunftgebrauch vertraut. Der Versuch, sich von „hinten wieder ins Paradies zu schleichen“, bleibt eine schöne Hoffnung, die auf der Wahrnehmung eines elementaren Mangels gründet.

Wenn Goethe Faust, den Täter, Strebenden, Grenzüberschreiter, den „Pionier des Ich“ (Philip Roth), in Verblendung nach einem täuschungsreichen Leben, am Ende sein läßt, heißt die Szene „Grablegung“. In ihrem Verlauf lautet eine Regiebemerkung, bezogen auf den Chor der Engel: "Sie erheben sich, Faustens Unsterbliches entführend.“

Die Grablegung heißt das Gedicht von Hans Magnus Enzensberger (Kiosk, 1995), in dem die Kompetenz benennender Begrifflichkeit und menschlicher Wissenskraft im Hinblick auf das „Unsterbliche“ des Menschen in seine Grenzen verwiesen wird: 
Die Grablegung

Eine sterbliche Hülle,

so heißt es,

aber was war drin?

Die Psyche,

sagen die Psychologen,

die Seele,

die Seelsorger,

die Persönlichkeit,

sagen die Personalchefs.

Dazu noch die Anima,

die Imago, der Dämon,

die Identität, das Ich,

das Es und das Überich.

Der Schmetterling,

der sich aus diesem Gedrängel

erheben soll,

gehört einer Art an,

von der wir nichts wissen.

\section{Literaturhinweis}

Wolfram Buddecke / Helmut Fuhrmann, Das deutschsprachige Drama seit 1945, München 1981 (Dort eine Interpretation des Dramas von Hacks.) 


\title{
Shakespeare und die Bibel
}

\author{
THEODOR WOLPERS
}

„Shakespeare und die Bibel“ - das klingt vielleicht abwegig, wenn man an die Interpretations- und Bühnenpraxis der letzten zwanzig, dreißig Jahre denkt. „Shakespeare und die Politik und die Gesellschaftskritik“ - ja; „Shakespeare und Freud“ (Hamlet vom Ödipus-Komplex getrieben) - ja; oder „Shakespeare und die Homosexualität“ (eine Schwulengeschichte statt selbstloser Freundesliebe im Kaufmann von Venedig). Aber „Shakespeare und die Bibel“? Da gibt es Vorbehalte und Aversionen, auch in der Wissenschaft - trotz einiger grundlegender Arbeiten und Materialerschließungen zum Thema. ${ }^{1}$ Auf der Bühne tritt dazu wie bei anderen Klassikern die Tendenz, durch ironisches Sprechen oder Feixen oder auch Grotesk- und Nacktszenen eindeutige Wertaussagen auf alberne Art zu relativieren. Auf seine Weise hat selbst das 18. Jahrhundert am Biblischen in Shakespeare beharrlich vorbeigesehen. ${ }^{2}$ Man dachte vorzugsweise aufklärerisch und deistisch oder später - wie im Göttinger Hainbund und bei den Stürmern und Drängern - aus der Sicht empfindsamen oder leidenschaftlichen Erlebens. Herder, obwohl Theologe, und der junge Goethe haben nur das „Naturgenie“ in Shakespeare gesehen, und Bürger, der den Macbeth kraftgenialisch übersetzte, nur das „Despotische“ seiner Sprache. Das alles mag in Shakespeare sein, aber nicht nur. Und auch ich will ihn nicht auf ein einziges Moment, das biblische, festlegen. Das wäre absurd. Aber ich möchte die meist übersehene oder bewußt unterdrückte Mitwirkung der Bibel herausstellen. Sie läßt sich nicht nur in vielen Zitaten und Anspielungen greifen, sondern auch in Handlungsführung, Menschenauffassung und Thematik. Sie dringt bis in die Dichtungssprache ein, in die Shakespeare an zentraler Stelle biblische Bilder integriert, die er poetisch abwandelt und intensiviert.

Bevor wir aber einige Texte betrachten, müssen wir ein paar kulturhistorische Gegebenheiten ins Auge fassen: zunächst (1) die immense Bibelkenntnis, ja Bibelbegeisterung der Zeit und (2) - im Kontrast dazu - die extrem weltlichen Stoffe und Gattungen aller ingesamt 37 Dramen Shakespeares. Einerseits befinden wir uns im konfessionellen Zeitalter, im Zeitalter von Reformation und Gegenreformation - mit einer von den Lesefähigen nun auch privat, oft im Familienkreis betriebenen 
intensiven Bibellektüre oder -lesung, die sich oft mit konfessionellem Auslegungseifer verbindet. Andererseits versetzen uns die meisten der Dramen ins Globe Theatre, ein unternehmerisch von den Anteilseignern (darunter Shakespeare) betriebenes Repertoire-Theater im Amüsierviertel vor den Toren Londons südlich der Themse, wo ein sehr gemischtes, aus praktisch allen Ständen und aus Männern wie Frauen zusammengesetztes Publikum unterhalten und auf populäre Weise auch belehrt werden wollte (z.B. über englische Geschichte und Könige, antike Herrschergestalten wie Caesar, Marcus Antonius und Cleopatra, Probleme der Moral und der Herrschaft und immer wieder über die Natur des Menschen im Spannungsfeld von Tugenden und Lastern, von Schicksalsschlägen und Glück). Unter den Zuschauern befanden sich zum einen die Anspruchsvollen und Gebildeten, die auf den überdachten Rängen des Theaters Platz nahmen - wohlhabende Bürger, Handelsherren und ihr Anhang, Landadlige, Gelehrte und Studenten der Londoner Juristenschulen und sogar Angehörige des Hochadels und des königlichen Hofs, für die seitlich der Bühne Logen (Lords' rooms) bereitstanden - , zum anderen - auf den billigeren Stehplätzen im nicht überdachten Parterre, dem pit, wo es mitunter laut zuging - das einfache Volk in bunter Mischung, darunter (worüber der städtische Magistrat klagte) viele Lehrlinge. Man wartete dort auf Lied-Einlagen, Narrenspäße, Waffengeklirr, Leidenschaftsausbrüche, Bluttaten auf offener Bühne, aber ebenso auf große Königsauftritte und Thronreden oder auf hinreißende, bekenntnishafte Monologe von tragischen Helden wie Hamlet oder Schurkenmonologe von Intriganten und Mördern wie Richard III. Denn nicht nur Leute von Stand bewunderten Eloquenz, herrscherlich-höfisches Auftreten oder gegebenenfalls virtuoses Ränkespiel, auch und gerade die nicht lesefähige Menge war in hohem Maße auf die Effekte der mündlichen und szenisch-visuellen Darbietung eingestellt. Zugleich konnte Shakespeare aber bei seinem Publikum ein hohes Maß von Bibelkenntnis und -interesse, auch eine von sprichwortartigen Bibelwendungen durchsetzte Alltagssprache voraussetzen und sich zur Wahrheitsbekräftigung und Fundierung seiner Aussagen darauf beziehen. Bestimmend für die Bewußtseinslage des elisabethanischen Theaterpublikums war - so lassen die Texte erkennen - eine ungewöhnliche Mischung von vitaler, mitunter greller Weltorientierung einerseits und engagierter Bibelvertrautheit andererseits. Dies ist ein (viel zu wenig beachteter) kulturgeschichtlicher Faktor, der zu einem Teil - Shakespeares 
persönliches Bedürfnis nach Zusammenschau ergänzend - die für die Dramen charakteristische Synthese erklärt.

Wir müssen uns aber (3) auch die Herkunft und gewisse Schwerpunkte der beträchtlichen Bibelkenntnisse Shakespeares klarmachen. Abgesehen von einzelnen redensartlich gewordenen Formulierungen, die er überall aufgreifen konnte, lernte er die Bibel zunächst über sein streng katholisches Elternhaus kennen, dann - zeittypisch - zum großen Teil aus dem gesetzlich vorgeschriebenen Besuch des anglikanischen Sonntagsgottesdienstes (sein Vater mußte wegen Fernbleibens einmal eine Geldbuße zahlen). Die Bibel begegnete ihm hier in den Gebeten, besonders im Psalter, des Book of Common Prayer (1549, dritte Fassung 1559) und in den Schriftlesungen und Predigten. ${ }^{3}$ Bekanntlich hatte Heinrich VIII. die Anglican Church im Bruch mit Rom „von oben her" gegründet (Established Church, Church of England) und sich selbst die kirchliche Suprematie übertragen lassen (Act of Supremacy, 1534), weil der Papst ihm die Ungültigkeitserklärung seiner ersten Ehe (mit Catherine of Aragon) verweigert hatte. Als Oberhaupt der Staatskirche und herrschgewohnter Renaissancefürst wachte er - wie nach ihm Elisabeth I. und James I. - streng über die Einhaltung der neuen Ordnung, unter Beibehaltung des Titels „Defensor Fidei“ („Verteidiger des Glaubens"), den ihm einst der Papst für sein gegen Luther gerichtetes Buch $A$ Defence of the Seven Sacraments (Eine Verteidigung der sieben Sakramente, 1521) verliehen hatte.

Zur gottesdienstlich vermittelten Kenntnis der Hl. Schrift trat jedoch Shakespeares eigene Bibellektüre, zu der er nachweislich vor allem die Geneva Bible (1560 u.ö.) benutzte. Unter den damaligen englischen Bibeln war sie die populärste, übersetzt in Genf von englischen Puritanern, die vor Maria I., der Katholischen (Königin 1553-58), geflohen waren. ${ }^{4}$ Auf Shakespeare haben wahrscheinlich auch die vielen kleingedruckten Kurzkommentare in den Marginalien und die knappen Inhaltshinweise in den Kopfleisten - beides damals ein Novum in England - eingewirkt. Die Kommentare waren oft antipäpstlich polemisch ausgerichtet, dienten aber primär der Belehrung und Erbauung - „to good purpose and edification we have in the margent [= margin] noted“ („zu gutem Zweck und zur Erbauung haben wir in den Marginalien aufgeführt"), heißt es im Einleitungsbrief.5 Offensichtlich stammen einige der theologischen Begriffsdistinktionen Shakespeares von dort, z.B. die Unterscheidung von Gesetz und Gnade oder von Glauben und Werken. Weitere Anregungen 


\section{Peter reproued.}

\section{Chap.III. Who are iuftified. 88}

f tn tote that to me and to Barnabas the fright hands of we all agreed felownip, that we fhulde preache vnto the Gentiles, and thei vnto theCircumcifion, $1:, t, 30$, 10 * Witrning onely that we fhulde remems.cor 9,3 . ber the poore : which thing alfo I was diligent to do.

II And whe Peter was come to Antiochia,

c) Meaniog, ice I withftode himsto his face:for he was to be blamed.

12 For before that certeine came from Iames, he ate with the Gentiles : but when

nompowith \& they were come, he withdrewe \& fepararighe fur.

hIn bringie ted him felf, fearing them which were of their sonftes the Circumcifion. ces into doute 13 And the other Iewes diffembled likewiplestatoritic? Apotle com.
And was broght into their difsimulationa' ${ }^{\prime}$. acth to bis ${ }_{14}$ But when I fawe, that they went not the i Fot for te: "right way to the trueth of the Gofpel, I Gescilles in re- faid vnto Peter before all men, If y̆ being gentiles in tefroche.

$1 \mathrm{Excepe}$ ougr

frutes be agrca

ble to of faith.

we declare $\frac{f}{4}$

we have
Chriat.

Rom sto.

phil-3.9.

For he can.

fed the not to

clofed it, ne.

cher toke he

away 5 righ.

ttoufsesofiche

Law, bat fhe:
wed thirir hy.

wed therir hy-

were not able

to petforase
whereof-they whereof

in Formy do.

arine is to de.

Aroy fince by

and not to cfia

and nut to cfl
bluth finat.

A And fele his 19

Arength in me

Sinas.

- Notas 1 wes

once,but regz:
berat,andechan

ged into a ne
crature

qualitie, 8 no

in fishance.

pal bodic.
o As did the $2 t$ I do not abrogate the agrace of God:for

falie Apoftes

which prea-

ehed not the

a Iswe, liuclt asthe Gếtiles, \& not inke the

Iewes, why hoólt a aneft thou the Gentiles

to do like the Iewes?

is We which are Iewes by nature, and not finners of the Gentiles,

16 Krowe that a man is not iufified by the $w$ rkes of the Law, but by the faith of Iefus Chrift: euen we, $I$ fiy, haue beleued in Iefus Chrift, that we might be iuftified by the faith of Chrift, and not by the workes of the Law, becaufe that by the workes of the Law no "fleth fha!be iuftified.

"If then while we feke to be made righteous by $\mathrm{Chrift}$, we our felues are founde $\mathrm{k}$ finners, is Chrift therefore the minifter of finne?'God' forbid.

8 For if I buyldeagaine the things that I pafer.

For I through the Law am dead to the Law, o that I might liue vnto God, I am "crucified with Chrift.

ucd ye thebSpirit by the workes of $\hat{\mathrm{L}} \mathrm{L} 2 \mathrm{w}$, smeaning the or by the hearing of c faith preached? spirit.

Are ye fo foolin, that after ye haue be- $c$ That is, the gonne in the Spirit, yc wolde now be ma- datis through deperfite by the eflef?

4 Haue ye fuffred fo many things in vaine? 5,22 . (y22. if fo be it be euen in vaine. SThe falies.

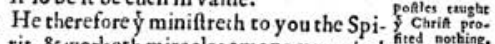
rit, \& worketh miracles among you, dseth fited nothing: be it through the workes of the Law, or re circuicifed, by the hearing of faith preached? 6 rea rather as Abrabam beleued God, \& perfecion, \& it was * imputed to him for righteoufnes. ne onely the 7 Knowe ye therefore, that they which a- rudimés there of faith, the fame are the children of A- $\begin{gathered}\text { CAnd } \\ \text { monies of the }\end{gathered}$ For the Scripture forefeing, $\dot{y}$ God wolde Gen.ts . iuftifie ý Gétiles through faith, preached rom 4.s. before ý Gofpel vnto Abrahä, faying, "In iam.s,2s. thee thal all the Gentiles be bleifed.

So then they which be of faith, are blef- alt.34,2s. fed with faithful Abraham.

10 For 2 many as are of the $f$ workes of the $f$ which thine Law, are vnder the curfe: for it is written, keto be inti* Curfed is euerie man that continueth not fied by them. in all things, which are writtê in the boke of the Law, to do them.

it And that no man is iuftified by the Law in the fight of God, it is euident: * for the Habak,2.4. iuft fhalliue by faith.

rom.t, 17 .

And the g Law is not of faith : but * the ebr, $10,3 s$. man that fhal do thofe things, fhal liue in Leturgs.

them. 8 The L,awe Chrif hathe redemedvs from the cur- betene, but $\$$ fe of the Law, when he was made a curfe worke, and fo for vs(for it is written, * Curfed is euerie chem which in one that hangeth on tre) 14 That the blefsing of Abrahá might co- Dot Dut tilit. me on the Gentiles through Chrift Iefus, that we might receiue the spromes of the h which is 8 Spirit through faith. Gofpel.

is Brethren, II fpeake as men do, ${ }^{*}$ Thogh

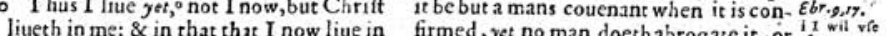
firmed, yet no man doethabrogate it, or il will vie a kaddech any thing thereto. ple 3 you may the rflef I liucby the faith in the Sonne of God, who hathe loued me, \& giuen him felf forme.

if righteoufnes be by ý Law, then Chrift dyed 'without a caufe.

faith is Chrift

CHAP. II $\mathrm{r}$.

He rebuleth them Sherpely. A And proueth ly diwers reafons that iuftufication is by faitio. o As ap. peareth by the example of Abraham, 10.49.24. And by the office, is the end, bothe of the Law, 1t,2s. And of faith.

- Foolifh Galatiăs, who hathe bewitched you that ye fhulde not obey the trueth, to whome Iefus Chrift before awas Cho whome defcribed in your fight, $\sigma$ among you cru lisery prex cified?

ched. as if his 2 This onely wolde I learne of you, Rccei-

re your cyes. of els had bene crucificd among you.
16 Now to Abraham and his fede were the attribute lifie promifes made. He faith not, And to the vato God, the fedes, as Speating of many:but, And to thy nants, whict fede, as of one, which 1 is Chrift. 17 And this I fay, that the Law which was $k$ No more is foure hundreth and thirtic yeres after, can coutense of not difanul the couenant that was confir. God abrogate med afore of $G$ od in refpect of Chrift, $\bar{y}$ yets ithe Law it fhulde make the promes of none effect. added to the 18 For if the inheritance be of the Law, it any thig away s no more by the promes, but God gaue that was fupcr it vnto Abrabam by promes. Wherefore then foruth the Lawa It was thed that was. added becaufe of the m träfgrefsions, til I $_{\text {clareth }}$ wats fede came vnto ý which the promes was iewes and Ge tiles are bothe promes, becaufe theiare ioysed in Chrift which is this bleficd fede. $\mathrm{m}$ Thit
finne mighe appeare and be mate more abandant, and fo all to be flut $\mathrm{vp}$ linne mighe appeare and be made more abandant, and fo all to be flut vp YY. iiii.

The Geneva Bible (1560), Seite aus dem Galaterbrief (Kap.2/3) mit Marginalien und Kopfleisten, wie S.91 erläutert. Links oben: „Peter reproued“ („Petrus geadelt“, von Paulus, weil er die Tischgemeinschaft mit den Heidenchristen vorübergehend aufgegeben hatte). Rechts oben: „who are iustified“ (,die gerechtfertigt sind“, durch den Glauben, nicht das Gesetz). Nach der Faksimile-Ausgabe von L.E.Berry (Madison, 1969), verkleinert. 
konnte er aus der weitverbreiteten Erbauungsliteratur, auch solcher katholischer Herkunft, übernehmen. Ein Passus in Hamlet beweist, wie genau er die Geneva Bible kannte: „I knew you must be edified by the margent [margin] ere you had done“ - wörtlich: „Ich dachte mir, daß du eine erbauliche Marginalie (also Erklärung) brauchtest, bevor du das verstehst". Das ist fast gleichlautend mit dem zitierten Passus in der Geneva Bible. Horatio sagt es wortspielerisch zu seinem Freund Hamlet, der die gekünstelte Rede eines Höflings nicht verstanden hat. Bei Schlegel-Tieck wird der Bibelbezug nicht deutlich: „Ich wußte, Ihr würdet Euch noch an seinen Randglossen erbauen müssen, ehe das Gespräch zu Ende wäre.“ Auch fast alle modernen Shakespeare-Herausgeber ignorieren den nach meiner Ansicht wichtigen Hinweis.

Wir haben also, Shakespeare eingeschlossen, das starke Bibelinteresse einerseits und das Unterhaltungs- und gewisse Bildungsbedürfnis andererseits, und Shakespeare verbindet beides. Er tut es nicht als Prediger, der weltliche Stoffe als Exempel für seine Gedanken heranzieht, sondern als Dramatiker, der die Stoffe imaginativ ausgestaltet und die biblischen Elemente in sie integriert, oft fast unauffällig und wie beiläufig. Weitgehend ohne Bibelbezüge bleiben nur, dem stofflichen Zeitkolorit gemäß, die stark auf Plutarch zurückgehenden Römerdramen wie Julius Caesar, Antony and Cleopatra und Coriolanus sowie die meisten Komödien, obwohl sich sogar in diesen eine Liebes- und (patriarchalische) Eheauffassung abzeichnet, die der biblischen zumindest nicht widerspricht und mit moderner Umdeutung von Liebe in Sex nicht das geringste zu tun hat.

Jedoch mußte Shakespeare einige von der anglikanischen Kirche und dem Staat erlassene Verbote beachten. Erlaubt war auf der Bühne nur das Anrufen der Namen Gottes und Jesu (wie es in zahlreichen Gebeten, Segenssprüchen und Prophezeiungen bei Shakespeare vorkommt), nicht aber das Antworten oder Auftreten der heiligen Personen. Das galt, zumal aus kalvinistisch-puritanischer Sicht, als götzendienerischer Bilderkult, Idolatrie, und hätte zu sehr an die inzwischen verbotenen mittelalterlichkatholischen Mysterienspiele erinnert. Später, 1606 (unter James I.), wurde sogar das Aussprechen heiliger Namen auf der Bühne untersagt mit der interessanten, von fast keinem Interpreten beachteten Folge, daß Shakespeare in seinem Spätwerk - in King Lear und in den sog. Romanzen oder Märchenspielen bis zu The Tempest - auf Märchenstoffe oder heidnische Mythologie auswich - offensichtlich, um über diese dann doch seine 
religiösen und durchaus biblischen Gedanken einzubringen. Vorher hatte er sie direkt ausdrücken können, besonders in den die englischen Könige darstellenden Historien und anderen Stücken mit mittelalterlichem oder katholischem Hintergrund wie Romeo and Juliet, Measure for Measure und The Merchant of Venice. Als Stückeschreiber der Truppe, die als „The King's Men“ (vorher „Lord Chamberlain’s Men“, Truppe des Schatzmeisters des Königs) unter königlichem Patronat stand und gelegentlich bei Hof spielte, hatte er besonderen Anlaß, die Bühnengesetzgebung jedenfalls äußerlich zu beachten. Insgesamt trugen die puritanisch strengen Verbote dazu bei, daß sich das Drama in England ganz anders entwickelte als etwa das Barockdrama in Spanien oder das Jesuitendrama in Deutschland. Im Jahre 1642 konnten die Puritaner im Parlament sogar die Schließung aller Theater durchsetzen.

Noch eine kleine philologische Vorbemerkung, damit wir das manchmal komplexe Zusammenführen von weltlichem Stoff und biblischer Aussage besser erkennen und benennen können. Das Zusammentreffen verläuft bei Shakespeare auf zweifache Weise: (1) auf der Wortebene in Form von Anspielungen (Allusionen), Echos, Zitaten und Namensnennungen sowie als Übernahme von Sprachbildern und (2) auf der Handlungs- und Themenebene durch Einbeziehung biblischer Geschehensmuster und Aussagen, auch durch Umstrukturierung tradierter weltlicher Stoffe und Charakterkonzeptionen nach biblischem Vorbild. Beide Verfahren durchdringen einander, und ich werde sie nebeneinander berücksichtigen. Die Auswirkungen des zweiten sind leichter zu erkennen, auch für ein bibelunkundiges Publikum, da hier Biblisches unmittelbar in Handlung und Charaktere oder in Gedanken umgesetzt wird. Das erste dagegen - die Bibelanspielungen, Zitate und Bilder auf der Wortebene - setzt voraus, daß man den evozierten biblischen Text erkennt, also eine gewisse, heute selten gewordene Bibelkenntnis einbringt. Liegt diese aber vor, so kommt es für den aufmerksamen Leser oder Zuschauer (in einer unverfälschten Aufführung) zu einer Art Interaktion zwischen den beiden sich überschneidenden Texten. Sie können etwa als übereinstimmend erkannt werden, also in ein Parallelverhältnis zueinander rücken, das den Shakespeareschen Versen zusätzliche Autorität gibt. Sie können aber auch in Kontrast zueinander treten. Auf jeden Fall spielt sich im Bewußtsein des Wahrnehmenden ein „intertextuelles“ Geschehen ab, wie man mit dem - hier zutreffenden - Modewort sagen kann. Denn für Augenblicke 
scheinen sich beide Texte - Handlungstext und evozierter Bibeltext - gegenseitig zu beleuchten und in ihrem jeweiligen, eventuell konträren Sinn zu verdeutlichen. Ich bin überzeugt, daß für Shakespeare selbst, der eine beziehungsreiche, mehrdimensionale Sprache liebte, diese Wechselbeziehung ein wesentliches Gestaltungs- und Ausdrucksmittel war.

Auffällig ist dabei, daß er jede konfessionelle Zuspitzung und Rechthaberei meidet und auch - besonders in den Historien und den genannten anderen Stücken, aber auch in Hamlet und King Lear - Toleranz und Vertrautheit mit katholischen Frömmigkeitsformen und Vorstellungen wie der vom Purgatorium (Fegefeuer) als dem Läuterungsort der abgeschiedenen Seelen zeigt (der Geist von Hamlets Vater berichtet von den Qualen). Eiferer wie den sich puritanisch gebenden Malvolio in Was ihr wollt (Twelfth Night) macht Shakespeare lächerlich. Er steht gewissermaßen über den Konfessionen und sucht das essentiell Biblische, zumal Neutestamentliche, Christliche. Er konzentriert sich also, wie auch sonst, auf eine Art Wesensschau, auf das Ganze, und argumentiert von dort her, übrigens immer auf den Menschen bezogen, auf sein Gewissen und Handeln einerseits und seine Begegnung mit biblischen Aussagen, Ereignissen und Personen andererseits. Nie stellt er das Heilige für sich dar, wie etwa Dante und später, in barocker Manier, Milton in Paradise Lost. Ich glaube nicht, daß das nur mit den genannten Bühnenvorschriften der Established Church zusammenhängt, sondern mehr mit Shakespeares eigener Sehweise, die den Menschen und sein Selbst als Schnittpunkt von naturgegebener und geistiger Welt verstand.

Fangen wir also mit den Texten an. Ich gehe von einem zentralen Wort Hamlets aus: „There is a special providence in the fall of a sparrow“ („es waltet eine besondere Vorsehung über den Fall eines Sperlings“, Hamlet, V,2). ${ }^{6}$ Der Bezug zu Matthäus 10,29 ist unverkennbar: „Verkauft man nicht zwei Spatzen für ein paar Pfennig? Und doch fällt keiner von ihnen zur Erde ohne den Willen eures Vaters.“ (AAre not two sparrows sold for a farthing? and one of them shall not fall on the ground without your Father?"). ${ }^{7}$ Sprechtext und evozierter Bibeltext ergänzen einander, sie stimmen überein. Und Hamlet, der seine eigene Schuld erkannt hat, nimmt das Walten der göttlichen Vorsehung an mit dem abschließenden (oft zitierten) Wort „the readiness is all. “Sein Bereitsein ist - nach der nun einmal gegebenen biblischen Assoziation ${ }^{8}$ - nicht antiker Stoizismus (wie oft in den Römerdramen), sondern verbindet sich mit dem Gedanken an 
Vorsehung und Tod wie bei Matthäus 24,42.44: „Wake therefore; for ye know not what hour your master will come. ... Be ye also ready; for in the hour that ye think not will the Son of Man come.“ („Seid also wachsam! Denn ihr wißt nicht, an welchem Tag euer Herr kommt. ... Darum haltet auch ihr euch bereit! Denn der Menschensohn kommt zu einer Stunde, in der ihr es nicht erwartet."). Zudem resigniert Hamlet nicht, sondern handelt von nun an auf eine neue Weise, so daß es zwischen ihm und Laertes, mit dem er auf Leben und Tod kämpfen muß, zu wechselseitiger Vergebung kommt. Zwar wird er seinen Racheauftrag an dem Brudermörder und Usurpator Claudius vollziehen. Die archaische Rechtsordnung und die Gehorsamspflicht des Sohnes, auch der ihm vom Geist des Vaters abverlangte Schwur fordern das vom Sohn des Gemordeten, so daß es hier - außer in Hamlets erster Empörung - weniger um subjektives Racheverlangen geht als um objektiv gebotene Vergeltung und den Vollzug gerechter Strafe wie bei der Tötung Richards III. und Macbeths. Wo Hamlet aber, wie gegenüber Laertes, nicht in den Rechtsvollzug und die Sohnespflicht eingebunden ist, ist er zu Vergebung und Versöhnung bereit. Hier liegt eine Handlungsumformung aus letztlich neutestamentlichem Geist vor, auf den auch die Wortwahl der beiden Sterbenden weist. ${ }^{9}$ Ich spreche von „Umformung“, weil Shakespeare mit der Verlaufsänderung die düstere, von Seneca beeinflußte Rachetragödie der Elisabethaner abwandelt und aufhellt. In dieser Gattung hatte es vorher nur den Automatismus von Rache und Gegenrache gegeben. Shakespeare selbst hatte als junger Autor mit seinem frühen Greuelstück über den Römer Titus Andronicus daran mitgewirkt und das herkömmliche Muster von Bluttaten noch überboten (mit entsetzlichen Morden, einer Vergewaltigung, grausamen Verstümmelungen und dem genüßlichen Abschlachten von Söhnen, die dann der ahnungslosen Mutter zum schaurigen Mahle vorgesetzt werden). Zwanzig Jahre später dagegen, im Sturm (The Tempest), kommt es zur völligen Absage an die Rache. Prospero vergibt denen, die ihn entmachtet und grausam verbannt haben, weil sie nun Reue zeigen, womit er den Zweck des von ihm entfesselten Sturms und anderer die Frevler ängstigenden Zauberkünste erreicht hat. In seiner Betonung tätiger Reue liegt - wie im Verzicht auf Rache, die Gott überlassen bleibt ${ }^{10}$ - ein unverkennbar christlicher bzw. biblischer Zug (V,1): 
Though with their high wrongs I am struck to th' quick,

Yet, with my nobler reason, 'gainst my fury

Do I take part. The rarer action is

In virtue than in vengeance. They being penitent,

The sole drift of my purpose doth extend

Not a frown further. Go, release them, Ariel.

My charms I'll break, their senses I'll restore,

And they shall be themselves.

Obschon ihr Frevel tief ins Herz mir drang,

Doch nehm' ich gegen meine Wut Partei

Mit meinem edlern Sinn: der Tugend Übung

Ist höher als der Rache; da sie reuig sind,

Erstreckt sich meines Anschlags ein'ger Zweck

Kein Stirnerunzeln weiter: geh, befrei' sie!

Ich will den Zauber brechen, ihre Sinne

Herstellen, und sie sollen nun sie selbst sein.

Kehren wir zu der wesentlich schwierigeren Situation Hamlets zurück, $\mathrm{zu}$ der noch etwas nachzutragen ist. Seiner Bereitschaft zur Annahme der göttlichen Vorsehung geht nämlich der hochkomplexe Prozeß eines tragischen Unschuldig-Schuldigwerdens und des allmählichen Erwachens des Gewissens voraus. Auch in seiner Mutter Gertrude regt sich diese Stimme und sogar in König Claudius, der sich in einem Augenblick vorübergehender Reue zur Ursünde von Kains Brudermord bekennt. Sein Verbrechen, so ruft er verzweifelt, trage den uranfänglichen aller Flüche auf sich (III,3) „O, my offence is rank, it smells to heaven, / It hath the primal eldest curse upon't, / A brother's murder.“ („Oh, meine Tat ist faul, sie stinkt zum Himmel, / Sie trägt den ersten, ältesten der Flüche, / Mord eines Bruders.") Auch Laertes, den Claudius zum Kampf gegen Hamlet mit einem vergifteten Degen angestiftet hat, vernimmt, bevor es zur wechselseitigen Vergebung mit Hamlet kommt, die Stimme des Gewissens: „yet 'tis almost against my conscience" $(\mathrm{V}, 2)$.

Die Sicht von Schuld und Sünde und das übergreifende Thema des erwachenden, schuldbewußten Gewissens ist ohne die biblisch geformte, besonders neutestamentliche Gewissens- und Schuldauffassung nicht denkbar, auch nicht ohne die jahrhundertelange und sich nun konfes- 
sionell neu artikulierende kirchliche Gewissenskultur und Beichtpraxis. Zwar spielt zusätzlich die antike Tragödie herein - in der Betonung des Erkennens der eigenen mißlichen Lage - , jedoch konzentriert sie sich mehr auf die eine vorgegebene Schicksalssituation, nicht auf die bei Hamlet oder Macbeth betonte innere Handlung und seelische Entwicklung, die lange vor dem Augenblick des Erkennens einsetzt, nicht erst gewissermaßen im letzten Akt. Die Shakespeare-Forschung überbewertet in der Regel die Einwirkung der antiken Tragödienauffassung, ohne die viel tiefer greifende christliche Fundierung der persönlichen Schulderfahrung zu sehen. Nur das frühe Rachestück Titus Andronicus enthält keinen von Gewissensnöten begleiteten Prozeß, sondern folgt dem einfachen Muster des drastischen Gefühlsumschwungs von furchtbarem Schmerz zu rasendem Racheverlangen. Shakespeare kannte dieses Schema aus Seneca und der (von Hamlet genannten) Hecuba (Hekabe) des Euripides, die ihm wahrscheinlich schon in der als Schullektüre verbreiteten lateinischen Übersetzung des Erasmus von Rotterdam begegnet war.

Verlassen wir für ein paar Minuten die Tragödien. Das Thema Vergebung behandelt Shakespeare noch deutlicher - mit geradezu parabelhafter Eindeutigkeit - in einer anderen Gattung, der Tragikomödie, heute meist als Problemstück (problem play) oder dark comedy bezeichnet. „Tragikomödie“ bedeutete damals, daß eine anfangs tragisch ausgerichtete Handlung schließlich doch zu einem komödienhaften, glücklichen Ende führt. Bei Shakespeare erscheint das Muster besonders in der Wende von der zu erwartenden Strafe zur Vergebung. In Maß für Maß (Measure for Measure) wird das schon im Titel angedeutet. Denn dieser steht nicht, wie man vermuten könnte, für den Sieg der strafenden Gerechtigkeit - nach dem Prinzip „wie du mir, so ich dir“ oder „Auge um Auge“ (nach Exodus 21,23-25) - , sondern für ihre Verneinung und das heißt für die dann doch folgende Vergebung, gemäß der vollständigen Stelle bei Matthäus 7,1-2: „Richtet nicht, damit ihr nicht gerichtet werdet. Denn wie ihr richtet, so werdet ihr gerichtet werden, und nach dem Maße, mit dem ihr meßt und zuteilt, wird auch euch gemessen werden“ (,and with what measure ye mete [„meßt"], it shall be measured to you again.") Aber statt auf diese Geschichte gehe ich auf den Kaufmann von Venedig (The Merchant of Venice) ein.

Auf dreifache Weise stellt Shakespeare hier - wenn man es formelhaft zusammenfaßt - die Bewährung des christlichen Ideals selbstlos schen- 
kender Liebe dar: in der Liebe zwischen Frau und Mann (Portia und Bassanio), in der wahren Freundesliebe (Antonio und Bassanio) und als Höchstes, wie besonders in der Bergpredigt hervorgehoben, in der Feindes- (hier auch Fremden-)liebe (Antonio und Shylock). Am Ende vergibt der christliche Kaufmann Antonio dem Wucherer und Juden Shylock, der ihm vor Gericht aufgrund eines monströsen Schuldscheins ein Pfund Fleisch aus dem Leib hat schneiden wollen. Innerlich angetrieben wird Shylock von einem zur Besessenheit gesteigerten $\mathrm{Haß}$ und Racheverlangen, weil Antonio und andere Christen ihn jahrelang wegen seiner Wucherei verachtet, einen Hund genannt und sogar angespuckt haben. Obwohl Shylock, als er der Mordabsicht überführt ist, sein Leben verwirkt hätte, bittet Antonio nun, als das von Shylock verfolgte Opfer, um Strafmilderung für ihn, die der Doge als christlicher Herrscher gewährt. Vergebung siegt über $\mathrm{Haß,} \mathrm{Rache} \mathrm{und} \mathrm{Tötungsverlangen,} \mathrm{obwohl} \mathrm{für} \mathrm{den}$ völlig gebrochenen Shylock, dem auch die christliche Taufe auferlegt wird, ein Rest unauflöslichen, tragischen Leidens bleibt. Dennoch wird das spezifisch Christliche des Vergebens immer wieder explizit formuliert und dem alttestamentlichen Gesetzesdenken in seiner jüdischen Ausprägung gegenübergestellt. Allerdings läßt sich Shylock gerade nicht von jüdischem Gerechtigkeitsdenken leiten, sondern von seinem Haß auf Antonio. Er ist ein extremer Außenseiter auch in der jüdischen Gemeinde. ${ }^{11}$

Der Höhepunkt christlicher Sinnaussage ist Portias berühmte Rede über mercy, die Gnade (IV,1). Portia, als Richter verkleidet, will Shylock von seiner unmenschlichen Forderung abbringen. Nach vergeblichen juristischen Argumenten und moralischen Appellen (an Menschlichkeit und Milde) wechelt sie zur religiösen Ebene über und stellt Shylock und dem Gerichtshof das Wesen christlicher Gnade und Vergebung vor Augen. Es ist eine der poetisch schönsten, oft zitierten Stellen Shakespeares und zugleich eine völlig begriffsklare Definition. Danach ist Gnade schenkende Liebe, die sich nicht erzwingen läßt („not strain'd“), sondern vom Himmel sanft herabträufelt, also zunächst Attribut Gottes ist, in ihrem Niedersinken aber die Herzen der Könige erreicht, deren furchtgebietende Macht sie mildert und über die sie weiterwirkt in die Welt.

The quality of mercy is not strain'd It droppeth as the gentle rain from heaven Upon the place beneath. It is twice blest: 
It blesseth him that gives and him that takes.

Tis mightiest in the mightiest, it becomes

The throned monarch better than his crown.

His sceptre shows the force of temporal power,

The attribute to awe and majesty,

Wherein doth sit the dread and fear of kings;

But mercy is above this sceptred sway,

It is enthroned in the hearts of kings,

It is an attribute to God himself;

And earthly power doth then show likest God's

When mercy seasons justice.

Die Art der Gnade weiß von keinem Zwang,

Sie träufelt, wie des Himmels milder Regen,

Zur Erde unter ihr; zwiefach gesegnet:

Sie segnet den, der gibt, und den, der nimmt;

Am mächtigsten in Mächt'gen, zieret sie

Den Fürsten auf dem Thron mehr wie die Krone;

Das Szepter zeigt die weltliche Gewalt,

Das Attribut der Würd' und Majestät,

Worin die Furcht und Scheu der Kön'ge sitzt.

Doch Gnad' ist über diese Szeptermacht,

Sie thronet in dem Herzen der Monarchen,

Sie ist ein Attribut der Gottheit selbst,

Und ird'sche Macht kommt göttlicher am nächsten,

Wenn Gnade bei dem Recht steht.

In dieser Wesensbestimmung christlicher Gnade wird ein Königsbild sichtbar, das in der Verbindung von Gerechtigkeit und Gnade dem Ideal des mittelalterlichen Sakralkönigtums entspricht. Der Doge handelt danach, und Shakespeare nimmt es auch in seine Historien auf. Biblisch konnte es auf die gesalbten, gottesfürchtigen Könige wie Saul und David bezogen werden. Ich habe Portias Rede aber auch deshalb gewählt, weil sie uns auf der sprachlichen Ebene zeigt, wie Shakespeare biblische Bilder aufnimmt und in seine eigene Dichtungssprache umsetzt. Dazu ein paar Hinweise. Der am Anfang stehende Vergleich der Gnade mit dem vom Himmel niederträufelnden, sanften Regen hat eine auffallende 
Ähnlichkeit mit dem Beginn des Liedes des Mose (Dtn 32,2) „Meine Lehre wird strömen wie Regen, meine Botschaft wird fallen wie Tau, wie Regentropfen auf das Gras und wie Tauperlen auf die Pflanzen.“ („My doctrine shall drop as the rain, my speech shall distil as the dew, as the small rain upon the tender herb, and as the showers upon the grass.") Hier tritt das Bild in zweigliedrigen Variationen und Wiederholungen auf (Regen und Tau, und noch einmal: Regentropfen und Tauperlen), wie es für die alttestamentliche Poesie typisch ist. Shakespeare dagegen geht in seiner typischen Weise von einer einzigen Bildvorstellung aus, der des sanften Niederfallens, die richtungweisend wird und die er - durch alle Begriffsdistinktionen und Begleitbilder hindurch - bis zur letzten Zeile führt, denn noch das „mercy seasons justice“ (Gnade mildert Gerechtigkeit) läßt etwas spüren von der Sanftheit des niedersinkenden Regens. Schlegel-Tiecks „Wenn Gnade bei dem Recht steht" hebt gerade dieses Moment auf. Ersetzt wird dort übrigens auch „God“ durch „Gottheit“, was rhythmusbedingt sein kann, aber zugleich typisch ist für das Nachwirken von Aufklärung und Deismus.

Wie immer Shakespeare verfährt, zwischen Portias Worten und dem evozierten biblischen Bild besteht völlige Harmonie. Es findet eine alles verschmelzende lyrische Integration statt. ${ }^{12}$ An poetischer Wirkung geht nichts verloren, wenn man die biblische Parallele nicht bemerkt. Bemerkt man sie aber, so sieht man, wie selbstverständlich und kreativ Shakespeare mit dem Bibeltext umgeht. Offensichtlich kannte er Stellen wie das Lied des Mose auswendig. Mit Sicherheit trifft das für die Psalmen des Psalters im Book of Common Prayer zu, die er schon als Kind auswendig lernen mußte und deren Bilder er, wie wir an Macbeths Monolog sehen werden, mehrfach aufgreift.

Aber zunächst noch einmal zurück zu Portia und Shylock. Nach ihrer Definition von Gnade wird Portia theologisch noch deutlicher. Nicht nur auf Erden, so erläutert sie, sei Gnade segensreich, auch das ewige Heil („salvation“) sei nicht über den Weg der Gerechtigkeit (,justice“), sondern nur über den der Gnade („mercy“) zu erlangen, und sie verlange auch von jedem einzelnen „deeds of mercy“, tätige Vergebung, Werke der Gnade und des Erbarmens. Mit einem furchtbaren Aufschrei jedoch weist Shylock dieses Wort zurück und kehrt es um: „My deeds upon my head! I crave the law“ („Meine Taten auf mein Haupt! Ich lechze nach dem Gesetz“, IV,1). Für einen Augenblick könnte man das positiv werten, 
denn Shylock beruft sich auf das Gesetz. Aber er will nur sein persönliches Racheverlangen rechtfertigen und stellt sich damit außerhalb der Gesetzesauffassung auch des Talmud. Entsprechend düster klingt das biblische Echo in seinem „My deeds upon my head“. Denn dieses Wort weist nicht nur auf das mosaische Gesetz ${ }^{13}$, sondern auch und deutlicher auf den Schrei der Menge vor Pilatus unmittelbar nach der Verurteilung Jesu (Mt 27,25): „His blood be on us and our children“ („Sein Blut komme über uns und unsere Kinder"). Ähnlich verbirgt der Schurke Jago, der Othello mit glühendem $\mathrm{Haß}$ verfolgt, sein gnadenloses Racheverlangen hinter der zynisch abgewandelten Formel des alttestamentlichen Gesetzesdenkens: „Till I am even'd with him, wife for wife“ („Bis ich ihm wett geworden, Weib um Weib“, Othello, II,1), und er spricht mit Leidenschaft von „der Gerechtigkeit, die Vergnügen macht“: „the justice of it pleases“ (IV,1).

Mit dem sog. To-morrow-Monolog Macbeths wenden wir uns wieder den Tragödien zu. Macbeth, der Königsmörder, Usurpator und blutige Tyrann, hat früher einmal auf die Stimme des Gewissens gehört. Jetzt ist sie auf tragische Weise verstummt, da er - als Folge seiner ungeheuerlichen Mordtat an seinem König und Gast - bis in die tiefste Seele hinein verwundet, erkrankt und korrumpiert ist, so sehr, daß er nach anfänglichen Schuldgefühlen nur noch von quälenden Ängsten und verwirrenden Halluzinationen (wie dem vor ihm schwebenden Dolch oder dem Geist Banquos) getrieben wird, zugleich aber weitermordet, um dem Zugriff der strafenden Gerechtigkeit zu entgehen. Schließlich scheint er wie abgestumpft, von nihilistischen Gedanken erfüllt, für die das Leben sinnlos geworden und nur noch ein täglicher, schleppender Weg zum Tode ist, zum Nichts. Dies ist der Augenblick des Monologs (V, 5):

To-morrow, and to-morrow, and to-morrow,

Creeps in this petty pace from day to day,

To the last syllable of recorded time;

And all our yesterdays have lighted fools

The way to dusty death. Out, out, brief candle!

Life's but a walking shadow; a poor player,

That struts and frets his hour upon the stage,

And then is heard no more: it is a tale

Told by an idiot, full of sound and fury,

Signifying nothing. 
Morgen, und morgen, und dann wieder morgen,

Kriecht so mit kleinem Schritt von Tag zu Tag,

Zur letzten Silb' auf unserm Lebensblatt;

Und alle unsre Gestern führten Narr'n

Den Pfad des stäub'gen Tods. - Aus! kleines Licht! -

Leben ist nur ein wandelnd Schattenbild;

Ein armer Komödiant, der spreizt und knirscht

Sein Stündchen auf der Bühn', und dann nicht mehr

Vernommen wird: ein Märchen ist's, erzählt

Von einem Dummkopf, voller Klang und Wut,

Das nichts bedeutet.

Die endgültig negative Existenzbewertung - „signifying nothing“ - entwickelt sich schrittweise aus der Betrachtung der aufgerufenen Bilder, die vom Konkreten zur abschließenden Abstraktion führen. In dieser Hinsicht wie in ihrer faszinierenden Verbindung von Einfachheit und Ausdruckskraft tragen sie unverkennbar die Handschrift Shakespeares. Vor allem kennzeichnend ist wieder, wie in Portias Rede, die zielbezogene Bewegung, die unaufhaltsam voranschreitet („creeps to“) und von Bild zu Bild aufgenommen und weitergeführt wird. Die Bilder sind: die eintönige Folge der Tage („To-morrow, and to-morrow, and to-morrow“), die Wegemetapher, die anfangs angedeutet, dann explizit genannt wird („way to dusty death“), die versteckte Buchmetapher („recorded time“), gewissermaßen das Reservoir, in das die Tage eingeflossen sind, das Verlöschen der Kerze („Out, out, brief candle!“) und schließlich die dreifache Definition des Lebens als wandernder Schatten („walking shadow"), Agieren auf der Bühne (Schauspielermetapher) und zuende erzählte, törichte Geschichte.

Trotz dieser unverkennbar Shakespeare'schen Züge - trotz auch des gelegentlich zynischen Tons - hat das Ganze eine spürbar biblische Resonanz. Die biblischen Bilder und Erfahrungen des Menschseins, die Shakespeare einbezieht, sind die der irdischen Vergänglichkeit und des fallenden, von seinen Ängsten verfolgten Frevlers, wie sie im Buch Hiob und in klagenden Psalmen erscheinen. Selbst die Verbindung von „Schatten“, „gestern“ und „Tage“ (Shakespeares „to-morrows") findet sich schon Hiob 8,9: „For we are but of yesterday, and know nothing, because our days upon earth are a shadow.“ („Wir sind von gestern nur und wissen 
nichts, wie Schatten sind auf Erden unsre Tage.") Ähnlich heißt es Psalm 39,7 (Geneva Bible): „Man walketh in a vayne shadowe“ („Nur wie ein Schatten geht der Mensch einher"). An anderer Stelle, Psalm 40,7 (8), klingt die Verbindung von Lebenszeit und Buch des Lebens an: „Lo, I come: in the volume of the book it is written of me." („Ja, ich komme. In dieser Schriftrolle steht, was an mir geschehen ist.").

Besonders interessant ist, daß eins der eindringlichsten Vergänglichkeitsbilder, das endgültige Verlöschen der Kerze, schon in Hiob 18,5-6,11 wie in Macbeths Monolog mit dem Schicksal des fallenden Frevlers verbunden wird, der Gott nicht kennt und nur noch von Ängsten getrieben wird: „Yea, the light of the wicked shall be put out, and the spark of his fire shall not shine. The light shall be dark in his tabernacle, and his candle shall be put out with him. ... Terrors shall make him afraid on every side and shall drive him to his feet.“ („Ja, der Frevler Licht erlischt, die Flamme seines Feuers strahlt nicht auf. Das Licht in seinem Zelte dunkelt, seine Leuchte über ihm erlischt. ... Ringsum ängstigen ihn Schrecken und scheuchen ihn auf Schritt und Tritt.").

Selbst das Leben als Geschichte oder Märchen, das erzählt wird, ist ein biblisches Bild (Ps 90,9: „we spend our years as a tale that is told.“), und sogar für die drastische Zuspitzung ,a tale / Told by an idiot“ könnte es eine biblische Anregung geben. Im Buch Jesus Sirach (Ecclesiasticus) 20,18 erscheint die Verbindung von erzählter Geschichte und Torheit als Bild für den Menschen, der wie Macbeth ohne Gott bzw. Gnade ist: „A man without grace is as a foolish tale which is oft told."

Wie in Portias Rede über die Gnade ist es nicht erforderlich, die biblische Herkunft dieser Bilder wahrzunehmen. Sie haben eine so starke eigene Ausdruckskraft, daß sie aus sich selbst eindringliche Vergänglichkeitsbilder sind. Sie verkörpern beispielhaft Shakespeares eigentümliches „Denken in Bildern" - das Gegenteil jeder dürren Rationalität und puritanischrigorosen Bildverachtung - , das die konkret gegebenen Bilder gedanklich und emotional durchdringt und zu einer Folge von Sinnbildern macht, die betrachtet und deutend erlebt werden können. Sucht man dafür nach einer konfessionellen Affinität, so liegt sie am ehesten in der kontemplativen Bildverwendung der katholischen Gebets- und Frömmigkeitstradition. Bemerkt man außerdem die biblischen Wurzeln, so stellt sich wieder eine intertextuelle Relation her, in der allerdings - anders als bei Portia - neben die ausdrucksintensivierende Parallelität der Bilder nun die Diskrepanz 
der jeweiligen Gesamtaussage tritt. In den Bibeltexten sind die Bilder mit dem Wissen um Gottes Allmacht und Zorn und mit der Bitte des Beters um Gnade verknüpft, während Macbeth gerade nicht um Rettung fleht, sondern der ins Nichts stürzende Frevler bleibt, dessen Kerze wie in Hiob 18,5-6 endgültig verlischt.

Ich gehe über zu King Lear, Shakespeares letzter und wohl größter Tragödie, deren weltweite Rezeption seit Mitte des 20. Jahrhunderts an die des Hamlet herankommt, der zuvor unangefochten die Spitzenstellung innehatte. Im Gegensatz zu den dort oder in Macbeth dargestellten komplexen Bewußtseinsprozessen und Charakteren - besonders zum „hamletischen Charakter“, wie ihn das 19. Jahrhundert verstand - findet hier keine psychologische Differenzierung statt, sondern eine durchgehende Vereinfachung, fast schon eine allegorische Typisierung. Die Figuren werden auf schlichte Weise in Gute und Böse eingeteilt, die Handlung in ein einfaches Gegenüber von Geben und Nehmen, Verlieren und Wiederfinden, Verstoßen und Suchen oder Töten und Heilen, und entsprechend konfrontiert werden Orte des Unheils (wie der Sturm auf der Heide) und Orte des Heils (wie die des Wiederfindens). Wir haben also fast schon ein lehrhaftes Moralitätendrama, aber mit einer vertieften Auffassung des Tragischen, auf die ich eingehen möchte.

Zunächst begegnen wir wieder der Erfahrung persönlicher Schuld, wie wir es aus Hamlet kennen. Der greise König hat - töricht und aufbrausend - die ihn treu liebende jüngste Tochter Cordelia verstoßen. Die heuchlerischen und bösartigen, dabei machtgierigen zwei älteren Töchter, Goneril und Regan, haben ihn, nachdem er ihnen sein ganzes Reich geschenkt hat, erbarmungslos hinaus auf die Heide in den Sturm getrieben, wo er mit seinem getreuen Narren herumirrt, hilflos, obdachlos, vom König zum Bettelmann geworden und halbwahnsinnig aus Empörung über den Undank der Töchter, die er mit furchtbaren Worten verflucht. Plötzlich aber murmelt er ohne erkennbaren Grund: „I did her wrong“ („Ich tat ihr Unrecht") und meint damit Cordelia. Er gesteht sich weiter ein, daß er als König - im Pomp der Herrschaft - die soziale Not der Elenden und Armen nie wahrgenommen hat und daß es einer besonderen Medizin, der persönlichen Erfahrung des Leidens, bedarf, um von dieser Blindheit geheilt zu werden (III, 4): 
Poor naked wretches, wheresoe'er you are,

... O, I have ta'en

Too little care of this! Take physic, pomp,

Expose thyself to feel what wretches feel,

That thou mayst shake the superflux to them,

And show the heavens more just. -

Ihr armen Nackten, wo ihr immer seid,

... Oh, daran dacht' ich

Zu wenig sonst! - Nimm Arzenei, o Pomp!

Gib preis dich, fühl' einmal, was Armut fühlt,

Daß du hinschütt'st für sie dein Überflüss'ges

Und rettest die Gerechtigkeit des Himmels!

Es geht also um Mitfühlen, Erbarmen, aber zweitens auch um tätige Nächstenliebe, Caritas. Und drittens um Tröstung durch das Wecken von Hoffung, Hoffnung auf die bessere Gerechtigkeit des Himmels. Daß hier die christliche Botschaft gemeint ist - in diesen wenigen Worten, auf engstem Raum -, steht außer Frage, auch wenn wegen des kirchlichen Verbots, das wir kennen, der Name dessen, der sie verkündet hat, nicht erwähnt wird und statt „Heaven“ im biblischen Sinne nur das Wort „heavens“ (im Plural) erscheint, das als poetisches Wort die Höhe, den kosmischen Bereich jenseits der Erde bedeutet. Entsprechend ist später von „Göttern“, nicht von „Gott“ die Rede.

So weit die Einbeziehung der persönlichen Schulderfahrung Lears. Aber jenseits dieser subjektiven Schuld tut sich nun, anders als in Hamlet und Macbeth, eine weitere Dimension des Tragischen auf: die Tragik des Menschseins überhaupt in seiner irdischen, existentiellen Begrenztheit und Not, damit aber auch - biblisch gesehen - in seiner Erlösungsbedürftigkeit. Am schlimmsten - und schuldlos - leidet der Mensch an der Paradoxie, daß gerade der meistgeliebte andere Mensch, der das höchste Glück für ihn bedeutet, ihm das größte Unglück bringt, wenn er ihn verlieren muß, zumal wenn es sich um ein innig geliebtes Kind handelt. So jedenfalls erfährt - und erfaßt - es Lear kraft seiner „reason in madness“ („Vernunft im Wahnsinn“, IV,6), und er reagiert auf diese Einsicht auf zweierlei Weise. Am Anfang steht (1) die bloße Annahme des Geschicks. Der Geburtsschrei des Kindes wird für Lear, der dem geblendeten Gloucester damit Mut 
machen will, zum Symbol für das mit Geduld zu tragende, schwere Dasein des Menschen (IV,6): „Thou must be patient. We come crying hither: / Thou know'st, the first time that we smell the air / we wawl and cry.“ („Du mußt geduldig sein, wir kommen weinend an. / Du weißt: wenn wir die Luft zum ersten Male riechen, / Dann schreien wir und winseln.") Lear findet also zu Demut und Geduld, zu letztlich christlichen Tugenden. Zugleich spricht aus ihm die natürliche Weisheit, die der Mensch aus Einsicht in seine Sterblichkeit gewinnt. Es ist aber höchst bezeichnend, daß wie an anderen thematisch zentralen Stellen der Dramen wieder ein biblischer Hintergrund auftaucht. Sowohl der ausgedrückte Gedanke wie das elementare, intensive Bild des Geburtsschreis wurzeln im Buch der Weisheit (Wisdom of Solomon) 7,3-5: „Geboren atmete auch ich die gemeinsame Luft, ich fiel auf die Erde, die Gleiches von allen erduldet, und Weinen war mein erster Laut wie bei allen. In Windeln und mit Sorgen wurde ich aufgezogen; kein König trat anders ins Dasein.“ („And when I was born, I drew in the common air, and fell upon the earth, which is of like nature, and the first voice which I uttered was crying, as all others do. I was nursed in swaddling clothes, and that with cares. For there is no king that had any other beginning of birth.")

Später nimmt Edgar, Gloucesters Sohn, den Grundgedanken Lears auf, wobei er ähnlich formuliert wie Hamlet im Augenblick der Einsicht (Hamlet, V,2; s.o.). Jetzt aber ist nicht mehr von Bereitsein die Rede, sondern von Reife, Erfahrung (V, 2): „Men must endure / Their going hence, even as their coming hither: / Ripeness is all!“ („Menschen müssen ihr Fortgehen von hier ertragen / wie ihr Kommen: Reifsein ist alles."). Bis in diesen einfachen Satz hinein fällt übrigens das genannte typisierende Komplementärverhältnis von Bewegung und Gegenbewegung, hier von Fortgehen und Kommen, auf.

Aber es gibt in Lear (2) auch etwas ganz anderes: eine Hoffnung und Heilserwartung, die aus der Misere dieses Daseins herausführt. Sie kann sich in der Doppelhandlung des Dramas auf zwei junge Menschen stützen: Cordelia, die Tochter Lears, und Edgar, den Sohn Gloucesters. Beide sind von ihren Vätern zu Unrecht verstoßen worden, beide aber sind bereit zu vergeben und tätige, mitmenschliche Hilfe zu leisten, verbunden mit tiefer Kindesliebe und sogar vorbehaltloser Opferbereitschaft. Sie handeln aus liebendem Herzen. So kommt es zu zwei Heilshandlungen, welche die scheinbar unaufhebbare Seinstragik durchbrechen. Cordelia, inzwischen 
zur Königin von Frankreich geworden, kommt mit einer Armee nach England, um den Vater aus dem Elend zu retten. Ihr späterer tragischer Untergang wird damit eine Art Opfertod mit durchaus biblischen Konnotationen. Vorher pflegt und tröstet sie den Vater und weckt ihn nach seinem heilenden Schlaf mit einem Kuß. Edgar, verkleidet als schwachsinniger Bettler, wird zum liebevollen Pfleger und Führer des grausam geblendeten Vaters, und er verhindert, daß dieser sich aus Verzweiflung von den Klippen von Dover stürzt. Er tut das mit Hilfe eines frommen Betrugs. Er redet dem Vater ein, auf schwindelnder Höhe zu stehen. In Wirklichkeit fällt Gloucester, als er springt, nur von einer kleinen Erhebung und bleibt unversehrt. Edgar deutet das für den Vater als ein Rettungswunder der Götter, die ihn zugleich vom bösen Geist befreit hätten. So gibt er ihm Hoffnung (IV,6): „Thy life's a miracle ... Think that the clearest gods, who make them honours / Of men's impossibilities, have preserved thee.“ („Ein Wunder, daß du lebst! ... Daß höchste Götter, die zum Ruhm vollführen, / Was uns unmöglich scheint, dich retteten.“)

Auch Lear werden erlösende, verheißungsvolle Bilder zuteil. Während Cordelia, die sich liebevoll über ihn beugt, ihm wie ein seliger Geist im Himmel erscheint, fühlt er sich wie auf ein glühendes Feuerrad gebunden, auf dem ihm die Tränen wie geschmolzenes Blei glühen (IV,7): „Thou art a soul in bliss, but I am bound / Upon a wheel of fire, that mine own tears / Do scald like molten lead“. Damit taucht ein Purgatoriumsbild auf. Jedoch wird dieser Bezug wie der auf den seligen Geist im Himmel durch den halbwirren Zustand Lears auch wieder verunklart. Das geschieht offenbar absichtlich, um nicht gegen das Verbot zu verstoßen, heilige Vorstellungen und Namen oder - mit dem Purgatorium - Bilder der katholischen Mysterienspiele auf die Bühne zu bringen. In einer späteren Szene (V,3) malt sich Lear trotz der bevorstehenden Gefangennahme durch die Feinde eine glückliche Zeit der Gemeinsamkeit mit Cordelia aus, in der sie „wie zwei Vögel im Käfig singen“, sich gegenseitig segnen, Vergebung schenken, beten, alte Geschichten erzählen und über goldene Schmetterlinge lachen werden. Daß ihm am Ende das wiedergefundene Glück durch die brutale Ermordung der geliebten Cordelia erneut genommen wird, will er nicht wahrhaben. Er stirbt in dieser Erschütterung und Verwirrung, aber er hat Visionen der Seligkeit und Hoffnung erfahren. Daß hier wieder Biblisches, besonders Christliches mitschwingt, obwohl es unter scheinbar nur menschlichen Bildern verborgen wird, ist unverkennbar. 
Nur noch ganz kurz kann ich auf die Historien oder Königsdramen eingehen. Ihnen liegen schon der mittelalterlichen Chronikstoffe wegen viele christliche und biblische Elemente zugrunde, bis in den sog. „TudorMythos" hinein. Nach diesem hat die Schuld des Usurpators Bolingbroke, des späteren Henry IV., die göttliche Strafe der langen, blutigen Rosenkriege ausgelöst, die erst von Henry Tudor als einem weltlichen Heilsbringer getilgt wird, der den machiavellistischen Schurken und blutrünstigen Tyrannen Richard III. zu Fall bringt und die verfeindeten Häuser Lancaster und York durch Heirat vereint. Nur zwei Motive hebe ich aus diesem ereignisreichen, acht Historien umspannenden Geschehen heraus.

Das erste ist das uns aus Portias Rede schon bekannte Ideal des gesalbten christlichen Königs des Mittelalters, der einerseits gerecht und auf furchtgebietende Weise mächtig ist, andererseits aber auch Gnade gewähren kann, und hinter dem als biblische Urbilder die gesalbten alttestamentlichen Könige Saul und David stehen. Während der schurkische Richard III. das abschreckende Gegenbild dazu ist, wird Heinrich V. zum Idealkönig erhoben, und dies um so deutlicher und biblischer, als er vorher als „madcap prince“ („toller Prinz“, Henry IV Part One, IV,1) den Weg des Verlorenen Sohnes gegangen ist (nach der Parabel in Lk 15,11-32). Er hat sich mit seinem Saufkumpan Falstaff in den Kneipen herumgetrieben, kehrt aber zum Vater zurück, als ihn die Pflicht ruft.

Das zweite Motiv, der Sturz der Könige und Mächtigen, ist ebenfalls mittelalterlich vermittelt, in diesem Fall über die De casibus-Geschichten (Geschichten vom Sturz der Mächtigen), in denen die wankelmütige Fortuna mit Duldung Gottes auf ihrem Rad die Könige, wenn sie ihr leichtsinnig vertrauen, zunächst zur Herrschaft empordreht, dann aber mit der Abwärtsdrehung wieder stürzen läßt. Der einfache Tragödienbegriff des Mittelalters beruht auf diesem „Sturz der Großen“, den zuerst Boccaccio in seiner Exempelsammlung De casibus virorum illustrium (Über den Sturz berühmter Männer und Frauen) an vielen Beispielen zur Belehrung der Fürsten dargestellt hatte. Auf Shakespeare kam diese Tradition über die auch englische Könige einbeziehende Sammlung Mirror for Magistrates („Spiegel für Amtsinhaber“, seit 1559 in mehreren Auflagen erschienen). Er differenzierte das Sturz-Motiv jedoch durch psychologische Innenperspektivierung. Besonders eindrucksvoll gelang das in Richard II, wo der König anfangs prunkvoll und leichtsinnig regiert, am Ende aber, bevor er im Kerker ermordet wird, sich einem elenden Bettler gleich fühlt, der 
sich einredet, über Steine zu herrschen. Zuvor, als er vor dem mächtigen Usurpator Bolingbroke und in Gegenwart der versammelten Großen des Reichs abdanken und seine Krone sogar selbst abnehmen muß - er hält sie verzweifelt und widerstrebend für einen Augenblick in seinen Händen (eine der großen Szenen Shakespeares) -, vergleicht er sein Leiden sogar mit dem des „Königs der Schmerzen“ und die Verräter, die zum Usurpator übergelaufen sind, mit Judas. Aber das Bild der Passion Christi wird von Shakespeare nicht etwa als volle Parallele eingesetzt, sondern nur partiell und vornehmlich konträr; denn bei allem Leid fühlt Richard besonders Selbstmitleid und neigt, wie auch sonst, zur Selbstinszenierung. Von einer wahren Nachfolge Christi ist er weit entfernt. ${ }^{14}$

Daß es auch in der Bibel zahlreiche Erwähnungen des Sturzes großer Könige und Reiche gibt, braucht man kaum zu belegen. Ich nenne nur Psalm 135,10 „Er schlug viele Völker nieder und tötete mächtige Könige" oder aus dem Neuen Testament - mit christlicher Einbeziehung der Demut, die erhöht wird - „er zerstreut, die im Herzen voll Hochmut sind; er stürzt die Mächtigen vom Thron und erhöht die Niedrigen“ (im Lobgesang Marias: Lk 1,51-52). Natürlich gibt es den Archetypus des Sturzes aus der Höhe der Macht auch außerhalb der Bibel. Caesar fällt und Marcus Antonius oder Coriolanus. Aber in der Bibel ist es der allmächtige Gott, der die Großen stürzen läßt, und mit dieser biblischen Resonanz, verbunden mit dem Wirken Fortunas, erscheint der Sturz der Könige bei Shakespeare. Das geschieht nicht nur in den Historien, sondern auch bei Macbeth, der wie Richard III. von einem gottesfürchtigen Gegner erschlagen wird, der mit dem Segen Gottes ein neues Reich der Gerechtigkeit und des Friedens errichten wird.

Zum Schluß greife ich noch einmal auf den Anfang zurück, auf Shakespeares Zugang zur Bibel. Die Bibel begegnete ihm nicht nur durch sein katholisches Elternhaus, den anglikanischen Gottesdienst und die private Bibellektüre, sondern auch über zwei andere, sehr volkstümliche und einfache Medien: die mittelalterlichen Mysterienspiele und die zahlreichen bildlichen Darstellungen, die bis Ende des 16. Jahrhunderts in und an den Kirchen sowie auf Wandvorhängen in Ratshäusern, Gaststuben und Wohnhäusern zu sehen waren. Auf Shakespeares genaue Kenntnis des Mysterienspiels deutet eine Stelle in Hamlet (III,2). Hamlet fordert die von ihm beauftragten Schauspieler auf, das Brüllen und Gestikulieren auf der Bühne tunlichst zu vermeiden, weil das einem „out-herod Herod“ 
gleichkomme, einem „Aus-Heroden des Herodes“, einem schlimmen Übertreiben also: „I would have such a fellow whipt for o'erdoing Termagant, it out-Herods Herod, pray you avoid it.“ („Ich möchte solch einen Kerl für sein Bramarbasieren prügeln lassen; es übertyrannt den Tyrannen. Ich bitte Euch, vermeidet das!") Auf genau diese Weise haben offensichtlich die ungeübten Handwerker in den Mysterienspielen den wütenden Herodes beim Bethlehemitischen Kindermord gespielt, auch den Termagant, ein überheblich auftretendes Schreckgespenst in den Spielen. Die Szenen wurden auf Wagen dargestellt, die man meist in der Karwoche auf verschiedene Plätze der Städte zog. Shakespeare hat diese bunten und frommen Spiele, die in Coventry (nahe bei Stratford) erst im späten 16. Jahrhundert verboten wurden, noch gekannt. Wir können das auch an der bildhaft-szenischen Art mancher seiner Anspielungen auf Kain, Judas, den Armen Lazarus oder den Verlorenen Sohn erkennen.

Entsprechendes gilt für die populären Bildvorhänge, die als billiger Ersatz für Wandteppiche und gewirkte Tapeten in den Gaststuben hingen und auf die Shakepeare sich an zwei Stellen bezieht. Für Falstaff (Henry IV Part One, IV,2) sind seine elenden Soldaten „ebenso zerlumpt wie Lazarus auf dem bemalten Tuch, wo ihm die Hunde des reichen Mannes die Geschwüre lecken“ (,as ragged as Lazarus in the painted cloth, where the glutton's dogs licked his sores“, nach Lk 16,19-31). Weiter scheinen sie ihm wie „hundertfünfzig abgerissene verlorene Söhne, die eben vom Schweinehüten und Abfall- und Schotenfressen kommen“ („a hundred and fifty tattered prodigals lately come from swine-keeping, from eating draff and husks"), womit erneut die bekannte, im 16. Jahrhundert oft dramatisierte Parabel vom Verlorenen Sohn (Prodigal Son) nach Lukas 15,11-32 einbezogen wird. Später (Henry IV Part Two, II,1) erwähnt Falstaff - neben „pretty slight drollery“ (kleinen lustigen Bildern) und „German hunting“ (Jagdszenen deutscher und niederländischer Herkunft) - eine ganze Vorhang-Serie mit der Geschichte vom Verlorenen Sohn. Mrs. Quickly, Falstaffs gutmütige Wirtin, der er viel Geld schuldet, soll sie verpfänden und durch „water-work“ („Wasserfarbenarbeit“, auf die Wand gemalte Vorhang-Imitationen) ersetzen, die mehr wert seien „als tausend solcher Bettvorhänge und mottenzerfressener Tapeten." Fallstaff bleibt übrigens - im Gegensatz zum Prinzen, der zu seinem Vater zurückkehrt - ein Verlorener Sohn. Doch der zum König gewordene Prinz will ihm helfen unter der Bedingung, daß er sich bessert und umkehrt. 
Ausgehend von konkreten Bibelbezügen und der poetischen Einbeziehung von Bildern auf der Wortebene habe ich einzelne Dramen in ihrem Handlungs- und Themenablauf beleuchtet. Wir haben dabei auch einige Gattungen betrachtet: die Tragödie mit der letztlich christlich fundierten Menschen- und Schuldauffassung wie in Hamlet (trotz tragischen Untergangs und antiker Einflüsse), aber auch mit dem Sturz des Frevlers wie in Macbeth oder wie in King Lear verbunden mit der tieferen, existentiellen Tragik des Menschseins und seiner Erlösungsbedürftigkeit im biblischen Sinn. Weiter beobachteten wir zunächst die Aufhellung der düsteren Rachetragödie in Hamlet, dann ihre völlige Überwindung in dem späten Märchenspiel The Tempest. An einem Problem Play wie The Merchant of Venice ließ sich erkennen, wie Shakespeare aus dem alten, bizarren Stoff der Fleischpfandgeschichte eine fast schon biblische Parabel macht, freilich auf seine Weise, nämlich im Gewand eines tragikomischen Spiels, das auch heitere Seiten hat. Nur einen kurzen Blick konnten wir auf Biblisches und Christliches in den Geschichtsdramen werfen.

Ich weiß, daß es in der universalen Welt Shakespeares viele andere Elemente als die biblischen gibt. Aber ich glaube, daß vieles bei ihm, vor allem seine Kernaussagen über den Menschen - besonders über das Leiden und das Vergeben - und die bis heute faszinierende, expressive Kraft seiner zentralen Sprachbilder erst im Rückgriff auf die Bibel möglich wurde, besonders auf das Neue Testament und die Psalmen, die er offenbar auswendig kannte. „Shakespeare und die Bibel“, so scheint mir, ist kein abwegiges oder zu belächelndes Thema; es ist von brennender Aktualität, gerade in unserer bibelfernen Zeit.

\section{Anmerkungen}

${ }^{1} \mathrm{Zu}$ nennen sind: Richmond Noble, Shakespeare's Biblical Knowledge and Use of the Book of Common Prayer as Exemplified in the Plays of the First Folio (1935) [noch heute richtungweisend, auch zu künstlerischen Funktionen der Bibelbezüge]; Ernst Th. Sehrt, Vergebung und Gnade bei Shakespeare (Stuttgart 1952) [über Shakespeares christliche Könige Henry V. und Henry VI., The Merchant of Venice, Measure for Measure und die Romanzen]; Peter Milward, SJ, Shakespeare's Religious Background (London 1973) [konfessionsgeschichtliches Gesamtbild mit Shakespeares Beziehung zu Liturgie, Bibel, Erbauungsliteratur, „elisabethanischem Atheismus" und Morallehren]; ders., Biblical Influences in Shakespeare's 
Great Tragedies (Bloomington, Indiana Univ. Press, 1987) [engagiertes Plädoyer für starken Bibeleinfluß]; James Black, Edified by the Margent. Shakespeare and the Bible. An Inaugural Lecture (Calgary 1979) [treffende Beispielanalysen zu Funktionen von Bibelbezügen]; Naseeb Shaheen, Biblical References in Shakespeare's Plays (Newark, Univ. of Delaware Press, 1999, ${ }^{2} 2002$ ) [kommentierte Listen, in Abgrenzung zu anderen Quellen; Standard, aber ohne weitergreifende Interpretation]; Steven Marx, Shakespeare and the Bible (N.Y., Oxford Univ. Press, 2000) [zu Charakteren und Themen von sechs Dramen]. Kritik an der Hervorhebung von Bibelelementen äußert Roland M. Frye, Shakespeare and Christian Doctrine (Princeton 1963). Ihm und seinen Nachfolgern ist zuzustimmen, wenn sich ihre Polemik gegen einseitig theologisierende Interpretationen und entsprechende Reduktionen der Shakespeare'schen Bedeutungsvielfalt richtet. Führt sie aber dazu, Biblisches überhaupt zu ignorieren und nur noch „Weltliches“ (wie Psychologie, Politik, dramatische Kunst, poetische Sprache usw.) zuzulassen oder auf endloser Ambiguität und Relativierung zu bestehen, so entsteht nur eine andere, säkularisierende Einseitigkeit oder eine die thematische Ebene auflösende Beliebigkeit, die weder der Reichweite und Werthierarchie noch dem erkennbaren Brennpunkt des jeweiligen Aussagespielraums gerecht wird. Ziel müßte eine Synthese von weltlicher und biblisch-religiöser Betrachtungsweise sowie von (begleitender) Mehrdeutigkeit und dominanter Bedeutung sein.

${ }^{2}$ Bibelbezüge erkannte erst Walter Whiter, A Specimen of a Commentary on Shakespeare (London 1794; ed. Alan Over u. Mary Bell, London 1967); er stand damit lange Zeit allein.

${ }^{3}$ Über das Book of Common Prayer wurde Shakespeare mit den Psalmen-Versionen der Great Bible (1539) und über die Schriftlesungen mit der Bishops' Bible (1568, rev. 1572) vertraut. Die Predigten an Sonn- und Feiertagen wurden aus dem Book of Homilies (ursprünglich zwei Bücher, 1547, 1563, zusammen 33 Predigten) vorgelesen, wenn, was oft der Fall war, kein lizenzierter Prediger mit einer eigenen Predigt verfügbar war. Späterer Nachdruck: Certain Sermons or Homilies Appointed to be Read in Churches in the Time of Queen Elizabeth of Famous Memory (London [1864] 1938). Vgl. dazu auch N. Shaheen (s. Anm. 2), S. 55-58.

${ }^{4}$ Übersicht über die englischen Bibelübersetzungen der Zeit und die wahrscheinlich von Shakespeare benutzten Versionen s. R. Noble (s. Anm. 2), S. 58-89, und N. Shaheen (s. Anm. 2), S.17-50.

${ }^{5}$ The Geneva Bible [Faksimile], ed. L. E. Berry (Madison, Wisconsin, 1969), Blatt iiii.

${ }^{6}$ Shakespeare-Zitate nach Shakespeare Complete Works, Riverside Edition, ed. G. B. Evans (Boston 1974 u.ö.). Deutsche Übersetzung nach Schlegel-Tieck, ed. A. Schlösser (Berlin 1975).

${ }^{7}$ Bibelzitate englisch, sofern nicht anders angegeben, nach der King James Bible 
(Authorized Version), zuerst 1611, deutsch nach der Einheitsübersetzung (Stuttgart 1980 u.ö.).

${ }^{8}$ In derselben Szene erscheint schon vorher der Gedanke an eine wohlwollend lenkende göttliche Macht: „There's a divinity that shapes our ends, / Rough-hew them how we will“ - (,[und das lehr' uns, /] Daß eine Gottheit unsre Zwecke formt, / Wie wir sie auch entwerfen.“) Vgl. Proverbs 16,9 „A man's heart deviseth his way: but the Lord directeth his steps.“ (Sprichwörter 16,9 „Des Menschen Herz plant seinen Weg, doch der Herr lenkt seinen Schritt.“)

${ }_{9}^{9}$ Auf Laertes' Bitte „Exchange forgiveness with me, noble Hamlet. / Mine and my father's death come not upon thee, / Nor thine on me.“ („Laß uns Vergebung wechseln, edler Hamlet! / Mein Tod und meines Vaters komm’ nicht über dich, / Noch deiner über mich!“) antwortet Hamlet: „Heaven make thee free of it! I follow thee.“ („Der Himmel mache / Dich frei davon! Ich folge dir.“, V,2). Zusätzliches Gewicht gewinnen diese Worte als Ausdruck der christlichen Gegenposition zu dem echohaft anklingenden Schrei der erbarmungslosen Menge bei der Verurteilung Jesu gemäß Matthäus 27,25: „His blood be on us and on our children“"(,Sein Blut komme über uns und unsere Kinder.“). - Zu Shylocks Unversöhnlichkeit in The Merchant of Venice s.u.

${ }^{10}$ Explizit ausgedrückt wird die Übernahme der Rache durch Gott in King Lear, IV,2: Albany: „This shows you are above, / You [justicers], that these our nether crimes / So speedily can venge!“ („Das zeigt, ihr waltet droben, / Ihr Richter, die so schnell der Erde Freveln / Die Rache senden."). Lear selbst formuliert (II, 4): „All the stor'd vengeances of heaven fall / On her ingrateful top!“ (Des Himmels aufgehäufte Rache fall' / Auf ihr undankbar Haupt“). Biblische Entsprechungen sind Deuteronomium 32,35 („To me belongeth vengeance, and recompence“) und, darauf basierend, Römer 12,19: „Dearly beloved, avenge not yourselves, but rather give place unto [God's] wrath; for it is written, Vengeance is mine: I will repay, saith the Lord.“ („Rächt euch nicht selbst, liebe Brüder, sondern laßt Raum für den Zorn [Gottes]; denn in der Schrift steht: Mein ist die Rache, ich werde vergelten, spricht der Herr." Vgl. auch Psalm 94,1-3, Offenbarung 6,10 und Lukas 18,7-8. - In blindem Racheverlangen dagegen verharren Othello (Othello, III, 3: „Arise, black vengeance“) und Shylock (s.u.).

${ }^{11}$ Einzelheiten s. Verf., „Shakespeares The Merchant of Venice. Literarische Aspekte und dargestellte Gerechtigkeit", in: Ulrich Mölk (Hrsg.), Literatur und Recht. Literarische Rechtsfälle von der Antike bis in die Gegenwart (Göttingen 1996), S. 150-185.

${ }^{12}$ Im Gegensatz zu dieser Bibelstelle nennt N. Shaheen (s. Anm. 2), S. 180, als erste Quelle Jesus Sirach (Ecclesiasticus) 35,26: „O how faire a thing is mercy in the time of anguish and trouble! It is like a cloud of rain that cometh in the time of a drought." Hier wird die Köstlichkeit des Erbarmens des Herrn in der Not 
mit einer Regenwolke verglichen, die zur Zeit der Dürre herankommt. Jedoch fehlt die für Shakespeare bildbestimmende Vorstellung des Herabträufelns. Eine stärkere Einwirkung dieser Stelle ist deshalb eher unwahrscheinlich.

${ }^{13}$ Exodus 21,23-25 „And if any mischief follow, then thou shalt give life for life, eye for eye, tooth for tooth, hand for hand, foot for foot, burning for burning, wound for wound, stripe for stripe.“ („Ist weiterer Schaden entstanden, dann mußt du geben: Leben für Leben, Auge für Auge, Zahn für Zahn, Hand für Hand, Fuß für Fuß, Brandmal für Brandmal, Wunde für Wunde, Strieme für Strieme.").

${ }^{14}$ Einzelheiten s. Verf., „Der ,Sturz des Mächtigen' in Shakespeares Richard II, Richard III und Macbeth“, in: ders. (Hg.), Der Sturz des Mächtigen. Abh. d. Akad. d. Wissenschaften in Göttingen, Phil.-Hist., III, 234 (Göttingen 2000), S. 203-247. 



\section{Die Heilige Schrift und die Schriftstellerei in Amerika: der Fall Melville}

DANIEL GÖSKE

\section{Die Weisheit des unchristlichen Salomo}

Jener Sterbliche, der mehr Freude als Schmerzen in sich spürt, [kann] nicht wahrhaftig sein - nicht wahrhaftig und [nicht] vollkommen. Dasselbe gilt für Bücher. Der wahrhaftigste aller Menschen war der Schmerzensmann, und das wahrhaftigste aller Bücher sind die Sprüche Salomos, und der Prediger Salomo ist aus dem feingehämmerten Stahl des Leids geschmiedet. ,Es ist alles ganz eitel.' Alles. Die Weisheit des unchristlichen Salomo hat diese mutwillige Welt noch nicht begriffen.

Dieses eigenartige Bekenntnis eines offenbar unorthodoxen Bibellesers steht im 96. Kapitel des wohl wagmutigsten und sprachmächtigsten Romans der klassischen amerikanischen Literatur - Herman Melvilles Moby-Dick von 1851. Es stammt von einem, der sich „Ismael“ nennt, obwohl er eigentlich nicht so heißt. „Nennt mich Ismael“ - mit dieser brüsken Aufforderung beginnt Melvilles Ich-Erzähler seine Geschichte, im ersten Satz des ersten Kapitels. Er stellt sich uns also vor als moderne Postfiguration, als Abbild oder geistiger Nachkomme von Stammvater Abrahams erstgeborenem Sohn. Man kennt die im ersten Buch Mose erzählte Geschichte: Da Abrahams Frau Sarai lange unfruchtbar geblieben ist, zeugt er auf ihr Drängen mit seiner ägyptischen Magd Hagar den Ismael. Als ihm dann aber Sarai wunderbarerweise einen Sohn namens Isaak schenkt, wird Ismael mit seiner heidnischen Mutter verstoßen, in die Wüste geschickt. Ein Engel prophezeit Hagar folgendes über Ismaels Zukunft: „Er wird ein wilder Mensch sein; seine Hand wider jedermann, und jedermanns Hand wider ihn; und er wird wohnen all seinen Brüdern zum Trotz" (1. Mose 16,12).

Melvilles Romanhandlung beginnt also mit einem Hinweis auf einen der großen Parias des Alten Testamentes. Der bibelkundige Erzähler gibt sich den Namen eines verlorenen Sohnes, eines schuldlos Ausgestoßenen und Entrechteten. Vor dem Hintergrund der Geschichte, die dieser 
neuzeitliche Ismael erzählen wird, wirkt die tröstliche Bedeutung seines hebräischen Namens („Gott hört“) abgründig ironisch. Es ist - sehr kurz gesagt - die Geschichte einer katastrophal endenden Walfangfahrt unter einem despotischen Kapitän namens Ahab, dem im Kampf gegen Moby Dick, einen riesigen weißen Wal, ein Bein weggerissen wurde. Der alte, wahnsinnige Kapitän sieht in dem vermeintlich „arglistigen“ Geschöpf ein Werkzeug des Schöpfers oder aber - das kann und will er nicht entscheiden - das Prinzip der gottlosen Natur oder die Vorstellung des Bösen schlechthin. In seiner rücksichtslos rachsüchtigen Jagd nach Moby Dick geht dieser Kapitän Ahab über Leichen, und die Reise endet in einer Katastrophe - dem Untergang des Schiffs und der gesamten Mannschaft. Nur der Ich-Erzähler wird gerettet.

Aber nicht weil er es verdient hätte. Und so verschmilzt am Schluß des Romans die Gestalt des verstoßenen Sohnes Ismael mit dem namenlosen Knecht aus dem Buch Hiob, der - als einziger Zeuge - nur überlebt, damit er seine Hiobsbotschaft überbringen kann. „Und ich allein bin entronnen, daß ich dir's ansagte" (Hiob 1,15-19) - so lautet das Motto des Epilogs. Die Figur Hiobs jedoch, die, wie Gerhard Lauer gezeigt hat, in der Erzählliteratur selten überzeugend gestaltet wurde, die Figur des leidenden Gerechten sucht man auch in diesem Roman vergeblich. Seine Frage nach dem Sinn menschlichen Leids aber stellt sich auch hier, und zwar in besonderer Schärfe.

Man muß also das Ende des Romans kennen, um den Anfang recht zu verstehen. Ismael erzählt seine Geschichte als der namenlose Zeuge vom Anfang des Buches Hiob. Im ersten Kapitel geht dieser Ismael - wie Melville selbst ein verarmter, arbeitsloser Sohn aus ehemals gutem Hause - wieder hinaus auf See, weil er ein Gezeichneter ist. Er hat „the horrors of the half-known life“ gesehen, „das ganze Grauen unseres kaum gekannten Lebens“, wie es im 58. Kapitel heißt. Er paßt nicht mehr in die bürgerliche Gesellschaft an Land, er fühlt sich ausgestoßen wie sein alttestamentlicher Namenspatron, ist wirklich ein „wilder Mensch“ geworden, dessen „Hand“ sich „wider jedermann" zu richten droht, wie er anfangs, nur halb scherzhaft, andeutet. Das ist die Ausgangssituation Ismaels als Figur in der Handlung. Als Erzähler seiner Geschichte aber mischt sich, Melville sei Dank, die lebensmüde Melancholie und das manchmal geradezu cholerische Rechtsempfinden dieses Ismael mit einem überbordenden Sprachwitz und einer mal derb humorvollen, mal subtil ironischen Spekulationslust, 
ohne die seine tragische Geschichte nur schwer zu ertragen wäre. Ismaels eingangs zitierte Anspielungen auf das prophetische Gottesknechtslied aus Jesaja 53 und die illusionslose Weisheitslehre der Sprüche und des Predigers Salomo sind jedoch bitterernst gemeint:

Der wahrhaftigste aller Menschen war der Schmerzensmann, und das wahrhaftigste aller Bücher sind die Sprüche Salomos, und der Prediger Salomo ist aus dem feingehämmerten Stahl des Leids geschmiedet. Die Weisheit des unchristlichen Salomo hat diese mutwillige Welt noch nicht begriffen.

In der „mutwilligen Welt“ der nicht nur nach Westen expandierenden, scheinbar grenzenlos optimistischen, zugleich bibelfesten und fortschrittsgläubigen Gesellschaft der USA um 1850 waren diese Sätze höchst unorthodox. Vielleicht sind sie es auch hier und heute, im alten Europa. Ganz sicher aber in einer Nation, die ihre Dollarscheine mit folgendem bekenntnishaften Motto bedruckt: „In God We Trust“ - Wir vertrauen auf Gott.

\section{Die Heilige Schrift in Amerika}

Die USA verstehen sich ganz offiziell als „A Nation under God“. Diese scheinbar fromme Selbstbezeichnung, die übrigens erst nach dem Zweiten Weltkrieg in den Fahneneid gelangte, wird von der großen Mehrheit der US-Amerikaner ganz selbstbewußt und sozusagen zweifelsohne verwendet. Das damit verbundene Sendungsbewußtsein befremdet oder empört heutzutage viele Menschen im alten Europa oder im noch älteren Morgenland, wenn es im Regierungshandeln der USA instrumentalisiert wird: in manichäischer, also schwarz-weiß malender Rhetorik (gegen das Reich oder die Achse des Bösen), in arroganter Außenpolitik (gegenüber den vermeintlich Vereinten Nationen) oder in ebenso „robusten“ wie riskanten Militäreinsätzen, gegen angebliche Schurkenstaaten und ihre Einwohner.

Das Selbstverständnis und Sendungsbewußtsein der USA, dem freilich eine mehr oder weniger starke isolationistische Strömung immer entgegenstand, wurde und wird von Befürwortern und Kritikern auf beiden Seiten des Atlantiks immer wieder auf biblische Texte zurückgeführt. So war das schon am Anfang der europäischen Besiedlung Nordamerikas. 
Die englischen Puritaner des 17. Jahrhunderts, die seit dem frühen 19. Jahrhundert - und zu Lebzeiten Melvilles - immer mehr zu Vor- und Gründungsvätern der späteren Republik stilisiert wurden, bezogen auf ihrem „Exodus“ in die Neue Welt die alttestamentliche Vorstellung vom auserwählten Gottesvolk auf sich. Und sie verstanden ihr im „Kanaan von Neuengland“ gegründetes Gemeinwesen als jene weithin sichtbare, vorbildhafte "Stadt, die auf einem Berge liegt“, von der Jesus in der Bergpredigt spricht (Mt 5,14). Das quasi urchristliche, in Grundzügen basisdemokratische Gesellschaftsexperiment der Puritaner konnte - als sozusagen real existierender, sittenstrenger Gottesstaat - im Zeitalter fortgesetzter europäischer Einwanderung, Besiedlung und Landnahme nicht gut gehen. Aber auf dem gut evangelischen Grundsatz, daß jeder und jede die frohe Botschaft selbständig aus der Heiligen Schrift herauslesen können soll, entwickelte sich bald auch in den weniger begüterten Bevölkerungsschichten Nordamerikas ein Bildungsstandard, der sogar im protestantischen Europa seinesgleichen suchte. Man hat diese Kultur daher zu Recht als eine „culture of the word“ bezeichnet - eine intellektuell durchaus anspruchsvolle Kultur des Wortes, in deren Zentrum die Lektüre und das Studium der Bibel stand.

Unterhaltsame Romanliteratur oder gar Theater waren im puritanischen Neuengland freilich lange verpönt, und die Bibel blieb als primärer Lesestoff und Vorlesebuch in Familie, Schule und Kirche bis weit ins 19. Jahrhundert (und in ländlichen Gebieten bis heute) konkurrenzlos. Diese Prägung ist in den Werken vieler amerikanischer Schriftsteller der beiden letzten Jahrhunderte deutlich erkennbar. Meist richtete sich aber ihre dichterische Kritik nicht so sehr gegen die Heilige Schrift selbst als gegen ihre Vereinnahmung durch Eltern, Moralapostel, Pädagogen, Prediger und Politiker - und das um so mehr, nachdem sich um die Wende zum 20. Jahrhundert in den USA ein rabiater evangelikaler „Fundamentalismus“ entwickelte (der Begriff stammt übrigens daher).

Schriftsteller aber sind keine Fundamentalisten. Sie rechnen und arbeiten mit der Mehrdeutigkeit von Worten und Geschichten, auch denen von Heiligen Schriften. Man könnte also den anti-fundamentalistischen Satz des Paulus aus 2. Kor 3,6 auf sie beziehen: „Denn der Buchstabe tötet, der Geist aber macht lebendig. "Viele der bedeutendsten amerikanischen Autoren fühlten sich von der Bibel zugleich angezogen und abgestoßen. Sie rieben sich an ihr und konnten doch nicht von ihr lassen. Emily 
Dickinsons zu Lebzeiten unveröffentlichtes Gedicht von 1882 mit der Anfangszeile "The Bible is a Antique Volume“ ist dafür ein gutes, nur scheinbar respektloses Beispiel.

Ein antiker Band ist die Bibel -

Verfaßt von verblichenen Männern

Angeregt von Heiligen Geistern

Themen - Bethlehem -

Eden - die alte Heimat -

Satan - der Kommandeur -

Judas - der große Verweigerer -

David - der Troubadour -

Sünde - ein berühmter Abgrund

Andere müssen ihn meiden -

„Gläubige“ Jungs sind sehr einsam -

Andere Jungen ,verloren“-

Würd' die Geschichte trällernd gesungen -

Kämen die Jungen herbei -

Orpheus Predigt war fesselnd -

Sie verdammte nicht -

Die kritische Lektüre der Bibel, die Dickinson und viele andere amerikanische Autoren des 19. Jahrhunderts auf ihre sehr selektiv bibelgläubige „Nation under God“ bezogen, setzte sich, stärker als im säkularisierteren Europa, in der klassischen Moderne und bis heute fort. Das lag auch daran, daß sich der evangelikale, wissenschaftsfeindliche Fundamentalismus der Jahrhundertwende über einige Kirchen oder Sekten vor allem im sogenannten „Bibelgürtel“ des ländlichen Mittelwestens und des Südens zu einer großen überkonfessionellen Bewegung auswuchs. In den vergangenen 30 Jahren hat sie nicht zuletzt durch fundamentalistische Fernseh- und Radiosender zunehmend an politischem Einfluß gewonnen.

Ohne Bibelkenntnisse sind also auch die heutigen USA nicht zu verstehen. Ahnungslose Touristen wundern sich z.B. oft über die vielen orientalisch klingenden Städtenamen: Bethesda, Canaan, Egypt, Galilee, Shiloh. Ohne Bibelkenntnisse wird man aber auch die Rhetorik mancher amerikanischer Politiker nur mit Entgeisterung wahrnehmen - schlimmer noch, man wird dieser Rhetorik nicht kritisch (also auch und gerade im 
Rückgriff auf die Bibel) begegnen können. Was aber für die öffentliche Rhetorik der USA zutrifft, gilt für die amerikanische Literatur in besonderer und besonders komplizierter Weise: Ohne die gründliche Kenntnis der englischen Bibel sind viele große Autoren, von Nathaniel Hawthorne, Walt Whitman, Emily Dickinson oder Mark Twain über die Modernisten T.S. Eliot, Ernest Hemingway und William Faulkner bis zu John Updike, Toni Morrison, Norman Mailer und vielen anderen Zeitgenossen nicht wirklich zu verstehen und zu genießen. Die Heilige Schrift ist das Grundbuch der Schriftstellerei in den USA.

\section{Moby-Dick und die Bibel}

Das gilt, wie schon anfangs angedeutet, auch für Herman Melvilles erzählerisches und lyrisches Werk. Die kenntlich gemachten Schriftzitate dieses bibelkundigen und theologisch versierten Dichters, aber auch seine verkappten Anspielungen und die ihm offenbar unbewußten Echos auf die Bibel gehen in die Hunderte. Sie stammen aus mehr als der Hälfte der 66 Bücher des Alten und des Neuen Testaments. Die meisten Schriftzitate entstammen den Büchern, die er in seinen Exemplaren der Bibel am meisten markiert und kommentiert hat: Matthäus, Jesaja, Johannes, die Korintherbriefe, der Psalter, Lukas, die Genesis, das Buch Hiob. Aber auch Melvilles Briefe und Tagebücher zeigen, wie sehr Sprache und Denken dieses durchaus zweifelsüchtigen Autors in der Wolle der King James Bible, also der klassischen englischen Bibel von 1611, gefärbt war.

Diese Bibelübersetzung prägt Melvilles Meisterwerk, den Moby-Dick von 1851, in ganz besonderer Weise. Viele Leser des englischen Originals oder seiner Übersetzungen ahnen nicht, wie sehr Melvilles Sprache von der King James Bible geprägt, ja gewürzt ist. In der neuen, preisgekrönten Übersetzung des Moby-Dick von Matthias Jendis, der die Echos aus der King James Version mit Hilfe der ebenso sprachmächtigen und kulturprägenden Fassung Luthers ersetzte, schmeckt man den Sauerteig der Heiligen Schrift aber allerorten durch. Ich möchte auf der Basis seiner Übersetzung nun an einigen Beispielen zeigen, wie sich Melvilles Phantasie an der Bibel entzündete.

Schon in den „Auszügen“ aus der Weltliteratur, die der eigentlichen Romanhandlung des Moby-Dick vorangestellt sind, deutet Melville an, wie sehr sein Buch nicht nur von der Sprache, sondern auch von den Geschichten, den Figuren und den Grundgedanken der Bibel zehrt. 
„Und Gott schuf große Walfische“ - auf das Zitat aus Genesis 1,21 mit dem Hinweis auf die zuerst erschaffenen und größten Geschöpfe Gottes folgen „Auszüge“ aus anderen biblischen Texten, die diesen Roman nachhaltig prägen: das Buch Hiob, die Geschichte von Jona, die Psalmen, der Prophet Jesaja. Die Bildlichkeit und der Rhythmus des Psalter, dessen „verblümte Worte“ - wie Luther schrieb - „so wohl und süße riechen“, klingen in den lyrischen Höhenflügen des Moby-Dick deutlich hörbar an - wie die Sprache der Propheten in den zornig sozialkritischen oder den visionären Passagen.

Für den Stoff dieses Walfangepos ist natürlich die Geschichte von Jona und dem Walfisch besonders einschlägig. Im 9. Kapitel gestaltet Melville in der zugleich wortgewaltigen und feinfühligen Predigt des Pastors Mapple ein Stück narrativer Theologie, das in der Literatur seinesgleichen sucht. Für den Erzähler ist dabei die Gattung der Predigt keine wohlfeile Verlautbarung von Heilsgewißheiten. Die Kanzel ist der Ort von Verkündigung als schriftgeleitete Erkundung des menschlichen Daseins. Das legt jedenfalls Ismaels einleitender Satz am Ende von Kapitel 8 nahe: „Wahrlich, die Welt ist ein Schiff am Anfang seiner Reise ..., und die Kanzel ist ihr Bug."

Was nun Father Mapple, selbst ein ehemaliger Seemann, im 9. Kapitel aus dem Buch Jona herausliest und was er wegläßt, ist ein Paradebeispiel für eine derart erkundende Verkündigung. Seine Predigt ist durchaus überraschend, ja unorthodox. Keine Rede von Jonas Strafpredigt in Ninive, von der Umkehr der vormals sündigen Stadt, von Gottes Erbarmen und Jonas „Verdruß“ darüber. Father Mapples Jona hat nichts vom eigentlich ja rachsüchtigen Eifer des biblischen Propheten, der sich als Strafprediger lächerlich vorkommt und seinem Gott vorwirft, daß er "gnädig [ist], barmherzig, langmütig und von großer Güte“ (Jona 4,2). Jona ist für Father Mapple erstens „ein Vorbild für ehrliche Reue“. Die zweite „Lektion“ seiner Schriftauslegung macht Jona zum entschiedenen Vorkämpfer der Wahrheit, des individuellen Gewissens. Damit wird der widerstrebende Prophet zum unerreichbaren Vorbild, nicht zuletzt für diesen gestrengen Pastor selbst. Am Schluß seiner Predigt bricht er in prophetische Wehrufe und Seligpreisungen aus, die ihre biblischen Muster deutlich durchhören lassen: 
Jona tat, was der Allmächtige ihn geheißen. Und was war das, Kameraden? Die Wahrheit zu predigen im Angesicht der Lüge! Das war's! Kameraden, das ist jene andere Lektion, und wehe dem Lotsen des lebendigen Gottes, der sie mißachtet. Weh dem, den diese Welt weg lockt von den Pflichten des Evangeliums! Weh dem, der Öl auf die Wogen zu gießen trachtet, wenn Gott sie zu einem Sturme aufwühlt! Weh dem, der zu gefallen trachtet statt zu erschrecken! ... Ja, weh dem, der (wie der große Lotse Paulus spricht) anderen predigt und dabei selbst verworfen wird!

Gegen Ende von Father Mapples Predigt vermischen sich jedoch seine Wehrufe mit einer Seligpreisung:

Freude gewinnt, wer in Fragen der Wahrheit kein Pardon gibt und alle Sünde tötet, niederbrennt und vernichtet, selbst wenn er sie unter den Roben und Talaren von Senatoren und Richtern hervorholen müßte. ... Freude gewinnt, wen die Wogen aller wütenden Meere des lärmenden Pöbels niemals vom sichren Kurs des Kiels der Zeiten abbringen können.

Und schließlich mündet Father Mapples Predigt in ein Gebet, das an die demütigen, kleinlauten Worte Hiobs aus Hiob 41 erinnert:

Ewige Freude und Lust wird gewinnen, wer mit seinem letzten Atemzug, wenn er sich niederlegt, sagen kann: O Vater ..., ich habe getrachtet, der Deine zu sein, mehr als von dieser Welt und mehr als der meine. Doch das ist nichts; ich lasse Dir die Ewigkeit; denn was ist der Mensch, daß er seinen Gott überleben sollte?

In der Bibel folgt das demütige Gebet des Hiob unmittelbar auf die großartige, furchterregende Schilderung des Leviathan, die Melville schon in den anfänglichen „Auszügen“ zitierte. Dieser Leviathan ist ein mysteriöses Monstrum. In den erklärenden Überschriften der Lutherbibel wird es als Krokodil, in denen der King James Bible aber - wie bei Melville - als Wal gedeutet. (Die Differenzen zwischen den klassischen Bibelversionen der binnenländischen Deutschen und der englischsprachigen Seefahrernationen machen die Arbeit des bibeltreuen Moby-Dick-Übersetzers 
nicht gerade leicht.) Ob Moby Dick nun ein Abkömmling des von Gott geschickten Jonas-Wals oder eher des Hiobswals ist, darüber streiten sich die Gelehrten, denn Melville hat den rätselhaften Leviathan der Bibel in seinem Roman noch mehr verrätselt. Moby Dick ist kein gewöhnlicher Wal. Er ist schneeweiß, ein Albino, ein Sonderling der Natur - oder ein Irrtum der Schöpfung. Für den von ihm versehrten Kapitän Ahab ist er die Perversion von Jonas' Wal - entweder ein Instrument oder aber die allegorische Verkörperung eines rachsüchtigen, bösen Gottes.

Für Ismael stammt der weiße Wal wohl eher vom „Hiobswal“ ab. Anders als Ahab deutet er ihn in seiner berühmten Meditation des 42 . Kapitels nicht als eindeutige Allegorie, sondern als vieldeutiges Symbol. Zwar häuft er anfangs zahlreiche Belege aus der Ethnologie sowie der antiken und christlichen Überlieferung an, die das Weiß als Zeichen der Reinheit des Gotteslamms, der „Unschuld der Braut, der Milde des Alters" ausweisen. Und er zitiert die Offenbarung Johannis, die von den Erlösten erzählt, wie sie, „angethan mit weißen Kleidern, vor dem großen weißen Stuhl und dem Heiligen stehen, der dort sitzet, [weiß wie] Wolle“ (Offb Joh 4,4 und 1,13-14). Aber, so fährt Ismael fort, es „lauert doch in der innersten Vorstellung von diesem Farbton etwas Ungreifbares, das die Seele stärker in Panik versetzt als jenes Rot des Blutes, das soviel Furcht erregt.“ Und am Ende des 42. Kapitels droht ihm „das Weiß“ zur „farblosen Allfarbe der Gottlosigkeit“ zu werden, zur unheimlichen Chiffre eines unerforschlichen Kosmos, der nicht mehr als Schöpfung erkennbar ist:

Ist es so, daß das Weiß durch seine Unbestimmtheit die herzlose Leere und unermeßliche Weite des Weltalls andeutet und uns so den Gedanken an Vernichtung wie einen Dolch in den Rücken stößt, wenn wir in die weißen Tiefen der Milchstraße blicken? Oder ist es so, daß das Weiß seinem Wesen nach nicht so sehr eine Farbe ist als vielmehr die sichtbare Abwesenheit von Farbe und zugleich die Summe aller Farben, und daß deshalb eine weite Schneelandschaft dem Auge eine so öde Leere bietet, die doch voller Bedeutung ist - eine farblose Allfarbe der Gottlosigkeit, vor der wir zurückschrecken?

Und wenn wir jene andere Theorie der Naturwissenschaftler bedenken, daß alle anderen Farben dieser Erde ... nur arglistige Täuschungen sind, die den Dingen nicht wirklich innewohnen, sondern ihnen bloß 
von außen aufgetragen sind, so daß die ganze vergötterte Natur sich in Wahrheit anmalt wie die Hure, deren verlockende Reize nur das Leichenhaus in ihr verdecken ... - wenn wir das alles erwägen, so liegt das gichtbrüchige Universum vor uns wie ein Aussätziger, und wie ein mutwilliger Reisender in Lappland, der sich weigert, farbige und färbende Augengläser zu tragen, so starrt sich der elendige Ungläubige blind, da er den Blick nicht vom endlosen weißen Leichentuche wenden kann, das alles, was er ringsum sieht, verhüllt. Und für all dies war der Albinowal das Symbol.

Es ist bezeichnend, daß Ismael anders als Ahab diese abgründigen Gedanken nicht als steile Thesen formuliert, sondern als drängende Fragen. Und es ist charakteristisch für Melville, daß es nicht allein die neuen naturwissenschaftlichen Theorien über "die unermeßliche Weite des Weltalls“ oder das Wesen der Farben sind, die die von Ismaels Zeitgenossen so „vergötterten Natur“ als „,arglistige Täuschung“ erscheinen lassen. Hinter dem Bild der Natur als geschminkter „Hure, deren verlockende Reize nur das Leichenhaus in ihr verdecken", tauchen schemenhaft die Warnungen des weisen, „unchristlichen“ Salomo auf. Das siebte Kapitel der Sprüche Salomos erzählt nämlich die Geschichte eines „närrischen Jünglings“, dem „ein Weib im Hurenschmuck“ auflauert. „Listig, wild und unbändig“, verführt sie ihn und raubt ihm das Leben, denn: „Ihr Haus sind Wege zur Hölle, da man hinunterfähret in des Todes Kammern." Vor dem Hintergrund dieses uralten Textes entspräche Salomos „närrischer Jüngling“ jenem „elendigen Ungläubigen“, der sich (wie der „mutwillige Reisende“ im schneebedeckten Lappland) am „gichtbrüchigen Universum“ blind starrt. Ismael spürt diese Versuchung, schreckt aber, unentschieden zweifelnd, davor zurück. Das will und kann Kapitän Ahab nicht, und deshalb kommt es zur Katastrophe.

An diesem berühmten Kapitel 42 kann man schön sehen, wie sehr sich bei Melville alte biblische Spurenelemente mit anderen Textbausteinen und Wissenssplittern zu einer eminent modernen, spekulativen poetischen Prosa vermischen. Häufig sind es gerade die biblischen Anklänge, ihre ausdrucksstarke Bildlichkeit und klangvollen Rhythmen, die Melvilles Sprache so zum Klingen und Leuchten bringen. Sein Werk ist ein Paradebeispiel dafür, auf welchen Ebenen die Heilige Schrift die Schriftstellerei bereichern kann. Das gilt auch für den Bereich der Figu- 
rendarstellung. Am Beispiel des Erzählers Ismael und des monströsen „Titelhelden“" Moby Dick haben wir das schon gesehen. Aber auch viele der Nebenfiguren verweisen auf biblische Vorbilder. Melville nimmt sie freilich nicht „buchstäblich“, sondern wandelt sie ab und kombiniert sie mit anderen literarischen oder zeitkritischen Anspielungen.

Da ist zum Beispiel ein gewisser Elias, der im 19. Kapitel auftritt, das denn auch „Der Prophet“ betitelt ist. Anders als der biblische Gegenspieler des bösen Königs Ahab im 1. Buch der Könige aber begnügt sich dieser halbverrückte Prophet mit ominösen Andeutungen, um Ismael und seinen Busenfreund, den heidnischen Harpunier Queequeg, davon abzubringen, auf der Pequod, dem Walfänger des berüchtigten Kapitäns Ahab, anzuheuern. Auch Bildad, der Schiffseigener der Pequod, ist einem alttestamentlichen Vorbild nachgebildet. Sein Name erinnert an einen der drei Ratgeber, die Hiob mit frömmelnden Vorwürfen „plagen und peinigen“, anstatt brüderlich oder freundschaftlich sein Leid mit ihm zu tragen (Hiob 16,2). Bei Melville ist dieser Bildad ein ebenso geschäftstüchtiger wie (scheinbar) frommer Quäker. Zynisch zitiert er - ausgerechnet! - die Bergpredigt, um Ismaels „Schätzteil“ (also seinen Anteil am Ertrag der bevorstehenden Walfangreise) so klein wie möglich zu halten: „Ihr sollt euch nicht Schätze sammeln auf Erden, da sie die Motten und Rost fressen. Sammelt euch aber Schätze im Himmel. Denn wo euer Schatz ist, da ist auch euer Herz" (Mt 6,19-21). Nur Bibelkundige wissen, daß der bigotte Bildad in seiner fromm kaschierten Gier nach Gewinnmaximierung sich damit selbst das Urteil spricht. Die von ihm zweckentfremdete Bergpredigt gehörte übrigens auch für Melville zum untastbaren Kern des Buchs der Bücher. Und daß er - wie viele seiner Schriftstellerkollegen - die Heilige Schrift auch als große Literatur las, wird in einem Brief aus dem Jahr 1849 deutlich, in dem er - nur halb scherzend - seine Begeisterung für Shakespeare, den „göttlichen William“, so äußert:

Ah, er steckt voller Bergpredigten, \& ist, fürwahr, beinahe so sanftmütig wie Jesus. Einen solchen Mann nenne ich inspiriert. Ich stelle mir vor, daß Shakespeare jetzt neben [den Erzengeln] Gabriel, Raphael und Michael im Himmel sitzt.

Zurück zu den biblisch inspirierten Gestalten von Melvilles Roman, deren wichtigste literarische Quelle - nach der Bibel - übrigens Shakespeares 
Dramen sind. Neben Ismael und dem weißen Wal selbst ist Kapitän Ahab der wohl komplizierteste Fall einer Amalgamierung von biblischen und anderen Figuren der Weltliteratur. Der Name des ,gottlosen, gottgleichen“ Kapitäns der Pequod erinnert natürlich an den hochfahrenden, götzendienerischen Herrscher Israels, von dem der bibelfeste Ismael aus dem 1. Buch der Könige gelernt hat, daß „er tat, was dem Herrn übel gefiel“. Auch die Warnungen des biblischen Propheten Elias fruchten nichts. Nach Ahabs Tod in der Schlacht, so heißt es in 1. Könige 22, „leckten die Hunde sein Blut (es wuschen ihn aber die Huren)“. Es kümmert Melville wenig, daß in Amerika natürlich schon damals niemand nach diesem bösen König hieß. Für ihn und seine Leser stand der Name für die gottlose Hoffart eines gefährlichen Despoten. Dennoch ist sein Kapitän Ahab, der im 113. Kapitel die Harpunen im Blut seiner heidnischen Harpuniere im Namen des Teufels tauft und sich zum Sonnen- und Feueranbeter stilisiert, kein eindimensionaler Bösewicht. Er ist auch ein Leidender und ein Wahrheitssucher. Deshalb hat er auch Anspruch auf die Anteilnahme, die Sympathie des Erzählers Ismael - und die der Leser, die er an andere "große, gottlose, gottgleiche" Widersacher der Weltliteratur erinnert.

$\mathrm{Zu}$ diesen Figuren, die man schemenhaft hinter dem alten Kapitän ausmachen kann, gehört z.B. die Gestalt des Prometheus, auf die Ahab - „stolz wie ein griechischer Gott“- später selbst Bezug nimmt (Kap. 108). Hinzu treten Spurenelemente von Shakespeares Hamlet, Jago, Macbeth oder Lear, Christopher Marlowes und (vielleicht) Goethes Faust, Byrons Helden und die Schurken der britischen Schauerromantik. Und noch einer kommt dazu: der dämonische Seemann Jackson aus Melvilles früherem Roman Redburn (1849). Der junge Erzähler beschreibt ihn, wieder im Rückgriff auf die Bibel, als „grausigen Desperado“, als einen „Kain der See, auf dessen gelber Stirn ein unerforschlicher Fluch sein Mal eingebrannt hatte.“ Aber er ergänzt: „es schien mehr Leid als Verruchtheit in [diesem Jackson] zu stecken, und seine Verruchtheit schien seinem Leid zu entspringen" (Kap. 22). Auch hinter dieser Anspielung des Schriftstellers Melville steckt eine unorthodoxe Rückfrage an die Heilige Schrift: warum sah Gott das Brandopfer Kains „nicht gnädiglich an“ (1. Mose 4,5)? Inwiefern stammte der Brudermörder, wie es im 1. Johannesbrief heißt, „von dem Bösen“ (1. Joh 3,12)? Viele biblische Echos in Melvilles Werk stellen die Heilige Schrift derart gründlich in Frage und setzen sich so mit ihrer Deutung und Deutungsgeschichte auseinander. 
IV. Billy Budd und das „lexicon based on Holy Writ“

Spuren dieser Auseinandersetzung entdeckt man auch in Melvilles Spätwerk allenthalben: in seinem Gedichtband von 1866, der auf das Grauen des amerikanischen Bürger- und Bruderkriegs antwortet, oder in seinem viele tausend Verse umfassenden Epos Clarel von 1876. Da wandert ein junger amerikanischer Theologiestudent durch das von Glaubenskriegen zerrüttete, unheilige Heilige Land Palästina, auf der Suche nach Sinn und Wahrheit, die er nicht findet. Selbst da, wo der Lyriker Melville über die Literatur als Ersatz- oder besser Kunstreligion schreibt, bleibt er biblischen Mustern verhaftet. Das belegt sein spätes Gedicht mit dem Titel Art:

\section{Kunst}

Oft träumen wir in müßiger Stunde

Von manch einem kühnen, luftigen Plan.

Doch um Form zu geben, Leben zu schaffen,

Muß sich gar Ungleiches paaren und treffen:

Schmelzende Flammen - kühlende Winde;

Bedrückte Geduld - freudige Kraft;

Demut - jedoch auch Hoffart und Stolz;

Fleiß und Instinkt; Liebe und Haß;

Frechheit und Andacht. All das muß verschmelzen

Mit Jacobs Seele in mystischer Brunst,

Um mit dem Engel zu ringen - der Kunst.

Wahre Kunst, so der alte Melville, entspringt gegensätzlichen Impulsen: demütiger Geduld und stolzer Kraft, spontanen Instinkten und fleißigem Studium, Liebe und Haß, Frechheit und Andacht. Diese müssen im Herzen des Künstlers verschmelzen, erst dann kann er, wie Jakob am Jabbok in Genesis 32, das Ringen mit dem rätselhaften Abgesandten Gottes wagen.

Melville ließ das Gedicht wenige Monate vor seinem Tod im September 1891 drucken, in einem privat finanzierten Bändchen mit einer Auflage von 25 Stück. Zu dem Zeitpunkt hatte die Denk- und Redeweise der Naturwissenschaften in die öffentliche Debatte und also auch die Sprache der Literatur der USA Einzug gehalten und das „lexicon which is based on Holy Writ", also das auf der Heiligen Schrift basierende Wörterbuch, weitgehend verdrängt. Das jedenfalls meint der Erzähler von Melvilles 
letztem Werk, der zum Zeitpunkt seines Todes noch nicht ganz vollendeten Novelle Billy Budd.

Mit einem Blick auf dieses besonders ergreifende Beispiel seiner lebenslangen schriftstellerischen Auseinandersetzung mit der Heiligen Schrift möchte ich schließen. Im Zentrum dieser Erzählung, die Benjamin Britten um $1950 \mathrm{zu}$ einer wundervollen Oper inspirierte und den alten Thomas Mann ebenso begeisterte wie die jüdische Philosophin Hannah Arendt - im Zentrum dieser späten Problemnovelle steht - wiederum - das „mystery of iniquity“. Melville zitiert hier die gelehrte Übersetzung der King James Version von 2. Thessalonicher 2,7; Luther übersetzt die Stelle, dem Volk aufs Maul schauend, mit „das Geheimnis der Bosheit“. Dies Geheimnis, das Melville schon immer faszinierte, liegt der Novelle Billy Budd zugrunde.

Ihre scheinbar simple Oberflächenhandlung, die an Bord eines britischen Kriegsschiffs zur Zeit der französischen Revolution spielt, ist rasch skizziert. Billy Budd ist ein schöner, gutmütiger, allseits beliebter Matrose, den ein verschlagener Offizier namens Claggart allerdings mit abgründigem und unergründlichem $\mathrm{Haß}$ verfolgt, ohne daß dieser es in seiner unschuldigen Einfalt merkt. Als Claggart ihn im Angesicht des hochgeachteten und feinfühligen Kapitäns Vere plötzlich verschwörerischer Umtriebe bezichtigt, ist Billy entgeistert. Eine rätselhafte Sprachhemmung hindert ihn, auf Claggarts teuflische Anklage zu antworten, und er erschlägt den Versucher mit einem einzigen Fausthieb. Nach dem Kriegsrecht steht darauf die Todesstrafe, und Kapitän Vere läßt Billy, obwohl er von seiner Unschuld überzeugt ist, standrechtlich aburteilen und hängen.

Vorher jedoch bestellt er den Todgeweihten allein zu sich. Diese Szene wird aber eigenartigerweise nicht erzählt. Sie bildet das rätselhafte, gleichsam leere Zentrum der ganzen Geschichte. Vielleicht, so spekuliert der Erzähler, habe der Kapitän den jungen Matrosen zärtlich umarmt, wie es Abraham mit Isaak getan haben mag. Kurz vor seiner Hinrichtung jedenfalls segnet der Verurteilte seinen Richter. „God bless Captain Vere!" ruft Billy aus und verhindert so, daß die Mannschaft gegen das als ungerecht empfundene Urteil revoltiert. Die Hinrichtung Billys an der Kreuzrah des Großmastes, im Original durchaus subtil als mysteriöses und mystisches Ereignis gestaltet, erinnert zugleich an Christi Kreuzigung und Himmelfahrt (engl. ,ascension“). Man könnte die Stelle etwas verdeutlichend so übersetzen: 
Im nämlichen Augenblicke geschah es, daß das tief im Osten hängende, dunstige Vlies von einem sanften Schein durchleuchtet wurde wie das Vlies des Gotteslamm in mystischer Schau, und gleichzeitig fuhr Billy, von der dicht verkeilten Masse emporblickender Gesichter beobachtet, gen Himmel und - auffahrend - empfing er das volle Rosenrot des Morgens.

In einer späten Überarbeitung hatte Melville im Manuskript den ursprünglich vorgesehenen hebräischen Begriff für die Präsenz Gottes („Shekinah“) durch das unspezifischere Wort „rose of the dawn“ (also etwa: „Morgenrosenröte“) ersetzt. Dennoch bleibt die Hinrichtungsszene mit ihren Anspielungen auf die Kreuzigung und Himmelfahrt Jesu und das Gotteslamm der Offenbarung mit christlichen Deutungsangeboten aufgeladen. Bei Melvilles letzter Erzählung handelt es sich jedoch nicht um ein frommes, allegorisches Mysterienspiel. Kapitän Vere ist nicht Abraham oder Pilatus oder gar Gottvater selbst. Nach dem Kriegsrecht hätte Vere den Fall seinem Vorgesetzten zur Entscheidung vorlegen können, was er aber unterließ. Und er ist offenbar traumatisiert von seinem Urteilsspruch. Als er kurz darauf in einer Seeschlacht mit einem französischen Kriegsschiff namens Athée (oder Athéiste) tödlich verwundet wird, stirbt er mit dem Namen Billy Budds auf den Lippen.

Auch der hinterhältige Claggart ist keine eindeutige Teufelsgestalt. Der Erzähler nennt Claggarts gleichsam natürliche Verworfenheit („,a depravity according to nature") auch eine Krankheit: „the mania of an evil nature“. Aber was heißt das? Ist das nicht ein Widerspruch? An anderen Stellen wird angedeutet, daß der Offizier den schönen Matrosen haßt, weil er ihn nicht lieben kann oder darf, obwohl er wie Billy von unbekannter, offenbar edler Abkunft ist. Claggart spielt erst die Rolle des Versuchers und dann die des Verräters Judas. Aber Billy ist nicht Jesus, der - unschuldig und im Bewußtsein seiner Aufgabe - die Sünden der Welt auf sich nimmt. Der schöne Matrose ist auch nicht Isaak, denn Abrahams Sohn war unschuldig, und er wurde eben nicht geopfert. Eher gleicht Billy dem ursprünglichen Menschen, vor dem Sündenfall. Zu Beginn beschreibt der Erzähler ihn als einen „aufrechten Barbaren, so wie Adam es gewesen sein mochte, bevor die weltgewandte Schlange sich in seine Gesellschaft schlängelte“. Anderswo heißt es von Billy, daß er mit dem 
Fatalismus eines Tieres ausgestattet ist. Sein Tod mag an Jesu Hinrichtung erinnern, sein Leben und seine Natur nicht.

Die Novelle wirft also viele Fragen auf. Zum ersten und letzten Mal in Melvilles Werk erscheint mit Vere die Figur des Schiedsrichters zwischen Gut und Böse. Aber warum kann dieser Richter nicht zweifelsfrei Recht sprechen? Wie wäre die Schuld Claggarts und Billys gerecht zu bewerten und zu sühnen? Worin liegt das Geheimnis der Bosheit, das mysterium iniquitatis, das mit Claggarts Tod ja nicht gelüftet ist? Und was ist mit dem Kriegsrecht, dem sich Vere unterwirft? Gleicht es dem unerbittlichen mosaischen Gesetz, ohne dessen starre Regeln und harte Sanktionen auf Erden kein Staat zu machen ist? Oder dem rätselhaften Ratschluß Gottvaters, seinen Sohn zu opfern, von dem das Neue Testament spricht?

\section{Kunst und Glaube - Heilige Schrift und Schriftstellerei}

Sie merken, ich ziehe mich hier aus der Affäre, indem ich - ganz wie Ismael im 42. Kapitel des Moby-Dick - Fragen über Fragen stelle. Aber Melvilles Werk legt das nahe, auch und gerade weil es die Bibel nicht als Fundus für dogmatische Glaubenssätze verwendet, sondern sie - im besten Sinn - in Frage stellt. Melvilles Werk ist also nicht mehr, aber auch nicht weniger als ein fesselndes Beispiel für die literarische „Säkularisation als sprachbildende Kraft". (So lautet der thesenhafte Buchtitel eines Göttinger Gelehrten, der mich schon als Student sehr beeindruckt hat.) Freilich muß man den Begriff der Säkularisation stets differenziert verwenden. Das lehren zahlreiche Beispiele, von Shakespeare bis Salman Rushdie, von Andreas Gryphius bis Bertold Brecht oder Thomas Mann. Nur fundamentalistische Eiferer werden den Umgang dieser und anderer Schriftsteller mit den Heiligen Schriften der großen Buchreligionen als schändliche Entweihung verurteilen.

Auch Melvilles dichterische Ausbeutung des Buchs der Bücher ist nicht die billige Polemik eines gebildeten Verächters der Religion. Es ist die ernsthafte Suche eines Menschen, der zeitlebens mit der Bibel Umgang pflegte, sich auch an ihr wund rieb. Ob und inwiefern und wann Melville "gläubig" war, wissen wir nicht. Viele aus seinem Umkreis haben immer wieder daran gezweifelt; er wohl auch. In dem Neuen Testament, das er 1860 auf seine letzte große Seereise um Kap Hoorn mitnahm, markierte er Paulus' ermutigenden Rat im Römerbrief: „Hast thou faith? Have it 
to thyself before God“ - bei Luther: „Hast Du den Glauben, so habe ihn bei dir selbst vor Gott. Selig ist, der sich selbst kein Gewissen machet in dem, was er für recht hält.“ Melville kritzelt an den Rand: „Der einzig mögliche Glaube - der eigene." Melvilles Freund und Kollege Nathaniel Hawthorne, der ihn vielleicht am besten kannte, notierte nach einem ihrer letzten Gespräche voller Verwunderung: „Weder vermag er zu glauben, noch kann er sich in seinem Unglauben behaglich einrichten; und er ist $\mathrm{zu}$ aufrichtig und zu couragiert, um nicht das eine oder das andere immer wieder zu versuchen." Spuren dieser Versuche findet man nicht nur in Melvilles Briefen und Tagebüchern, sondern immer wieder auch in seinem literarischen Werk, und dies vor allem da, wo die Verse der Bibel hindurchschimmern. In dem Maß, in dem ihm die optimistische Menschheits- und Fortschrittsgläubigkeit seiner Zeitgenossen naiv und verlogen vorkam, suchte er offenbar in den Heiligen Schriften der Juden und Christen nach Zeugen und Belegen einer aufrechten Haltung, die die prinzipielle Erbärmlichkeit der Menschen - und auch ihre Erbarmungswürdigkeit - nicht ausblendete. Denn, wie Ismael sagt:

Der wahrhaftigste aller Menschen war der Schmerzensmann .... Jener Sterbliche, der mehr Freude als Schmerzen in sich spürt, [kann] nicht wahrhaftig sein - nicht wahrhaftig und [nicht] vollkommen. Dasselbe gilt für Bücher. 



\title{
„Ein Fest der Erzählung“ \\ Thomas Manns Romanzyklus Joseph und seine Brüder
}

\author{
IRMELA VON DER LÜHE
}

Gern und regelmäßig hat Thomas Mann über seine persönliche Bildungs- und intellektuelle Entwicklungsgeschichte Auskunft gegeben; mit gleichsam autoritärer Attitüde hat er seinen Lesern, Kritikern und schließlich auch der Wissenschaft Deutungsvorschläge für sein Werk gemacht. Autor und Künstler tragen bei Thomas Mann durchaus die Züge eines „,alter deus“, eines gottähnlichen Schöpfers, dem folglich auch die Deutungshoheit über das von ihm Geschaffene gebührt. Leser, Kritiker und Wissenschaft tun gut daran, sich über derartige Selbsterhöhungsansprüche hinwegzusetzen, aber sie wären zugleich schlecht beraten, würden sie die Selbstaussagen von Autoren/innen zu ihrer Person und ihrem Werk gänzlich ignorieren.

Gerade für Thomas Manns episches „Monstrum“ (Sk, 170), für den - wie üblich als „Novelle“ (ebd.) geplanten und in einer Zeitspanne von annähernd 16 Jahren zu einer vierbändigen Romanfolge angewachsenen - Joseph erweist sich der Rückgriff auf zumindest einige der interpretatorischen Selbstermächtigungen Thomas Manns als unbedingt zwingend. Sie betreffen Thomas Manns Verhältnis zur Religion im Allgemeinen und zur Bibel im Besonderen und betreffen damit das Thema dieser Vortragsreihe.

So fraglos die weltliterarische Relevanz der Bibel ist, so singulär ist ihre Präsenz in einem Werk der Weltliteratur, eben in Thomas Manns Tetralogie. Ihren Helden, Joseph, hat Thomas Mann als „religiösen Hochstapler“, als narzisstischen Künstler und schließlich als Repräsentanten und Retter religiöser Humanität entworfen. Damit aber hat der Thomas Mann'sche Joseph wenig gemein mit der Figur, die wir aus der biblischen Erzählung kennen. Umgekehrt wiederum hat diese Erzählung selbst wohl niemals in der Weltliteratur eine solche Ausgestaltung (Amplifikation) und ausufernde Ausweitung erfahren wie durch Thomas Mann, der denn auch nicht zögerte, von seinem „spleenigen Epos“ (Sk, 92) zu sprechen, das man seiner Länge wegen durchaus auch „[1]angweilig“ (Sk, 144) nennen dürfe: „, [a]ber es gibt so viele verschiedene Arten von Langweiligkeit, und 
man wird sagen müssen, dass diese einzigartig ist, auch dass sie ... den besseren Arten beizuzählen ist" (ebd.).

Auch ihm selbst, der zwischen Dezember 1926 und August 1936 an den ersten drei Bänden schrieb, unterbrochen von Vorträgen, Aufsätzen und literarischen Arbeiten wie der Novelle Mario und der Zauberer (1930) und aufs äußerste bedrängt durch die politischen Ereignisse seit 1933, der nach dem "Goethe“-Roman (Lotte in Weimar, 1939) erst 1940 die Arbeit am Joseph wieder aufnahm, um sie schließlich in Kalifornien (unter biblischen Palmen) im August 1943 abzuschließen, Thomas Mann selbst ist die Arbeit an seinem „biblischen Roman“ nicht selten schwer, ja manchmal sogar langweilig geworden. Wenn man den Briefen glauben darf, so half auch in diesem Falle die Orientierung an großen Vorbildern. Gegen das lästige Gefühl der Müdigkeit angesichts des immer noch nicht absehbaren Endes von Band 4 ruft er sich Tolstois Aussage in Erinnerung: „Die dumme, langweilige Anna Karenina, die ich nun einmal fertig machen muss" (Sk, 206).

Spleenig, langweilig, aber natürlich als Sprachkunstwerk, als „Meisterwerk synkretistischer Beziehungskunst" (Heftrich, 453) ist Thomas Manns Joseph-Tetralogie vor allem in der Sicht seines Verfassers ein Menschheitsbuch; ein Werk, das nicht nur von den Anfängen der Menschheit handelt, sondern das die Schöpfungs- und biblische Urvätergeschichte im Horizont der Moderne, im Angesicht ihrer Katastrophen erzählt: des Ersten Weltkriegs und seiner Folgen, der Hitler'schen Machtergreifung, des Zweiten Weltkriegs und des damit drohenden Untergangs von $\mathrm{Hu}$ manität und Zivilisation. Und nicht zuletzt erzählt Thomas Mann von den israelitischen Urvätern, von jüdischer Geschichte und Überlieferung zu einem Zeitpunkt, da der Massenmord an den europäischen Juden geplant und exekutiert wurde.

Das epische „Monstrum“ verdankt sich in mehrfacher Hinsicht einem ubiquitären Mangel, es entstammt und artikuliert eine globale Krisenerfahrung, die an die Wurzeln reicht und angesichts derer die große Erzählung, der moderne Roman auf diese Wurzeln, auf die Ursprünge der göttlichen Schöpfung und der Menschheitsgeschichte zurückgeht. Freilich geschieht dies mit spezifisch modernen Mitteln, unter Beiziehung einer Fülle von Quellen und Materialien, Dokumenten und so genannter Sekundärliteratur. 
Thomas Manns Joseph entstammt, wenn nicht gänzlich, so doch zuvörderst, einer kultur- und mentalitätsgeschichtlichen, einer historischpolitischen Krisen- und Katastrophenerfahrung. Zugleich liegt ihm die Wahrnehmung eines spezifisch ästhetischen, eines narrativen Mangels zugrunde. Diesen hat nach eigenem Bekunden Thomas Mann immer empfunden, wenn er als Knabe die biblische Geschichte vom Verkauf, Aufstieg und Wiederfinden des verhassten Bruders hörte. Im Lebensabriß aus dem Jahre 1930 erläutert der damals 55-jährige Autor den erzählerischen Mangel der biblischen Josephs-Geschichte bezeichnenderweise mit Goethes Worten aus Dichtung und Wahrheit.

Goethe, den Thomas Mann zustimmend zitiert, schreibt: „Höchst anmutig ist diese natürliche Erzählung, nur scheint sie zu kurz, und man fühlt sich berufen, sie ins einzelne auszumalen" (Sk, 37). In der Tat fühlte sich Thomas Mann nicht nur berufen, sondern entschieden herausgefordert, nicht lediglich zur narrativen Ausmalung einer biblischen Erzählung, sondern zur epischen Integration heterogener Überlieferungsstränge, divergenter fachwissenschaftlicher Forschungen aus Orientalistik, Ägyptologie, Religionsgeschichte, Theologie und zeitgenössischer Kulturanthropologie. Der Autodidakt und wissenschaftliche Dilettant, der weder Abitur gemacht noch ein Studium absolviert hatte, hat für die Josephs-Tetralogie wie bekanntlich für alle seine Werke ein enormes Lesepensum absolviert: Darunter war vor allem Alfred Jeremias' große Studie Das Alte Testament im Lichte des Alten Orients von 1916, die auf der Grundlage der seinerzeit umwälzenden archäologischen Neuentdeckungen im vorderasiatischen Raum in der sumerisch-babylonischen Kultur, vor allem in der Astral-Religion, die Hauptquelle für die biblischen Mythen, ja insgesamt für die antike Kultur sah. Neben Jeremias als Vertreter des so genannten Panbabylonismus spielte Edgar Dacqués Urwelt, Sage und Menschheit (1926), spielte die höchst problematische Arbeit von Oskar Goldberg (der im Doktor Faustus als Chaim Braisacher parodiert wird) über Die Wirklichkeit der Hebräer (1925) eine Rolle, und schließlich die Schriften des akademischen Außenseiters und Matriarchatstheoretikers Johann Jakob Bachofen, dessen Mythos von Orient und Okzident (1926, eingeleitet von Alfred Baeumler!) Thomas Mann ebenso faszinierte wie provozierte. 
Die Liste der Namen und Texte ließe sich mühelos erweitern. In ihr firmiert der intellektuelle und wissenschaftliche Zeitgeist der 20er bis 40er Jahre; auf ihr rangieren Freuds Schriften, vor allem der Aufsatz Totem und Tabu (1913) an vorderster Stelle. Nicht zufällig ist Thomas Manns Essay von 1936 Freud und die Zukunft sowohl eine fulminante Hommage zum 80. Geburtstag des Begründers der Psychoanalyse als auch eine die gegenseitigen Inspirationen und Parallelen zwischen Freud und Thomas Mann unterstreichende Selbstdeutung des Joseph-Romans, dessen drei erste Bände zu diesem Zeitpunkt abgeschlossen waren. Aber nicht von seinen Quellen, sondern von dem Werk selbst soll hier gesprochen werden; von einem Werk, das Thomas Mann trotz der in ihm erzählerisch synthetisierten Materialfülle in erster Linie als Kunstwerk, nicht als Bibelepos, verstanden wissen wollte. Mehrfach hat er gegenüber allzu bewunderungsbereiten Lesern den durchweg fiktionalen Charakter des Werkes unterstrichen, für das das gelehrte Wissen Material, aber nicht Substanz bedeute. Die Erfindung reiche schließlich doch weiter als das Studium: der Joseph sei „Dichtung“ und „Dichten heißt: die Wirklichkeit ,erfinden'“ (Th. Mann, Über mich selbst, 90).

In der Tat ist das vierbändige „komische Menschheitsmärchen“ (Sk, 217), dieser gigantische „epische Scherz“ (ebd.), Erfindung im besten und anspruchsvollsten Wortsinne. Erfunden sind Personen (z.B. Mai-Sachme, Josephs Hausmeier in Ägypten, dem der Arzt und Romanautor Martin Gumpert als Vorbild diente), Situationen und konflikthafte wie heitere Konstellationen. Diese sind überlieferungsgeschichtlich nicht verbürgt, sie mögen wissenschaftlich schlichtweg Humbug sein, ihr Wahrscheinlichkeits- und Wahrheitsgehalt indes liegt auf zeitgeschichtlich-aktueller Ebene und entspricht Thomas Manns persönlichen Neigungen, Befürchtungen und Intentionen.

Im Zentrum steht - wiewohl erst mit dem zweiten Band kontinuierlich präsent - Joseph. Sein Lebens-, Bildungs-, Erkenntnis- und Selbsterhöhungsprozess ist mehr als ein roter Faden für das üppig wuchernde Erzählganze. Als verwöhnten, selbstverliebten, schönen Knaben entwirft Thomas Mann diesen Joseph. Ein knapp 50-seitiges „Vorspiel“ unter der Überschrift „Höllenfahrt“ geht voraus, in dem Thomas Mann an den Anfang von Goethes Faust parodierend anknüpft und narrative bzw. narratologische Reflexionen über die Erzählbarkeit der Geschichte, über 
die abgründige Tiefe des „Brunnens der Vergangenheit“ anstellt. Wer immer den Roman zum ersten Mal liest, dürfte seine Schwierigkeiten mit diesem Anfang haben. Erst nach dieser Höllenfahrt erleben wir den eigentlichen Beginn der Erzählung und zwar als Gespräch zwischen Vater Jakob und Sohn Joseph. Letzterer hatte buchstäblich am Brunnen gestanden, in pikanter Transformation des Narzissus-Mythos sich nackt dem Monde und den Gestirnen exponiert und war dafür vom Vater streng getadelt worden. „Bedecke deine Blöße“, sind Jakobs erste Worte an seinen Sohn. Mit gespielter Demut, schmeichlerisch auftrumpfend, aus dem Wissen um seine Vorzugsstellung beim Vater, reagiert Joseph. Harmlos und frei von jeder gotteslästerlichen Intention habe er sich dem Mond und den Gestirnen präsentiert. Der Knabe ist ein Angeber und ein Petzer, und er weiß es. Er ist schön und gescheit, er weiß auch dies. Und schließlich ist er wortgewandt: Seine Selbstliebe äußert sich schon zu Beginn als Verliebtheit in die eigene Sprachkraft; in die Fähigkeit, den Vater nonverbal und verbal zu umgarnen. Er weiß, dass er in seiner lasziv-narzißtischen, eben buchstäblich nackten Jünglingserscheinung, in der Pose des enthemmten Mondanbeters, der den Gestirnen Kußhände zuwirft, den Vater notwendig erzürnen muss. Und dieser ist nicht wenig erzürnt, denn der Sohn gebärdet sich, als lebe er im „äffischen Ägyptenland“, wo die Menschen nackt und lüstern, tierisch und dünkelhaft sind. Die Leinwand, die sie tragen, ist „dünn wie Spinnenwerk, bedeckt ihre Blöße, ohne sie zu verbergen" (Joseph, I, 95) und dabei bilden sich die Ägypter ein, sie „trügen gewebte Luft“ (ebd.). Jakob fährt fort:

Geht eine Frau über den Markt und sieht einen Jüngling, nach dem es sie gelüstet, so legt sie sich zu ihm. Sie sind wie Tiere und bücken sich vor Tieren im Innersten ihrer uralten Tempel, und ich bin berichtet, dass ein bis dahin reines Mädchen sich dort vor allem Volke von einem Bock namens Bindidi hat bespringen lassen. Billigt mein Sohn diese Sitten? (ebd., I, 95f.)

Joseph ist freilich weit entfernt, dergleichen götzendienerische Sittenlosigkeit, die alle Schrecken des göttlichen Strafgerichts über Sodom und Gomorrha wachruft, zu billigen. Er riskiert aber trotzdem den Einwand, solch dünne Leinwand herzustellen zeuge doch wohl vom Geschick der 
ägyptischen Handwerker; auch könne das Fehlen eines Schamgefühls wohl damit entschuldigt werden, dass die Ägypter „meistens recht mager am Leibe sind und spärlichen Fleisches, dass aber feistes Fleisch mehr Anlaß hat, sich zu schämen, als dürres ..." (ebd.).

Solche Sophistereien amüsieren den Vater natürlich und lassen ihn mit einer Stimme antworten, ,in der scheltende Ungeduld und Zärtlichkeit einen bewegten Kampf führten“ (ebd., 96). Ambivalenzen des Gefühls, paradoxe Dimensionen im Empfinden und im Selbstentwurf von Vater und Sohn verhindern nicht, dass beide sich aus einer Gottes- und Herkunftsbindung heraus entwerfen, die sie ebenso widerspruchsfrei wie wiederum selbstüberhoben zu artikulieren vermögen. Auf der einen Seite steht die Sorge des Vaters um den nicht selten sozial auffälligen, zur angeberischen Selbststilisierung und damit zur familiären Unverträglichkeit neigenden Lieblingssohn, auf der anderen die ebenso frühreife wie alberne, altkluge, aber eben auch raffiniert inszenierte intellektuelle Demutsposition des Sohnes. Diese exaltiert effektive und zugleich exzentrisch exklusive VaterSohn-Konstellation entwirft der Erzähler schon im „ersten Hauptstück“ als veritables Psychodrama mit mythisch verbürgtem Erlösungspotenzial. Es zeigt sich, dass diese aus Liebe und Sorge, Demut und Hochmut, Ermahnung und Schmeichelei gespeiste Beziehung für Vergangenheit und Zukunft von Vater und Sohn eine rückverweisende und präfigurative, imitative und antizipatorische Bedeutung hat. Nicht etwa eine spezifische, auf personale Individualität und subjektive Einmaligkeit zielende, sondern eine modellhafte, eine mythische Vater-Sohn-Konstellation besteht zwischen Jakob und Joseph. Nicht nur in der Sicht des Erzählers, sondern auch im Bewusstsein von Jakob und Joseph selbst ist beider Beziehung durch mythische Muster bestimmt. Beide empfinden und entwerfen sich in der Generationen- und Geschlechterkette, als Nach- und zugleich als Vorfahren, als Personen, die in einem Verheißungs- und Erfüllungskontext stehen. Ein eigenes Leben ist damit keineswegs ausgeschlossen, eine besondere, eben die Geschichte Jakobs und die seines Sohnes „Joseph und seine[r] Brüder" wird damit gerade nicht unmöglich.

Die Form, in der sich Vater und Sohn dieser ihrer Eingebundenheit in eine sie übergreifende, damit aber keineswegs determinierende Ordnung vergewissern, ist nicht, wie man erwarten könnte, das Gebet, das Opfer, der Gottesdienst. Es ist vielmehr das Gespräch, mehr noch, es ist - in des Erzählers Worten - „ein ,schönes Gespräch'“ (Joseph, I, 114). In ihm 
vollzieht sich die Intellektualisierung und Ästhetisierung einer scheinbar archaischen, urweltlichen Frömmigkeit und Religiosität. Die wortgewaltige Narrativierung der Gottessuche ist zugleich eine Ich-Suche. Das gebildete „schöne Gespräch“ über Herkunft und Väterweisheit zielt auf die glaubensgestützte und dennoch selbstüberhobene Bekräftigung einer angeblich gottgewollten Auszeichnung, durch die Vater und Sohn sich aus der Generationenkette herausheben. All dies veranschaulicht, was Thomas Mann erklärtermaßen intendierte: eine „mythische Psychologie“ bzw. eine „Psychologie des Mythus“ (Sk, 182).

Bereits in der großen Szene am Brunnen, da Jakob seinen Sohn zu ermahnen und dieser den Vater mit ebenso klugen wie schmeichlerischen Worten (und Gebärden) zu beschwichtigen sucht, wird diese Idee einer analogisierenden und damit humanisierenden Integration von Mythos und Psychologie, von Gotteserzählung und Menschheitsgeschichte, greifbar. Im Arm des Vaters entwirft sich Joseph als Gotteskind, als den Auserwählten, dem - wie eben auch dem Vater - seine Erwähltheit indes keinen Schutz vor dem Verderben bietet. Und doch stattet er sich als Erzähler seines künftigen Schicksals mit der narrativen Verfügungsgewalt über Vergangenheit und Zukunft, nicht zuletzt über seine eigene Zukunft aus. Dem noch unter väterlicher Aufsicht stehenden jungen Joseph legt Thomas Mann die zeitlich erst sehr viel später erfolgende Doppelsegnung des Sohnes durch den Vater in den Mund. Im „schönen Gespräch“, im "Zwiegesang" zwischen Vater und Sohn, vergewissern sich beide einer mythischen Verheißung: der Geschichte vom Öl- und Feigenbaum im Garten der Welt, aus dessen Produkten der Sonnensegen und der Mondsegen, der Segen von oben und der Segen aus der Tiefe (Joseph, I, 109) stammt. Die uralte Überlieferung, die in der Gegenwart des „schönen Gespräch[s]“ aktualisiert und als ihm bestimmte Zukunft von Joseph sicher angenommen wird, bekräftigt das Band zwischen Vater und Sohn auf ebenso abenteuerliche wie amüsante Weise. Bekanntlich ist es der sterbende Jakob, der (1. Mose 49) für Joseph den Doppelsegen aus der Höhe und aus der Tiefe beschwört. Thomas Mann legt dem selbstverliebten Joseph die Prophezeiung des Doppelsegens zu einem Zeitpunkt und bei einer Gelegenheit in den Mund, der für derartige väterliche Segnungen einigermaßen ungeeignet ist: Der Knabe ist noch jung, der Vater berechtigterweise besorgt um seine charakterliche Entwicklung. 
Um solche Sorge gleichsam gegenstandslos zu machen, wird der Junge zu seinem eigenen Propheten und bekräftigt mit solchen Visionen die herausgehobene Position, in der sich Vater und Sohn gegenüber Gott und Mensch befinden.

Das ist nicht nur kühn, es trägt - zumal in den Augen des Erzählers - alle Zeichen intellektueller Übergeschnapptheit. Mit radikalem Fiktionsbruch, mit schonungsloser Desillusionierung reagiert der Erzähler - an des Vaters Statt, der den Worten und dem Gebaren seines Sohnes vollständig zu erliegen droht - wenn es heißt:

Wie sprach er? Er flüsterte. Es war, wie früher schon einmal, bevor der Vater ihn fand, es war nicht geheuer. Er verstellte die Schultern, die Hände zitterten auf seinen Knien, er lächelte, aber dabei, unpassenderweise, verkehrten die Augäpfel sich ihm ins Weiße (Joseph, I, 110).

Man kennt Thomas Manns Neigung, die Überspanntheit seiner Helden durch minutiöse, nein, maliziöse Beschreibung körperlicher bzw. körpersprachlicher Details zu demonstrieren; die mythisch-narzisstische Großspurigkeit des jungen Joseph findet - auch dies ein Beispiel für die Psychologisierung und Ironisierung des Mythischen in diesem Roman - ihr Korrektiv in seiner verzerrten, ins Unschöne gleitenden Körperhaltung im Augenblick seiner vermessenen Selbsterhöhung. Bis in die Formulierung hinein (verstellte Schultern, sich ins Weiße verdrehende Augäpfel usw.) kehren diese Beschreibungen im zweiten Band wieder, da Joseph den Brüdern seinen Traum von den vor ihm sich neigenden aufgebundenen Getreidegarben erzählt.

Mit dem Vater zeigt auch der Erzähler sich besorgt um die Entwicklung des ,jungen Mondschwärmers am Brunnen“ (ebd., 63); aber anders als der Vater kann der Erzähler seine ambivalenten Empfindungen gegenüber dem selbsternannten Gotteskind in der voyeuristischen Detailgenauigkeit, mit der er seine äußere Erscheinung beschreibt, objektivieren. Das klingt z.B. so: „[N]och in seinen Fehlern“ sei Josephs Gesicht „liebenswürdig“ (ebd.). „Es waren zum Beispiel die Nüstern seiner ziemlich kurzen und sehr geraden Nase zu dick .... Den Ausdruck hochmütiger Sinnlichkeit, den aufgeworfene Lippen hervorrufen, wollen wir nicht rügen ... Dagegen würden wir uns für berechtigt halten, die Gegend zwischen Mund und Nase zu gewölbt zu finden“" usf. (ebd.). Solche physiognomisch-psycho- 
logischen Demaskierungen erfahren auch die anderen Romangestalten: Man denke an das greise Geschwister- und Zwergenpaar Huij und Tuij und ihr „seniles Liebesgequake“ im dritten Band.

Der mythischen Hochgestimmtheit der Diktion, dem Pathos von Gottesnähe und Erwähltheit, dem frühreifen Geraune Josephs und der altersnaiven Gefühlsseligkeit von Vater Jakob begegnet der Erzähler durch Ridikülisierung, durch humoristische Demontage der selbstverliebten Wirklichkeitsentrücktheit von Vater und Sohn. Freilich mindert das die Sympathie, ja Empathie des Erzählers für seine Helden keineswegs. Den besten Beleg für diese Empathie, die sich als Parodie und ironischhumoristische Travestie der biblischen Überlieferung zeigt, liefert der Erzähler ebenfalls schon zu Beginn, als er nicht nur den „Angeber“ und petzenden Narziss, sondern den Vater, Jakob also, in seiner „erhabene[n] Gefühlsgegebenheit“ (Joseph, I, 82) porträtiert. Ähnlich wie Joseph, der als Person mit dem Bewusstsein einer transpersonalen mythischen Erwähltheit ausgestattet ist, agiert auch der meist in sinnender Haltung verharrende Vater selbstreflexiv. Auch er lebt aus dem Wissen um seine Schwächen und Besonderheiten. In seiner greisenhaften Schwäche für den verspielt-überheblichen Sohn imaginiert er sich ebenfalls als nachgerade gottgleich. Man habe es - so belehrt uns der Erzähler - in Jakob mit einem „gefühlvollen Mann“ (ebd.) zu tun, der aus seiner Vorliebe für den Rahel-Sohn eben auch deswegen keinen Hehl mache, weil das Gefühl „von Natur zur Zügellosigkeit und einem weichlichen Kult seiner selbst“ (ebd.) neige. Das Gefühl wolle sich zeigen und aussprechen, es möchte sich - so der Erzähler - aller Welt mitteilen.

Zu dieser „Unenthaltsamkeit“ des Gefühls, diesem, wie wir heute mit Niklas Luhmann sagen würden, Diskursivierungszwang, dem das Gefühl unterliegt und in dem es sein eigentliches Medium hat, zu dieser Entäußerungsfreude sieht Jakob mit seinem Gefühl für Joseph sich auf besondere Weise legitimiert. Gott selber sei in „Gefühlsdingen und Dingen der Vorliebe“ von „Unenthaltsamkeit und majestätischer Launenhaftigkeit“ (ebd.). Die „weiche Unbeherrschtheit“ Jakobs für seinen Sohn ist in dieser Sicht nicht nur legitim, sie kann sich auf Gottes gleichgeartetes Verhalten in Gefühlsdingen berufen. Die Bevorzugung Josephs durch seinen Vater, dessen Schwäche für jenen, ist somit Nachahmung göttlichen Tuns, sie ist imitatio dei, affektiv-emotionaler Gottesdienst. 
In ihrer Bereitschaft und in ihrer fraglosen Gewissheit, dem eigenen Tun und Empfinden den Anstrich gottgewollten, Gott nachahmenden Verhaltens zu geben, in der Gewissheit, auserwählt und gottnah zu agieren und zu empfinden, sind Vater und Sohn sich nicht nur ähnlich, hier liegt ihre Gemeinsamkeit. Dieser Gleichklang des Gefühls, als übereinstimmende Auffassung von der personalen und transgenerationellen Auserwähltheit scheinbar objektiviert, wird freilich als dialogischer Singsang vom Erzähler entschieden ironisiert. Das Medium, in dem sich Vater und Sohn ihrer liebenden Nähe versichern, das „schöne Gespräch“, wird gelegentlich zur singenden Wechselrede, ja zur litaneihaft-liturgischen Reinszenierung der bekannten Geschichten vom Urvater Abraham, vom Isaak-Opfer, von Lot und Rebekka. Im „schönen Gespräch“ erleben sich die Beteiligten selbst als Medium, in ihm verkörpern sie das Bekannte und Überlieferte. Es dient der „Erinnerung, Bestätigung und Erbauung“ (Joseph, I, 114), nicht dem praktisch-pragmatischen Austausch. Das so inszenierte „Fest der Erzählung " ist ein narratives Ritual, das den transindividuellen, metasubjektiven Ich-Entwurf der Protagonisten begründet und bekräftigt, voraussetzt und verstärkt, inszeniert und illustriert.

Dem montierenden und reflektierenden, das Geschehen regelmäßig parodistisch transformierenden Erzähler und auch den handelnden Figuren legt der Autor Thomas Mann Konzepte von Individualität und personaler Subjektivität in den Mund, die modernem Bewusstsein als reaktionär oder als Antizipation dekonstruktivistischer Subjektkritik erscheinen mögen. Sowohl Jakob als auch sein Sohn sind mit einem mythischen Bewusstsein ausgestattet, aufgrund dessen ihre Identitäts- und Ich-Suche als Bestätigung mythischer Überlieferung und göttlicher Prophezeiung erfolgt. Sie entwerfen sich im Horizont erzählter Geschichten, in der ins Unendlich-Abgründige reichenden Generationenfolge und im diskursiv bekräftigten Wissen um ihre bzw. ihrer Urväter göttliche Auserwähltheit. Der Erzähler zeigt sich selbst oft nicht wenig erstaunt über solche zwischen Hybris und Demut schwankende Identitätsgewissheit, die doch auch Suche ist. Er charakterisiert das mythische Bewusstsein seiner Protagonisten als eine „Lebensauffassung ..., die die Aufgabe des individuellen Daseins darin erblickt, gegebene Formen, ein mythisches Schema, das von den Vätern gegründet wurde, mit Gegenwart auszufüllen und wieder Fleisch werden zu lassen“ (Joseph, I, 125). 
Spätestens an dieser Anspielung auf die berühmten Eingangsworte aus dem Johannes-Evangelium, das bekanntlich erheblich jünger ist als die Jakobs-Geschichten, mit denen sie hier ganz selbstverständlich verknüpft werden, sieht man, dass der Erzähler das mythische Bewusstsein seiner Helden auch zum Kompositionsprinzip seiner eigenen Erzählung gemacht hat. Es ist zwar, wie er gesteht, einigermaßen schwierig, „,von Leuten zu erzählen, die nicht recht wissen, wer sie sind“ (ebd., 126), aber eine solche „schwankende Bewußtseinslage“ schafft eben auch Freiräume für die poetische Gestaltung. Sie hat Thomas Mann seinen Erzähler weidlich ausschöpfen lassen, so dass bekanntlich im ersten und zweiten Band gegen die in der Genesis (1. Mose 37) vorgegebene Chronologie erzählt wird.

Die eigentliche Erzählung vom jungen Joseph beginnt erst im zweiten Band, nachdem uns aber im ersten, den „Geschichten Jaakobs“, der mondanbeterische Lieblingssohn bereits im „schönen Gespräch“ mit dem Vater über dessen von Rebekka ausgeheckten Segensraub begegnet war. Zeitlich greift der Erzähler vor und wieder zurück. Der tiefe „Brunnen der Vergangenheit“, von dem auf den ersten 50 Seiten der Tetralogie gehandelt wird und in den zu steigen einer „Höllenfahrt“ gleichkommt, dieser „Brunnen der Vergangenheit“ bezieht sich auf die Phylo- wie Ontogenese des Menschen. Die Metapher vom „Brunnen der Vergangenheit“ parallelisiert die kollektive mit der individuellen Vergangenheits- und Herkunftssuche und operiert mit einem programmatisch antichronologischen Zeitverständnis.

Was uns beschäftigt, ist nicht die bezifferbare Zeit. Es ist vielmehr ihre Aufhebung im Geheimnis der Vertauschung von Überlieferung und Prophezeiung, welche dem Worte ,Einst' seinen Doppelsinn von Vergangenheit und Zukunft und damit seine Ladung potentieller Gegenwart verleiht (Joseph, I, 30).

Die Idee vom Ineinander der Zeitstufen, von der Überlagerung der Gegenwart durch ein Bewusstsein von Vergangenheit und Zukunft hat Thomas Mann seit dem Zauberberg beschäftigt. Im Joseph wird ein solches mythisches Zeitempfinden, dem Wiederholung und Reinkarnation, nicht aber Progress und Innovation wesentlich sind, zwar biblisch fundiert, aber narrativ, d.h. ästhetisch funktionalisiert. Die Akteure, Jakob, Joseph, 
Rahel, die auf so erschütternde Weise am Wegesrand, in glühender Sonne und im Staub der Wüste mit Benjamin niederkommt, aber auch Laban oder später Potiphars Weib, die dem Keuschheitsstreben Josephs wahrlich schwer zusetzt, alle diese Figuren in Thomas Manns Roman erleben und entwerfen sich noch in ihren elementaren irdischen Bedürfnissen als transpersonale Verkörperung jahrtausendealter, zeitlich oder wohl gar chronologisch nicht präzis fixierbarer Überlieferungen. Der Erzähler bezeugt, ja bekräftigt solche, modernem Bewusstsein strikt widerstreitenden Figurenentwürfe als völlig unanstößig. Er ist nachgerade fasziniert vom mythischen, d.h. strikt antimodernen Bewusstsein seiner Figuren und sorgt gerade deswegen dafür, dass sie in ihrem irdischen, sozialen, ja politischen Profil präsent, d.h. gegenwartsbezogen bleiben.

Wenn er uns darüber belehrt, dass erst 3000 Jahre nach der Zeit, von der er erzählt, Menschen über die Frage streiten mussten, ob die Oblate der „Leib“ des Opfers „sei“ oder lediglich „bedeute“, dass also das Auseinanderfallen von Sein und Bedeutung, Geschehen und Sinn für Zeit und Personal seiner Erzählung ganz unerheblich gewesen sei, so heißt dies doch nicht, dass wir kritiklos oder sehnsüchtig, nostalgisch oder wohl gar programmatisch an die Vorteile vormodernen Bewusstseins und archaischer Lebensformen gemahnt werden sollen. Das strukturell Parodistische der Tetralogie, der durchgängig humoristische Erzähl- und Darstellungsgestus, und damit spezifisch narrative, ästhetische Mittel garantieren, dass dem Roman weder eine fromme noch eine reaktionäre Botschaft abgelesen werden kann.

Eher schon wird man anlässlich einzelner als „Fest der Erzählung“ opulent und damit vorzugsweise voyeuristisch ausgemalter Szenen von einem selbstverliebt sich verselbständigenden Erzählfuror Thomas Manns bzw. seines Narrators sprechen dürfen. So etwa im dritten Hauptstück des 1. Bandes, da die "Geschichte Dina's“, der einzigen Tochter Jakobs, vor allem aber ihrer Hochzeit erzählt wird. Diese hat sich ja bekanntlich als Raub vollzogen, nachdem man dem hemmungslos verliebten Bewerber Sichem, dem Burgsohn von Schekem, abverlangt hatte, sich zuvor beschneiden zu lassen. Dies war geschehen, hatte aber nicht zur Einlösung des gegebenen Eheversprechens geführt, denn Jakobs Söhne, Dinas Brüder, suchten (und fanden schließlich auch) einen Anlass zum Streit. Sie provozierten den Raub der Schwester und damit die Forderung, nur unter der Bedingung einer Hochzeit zwischen der bereits entführten 
Schwester und Sichem nachträglich zuzustimmen, wenn sich nunmehr alle Männer Schekems beschneiden ließen. Man weiß, was folgte: ein blutiges Gemetzel in der wehrlosen Stadt. Jakob, empört über das von langer Hand geplante Verbrechen seiner Söhne, konnte / wollte es nicht verhindern. Den Grund nennt der Erzähler und illustriert mit ihm die entschieden fatalen Seiten mythischen Bewusstseins:

Was ihn verblendet hatte, war die Freude an Imitation und Nachfolge gewesen. Er hatte Abrahams gedacht, und wie er auf des Herrn Befehl ... alles, was Mannesnamen war in seinem Hause, eines Tages am Fleische beschnitten hatte ... (Joseph, I, 177).

Die riskanten, durchaus verbrecherischen Implikationen eines jede Gegenwart ignorierenden mythischen Bewusstseins werden durch den Erzähler unmissverständlich entlarvt. Andererseits entmythologisiert die Erzählung selbst, vergnüglich in ihrer Detailversessenheit, komisch in der demaskierenden Beschreibung des tölpelhaften Bräutigams, der das Komplott der Jakobsöhne nicht durchschaut, das dem mythischen Bewusstsein entstammende Geschehen. Indem der Roman vom biblischen Mythos, von Jakob und seinen Söhnen, von Joseph und seinen Brüdern erzählt, markiert er doch auch die Grenzen der in ihre Herkunft und Zukunft fraglos eingebundenen Personen. Wovon der Roman erzählt, mit großer Geste und leidenschaftlichem Engagement erzählt, das rückt er vor dem Leser immer wieder in kritische Distanz. So attraktiv mythisches, glaubensgeleitetes Selbstbewusstsein einem modernen, der „transzendentalen Obdachlosigkeit“ (G. Lukács) überantworteten Bewusstsein auch scheinen mag, Thomas Mann und sein Erzähler konstruieren und dekonstruieren, kommentieren und kritisieren, illustrieren und persiflieren diese Attraktivität.

Letzteres tut Thomas Mann nun auch in entschieden politischer, in aktueller Absicht. Der parodistische Tenor der Erzählung, der selbst die dramatischen Passagen, da Joseph dem Vater das „bunte Kleid“ (Joseph, II, 86-99) abschwätzt, da er bewusst provokativ und im Wissen um seine blendende Jünglingsschönheit vor den Brüdern erscheint, ja selbst noch in der berühmten Szene, Jahrzehnte später in Ägypten, da er sich seinen Brüdern als derjenige zu erkennen gibt, den sie einst (aus nachvollziehbarem Hass, wie Thomas Manns Erzähler stets betont) in die Grube 
stießen und verkauften, in all diesen Szenen dominiert die parodistische (wohlgemerkt, nicht die denunziatorisch-sarkastische) Perspektive. Dadurch bleiben Distanz und intellektueller Abstand gewährleistet, wird verhindert, dass das mythische Einheitsbewusstsein der Protagonisten zum unreflektierten Identifikationsgegenstand des Lesers wird.

Schon in seinem frühen Aufsatz Pariser Rechenschaft (1926) hatte Thomas Mann sich gegen eine nostalgisch-identifikatorische, eine irrational-völkische Inanspruchnahme des Mythos gewandt. Er hatte entschieden gegen eine Position polemisiert, die Nationalität gegen Humanität, Mythos gegen Vernunft und das Leben gegen den Geist glaubte ausspielen zu müssen. Vor solchem „revolutionärem Obskurantismus", der 1933 politische Realität werden sollte, hat Thomas Mann seit Mitte der 20er Jahre gewarnt und mit seinen Repräsentanten, Alfred Baeumler und Ernst Bertram, entschieden gebrochen. Durch zahllose Selbstkommentare während der 16-jährigen Arbeit am Joseph zieht sich der Gedanke, dass Mythos und Psychologie zu vereinigen seien; dass es ästhetisch und politisch darauf ankomme, den Mythos für eine humane, progressive Geschichtsauffassung zu nutzen, ihn für das Konzept einer neuen und erneuerten Humanität „umzufunktionieren“ und nicht den Faschisten zu überlassen: „Man muss dem intellektuellen Faszismus den Mythos wegnehmen und ihn ins Humane umfunktionieren", fordert Thomas Mann im September 1941 in einem Brief an Karl Kerényi und fügt hinzu: „Ich tue längst nichts anderes mehr“ (Sk, 201).

In seinem ,intellektuelisierte[n] Epos“ (Sk, 35), dem Joseph-Roman, der zu diesem Zeitpunkt noch immer nicht abgeschlossen war, erfolgt die politisch-antifaschistische Arbeit an der Umfunktionierung des Mythos - wie gesagt - als Parodie und Travestie, als unendliches humoristisches Spiel mit einem uns bekannten Stoff. Das „Fest der Erzählung“ soll das Gründungsdokument einer erneuerten Humanität, einer säkularen Religion sein, die ihrerseits ihre biblischen, d.h. mythischen Ursprünge nicht verleugnet, sondern nutzt. Wie Thomas Mann sich eine solche für Theologen gewiss provokative, moderne Religiosität denkt, wäre einen eigenen Vortrag wert. Dafür ist hier zwar der Ort, nicht aber die Zeit.

Ich beschränke mich auf wenige abschließende Hinweise zu dieser den Joseph-Roman als ganzen beherrschenden Grundidee einer Erneuerung der Humanität aus dem Geiste des Mythos (in unserem Falle also der biblischen Erzählung von Joseph und seinen Brüdern). Wer die vier Bände 
kennt, weiß, dass mit Beginn des zweiten Bandes („Der junge Joseph“) im Grunde ein Entwicklungs- und Bildungsroman erzählt wird. Aus dem bestechend schönen, aber „unausstehliche[n] Bengel“ (Joseph, II, 7), einem verzogenen, egomanen Jüngling mit außergewöhnlichen geistigen Gaben wird ein verantwortungsvoller, pflichtbewusster Mensch, ein - wie der 4. Band ihn nennt - „Ernährer“. Leben und Erfahrung bilden ihn, der unter dem doppelten, dem berühmten Jakobsegen steht. In dieser auf sozialen Dienst, politische Verantwortung und damit Ausbildung von wahrer Menschlichkeit zielenden Entwicklung trägt Joseph - daraus macht der Text kein Geheimnis - christusähnliche Züge: Als Ernährer ist er in gewissem Sinne auch Erlöser.

Zugleich aber zeichnet Thomas Mann mit diesem zum Ernährer gewordenen und damit politisch höchste Verantwortung tragenden Joseph das Bild eines Politikers, dem seinerzeit nicht nur Thomas Manns ganze Bewunderung galt, sondern mit dem er in dessen Amtssitz zwei volle Tage (13./14.1.1941) verbracht hatte. In Briefen und Tagebüchern hat Thomas Mann seine Eindrücke von dieser Begegnung festgehalten. Die Kapitel „Vom schelmischen Diener“ und „Herr über Ägyptenland“ aus dem vierten Band (Joseph der Ernährer) sind nach Thomas Manns eigenem Bekunden eine deutliche Beschreibung von Person und Politik Roosevelts. Umgekehrt lesen sich gewisse Passagen aus Briefen an Agnes Meyer, der Thomas Mann von seinem Besuch im „Weißen Haus“ berichtete, wie eine Charakteristik Josephs. Das aber bedeutet, dass Joseph Züge von Roosevelt und der amerikanische Präsident Züge des Thomas Mann'schen Joseph erhielt. Der biblische Mythos wird nicht nur narrativ ausgestaltet, er wird nicht nur psychologisch motiviert, er wird politisch aktualisiert. Diese Aktualisierung, gegen die Rebarbarisierung der damaligen Gegenwart entwickelt, sieht in der Geschichte von den israelitischen Urvätern und vor allem in der Person Josephs die Verkörperung einer säkularen Religion der Humanität. Diese wiederum speist sich, anders als das idealistische Postulat der Weimarer Klassiker, aus der Integration des Bösen. Die moderne Humanitätsreligion im Sinne Thomas Manns nutzt Mythos und Psychologie. Sie verankert den möglichen, wenngleich widersprüchlichen Zusammenhang von Irrationalität und Rationalität, von Leben und Geist, von Trieb und Moral im Doppelsegen, den Jakob seinem Sohn spendet. Denn mit Licht und Dunkel, mit Geist und Sinnlichkeit, mit produktiven und mit destruktiven Kräften ist dieser Jüngling 
bei Thomas Mann ausgestattet, und dass er den erwähnten Dualismus als politisch handelnder, fürsorgender Landesvater zu überwinden vermag, das eben macht ihn in der Sicht Thomas Manns zum Repräsentanten einer säkularen Religion der Humanität.

Viel zeittypischen Optimismus, vielleicht gar abwegigen Idealismus mag man in solchen Konzepten erkennen, die ihrerseits bei Thomas Mann gerade nicht als theoretisches oder theologisches Konzept, sondern als episches Großprojekt, als ein „Fest der Erzählung“ entworfen werden. Insofern ist diese durch Joseph repräsentierte und in Thomas Manns Tetralogie vielfältig illustrierte Integration von Mythos und Psychologie eine ästhetische, eine Integration mit den Mitteln und im Medium der Kunst, der Kunst der großen Erzählung. Diese wiederum schließt den skeptisch-ironischen Blick auf sich selbst stets ein. Niemand wusste das besser als Thomas Mann, der denn auch 1944 in einem Vortrag über das „Buch der Bücher“ also über die „Bibel“ und seinen „Joseph“ von der „Heiligen Schrift“ als dem „sowohl seltsamsten wie gewaltigsten Monument der Weltliteratur" gesprochen hat. Es handele sich um ein „Buchgebirge“ und „konglomerathafte[s] Schriftmassiv“ (Sk, 256), als dessen eigentlichen Verfasser man Gott selbst ansehen könne.

Die Autorschaft an seinem eigenen epischen Monumentalwerk hat Thomas Mann zwar Gott nicht direkt angetragen, wohl aber hat er in einem Satz aus dem 1951 erschienenen Gregorius-Roman (Der Erwählte) das Motto für seine 16-jährige Arbeit am Joseph gesehen. Der Satz lautet: „Ich tat es, um Gott eine Unterhaltung zu bereiten“ (Sk, 336).

\section{Literaturhinweise:}

Thomas Mann: Joseph und seine Brüder, Bd. I-IV. In: Gesammelte Werke in Einzelbänden, hrsg. v. Peter de Mendelsohn, Frankfurt/M. 1983. (im Text zitiert mit Joseph, Band und Seitenangabe)

Thomas Mann: Selbstkommentare: „Joseph und seine Brüder“, hrsg. v. Hans Wysling unter Mitwirkung v. Marianne Eich-Fischer, Frankfurt/M. 1999 (im Text zitiert mit SK und Seitenangabe).

Thomas Mann: Über mich selbst. Autobiographische Schriften. In: Gesammelte Werke in Einzelbänden, hrsg. v. Peter de Mendelssohn, Frankfurt/M. 1983, S.51-93.

Eckhard Heftrich: Joseph und seine Brüder. In: Thomas-Mann-Handbuch, hrsg. v. Helmut Koopmann, Stuttgart 2001, S.447-474. 


\title{
Wiederkehrender und revolutionärer Christus in der russischen Literatur ${ }^{*}$
}

\author{
REINHARD LAUER
}

In der russischen Religions-, Geistes- und Literaturgeschichte spielt die Wiederkunft Christi, die Parusie, eine herausragende Rolle. Wenn man vernimmt, daß in den Weiten der sibirischen Taiga vor einigen Jahren Vissarion, ein früherer Arbeiter und Milizionär, als Reinkarnation Jesu erschienen ist, Apostel und eine rasch anwachsende gläubige Gemeinde um sich versammelt hat und, als Sprachrohr Gottes, ein Leben in unentgeltlicher Arbeit und ökologischer, wenn auch nicht fleischlicher Enthaltsamkeit verkündet, so zeigt sich auch heute noch die ungebrochene Kraft der Vorstellung vom wiederkehrenden Christus bei den Russen.

$\mathrm{Da}$ das russische Geschichtsdenken in der Vergangenheit stärker eschatologisch, heilsgeschichtlich, ausgerichtet war und die historische Entwicklung aus den Voraussagen der Apokalypse ableitete, lag auch die Vorstellung vom Auftreten des Antichrist, des falschen Christus, immer nahe, und so werden wir sehen, daß sich gerade bei den bedeutendsten Gestaltungen des wiederkehrenden bzw. des revolutionären Christus - bei Fedor Dostoevskij, Vladimir Solov'ev, Aleksandr Blok, Vladimir Majakovskij - schillernde Zweideutigkeiten ergeben. Immer aber erzeugt das Wiederauftauchen Christi in dieser Welt, sei es als Wirklichkeit oder als Potentialität gedacht, Irritation. Die Liedermacherin Bettina Wegner, die sich in den 80er Jahren Jesus, lebte er unter uns, nicht anders als rot und militant denken konnte, hat damals drastisch ausgerufen: „Mensch, Jesus, bleib oben [im Himmel], sonst schlagen sie dich tot!“

Die Vorstellung vom wiederkehrenden Christus, von der hier die Rede ist, besagt, daß Christus noch vor seiner endgültigen Wiederkunft als Richter über Lebende und Tote, vor Anbruch des Reiches Gottes, nochmals unsere Welt betritt und erneut abgelehnt, verfolgt, umgebracht wird (A. Rammelmeyer). Das Motiv vom wiederkehrenden Christus kommt in der Literatur vor allem in drei Erscheinungsformen vor:

1. Zunächst als die uralte Vorstellung von der Rückkunft Christi, also die eigentliche christliche Parusie, die in der christlich-abendländischen Theologie und Literatur eine lange Tradition aufweist und oft in Zeiten der 
sozialen und geistigen Not oder in Zeiten des Umbruchs hervortrat. Die Konfrontation Christi mit den Verhältnissen der Gegenwart ist denn stets auch intendiert als Konfrontation der reinen Lehre Christi mit späteren Fehlentwicklungen. Sie dient der Kritik an den etablierten Kirchen und sozialen Verhältnissen. Dostoevskijs Legende vom Großinquisitor kann als Musterstück dieser Variante dienen.

2. In zahlreichen literarischen Werken wiederholen die Helden in neuem Gewand und in neuen Verhältnissen den Lebensweg Christi, meist mit dem Ergebnis, daß die christusgleichen Gestalten in der rauhen Gegenwart scheitern. Diese Imitatio Christi finden wir etwa bei Antonio Fogazzaro (Il Santo, 1906), bei Gerhart Hauptmann (Der Narr in Christo Emanuel Quint, 1910), bei Ricarda Huch (Der wiederkehrende Christus. Eine groteske Erzählung, 1925), in der Gestalt des Ivan Babičev in Jurij Olešas Roman Neid (1927) oder in Nikos Kazantzakis Griechischer Passion (1950). Das eindrucksvollste Beispiel aber stammt wieder von Dostoevskij; in seinem Roman Der Idiot (1868) erscheint ein christusgleicher, „positiv guter und schöner Mensch“ in der Petersburger Gesellschaft der 1860er Jahre.

3. Die dritte Variante, der revolutionäre Christus, ist in der russischen Literatur am stärksten ausgebildet. Sie nimmt ihren Ausgang vom christlichen Sozialismus und der materialistischen Bibelkritik eines David Friedrich Strauß oder Ernest Renan und deutet Jesu Leben und Wirken in einer säkularisierenden Darstellung als das eines sozialen Schwärmers und Sozialrevolutionärs. Alfred Rammelmeyer hat in einem unvollendeten, posthum publizierten Aufsatz von 1965/66 die theologischen und ideengeschichtlichen Hintergründe des Motivs vom wiederkehrenden Christus beleuchtet. Vor allem im christlichen bzw. utopischen Sozialismus, beginnend schon mit Gracchus Babeuf, bei Henri de St. Simon, Charles Fourier, aber auch bei Wilhelm Weitling, ferner in Werken von George Sand, Victor Hugo und in Heinrich Heines Deutschland - ein Wintermärchen wird die These vom revolutionären Christus vertreten. In diesem Umfeld wird es geradezu zum Topos, sich auf Christi Lehre zu berufen, um Gleichheit der Menschen, soziale Gerechtigkeit und Umverteilung der Güter einzufordern. So sah etwa Arno Holz (im Buch der Zeit, 1885) Jesus als „ersten Sozialisten“; und noch weiter ging Henri Barbusse (Jésus, 1927), wenn er Jesus als atheistischen Kommunisten darstellte. 
Im Werk Fedor Dostoevskijs sind alle drei Varianten des Motivs in unvergleichlicher Weise ausgespielt. Er gehörte in den 1840er Jahren in Petersburg einem geheimen Zirkel an, dem Petraševskij-Kreis, in dem die Theorien der französischen utopischen Sozialisten (vor allem Fouriers) intensiv diskutiert wurden. Das Motiv des revolutionären Christus gewann hier herausragende Bedeutung. Wir haben Gedichte von Aleksej Pleščeev, Sergej Durov, Apollon Grigor'ev u.a., in denen Christus als „Demagoge“, d.h. als sozialer Revolutionär, beschworen wird. Rammelmeyer hat in dem genannten Aufsatz einige Texte dieser Dichter analysiert. Er zeigt ferner, daß russische Dichter Christus als Führer des Kommunardenaufstandes 1870 in Paris besungen haben. Bei Petr Lavrov und Vsevolod Krestovskij erscheint er als Führer der Aufständischen. Krestovskij zeigt ihn in Rauch und Feuer auf den Barrikaden - mit einer roten Fahne in der Hand: eine Vorwegnahme der Vision von Aleksandr Blok, wie wir sehen werden.

Wohl als erster russischer Dichter hat Apollon Grigor'ev das Christusmotiv mit der Aufforderung zur Revolution verknüpft, und zwar in dem Gedicht Aufruf(Vozzvanie) das bereits im Januar 1844 entstand und 1846 veröffentlicht wurde. Das Gedicht muß in seiner revolutionären Schärfe von außerordentlicher Wirkung auf die Zeitgenossen gewesen sein. Christi Worte am Kreuz (Eli, Eli, lama asabthani) werden in die Verse übernommen; ferner spielt der Dichter auf die Reinigung des Tempels (Mt 20,20) an. Christi Leiden werden in Bezug gesetzt zu den Leiden der Unterdrückten, die zum Aufstand aufgerufen werden:

Steh auf, o Gott! - nicht für sie,

Die Sklaven der Sünde, die Priester des Götzen,

Sondern für die Hinfälligen und Kranken,

Für deine dürstenden Kinder -

Steh auf, steh auf, Erretter der Welt,

Dich zu suchen, sind sie gegangen

Den Weg des Leidens und des Durstes...

Wie du schrien sie nicht nur einmal

Lama asabthani,

Und ebenso sahen sie

Dein Haus von Kaufleuten gefüllt

Und standen stolz auf - und allein

Bewaffneten sie sich mit Peitschen ... 
In die Jahre 1845/46 fällt ein zweites Gedicht von Grigor'ev, in dem die für die Petraševcy so bezeichnende These vom revolutionären Christus noch schärfer ausgedrückt ist. Das Gedicht zeugt von dem unbeugsamen Stolz Grigor'evs. Man spürt, daß es in einer für ihn erniedrigenden Situation entstanden ist:

Nein, ich bin nicht geboren, untertänig zu bitten

Oder geduldig im Vorzimmer zu warten ...

Nein, ich bin nicht geboren, Sklave zu sein,

Selbst bei der Messe in der Kirche

Ist mir immer übel, ich bedauere es,

Dem Kaiserhaus zu gehorchen.

Und das, was Marat fühlte,

Vermag ich bisweilen zu begreifen,

Und wäre selbst Gott ein Aristokrat,

Ich würde ihm stolz Flüche singen ...

Doch der ans Kreuz geschlagene Gott

War ein Sohn der Menge und ein Demagoge.

Am ersichtlichsten ist der Zusammenhang mit dem Diskurs um den revolutionären Christus im Petraševskij-Kreis in einem späteren Gedicht von Aleksej Pleščeev aus dem Jahre 1858. Hier spielt das romantische Motiv vom verkannten Propheten noch hinein, ebenso die Hoffnungen auf den Tag, an dem Christi Lehre die Welt erneuern werde:

Er ging ohne Murren und, ans Kreuz geschlagen,

Verkündete er den Völkern Brüderlichkeit und Liebe.

Der Aufruf am Schluß lautet:

Noch wird der Tag anbrechen ... Leben und Kraft wird In unsere verfallene Welt Christi Lehre hauchen.

Die Leitbegriffe sind in den angeführten Gedichten die gleichen. Es geht um Christi Lehre, um die Verkündigung seiner Ideale, um Freiheit, Brüderlichkeit und Liebe. Alle Gedichte sind erfüllt von bestimmten 
Heilserwartungen, die man unter dem Gesichtspunkt des utopischen Sozialismus zu verstehen hat.

Im Petraševskij-Kreis wurde mit begieriger Aufmerksamkeit jener Brief des bedeutendsten zeitgenössischen Literaturkritikers Vissarion Belinskij an Gogol' aus dem Jahre 1847 aufgenommen, der alsbald verhängnisvolle Folgen für einige der Petraševcy haben sollte.

In diesem Brief, der Kritik an Gogol's stockreaktionären Ausgewählten Stellen aus dem Briefwechsel mit Freunden (Izbrannye mesta iz perepiski s druz jami) übt und von einer stark antiklerikalen Tendenz getragen ist, steht der bedeutsame Satz: „Er [Christus] hat als erster den Menschen die Lehre von Freiheit, Gleichheit und Brüderlichkeit verkündet und durch sein Märtyrertum die Wahrheit seiner Lehre besiegelt."

Und weiter heißt es, daß Voltaire eher ein Sohn Christi sei, „Fleisch von seinem Fleisch, Bein von seinem Bein, als alle Ihre Popen, Erzpriester, Metropoliten und Patriarchen".

Belinskij sieht in Christus also den ersten Verkünder jener großen Ideale, die in der Französischen Revolution erkämpft worden waren. Christus ist für ihn eine revolutionäre Gestalt; nur wurde seine Lehre von der kirchlichen Hierarchie verfälscht und in ihr Gegenteil umgekehrt. Belinskijs Brief wurde illegal von Hand zu Hand gereicht. Als Dostoevskij ihn im Petraševskij-Kreis - in Anwesenheit eines agent provocateur - verlas, flog der Zirkel auf. Fünf Teilnehmer, darunter Dostoevskij und Pleščeev, wurden verhaftet und zum Tode verurteilt, auf dem Schafott begnadigt und ins sibirische Zuchthaus verbracht. Hier, in dieser verhängnisvollen existentiellen Erfahrung Dostoevskijs, liegt die Wurzel für seine Beschäftigung mit dem Motiv des wiederkehrenden Christus, die bis an sein Lebensende anhalten sollte.

Im Roman über den Fürsten Myškin, Der Idiot (1869), unternahm Dostoevskij ein kühnes Experiment. Es ging ihm um die Darstellung eines „positiv guten und schönen Menschen“ (položitel'no prekrasnyj čelovek) in der zeitgenössischen russischen Umwelt; anders ausgedrückt, um die Frage: Was würde geschehen, wenn Christus plötzlich mitten in der Gegenwart erschiene? Nichts Schwierigeres könne es geben, schrieb Dostoevskij in einem Brief, „,besonders in unserer Zeit“. In den Entwürfen nannte Dostoevskij seinen Helden zunächst „Fürst Christus“ (knjaz’ Christos). Mit ihm sollte ein Gegenbild zu den schwachen Helden Turgenevs oder zu den „neuen Menschen“ Černyševskijs entworfen werden. 
Natürlich war sich Dostoevskij der Gefahr bewußt, daß sein Held ins Komische umschlagen und als ein neuer Don Quijote oder Mr. Pickwick erscheinen könnte. Und obwohl die Gratwanderung des Fürsten Myškin in den Eingangskapiteln des Romans zu gelingen schien - er ist, letzter Sproß eines alten, verarmten Fürstengeschlechtes, Epileptiker und mit einer besonderen menschlichen Anziehungskraft begabt, soeben aus einem Schweizerischen Sanatorium nach Petersburg zurückgekehrt - , so führte sie im Laufe einer recht komplizierten Handlung zum völligen Debakel. Als Myškin, der die Zuneigung zweier Frauen, der schönen, aber lasterhaften Nastas'ja Filippovna und der charakterstarken Generalstochter Aglaja Epančina, gewonnen hat, sich für die „große Sünderin“ entscheidet, um sie vor den Zudringlichkeiten der Männer, insbesondere vor seinem leidenschaftlichen Reisebekannten Parfen Rogožin, zu retten, kommt es zur Peripetie. Aglaja trennt sich von Myškin, Nastas'ja Filippovna flieht vor der Trauung zu Rogožin, der sie ermordet. Ehe er verhaftet wird, wachen Rogožin und Myškin in einer schauerlichen Szene zusammen am Bett der Getöteten und tauschen ihre Kreuze aus. Myškin fällt in seine Krankheit zurück.

In Dostoevskijs letztem großen Roman Die Brüder Karamazov (Brat'ja Karamazovy, 1879/80) ist das Motiv des wiederkehrenden bzw. revolutionären Christus als verschlungener Diskurs anwesend.

In seltsam verschlüsselter Weise bringt der Dichter Belinskijs Brief an Gogol' zur Geltung. Der frühreife Knabe Kolja Krasotkin wiederholt Belinskijs Thesen in einem Gespräch mit Aleša Karamazov. Kolja, der ungeachtet seiner dreizehn Jahre bereits überzeugter Sozialist ist, sagt:

Ich bin übrigens nicht gegen Christus. Er war eine durchaus humane Persönlichkeit, und wenn er in unserer Zeit lebte, würde er sich geradewegs den Revolutionären anschließen und vielleicht eine ansehnliche Rolle spielen ... sogar unbedingt.

Aleša fragt den Knaben darauf: „Aber wo haben Sie das nur aufgeschnappt?“ Und Kolja antwortet: „Erlauben Sie, die Wahrheit läßt sich nicht ersticken. ... Schon der alte Belinskij, sagt man, hat es gesagt." Und Aleša: „Belinskij? Ich erinnere mich dessen nicht. Das hat er nirgends geschrieben." Aleša konnte das in gutem Glauben behaupten, denn Belinskijs Brief an Gogol' wurde erst 1872 in Rußland veröffentlicht. Der 
frühreife Knabe Kolja hatte sein Wissen offenbar aus illegalen Quellen. Das ironische Moment dieser Szene ist unverkennbar.

Bekannter freilich als diese hintersinnige Stelle ist Dostoevskijs Gestaltung des Motivs vom wiederkehrenden Christus in dem Kapitel Der Großinquisitor, das man als das ideologische Kernstück der Brüder Karamazov anzusehen geneigt ist. Ivan Karamazov, der Westler und Rationalist, erzählt die Legende seinem Bruder Aleša in dem Kapitel „Pro und Kontra" des Zweiten Teiles. In diesem ingeniösen Text wird das Motiv des wiederkehrenden Christus in die Zeit der spanischen Inquisition verlegt. Das Volk hat den Erlöser, obwohl er sich von niemandem unterscheidet, sofort erkannt und folgt ihm, wohin er auch geht. Vor der Kathedrale von Sevilla erweckt er mit den Worten „Talitha kumi“ ein totes Kind zum Leben. Da tritt ihm der Großinquisitor im groben Mönchsgewand entgegen und läßt ihn von seinen Schergen verhaften. Im Kerker wirft der neunzigjährige Greis seinem Gefangenen vor, er sei nur gekommen, sie zu stören, und er wisse das auch. Er werde „als übelster Ketzer“ auf dem Scheiterhaufen enden, und das Volk, das ihm eben noch die Füße geküßt, werde Kohlen in das Feuer werfen. Christus, der Gefangene des Großinquisitors, schweigt zu den Vorwürfen und küßt den Greis zur Antwort auf den Mund. Der die Menschen erneut frei machen wollte, wird aus dem Kerker entlassen, um nie wieder zurückzukehren. Er hat den Versuchungen des Teufels in der Wüste widerstanden, Versuchungen, die der Großinquisitor zum Prinzip seines Handelns gemacht hat: Freiheit gegen Brot. Vasilij Rozanov, der scharfsichtige Deuter der Legende (Dostojewski und seine Legende vom Großinqusitor, 1894) wird in der Argumentation des Großinquisitors die leitende Idee der römischen Kirche wie auch der Nihilisten ausmachen; Šklovskij ihn mit dem stockreaktionären Oberprokuror des Synods Pobedonoscev und seine Lehre mit dem Faschismus gleichsetzen. Aleša aber, ganz außer sich, als er die „Phantasie“ des Bruders gehört hat, fragt, was denn dann alles noch zusammenhalte. „Die Kraft der Karamazovschen Niedertracht (sila karamazovskoj nizosti)“, lautet die Antwort Ivans.

Der wiederkehrende Christus im Großinquisitor ist selbstverständlich nicht der revolutionäre Christus; die Legende übt vielmehr gerade auch Kritik an der Auffassung der utopischen Sozialisten, die die von Christus gelehrte Freiheit und Gleichheit uminterpretiert haben in soziale Gleichheit und Freiheit und damit, wie der Großinquisitor, das Bündnis mit 
dem Antichrist eingegangen sind. Schon Nikolaj Berdjaev hat in seinem Buch über die Weltanschauung Dostoevskijs richtig bemerkt, daß der Großinquisitor gleicherweise den Theokraten wie den atheistischen Kommunisten verkörpert. Dostoevskij fordert vom wahren Christentum innere Freiheit und Armut und gerät damit in die Nähe der Christusauffassung der Slavophilen, die in Armut und Not das Leidenscharisma des russischen Volkes erblickten. Nicht zufällig läßt Dostoevskij Ivan Karamazov zu Beginn seiner Erzählung Fedor Tjutčevs berühmte Verse über Rußland zitieren:

Niedergedrückt von der Kreuzeslast,

Hat dich, Mütterchen Rußland,

Der Herr des Himmels in Knechtsgestalt

Mit segnender Hand durchschritten.

Tjutčevs Gedicht entstand im August 1855, zu einer Zeit also, in der auch die Petraševcy, teils in der Verbannung lebend, teils illegal schreibend und druckend, sich mit dem gleichen Thema beschäftigten. Zwei Jahre später, im August 1857, schrieb Tjutčev ein zweites Gedicht, das mit dem ersten in engem thematischen Zusammenhang steht. Auch hier spricht er von der Not des russischen Volkes, auch hier wird die Errettung durch Christus beschworen:

Wirst, über dieser finsteren Menge

Des unerweckten Volkes

Du, Freiheit, einmal aufgehen,

Wird dein goldener Strahl glänzen?

Gestank, Unordnung, Bettelarmut -

Hier verstummt die Menschlichkeit;

Wer kann all dies zudecken? ...

Du, Christi reines Gewand!

Das soziale Moment findet hier stärkeren Ausdruck als im ersten Gedicht. Auch „Freiheit“ ist hier wohl eher im politisch-sozialen Sinne gemeint. Eine Verwandtschaft zu Pleščeevs Gedicht „Er ging ...“, das ein Jahr später entstand, ist unverkennbar. Das Leidenscharisma des russischen Volkes verweist in beiden Gedichten in die Nähe der Slavophilen. 
Als ein Gegenstück, das das Christusmotiv nicht nur mit einer staatserhaltenden Botschaft verbindet, sondern den Zaren selbst mit dem Kreuzestod Christi assoziiert, möchte ich das Gedicht bezeichnen, das Afanasij Fet, einer der besten Dichter der Zeit, im März 1881 auf die Ermordung Alexanders II. schrieb. Alexander, der Zar-Befreier, einer der größten Reformatoren in der Geschichte des russischen Staates, war am 1. März 1881 (wenige Tage nach Dostoevskijs Tod) einem Attentat seitens der Terroristengruppe „Narodnaja volja“ (Volkswille) zum Opfer gefallen. Fet setzt in seinem Gedicht den Zaren mit dem Gekreuzigten und seine Mörder mit Judas gleich:

Tag des Erlösungswunders,

Stunde der Heiligung des Kreuzes:

Judas hat den blutüberströmten Christus

Golgatha überantwortet.

Und am Schluß heißt es:

Christus hat sein Kreuz und den Dornenkranz dem irdischen Zaren übergeben.

Sehr verschiedenartige Aspekte, so sehen wir, ergeben sich, wenn Dichter und Literaten wie Belinskij, Grigor'ev, Pleščeev, Dostoevskij, Tjutčev oder Fet das Thema, das Motiv des wiederkehrenden Christus aufnehmen. Christus kann das einfache Volk segnen - wie bei Tjutčev; er kann für den ermordeten Zaren stehen - wie bei Fet; er kann die herrschende Amtskirche, die mit der Herrschaft des Antichrist gleichgesetzt wird, in Frage stellen - wie bei Dostoevskij; er kann - und das scheint der bemerkenswerteste Ansatz zu sein - als politischer Demagoge und sozialer Revolutionär gedeutet werden - bei Belinskij, Grigor'ev, Pleščeev. Das Motiv des revolutionären Christus konnte ganze Generationen freiheitlicher Dichter anziehen, weil es in zweifacher Hinsicht revolutionär war: die Identifikation der Revolutionäre mit Christus und seiner Lehre stellte eo ipso einen revolutionären Akt dar, der sich gegen das geistige und politische Gefüge der Zaren-Autokratie richtete. Zugleich bedeutete es aber auch die Säkularisierung und Politisierung der Gestalt Christi und seiner Lehre. 
Nach dem Revolutionsjahr 1917, nach Februar- und Oktoberrevolution, hat sich die politische und geistige Situation in Rußland vollständig geändert. Den Dichtern stellen sich nach der Revolution grundsätzlich andere Fragen als den Petraševcy, die von Revolution und Befreiung vom Zarenjoch nur träumen konnten. Der „Tag“, von dem jene die Verwirklichung ihrer politischen Heilserwartungen erhofften, ist inzwischen mit der Revolution eingetreten. So erhebt sich für sie vor allem die Frage: Ist Christus mit der Revolution oder gegen sie?

Eines der ersten Gedichte, die Christus mit der russischen Revolution in Beziehung brachten, und zwar bereits nach der Februar-Revolution, stammt von Sergej Esenin: Der Genosse (Tovarišč). Das Gedicht entstand im März 1917, ist also ein unmittelbares Echo auf die Ereignisse der Februarrevolution.

Esenin berichtet in seinem Gedicht von dem Arbeitersohn Martin, der mit zwei Gefährten, dem Jesusknaben auf der Ikone und der Katze, heranwächst. Als sein Vater in den Kämpfen der Revolution fällt, wendet er sich an den Christusknaben mit den Worten:

Jesus, Jesus, hörst du,

Siehst du? Ich bin allein.

Es ruft zu dir und schreit

Dein Genosse Martin!

Der Vater liegt erschlagen, Aber er fiel nicht als Feigling.

Ich höre, wie er uns ruft.

$\mathrm{O}$ mein treuer Jesus.

Er ruft uns zu Hilfe,

Wo das russische Volk sich schlägt.

Er befiehlt, einzustehen für Freiheit,

Für Gleichheit und Arbeit...

Das Jesuskind versagt sich den Bitten Martins nicht. Er tritt aus der Ikone heraus und zieht gemeinsam mit Martin in den Kampf; doch nicht lange - da fällt Christus, von einer Kugel getroffen: 
Doch plötzlich blitzten die Feuer ...

Aufbellte die kupferne Ladung,

Und es fiel, von einer Kugel ereilt,

Das Jesuskind.

Nun gibt es keine Auferstehung mehr: Christus ist auf dem Marsfeld begraben.

Esenin war bekanntlich den religiösen Traditionen der Altgläubigen, wie sie auf dem russischen Land vielfach bewahrt wurden, eng verbunden. So ist ein Zug aufrichtiger, ja rührender Gläubigkeit in seinem Gedicht erkennbar. Die Vorstellung vom revolutionären Christus erhält bei ihm fast naive Gestalt: Der Jesusknabe, ebenso hilflos wie die Waise Martin, zieht in die Kämpfe der Revolution. Jesus ist bei Esenin eindeutig auf Seiten der Revolution und kämpft für die alten revolutionären Ideale Freiheit, Gleichheit und Arbeit, die auch schon von den Petraševcy immer wieder beschworen worden waren. Bei Esenin fällt das Christkind, „von einer Kugel ereilt", gleich im ersten Gefecht. Für ihn bedeutet Christi Tod in den Kämpfen der Revolution das tatsächliche Ende von Glauben und Unsterblichkeit. Nichts anderes sagt sein Gedicht, als daß Gottes Sohn mit der Revolution, und zwar bereits mit der Februarrevolution, tot ist.

Ganz anders in Aleksandr Bloks Poem Die Zwölf (Dvenadcat', 1918), dem wohl bekanntesten Beispiel einer Christusdarstellung in der russischen Revolutionsliteratur. Bei Blok schreitet Jesus Christus vor den Rotarmisten her, was nur bedeuten kann, daß die Revolution durch Christus ihren geschichtsphilosophischen Sinn erhält. Dies bedarf der Erläuterung.

Der Inhalt des Poems ist rasch berichtet: Zwölf Rotgardisten marschieren schießend und plündernd durch die Straßen des winterlichen Petrograds. In rasch aufeinanderfolgenden Episoden wird die Atmosphäre der Revolutionstage belichtet. Einziges Ereignis ist die Erschießung der Dirne Katja, die einen der Soldaten mit konterrevolutionären Offizieren betrogen hat. Der Schneesturm, eines der Lieblingssymbole Bloks, zieht sich leitmotivisch durch das ganze Poem, das die anarchischen Tage des Umbruchs vergegenwärtigt. Bewunderung und Kritik haben Blok die Schlußverse des Poems eingebracht, in denen Christus plötzlich mit einer roten Fahne vor den Rotarmisten erscheint und vor ihnen herzieht: 
So gehen sie mit mächtigem Schritt

Hinten - ein hungriger Hund,

Vorn - mit blutiger Flagge,

Und hinterm Schneesturm unsichtbar

Und von keiner Kugel verletzbar,

Mit schneesturmüberwindendem Schritt,

Wie ein schneeiges Perlenfeld

Im weißen Rosenkranz

Vorn - Jesus Christus.

Die Bedeutung scheint auf der Hand zu liegen: Die zwölf Rotarmisten werden symbolisch zu den zwölf Aposteln und Christus, ihr Meister, zum Führer der Revolution. Man könnte also von einer Transzendierung der Revolution durch Blok sprechen, wie sie sich aus seiner symbolistischen Weltsicht ergeben mochte. Die Kritik an der Institution der Kirche, die mit dem Gedanken vom wiederkehrenden Christus immer gegeben ist, kommt auch in Bloks Poem scharf zur Geltung. Eine Tagebuchnotiz vom 10. März 1918, die sich auf Die Zwölf bezieht, zeigt eine erstaunliche Parallele zu Belinskij:

Wenn in Rußland eine wirkliche Geistlichkeit bestanden hätte und nicht nur ein Stand charakterlich stumpfer Leute geistlichen Berufs, so hätte sie längst den Umstand berücksichtigt, daß Christus , mit den Rotarmisten' ist. Man kann diese Wahrheit wohl kaum bestreiten, die für alle Menschen einfach ist, die das Evangelium gelesen und darüber nachgedacht haben ... Habe ich Christus gelobpreist? ... Ich habe nur ein Faktum konstatiert: wenn man auf die Schneesturmsäulen auf diesem Weg schaut, so sieht man ,Jesus Christus'. Aber ich hasse manchmal selbst zutiefst dieses weibliche Phantom.

Diese Tagebuchnotiz klingt nach Rechtfertigung. Blok hatte zunächst Zweifel an der Berechtigung, Christus in das Poem einzuführen. Das Tagebuch aus dem Jahre 1918 gibt weiteren Aufschluß darüber. So heißt es am 18. Februar: 
Daß Christus vor ihnen geht, ist unzweifelhaft. Es geht nicht darum, ob sie, seiner würdig sind', schlimm ist vielmehr, daß er wiederum mit ihnen ist und es vorläufig keinen anderen gibt; aber ist ein anderer nötig?

Und schon zwei Tage später notiert er zu der gleichen Frage:

Religion ist Schmutz (Popen usw.). Furchtbarer Gedanke dieser Tage: es kommt nicht darauf an, daß die Rotarmisten Jesus' unwürdig sind, welcher sofort mit ihnen zieht, sondern darauf, daß ausgerechnet ER mit ihnen zieht; es müßte ein Anderer mit ihnen ziehen.

Mit dem Anderen dürfte der Antichrist gemeint sein. Für die Interpretation des Poems ist natürlich die Frage entscheidend, um welche Aussage es Blok ging. Hier kann ein Blick in Bloks Tagebücher helfen, aus denen viele Momente der Entstehungsgeschichte der Zwölf rekonstruiert werden können. Aus den Tagebüchern geht hervor, daß auf Blok zur Zeit der Entstehung des Poems (8.-28. Januar 1918) besonders zwei Probleme lasteten: Einmal beschäftigte ihn das Leben Christi, zum anderen bemühte er sich, die geistigen Zeichen der Revolution zu erkennen.

Wenige Tage, bevor er mit der Niederschrift des Poems begann (6., 7., 11. Januar), war er in die Lektüre von Ernest Renans Vie de Jésus vertieft. Am 7. Januar begann er, was bisher viel zu wenig beachtet wurde, augenscheinlich unter dem Eindruck dieses Buches mit der Skizzierung eines Dramas über das Leben Jesu. Hätte er dieses Stück verwirklicht, so wäre es vielleicht der bedeutendste Versuch einer Verquickung der Person Christi mit den revolutionären Ereignissen der Gegenwart geworden. Schon die wenigen Notizen zu diesem Drama vermitteln ein großartiges Bild:

... Hitze (Blau und Gelb). Fette Kakteen. Der Dummkopf Simon angelt, mit abstehender Lippe. Gespräch darüber, wie man jeden Fisch angeln muß (Barsch so, Rütten so). Jesus tritt auf (nicht Mann, nicht Weib). Der sündhafte Jesus. Die schöne Magdalena. Thomas (der ungläubige) - ,kontrolliert‘. Er muß glauben - sie zwingen ihn - und hauen ihn übers Ohr. Er faltet die Hände - und wird Propagandist: aber sie zwingen ihn, Inquisition, Papismus, rülpsende Popen ... zu propagieren. Andreas (der Erstgerufene) - treibt sich herum (ihn hält 
es an keinem Ort): war in Rußland (suchte das Ungewöhnliche). Die Apostel stehlen für Christus (Kirschen, Weizen). Man schämt sich ihrer. ... (Hochzeit zu Kaana). Maria und Martha ... Aber wie aufersteht er? $\mathrm{X} \alpha \lambda \varepsilon \pi \alpha \tau \alpha \varkappa \alpha \lambda \alpha$ [das Schöne ist schwer] ... Jesus - Künstler. Er erhält alles vom Volk (weibliche Empfänglichkeit) ... Bergpredigt - Meeting. Die Behörden sind beunruhigt. Jesus wird verhaftet. Die Jünger machen sich natürlich aus dem Staube. Es ist zudem Wahrheit, daß sie entwischten (mehr ist auch nicht nötig, der Rest ist eine Gerichtskomödie). Höhere Wahrheit: einer blieb. Judas hat Stirn, Nase und Bartflaum wie Trockij. Gauner ( große Zartheit der Seele, hohe Ansprüche). ,Simon“ streitet sich mit Spießern, Philistern und Dorfgenossen herum. Geht hin zu Jesus. Um Jesus sind schon einige andere (die sich ebenfalls mit jemandem in die Haare geraten sind; brummen irgend etwas, Gespräche Unzufriedener). Mitten unter ihnen Jesus - nachdenklich und zerstreut, läßt ihre Gespräche zum anderen Ohr wieder hinaus: was nötig ist, bleibt im Künstler hängen. Hier ebenfalls Prostituierte.

Aus dieser rasch hingeworfenen Skizze geht hervor, daß Blok, wie Renan, Christi Erdendasein säkularisiert darstellen wollte. Es geht ihm darum, menschliche Beweggründe zu schaffen und gesellschaftliche Hintergründe klarzulegen. Vor allem aber wollte er deutliche Zeitbezüge herstellen: Christus ist ein aufrührerischer „Künstler“, ein Intellektueller, der von den Behörden verhaftet wird; die Apostel Unzufriedene, die sich um ihn scharen; die Bergpredigt wird zur politischen Versammlung (Meeting). Und auch Prostituierte fehlen in dem Bild natürlich nicht. Bei Judas endlich geht Blok so weit, Ähnlichkeiten zu Trockij zu vermerken. Aber wie aufersteht Christus? Das Schöne ist schwer.

Blok hat sich bei diesem Entwurf nicht lange aufgehalten. Schon einen Tag später, am 8. Januar, verzeichnet das Tagebuch: „Den ganzen Tag - Die $Z w \ddot{o l} f^{x}$; die erste Erwähnung des Poems, in das dann die Christusgestalt auf geniale Weise eingeführt wurde. Während das Christusdrama, sub specie revolutionis, zu einer säkularisierten Vita Christi geführt hätte, erfuhr die Revolution im Poem, sub specie Christi, ihre Transzendierung.

Die Transzendierung der Revolution steht in engem Zusammenhang mit geistigen Konzepten, denen Blok in seinem etwa gleichzeitig mit den Zwölf verfaßten Aufsatz Intelligenz und Revolution (Intelligencija i revoljucija, Januar 1918) Ausdruck verlieh. Hier versuchte er, jenseits von 
Aufbau und Zerstörung, die neuen geistigen Leitbilder der Revolution zu konstruieren. Der Essay ist ein Appell an die russische Intelligenz. Als sei dieser ein Bär aufs Ohr getreten, klagt er, sei sie nicht in der Lage, in dem Chaos der Ereignisse der Musik der Revolution zu lauschen. Es komme aber darauf an, „mit ganzem Leib, mit ganzem Herzen, mit ganzem Bewußtsein die Revolution anzuhören“. Man weiß, welche Bedeutung die Musik für Blok besaß. Sie ist für ihn Geist schlechthin. Einmal (Tagebuch, 5. Januar 1918) spricht er von der Musik als dem „ETHISCHEN“. Was also in der Revolution, jenseits von politischem Umsturz, blutigem Gemetzel und Anarchie, vernommen werden soll, ist die ethische Erneuerung, sind die neuen geistigen Leitbilder, die von ihr ausgehen.

In welcher Weise Christus hier hereinspielt, darüber gibt der Vortrag Vladimir Solov'ev und unsere Tage (Vladimir Solov'ev i naši dni) Aufschluß, den Blok im August 1920 in der Freien Philosophischen Gesellschaft hielt. Er versuchte hier eine Deutung des Religionsphilosophen und nannte ihn einen zukunftsträchtigen Geist, der die Erschütterungen, den Geist der Epoche wie kein anderer erspürt habe und deshalb vielen unverständlich sei. Diejenigen, die die russische Revolution mit der französischen vergleichen, haben nach Blok nur zum Teil recht. Beide Revolutionen seien nur zwei zeitlich verschiedene Phasen in einem großen Prozeß. Eher möchte Blok eine Parallele zum ersten nachchristlichen Jahrhundert ziehen, in welchem freilich nicht die wirkenden politischen Kräfte (Rom und Germanien) von Bedeutung seien, sondern ,irgendein dritter Ton, der weder den einen noch den anderen glich“. Lange Zeit, durch zwei bis drei Jahrhunderte, sei dieser Ton erstorben, doch schließlich sei es ihm bestimmt gewesen, alle übrigen Töne zu überlagern. Mit diesem „dritten Ton“ oder dieser „dritten Kraft“ ist das Christentum gemeint. Von ihm schweigen die römischen Schriftsteller, schweigt selbst Tacitus. Das Verdienst Solov'evs bestand, nach Blok, gerade darin, daß er, Ausschau haltend, den Zugwind seiner Epoche geatmet habe, seiner Epoche, welche wie das erste nachchristliche Jahrhundert eine Übergangszeit sei. Solov'ev, sagt Blok am Schluß seines Vortrages, „war Träger eines bestimmten Teiles dieser dritten Kraft, jener... auf uns zukommenden Welt“.

Ein weiterer kühner und interessanter Versuch, Christus mit der Revolution in Verbindung zu bringen, stammt von Vladimir Majakovskij. In seinem dramatischen Werk Mysterium buffo (Misterija buff, 1918), das er zur Feier des ersten Jahrestages der Oktoberrevolution schrieb, verarbeitete 
Majakovskij alt- und neutestamentliche Stoffe, um eine „heroisch-epischsatirische Darstellung unserer Epoche“ zu geben. Schon seit 1917 trug sich Majakovskij mit dem Gedanken, die umwälzenden Ereignisse der Zeit in einem großen mirakulösen Spiel darzustellen. Obwohl er auf die alte christliche Form des Mysterienspiels zurückgriff, schuf er mit seinem Stück das erste große Werk der futuristischen Literatur und zugleich das erste Beispiel epischen Theaters in Rußland. Er wollte mit diesem Stück den „Weg der Revolution“ zeigen. Eine neue Sintflut ist hereingebrochen, die die alte Welt zerstört. Die einzigen Überlebenden, sieben Paar Reine und sieben Paar Unreine, bauen nach dem Vorbild Noahs eine Arche. Auf der Arche werden Absolutismus, Demokratie und Sozialismus der Reihe nach durchexerziert. Am Ende gehen die Unreinen den beschwerlichen Weg durch Himmel und Hölle, um endlich ins „Land der Dinge“ zu gelangen. Den Höhepunkt des Stückes bildet das Erscheinen eines Fremden, des „einfachen Menschen“ (prosto čelovek), am Ende des II. Aktes. Zuerst vernehmen die hungernden und frierenden Unreinen nur einen Ton. Dann aber erscheint ihnen der Fremde, der über die Wellen schreitet und auf seinen Knochen wie auf einem Instrument spielt. Hier schon sieht es ganz so aus, als sei der Fremde Christus selbst, welcher „kam, teilend die Wasser von Genezareth“.

Der „einfache Mensch“ läßt sich von den Unreinen aus Hobeln und Werkbänken einen Berg errichten, tritt herauf und hält eine neue Bergpredigt. Er, der mit einer Reihe von Attributen Christi ausgestattet ist (er schreitet übers Wasser usw.), spricht aber nicht vom himmlischen Paradies, sondern von „richtigen, irdischen Himmeln“. Er gehört also zu jenen, die das Himmelreich auf Erden schon errichten wollen. Vollends zur Blasphemie gerät der zweite Teil seiner neuen Bergpredigt. Auf die Frage der Unreinen, für wen das irdische Paradies sei, antwortet ihnen der Fremde in einer Rede, die sich in Aufbau und Formulierung eng an die Seligpreisungen (Mt 5,3-11) anlehnt, den Inhalt derselben jedoch Punkt für Punkt umkehrt. So ergeben sich bei Majakovskij sechs lästerliche Seligpreisungen, die eine Negation der christlichen Bergpredigt darstellen:

1. Mein Paradies ist für alle, außer den geistlich Armen ... Leichter kann ein Kamel durch ein 
Nadelöhr kriechen

als zu mir ein solcher Elefant. (Mt 5,6; 19,24)

2. Zu mir, wer ruhig mit dem Messer erstach und vom Leib seines Feinds mit einem Lied ging!

(Mt 5,9; 5,21)

3. Komm, der du nicht verzeihst!

Geh du als erster ein in mein Himmelreich.

4. Komm ... schlafloser Ehebrecher, in dessen Adern der Dämon des

Aufruhrs sich regt -

Deiner...

sei mein Himmelreich.

5. Kommt alle, die ihr keine

Packesel seid.

(Mt 5,11)

6. Jeder, dem es unerträglich und

eng ist,

Wisse:

seiner

ist mein Himmelreich.

(Mt 5,5)

Die Übereinstimmung mit der biblischen Seligpreisung geht bis in Lexik und Syntax hinein. Nur wird die entscheidende Aussage jeweils umgekehrt. Das ist vielleicht am deutlichsten an der ersten These bei Majakovskij. Im Evangelium heißt es: „Selig sind die geistlich Armen, denn ihrer ist das Himmelreich" (Mt 5,3). Majakovskij behält den Evangelientext fast wörtlich bei, um jedoch genau das Gegenteil auszusagen: „Mein Paradies ist für alle, außer den geistlich Armen.“ Es handelt sich um die blasphemische Zurücknahme der Bergpredigt.

Damit rückt Majakovskijs „einfacher Mensch“ in die Nähe des Antichristen, besonders auch in der Form, wie ihn Vladimir Solov'ev 
im letzten seiner Drei Gespräche (Tri razgovora, 1899/1900) dargestellt hatte. Solov'evs Antichrist ist nicht ganz einheitlich komponiert. Vielmehr erscheint er zuerst als „Übermensch“, später als Weltimperator und Wundertäter. Beiden Antichristversionen ist indes die Art gemein, wie sie anfänglich ihre Macht errichten. Der erste Antichrist schreibt ein gewichtiges Werk: "'Der offene Weg zu Frieden und Wohlfahrt der Welt', ein Werk, von dem jeder sagen wird: Ja, das ist es, was wir brauchen; das ist ein Ideal und doch keine Utopie, ein Plan und doch keine Chimäre!““ Auch der zweite Antichrist, „der Mensch der Zukunft“, wie er heißt, verkündet als erstes nach seiner Wahl zum neuen Römischen Kaiser den allgemeinen Frieden. Sein zweiter Regierungsakt aber ist der Erlaß eines Manifestes zu einer allumfassenden Sozialreform:

Völker der Erde! Ich habe euch den Frieden versprochen und ich habe ihn euch geschenkt. Aber nur durch Wohlstand wird der Friede schön. Wem im Frieden die Nöte der Armut drohen, dem wird auch der Friede nicht zur Freude. Kommt nur her zu mir alle, die ihr hungert und friert, ich will euch satt und warm machen.

Ziel des Antichrist ist also die Verwirklichung des Himmelreichs bereits auf Erden. Das wird vollends deutlich in einer Betrachtung des Antichrist, in der er sich selbst vor Christus den Vorzug gibt:

Christus, der das sittlich Gute predigte und in seinem Leben darstellte, war ein Besserer der Menschheit, ich aber bin berufen, der Wohltäter dieser teils gebesserten, teils aber unverbesserlichen Menschheit zu sein. Ich werde allen Menschen alles geben, was sie brauchen. Als Moralist trennte Christus die Menschen durch die Unterscheidung von Gut und Böse, ich werde sie vereinigen durch die Güter, deren Gute und Böse in gleicher Weise bedürfen ... Christus brachte das Schwert, ich bringe den Frieden.

Es kann kaum bezweifelt werden, daß Majakovskijs „einfacher Mensch“ - schon das eine Zurücknahme des „Gott-Menschen“ - ähnliche Züge trägt wie Solov'evs Antichrist. Wie dieser predigt er aus einer geschichtlichen Endphase heraus. Wie dieser verkündet er Frieden und wirkliche Sättigung der Hungrigen. Auch von Christi Paradies distanziert er sich, 
indem er von „richtigen, irdischen Himmeln“ spricht. Während aber Solov'evs Antichrist seine Güter über Gut und Böse ausschüttet, Gut und Böse nur relativiert, verkündet Majakovskijs Mensch ganz offen das Böse, eben durch jene Umkehrung der Bergpredigt. Im Gegensatz zum Antichrist fordert er aber nicht die Christus zukommende Verehrung. Diesen entscheidenden Schritt vollziehen erst die Unreinen, die bei ihrem Eintritt in den Himmel singen:

\section{Wir sind uns selbst Christus und Heiland! \\ Wir sind selbst Christus! \\ Wir sind selbst Heiland!}

Der „einfache Mensch“, der, wie erwähnt, mit bestimmten Attributen Christi ausgestattet ist, zugleich aber auch wichtige Züge des Antichrist trägt, befindet sich gleichsam in der Mitte zwischen diesen beiden Polen.

Bei aller Tendenz zur radikalen Zurücknahme und Säkularisierung der christlichen Heilslehre darf keinesfalls übersehen werden, daß Majakovskijs Stück nur unter der stillschweigenden Voraussetzung der Lehre Christi möglich wurde. Hier eröffnet sich eine interessante Parallele zu Dostoevskijs Legende vom Großinquisitor, und es zeigt sich, daß das Mysterium buffo nicht zuletzt aus der nihilistischen Tradition der russischen Literatur des 19. Jahrhunderts heraus verstanden werden muß. Denn ebenso wie Dostoevskij den Triumph des „Fürsten dieser Welt“, des Großinquisitors, paradoxerweise in eine Legende, eine wesentlich christliche Erzählform, kleidet, tut es Majakovskij mit der Form des christlichen Mysterienspiels. Walter Rehm nannte Dostojevskijs Legende vom Großinquisitor, „eine Anti-Legende vom Anti-Christen“. Mit dem gleichen Recht wird man Majakovskijs Stück als Anti-Mysterium mit antichristlichen Zügen bezeichnen können. Dennoch wäre es falsch, in der biblischen Einkleidung des „Mysteriums“ und besonders in der Gestalt des einfachen Menschen einen Versuch Majakovskijs sehen zu wollen, die Revolution nach Art Bloks oder auch Esenins zu rechtfertigen. Für den Futuristen Majakovskij bedurfte die Revolution keiner metaphysischen Rechtfertigung.

Mit dem Sieg des Atheismus in Rußland nach der Revolution war freilich die klare Tendenz gegeben, die „legendäre“ Gestalt Christi ihrer Göttlichkeit zu entkleiden, seine Lehre als durch die umwälzenden 
Ereignisse überholt zu betrachten und Christus schließlich als Gegner der Revolution darzustellen. An Stimmen und Dichtern, die diesen Sachverhalt ausdrückten, hat es keineswegs gefehlt. Auch die sowjetische Literaturkritik neigte stets dazu, die Sicht der Revolution unter den christlichen Heilssymbolen oder in Verbindung mit der Gestalt Christi als reaktionär abzutun. Doch hat sich diese Wendung in der russischen Literatur selbst schon seit den Tagen der Revolution angebahnt. So hat beispielsweise Esenin, der in seiner Ballade Der Genosse den Christusknaben noch an den Kämpfen der Revolution teilnehmen ließ, in einem seiner besten Gedichte aus der imaginistischen Periode, Inonien (Inonija), dem Propheten Jeremias gewidmet (1918), den Gedanken vom Ende der Unsterblichkeit mit gleichzeitigem Bekenntnis zur Revolution apodiktisch ausgedrückt:

Ich will die Erlösung nicht annehmen

Durch seine Qualen und das Kreuz:

Ich habe eine andere Lehre begriffen

Von Sternen, die die Ewigkeit durchbohren.

Das Gedicht ist ein Jahr nach Der Genosse entstanden, und doch wird man nicht annehmen dürfen, daß sich Esenins Einstellung zu Revolution und Religion inzwischen wesentlich verändert habe. Der Dichter schwankte vielmehr von Jugend an zwischen den Polen inbrünstiger Frömmigkeit und roher Gotteslästerung hin und her. In späteren Jahren hat er wiederum seiner Trauer über den Rückgang der Frömmigkeit in Rußland bewegenden Ausdruck gegeben.

In den weiteren Zusammenhang unserer Fragestellung gehören auch einige Dichter des Proletkul't, jener mit der Revolution, besonders in den Jahren 1918-1920, um sich greifenden Massenbewegung, die den Versuch der Schaffung einer spezifisch proletarischen Kultur unternahm. Die Proletkul't-Dichter waren erfüllt von revolutionärer Leidenschaft, priesen den Kollektivismus, ihr Hauptthema war die Fabrikarbeit; ihre künstlerische Technik, Form, Vers, Metaphorik oft auch der Wortschatz stammten jedoch im wesentlichen von den Symbolisten, weniger von den Futuristen und Imaginisten. Die Fabrikthemen wurden allerdings nicht auf die gewohnte realistische oder naturalistische Art vorgebracht, sondern auf eine kosmisch-planetarischen Ebene gehoben. In einigen ihrer 
Gedichte haben die Vertreter des Proletkul't Industrie und Industrialisierung in messianistischer Verklärung besungen. Ein markantes Beispiel dafür ist das Gedicht Der eiserne Messias (Železnyj Messija, 1918) von Vladimir Kirillov, in dem die Aspekte der technischen und der politischen Revolution vereinigt sind:

Da ist er, der Heiland, der Herrscher der Erde,

Der Beherrscher titanischer Kräfte,

Im Geräusch der Drähte, im Funkeln der Maschinen, Im Glanz der elektrischen Sonnen.

Man hatte geglaubt, er käme in Sternengewändern, Im Heiligenschein göttlicher Mysterien, Doch er kam zu uns im grauen Rauch Der Fabriken, Werke und Vorstädte.

Jetzt schreitet er über die Abgründe der Meere, Unbesiegbar, ungestüm, Er schleudert die Funken rebellischer Ideen, Verströmt eine reinigende Flamme.

Eine neue Sonne bringt er der Welt, Reißt Throne und Kerker nieder, Zur ewigen Brüderlichkeit ruft er die Völker, Verwischt Linien und Grenzen.

Die Umdeutung der Wiederkehr Christi in den Triumph der Technik und der Materie ist nur ein konsequenter Schritt auf dem Wege zur Liquidierung des Christussymbols in der nachrevolutionären Periode. Die Frage, ob Christus für oder gegen die Revolution sei, ist damit im tiefsten nicht berührt, doch liefern uns die genannten Texte Hinweise, daß die Christusgestalt in diesen Dichtungen fortschreitend säkularisiert, ja, materialisiert und damit abgewertet wird.

In die gleiche Kerbe schlägt auch der proletarische Dichter Dem'jan Bednyj mit seinem Gedicht Christ ist erstanden (Christos voskrese, 1918). Es handelt sich um eine Art Fabel, genauer, um einen versifizierten Witz mit angehängter Moral: Der Pope hat in den unsicheren Revolutions- 
wirren sein Geld in einem Schrein unter dem Altar versteckt und darauf geschrieben: „Dies ist der Schrein mit Christi Leib.“ Der Dieb, der den Schrein ausplündert, schreibt frech dazu: „Hier sind keine Gebeine mehr, - Christ ist erstanden." Bednyj, militanter Atheist und später ständiger Mitarbeiter der antireligiösen Zeitschrift Der Gottlose (Bezbožnik), macht sich in seiner Fabel ungeniert über die Auferstehung und den russischen Ostergruß (Christos vozkrese) lustig. Die christlichen Symbole werden Gegenstand platter Witze.

Alle diese Dichtungen zeigen, daß sich seit oder gleichzeitig mit Bloks Die Zwölf ein Wandel in der Einschätzung des revolutionären Christus anbahnt. Die Logik dieser Entwicklung mußte über kurz oder lang dazu führen, daß man in Christus endlich einen Gegner der Revolution erkannte. Dieser Punkt ist, wie abschließend gezeigt werden soll, Ende der zwanziger Jahre tatsächlich erreicht.

Offen, ja plump, griff Majakovskij im August 1928 in dem Gedicht Die Erscheinung Christi (Javlenie Christa) das Motiv noch einmal auf, um es nun endgültig zum „reaktionären Christus“ umzumünzen. Man muß dabei im Auge haben, daß Majakovskijs dichterische Methode inzwischen einen merklichen Wandel durchgemacht hatte. Mit dem LEF, der Linken Front der Künste, hatte er eine Richtung eingeschlagen, in der sich die Kunst bedingungslos den Erfordernissen der Tagespolitik und Propaganda unterwarf und nicht selten zur Reklame degradiert wurde. So nahm Majakovskij den Abschluß des Kriegsächtungspaktes durch Kellogg und Briand („Kelloggpakt“, 22. August 1928) zum Anlaß für sein Gedicht, das schon vier Tage nach Abschluß des Paktes in der Arbeiterzeitung (Rabočaja gazeta) erschien. In der gleichen Nummer der Zeitung stand die Schlagzeile: „UdSSR fordert keine Worte, sondern Taten. Kelloggpakt gibt keinerlei Garantien“. Wir haben es also mit der dichterischen Untermalung einer Tagesparole, mit einem versifizierten Leitartikel zu tun.

Das Gedicht ist in Majakovskijs Manier der abgestuften Verse (lesenka) abgefaßt. Das Motiv vom wiederkehrenden Christus wird nach Art einer Travestie behandelt, denn kein anderer als der Initiator des Paktes, der amerikanische Außenminister Kellogg, ist mit dem wiederkehrenden Christus gemeint: 
Christus

kam nicht zu Fuß über das Wasser,

die Schuhsohlen

zu netzen

hat er keine Lust.

Der wiederkehrende Christus

und kam

hat den Smoking angezogen

nach Paris

mit dem Dampfer.

Majakovskij hat dabei, wie die handschriftlichen Varianten zeigen, besonderen Nachdruck auf die Wendungen „neuer Christus“ und „wiederkehrender Christus“ gelegt. Der neue Christus schreitet aber nicht, wie noch der „einfache Mensch“ im Mysterium buffo, über die Wasser, sondern kommt mit dem Dampfer nach Paris. Er trägt auch keinen Heiligenschein, sondern den bürgerlichen Smoking. Der travestierende Vergleich zwischen Christus und Kellogg wird im einzelnen durchgeführt. Am Ende wird Christus auf diese Weise zum diplomatischen Sprecher der kapitalistischen Welt. Zwar predigt er den Frieden, in Wirklichkeit aber ist sein Handeln gegen die Bolschewiken gerichtet:

Doch der wichtigste

Stein

in seinem Busen

ist die Wut,

die aufgespart ist

für alle,

die mit den Bolschewiken sind.

Das Gedicht dient unverhüllt dem Zweck, einen der sowjetischen Regierung inopportunen Friedenspakt zu diffamieren. Es benutzt die Form der Travestie, um zugleich einen blasphemischen, antireligiösen Effekt zu erzielen. Hier ist auch nichts mehr von der Antichrist-Spannung vorhanden, die dem „einfachen Menschen“ Profil verliehen hatte. 
Für unsere Fragestellung ergibt sich damit ein abschließender Aspekt: Die alte These vom revolutionären Christus, die seit Belinskij und den Petraševcy, bei Blok und Esenin in Rußland vertreten worden war, besaß im Jahre 1928 keine Gültigkeit mehr. Für den späten Majakovskij gab es nur noch einen kapitalistischen, das heißt einen reaktionären Christus, er ist ein Gegner der Revolution und aller, die „mit den Bolschewiken“ sind. Damit war die These vom revolutionären Christus in ihr Gegenteil verkehrt.

* Neue, stark veränderte und erweiterte Version eines Aufsatzes von 1961. Die Übersetzungen der russischen Texte aus V. Solov'ev stammen von Ludolf Müller, alle übrigen vom Verfasser.

\section{Literaturhinweise}

Lauer, R.: Der revolutionäre Christus. Eine geistesgeschichtliche Analyse der russischen Literatur. In: Moderne Welt 1961/62, H. 2, S. 166-190.

Lauer, R.: Zur Gestalt Ivan Babičevs in Olešas „Neid“. In: Die Welt der Slaven VII/1962, Heft 1, S. 45-54.

Močul'skij, K.: Aleksandr Blok. Paris 1948.

Orlov, Vl.: Poèma Aleksandra Bloka „Dvenadcat““.- Stranica iz istorii sovetskoj literatury. Moskau 1962.

Ramm, Th.: Die großen Sozialisten als Rechts- und Sozialphilosophen. Stuttgart o.J.

Rammelmeyer, A.: Dostoevskijs Begegnung mit Belinskij. (Zur Deutung der Gedankenwelt Ivan Karamazovs). In: Rammelmeyer, Alfred: Aufsätze zur russischen Literatur und Geistesgeschichte. Hg. von R. Lauer in Zusammenarbeit mit A. Graf und M. Rammelmeyer. Wiesbaden 2000, S. 105-138.

Rammelmeyer, A.: Der „Wiederkehrende Christus“ in der russischen Dichtung. In: Rammelmeyer, A.: Aufsätze aaO., S.375-391.

Rehm, W.: Experimentum medietatis. Studien zur Geistes- und Literaturgeschichte des 19. Jahrhunderts. München 1947.

Rothe, H.: Fragen an Dostojewskijs Idiot. In: Dostoevsky Studies, New Series. Bd. VII (2003), S. 131-152.

Sarkisyanz, E.: Rußland und der Messianismus des Orients. Sendungsbewußtsein und politischer Chiliasmus des Ostens. Tübingen 1965.

Smola, O.P.: „černyj večer, belyj sneg ...“. Tvorčeskaja istorija i sud'ba poèmy Aleksandra Bloka „Dvenadcat”. Moskau 1993.

Solowjew, W.: Übermensch und Antichrist. Über das Ende der Weltgeschichte. Hg. von L. Müller. Freiburg 1958. 


\section{Autorin und Autoren}

Siegmar Döpp, Professor für Klassische Philologie in Göttingen

JÜrgen Gidion, Hon.-Professor am Deutschen Seminar in Göttingen

DANIEl GÖSKE, Professor für Amerikanistik / Literaturwissenschaft in Kassel

Gerhard Lauer, Professor für Neuere deutsche Literaturwissenschaft in Göttingen

Reinhard Lauer, Professor em. für Slavische Philologie in Göttingen

IRMELA VON DER LÜHE, Professorin für Neuere deutsche Literaturwissenschaft in Göttingen

Jürgen von Stackelberg, Professor em. für Romanische Philologie in Göttingen

Theodor Wolpers, Professor em. für Englische Philologie in Göttingen 


Im Jahr 2003 fand in der Göttinger Jakobikirche eine hochkarätige und deshalb zu Recht viel beachtete Vorlesungsreihe zur Wirkungsgeschichte der Bibel statt. Namhafte Vertreter bester Göttinger Philologie fanden hier ihr Publikum - interessiert, oft gelehrt, aber in seinem Interesse nicht auf eine fachwissenschaftliche Binnendiskussion beschränkt. Diese nun gedruckt vorliegende Vorlesungsreihe ist nicht nur ein Beispiel für das gute Zusammenleben von Universität und Stadt, wie es typisch für Göttingen ist. Sie ist darüberhinaus Beispiel für ein fruchtbares Gespräch zwischen Wissenschaft und Kirche, wie es auch außerhalb der akademischen Theologie möglich und nötig ist. 